\title{
Vascular compliance and resistance changes during experimental heart failure
}

Citation for published version (APA):

Ceiler, D. L. B. (1998). Vascular compliance and resistance changes during experimental heart failure. [Doctoral Thesis, Maastricht University]. Universiteit Maastricht. https://doi.org/10.26481/dis.19980326dc

Document status and date:

Published: 01/01/1998

DOI:

$10.26481 /$ dis. $19980326 d c$

Document Version:

Publisher's PDF, also known as Version of record

\section{Please check the document version of this publication:}

- A submitted manuscript is the version of the article upon submission and before peer-review. There can be important differences between the submitted version and the official published version of record.

People interested in the research are advised to contact the author for the final version of the publication, or visit the DOI to the publisher's website.

- The final author version and the galley proof are versions of the publication after peer review.

- The final published version features the final layout of the paper including the volume, issue and page numbers.

Link to publication

\footnotetext{
General rights rights.

- You may freely distribute the URL identifying the publication in the public portal. please follow below link for the End User Agreement:

www.umlib.nl/taverne-license

Take down policy

If you believe that this document breaches copyright please contact us at:

repository@maastrichtuniversity.nl

providing details and we will investigate your claim.
}

Copyright and moral rights for the publications made accessible in the public portal are retained by the authors and/or other copyright owners and it is a condition of accessing publications that users recognise and abide by the legal requirements associated with these

- Users may download and print one copy of any publication from the public portal for the purpose of private study or research.

- You may not further distribute the material or use it for any profit-making activity or commercial gain

If the publication is distributed under the terms of Article $25 \mathrm{fa}$ of the Dutch Copyright Act, indicated by the "Taverne" license above, 


\section{Vascular compliance and resistance changes during experimental heart failure}

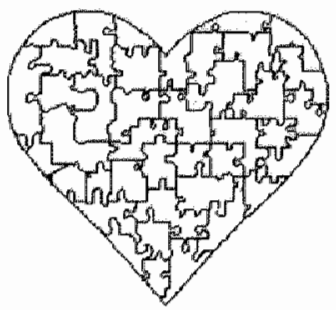


CIP-DATA KONINKLIJKE BIBLIOTHEEK, DEN HAAG

Ceiler, Deborah L.

Vascular compliance and resistance changes

during experimental heart failure / Deborah Lynn Ceiler

Universal Press

Thesis Maastricht - with ref.

ISBN 90-9011495-5

Subject headings: heart failure 


\section{Vascular compliance and resistance changes during experimental heart failure}

\section{PROEFSCHRIFT}

ter verkrijging van de graad van doctor aan de Universiteit Maastricht,

op gezag van Rector Magnificus, Prof. dr. A.C. Nieuwenhuijzen Kruseman, volgens het besluit van het College van Decanen,

in het openbaar te verdedigen

op donderdag 26 maart 1998 om 14.00 uur

door

Deborah Lynn Ceiler

geboren 27 februari 1968 te Pittsburgh 


\section{Promoters}

Prof. dr. J.F.M. Smits

Prof. dr. J.G.R. De Mey

\section{Compromoter}

Dr. H.J.M.G. Nelissen-Vrancken

\section{Beoordelingscommissie}

Prof. dr. R.S. Reneman, voorzitter

Prof. dr. P.W. de Leeuw

Dr. E.D. de Muinck

Prof. dr. P.D. Verdouw (Erasmus Universiteit, Rotterdam)

Dr. B.I. Lévy (Paris, France)

This thesis was supported, in part, by the Dutch Heart Foundation through the Dutch Scientific Research Organization.

The financial support of Pie Medical in the publication of this thesis is gratefully acknowledged. 
In things pertaining to enthousiasm, no man is sane who does not know how to be insane on proper occasions.

Henry Ward Beecher 


\section{Table of Contents}

$\begin{array}{lll}\text { Chapter } 1 & \text { Introduction } & 9\end{array}$

Chapter 2 Time-related adaptations in plasma neurohormoe levels and hemodynamics after myocardial infarction in the rat

Chapter 3 The influence of angiotensin II-induced increase in aortic wall mass on compliance in rats in vivo

Chapter 4 Static and dynamic mechanical behavior of the intact rat aorta is influenced by pressure but not by angiotensin II-induced increases in wall mass or tone

Chapter 5 Effect of chronic blockade of angiotensin II receptor subtypes on aortic compliance in rats with myocardial infarction

Chapter 6 Effect of nitric oxide synthase inhibition on the acetylcholine response in the perfused hindlimbs of rats

Chapter 7 Effects of chronic infusion of L-NAME or angiotensin II on arterial structure and reactivity in the hindlimb of rats

Chapter 8 Role of basal NO synthesis in vasoconstrictor hyporeactivity in the perfused rat hindlimb after myocardial infarction: Effect of captopril

Chapter 9 General discussion

Samenvatting, Curriculum vitae, Dankwoord

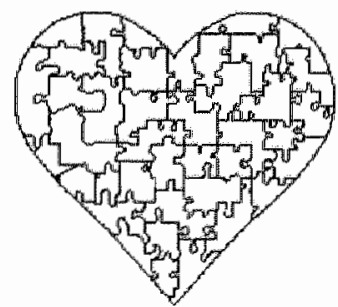




\section{Introduction}

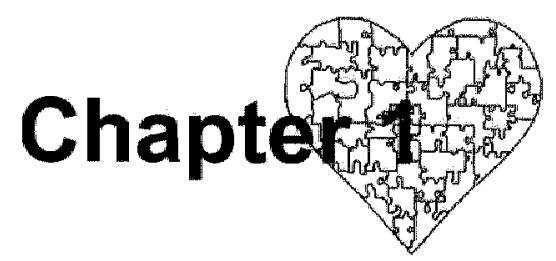




\section{Heart failure: general}

\section{Epidemiology and etiology}

A generalized decline in cardiovascular mortality can not mask the rising prevalence and incidence of heart failure. Epidemiological surveys indicate that heart failure affects $1-2 \%$ of the population in Europe and the United States (Dargie et al. 1996). With improved survival after acute myocardial infarction and an overall increase in life expectancy, heart failure incidence may be expected to increase up to $30 \%$ in very elderly people over the next decade (Department of Health, 1992), consequently increasing prevalence by as much as $70 \%$ by the year 2010 (Bonneux et al. 1994). It is thus not surprising that clinicians refer to the "heart failure epidemic".

This grim demographic trend is not improved when mortality and morbidity in patients with heart failure are further taken into account. Despite continued advances in treatment and care, heart failure remains a highly lethal condition. Once the clinical signs of heart failure are manifest, prognosis is poor and negatively correlated with the New York Heart Association heart failure classifications (Table 1.1). In the Framingham study, $37 \%$ of men and $38 \%$ of women died within two years after heart failure diagnosis; within six years, $82 \%$ of men and $67 \%$ of women had died (Kalon et al. 1993). This death rate was four to eight times that in the general population of the same age.

Table 1.1 Prognosis in heart failure (Erikkson, 1995).

\begin{tabular}{ccc}
\hline New York Heart Association Classification & Annual mortality rate \\
\hline II & $5-10 \%$ \\
III & $10-20 \%$ \\
IV & $20-50 \%$ \\
\hline
\end{tabular}

Even though left ventricular dysfunction may be asymptomatic, overt heart failure imposes a high symptom burden in most suffering patients. In a study concerning patient-reported quality of life in a variety of medical disorders, heart failure had the most negative effect on patient-assessed quality of life (Stewart et al. 1989). Furthermore, statistics from the Framingham study report that approximately $65 \%$ of heart failure patients experienced one or more recurrences of overt heart failure within a six year period (Kalon et al. 1993). In the United States, heart failure is the most common reason for hospitalization of patients over the age of 65 (Ghali et al. 1990 ) and $5.5 \%$ of the national health care budget is expended on the treatment of this disease. 
Ironically, the general consensus over the significance of heart failure as a public health problem is paralleled by the lack of consensus concerning the criteria for the diagnosis of the disease (Kalon et al. 1993; Dargie et al. 1996). Such discord arises from the fact that heart failure is not a single disease, but a syndrome with a wide range of pathophysiological states and etiologies. The main clinical manifestations of heart failure include dyspnea, fatigue and edema; the Framingham Heart Study established a list of major and minor criteria for the diagnosis of heart failure (Table 1.2). Diagnosis of heart failure was established by the simultaneous presence of two major or one major and two minor criteria (Kalon et al. 1993).

Table 1.2 Criteria for congestive heart failure (Kalon et al. 1993).

\begin{tabular}{ll}
\hline Major criteria & Minor criteria \\
\hline Paroxysmal nocturnal dyspnea & Bilateral ankle edema \\
Neck vein distention & Nocturnal cough \\
Rales & $\begin{array}{l}\text { Dyspnea on ordinary exertion } \\
\text { Hepatomegaly } \\
\text { Radiographic cardiomegaly }\end{array}$ \\
$\begin{array}{l}\text { Acute pulmonary edema }(>16 \mathrm{~cm} \\
\text { water at the right atrium) }\end{array}$ & Pleural effusion \\
Third sound gallop & Decrease in vital capacity by $33 \%$ \\
& from maximal value recordied \\
Increased central venous pressure & Tachycardia (rate $\geq 120$ beats $/ \mathrm{min}$ ) \\
Circulation time $\geq 25 \mathrm{~s}$ & \\
Hepatojugular reflux & \\
Weight loss $\geq 4.5 \mathrm{~kg}$ in 5 days in & \\
response to treatment of heart failure &
\end{tabular}

In terms of etiology, heart failure utimately develops from myocardial abnormalities (including both cardiac failure after ischemia and cardiomyopathies), cardiac valvular disease, pericardial abnormalities, arrhythmias or congenital heart disease. Of these causes, post-ischemic loss of myocardial contractile function is the most prevalent. While hypertension had long been the primary insult plaguing the heart, coronary artery disease has now assumed the role as the primary perpetrator leading to ischemic heart disease (Erikkson, 1995; Dargie et al. 1996). 


\section{Treatment}

Advances in the understanding of the pathophysiology of heart failure have resulted in changes in treatment paradigms. For several decades, heart failure was considered as a edematous disease with treatment aiming to reduce water retention. In the 1970 's treatment was based on reducing peripheral resistance and increasing cardiac function. However, several clinical studies showed that drugs which increase ejection fraction are not the most effective for improving prognosis (Cohn ot al 1991, Cleland \& Dutka, 1994). Recent studies demonstrate that treatment regimes which temper neurohormonal activation decrease mortality in patients with severe left ventricular dysfunction (Swedberg et al. 1990b) and with overt heart failure (Swedberg et al. 1990a; Francis et al. 1993). The effects of various drugs on patient symptoms, morbidity and mortality is shown in Table 1.3.

Table 1.3 Drugs for treating heart failure.

\begin{tabular}{lccc}
\hline Drug & symptoms & morbidity & mortality \\
\hline ACE inhibitors & $\downarrow \downarrow$ & $\downarrow \downarrow$ & $\downarrow \downarrow$ \\
Diuretics & $\downarrow \downarrow \downarrow$ & $\uparrow \downarrow$ & $?$ \\
Digoxin & $\downarrow$ & $\downarrow$ & $=$ \\
Hydralazine & $=$ & $=\uparrow$ & $?$ \\
Nitrates & $=$ & $=\uparrow$ & $?$ \\
B-blockers & $\uparrow \downarrow$ & $\downarrow$ & $\downarrow$ \\
aspirin (anti-thrombotic) & $=$ & $\downarrow$ & $\uparrow \downarrow$ \\
Coumarines (anti-thrombotic) & $=$ & $\downarrow \downarrow$ & $\uparrow \downarrow$ \\
\hline
\end{tabular}

table adapted from (Cleland \& Dutka, 1994) ACE: angiotensin converting enzyme. $\uparrow$ increase; = no change; $\downarrow$ decrease; $\uparrow \downarrow$ equivocal.

Currently, angiotensin converting enzyme inhibitors are a common first choice in heart failure treatment, due to their positive effect in reducing symptoms, morbidity and mortality (Cleland \& Dutka, 1994; Chatterjee, 1996). Nonetheless, individual regimens are likely to differ considerably due to the complex etiology of the heart failure syndrome, as seen in Table 1.4 
Table 1.4 Treatment of heart failure.

\begin{tabular}{llll}
\hline Diagnosis & first line treatment & add on & prophylaxis \\
\hline Asymptomatic & ACE inhibitor & & aspirin or coumarines \\
Symptomatic LVSD & ACE inhibitor & diuretic & aspirin or coumarines \\
Edema & Diuretic & ACE inhibitor & aspirin or coumarines \\
Atrial fibrillation & Digoxin & B-blocker & coumarines \\
LVDD & Diuretic & $?$ & aspirin or coumarines \\
Angina pectoris & Nitrate & $\beta$-blocker, & aspirin or coumarines \\
Elderly patients & $\downarrow$ dose ACE & digoxin & aspirin, coumarines (?) \\
& inhibitor \& diuretic & & coumarines \\
\hline
\end{tabular}

table adapted from (Cleland \& Dutka, 1994). LVS(D)D: left ventricular systolic (diastolic) dysfunction; ACE: angiotensin converting enzyme; $\downarrow$ decreased.

\section{Pathophysiology}

Hemodynamics: Heart failure develops as a consequence of unabated peripheral and cardiac compensatory mechanisms in response to ventricular dysfunction. After an acute ischemic insult, sympathetic activation ensues (Cohn, 1990; Rouleau et al. 1991). This increases cardiac contractility and heart rate to maintain cardiac output and also heightens peripheral resistance to maintain organ perfusion pressure. Via an intrinsic mechanism, coined homeometric autoregulation, the heart can overcome an increase in afterload by increasing contractile force (Sarnoff et al. 1960; Packer, 1992). If the ventricle fails to empty normally and venous return remains the same, preload increases and the heart utilizes the Frank-Starling mechanism to enhance cardiac output. Increases in loading are a considerable stress on the compromised heart. Unabated acute adaptations induce a new battery of long-term adaptive processes. Initially, the heart dilates in response to increased end-diastolic pressures; stroke volume is maintained at decreased ejection fractions. On a longer time scale, the heart muscle hypertrophies to normalize increased wall stress (Zelis et al. 1991; LeJemtel \& Sonnenblick, 1993).

Although these hemodynamic factors undoubtably play a role in advancing the symptoms of heart failure, they can not in their own right explain the continued progression of the disease. While under normal circumstances reductions of hemodynamic stresses reverse the functional response, treatments which reduce loading conditions in heart failure patients may retard, but do not prevent the course of the disease (Packer, 1992). This may stem from the fact that chronic hemodynamic stresses may lead to irreversible structural and functional alterations in the heart and peripheral organ systems. 
The heart: As mentioned above, the remnant left ventricle dilates after myocardial infarction (Pfeffer \& Braunwald, 1990). Increased cavity volume is compensatory in the early phases after myocardial infarction by restoring stroke volume, but becomes non-compensatory in the later (beyond four weeks in humans). stages, since stroke volumes are not further enhanced (Pfeffer \& Braunwald, 1990; Gaudron et al. 1993). Furthermore, dilation causes increased wall stress, due to increased diastolic volume and pressure, which is a stimulus for myocyte hypertrophy (Grossman et al. 1975). In addition to wall stress, numerous studies impart an important role for neurohormonal systems, and specifically the renin-angiotensin system, in inducing growth responses of both the myocyte and non-myocyte compartment (Baker et al. 1990; Grossman \& Lorell, 1993; Brilla, 1994; Smits \& Daemen, 1994). Excessive cardiac hypertrophy may impede myocardial efficiency if, as has been demonstrated, arterial growth (coronary reserve) does not parallel the increase in cardiac mass (Vatner et al. 1990; Brilla, 1994). Reduced capillary densities have also been reported in hypertrophied sections of failing hearts (Roberts \& Wearn, 1941; Olivetti et al. 1989; Sabbah et al. 1995). This reduction in microvascular density is partially due to increased interstitial collagen which surrounds cardiomyocytes (Volders et al. 1993; Brilla, 1994; Sabbah et al. 1995). The secretion of collagen by activated fibroblasts leads to diminished diastolic function due to decreased subendocardial perfusion and increased myocardial stiffness (Vatner et al. 1990; Brilla, 1994).

In terms of functional changes, the failing heart is unable to sufficiently increase contractility. This may be due to down-regulation of $\beta$-adrenergic receptors or a desensitization of down-stream signalling pathways (Bristow et al. 1982, 1986; Ungerer et al. 1993). On the other hand, studies report a shift in myosin isoform gene expression which sacrifice contractility for reduced energy expenditure (reviewed in Boheler \& Schwartz, 1992; Schwartz et al. 1993). Furthermore, sarcoplasmic reticulum $\mathrm{Ca}^{2+}$-ATPase expression and activity is reduced in heart failure (reviewed in Arai et al. 1994; Vankerl \& Schwartz, 1995). This protein is responsible for the re-uptake of calcium in the sarcoplasmic reticulum during diastole (Lompre et al. 1994). Reduced function thus hinders diastolic relaxation and subsequent systolic contractility.

Neurohormones: Under normal and pathological circumstances neurohormones play an important role in the acute and semi-acute regulation of hemodynamics. Nonetheless, during heart failure, chronic activation of these systems appears to induce adverse effects on cardiac function independent of their hemodynamic effects (Packer, 1992; Sigurdsson \& Swedberg, 1994; Teerlink, 1996). As such, several large clinical trials have examined the relationship between neurohormonal activation and the degree of heart failure (Table 1.5).

After acute myocardial infarction, increased plasma levels of catecholamines, atrial natriuretic peptide and angiotensin II have been reported (Rouleau et al. 1991, 1994; Sigurdsson et al. 1993). Elevation of catecholamines and angiotensin II help to 
compensate for decreased cardiac function by emhancing cardiac contractility and increasing venous return and to maintain systemic perfusion pressure by elevating vascular resistance and increasing water retention. Atrial natriuretic peptice is counter-regulatory, being released with elevations in atrial stretch. In patients without overt symptoms of heart failure, neurohormonal levels normalize within a few days (Rouleau et al. 1991; Sigurdsson et al. 1993). Nonetheless, in post myocardial infarction patients with severe left ventricular dysfunction, neurohormonal activation persists (Francis et al. 1990; Rouleau et al. 1994). In overt heart failure, plasma levels of neurohormones are again found to be elevated (Francis et al. 1990, 1993; Swedberg et al. 1990a; Sigurdsson et al. 1994).

The importance of neurohormones in the pathology of heart failure becomes clear when one considers that plasma levels of endothelin, atrial natriuretic peptide, angiotensin II and catecholamines all correlate with mortality rates (Cohn et al. 1984; Swedberg et al. 1990a; Svengaard et al. 1992; Clavell et al. 1993; Francis et al. 1993; Omland et al. 1993; Galatius-Jensen et al. 1996). Furthermore, data from both the CONSENSUS and V-HeFT II trials suggest that the effects of treatment with angiotensin converting enzyme inhibitors on reducing mortality rates are related to counteraction of neurohormonal activation (Swedberg et al. 1990a, b; Francis et al. 1993). 


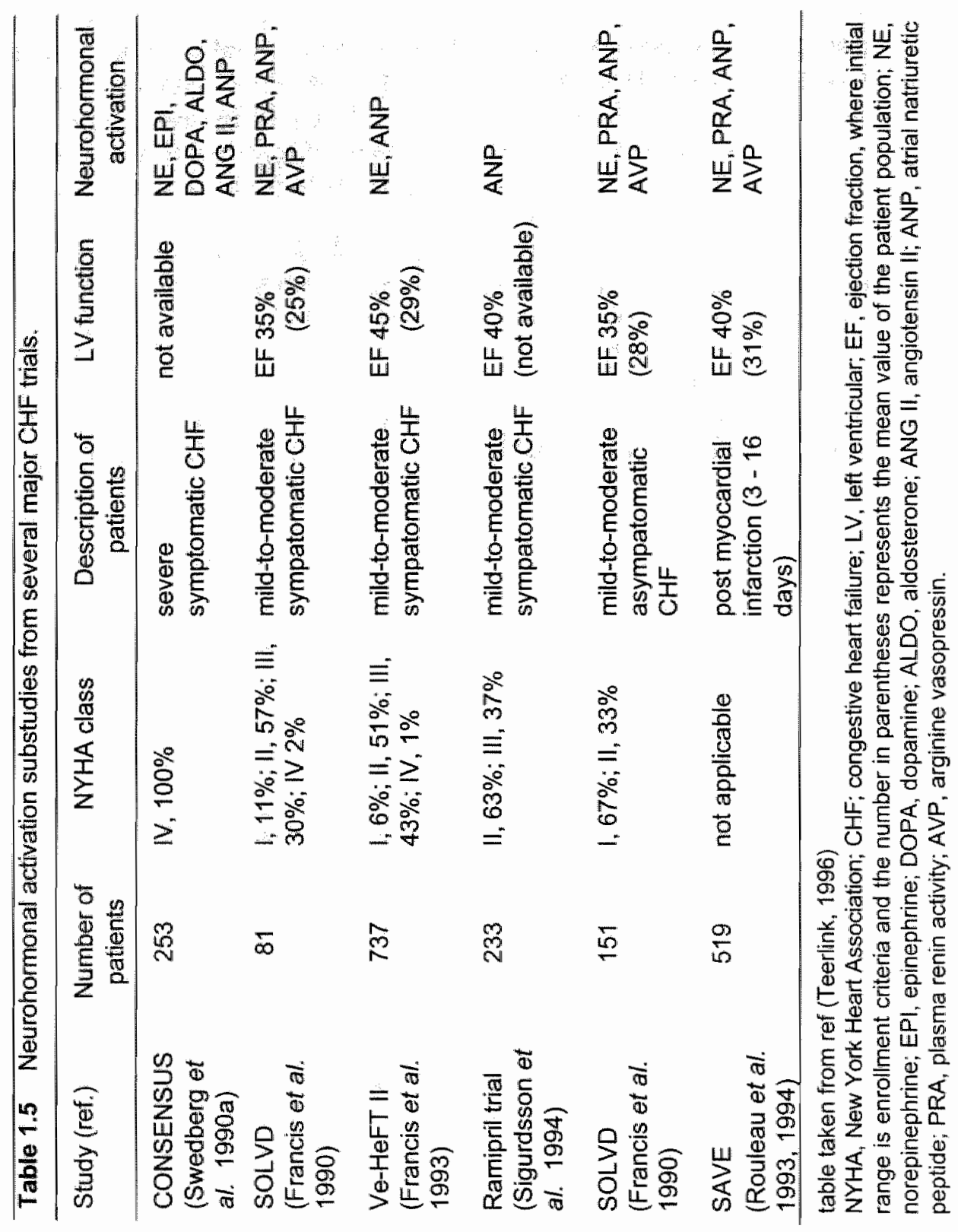


The viscious cycles

The progressive adaptation in hemodynamics, heart structure and neurohormone activation mentioned above points out that heart failure is not a steady state condition, but a progressive syndrome. The heart adapts to its impaired condition and the body responds to the diminished function of the heart as a pump and vice versa. The initial inability of the heart to supply sufficient blood to support the body's metabolic needs inititiates a cascade of renal, sympathetic and neurohormonal responses. Chronic changes in hemodynamics and neurohormonal levels may induce functional and structural changes in the heart, vasculature, and other peripheral organ systems. In turn, the changes in peripheral organ systems may further undermine heart function by placing a greater stress on the heart. This then also has a subsequent effect on hemodynamics and neurohormonal activation. A negative spiral ensues. While these adaptive processes maintain systemic homeostasis on a short term basis, they backfire when chronic compensatory adaptation is required. During heart failure, physiological feedback regulatory mechanisms that are intended for short-term adaptations lead to pathological conditions when the stimulus for regulation is chronic.

Although heart failure is a syndrome with a complex range of etiologies which ultimately result in myocardial dysfunction, many of the symptoms of overt heart failure, such as dyspnea and fatigue, arise from peripheral adlaptation mechanisms. Furthermore, the adaptations in the periphery have an influence on cardiac function. This thesis is concerned with adaptive processes in the peripheral vasculature after myocardial dysfunction induced by infarction of the left ventricle in rats. The second and third sections of this introduction respectively consider the nature of possible changes in the arterial vasculature under pathological conditions and documented changes in vascular and muscular organ systems during heart failure. Figure 1.1 shows the viscious cycle which constitutes the progression of heart failure. The possible contributory role of peripheral vascular changes in the symptomatic development of heart failure is clearly apparent. Relevant topics which are addressed in this thesis are highlighted in italics. 


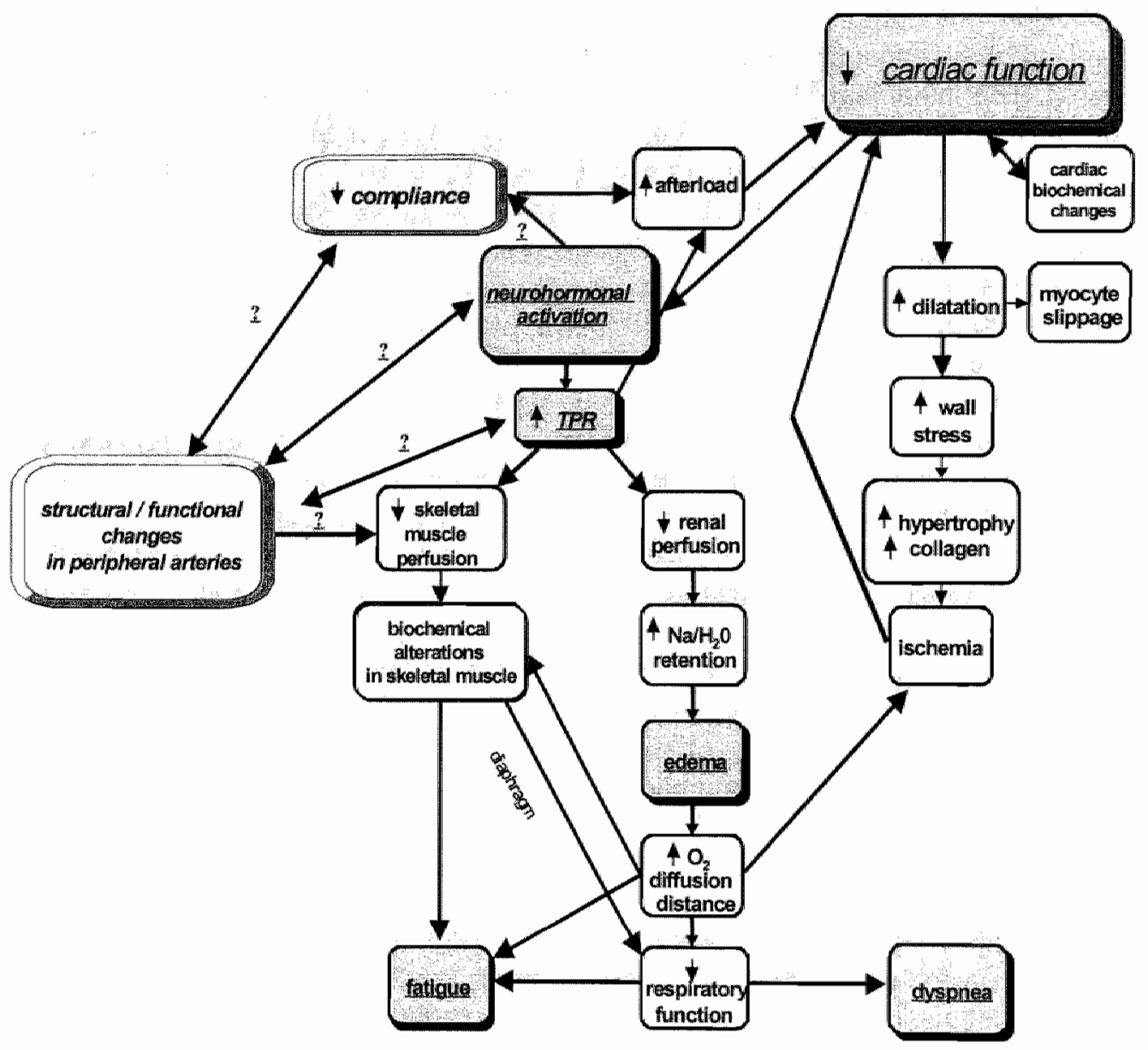

\section{Figure 1.1}

The viscious cycle of heart failure. Underlined alterations represent the classic indicators af heart failure. Italicized alterations are addressed in this thesis. TPR: total peripheral resistance. 


\section{Arterial vasculature: structure and function}

Large artery mechanics: definition and contributory factors

The contraction of the heart generates force to pump blood to the body organs. This force must be of sufficient magnitude to overcome the resistance of the vascular system and to provide enough blood flow to meet the metabolic needs of the body organs. The arterial system controls the continuity and distribution of blood flow. The large arteries convert pulsatile to continuous flow by acting as a capacitance chamber. By locally modifying resistance, small arteries and arterioles can control the distribution of blood flow. The venous circulation regulates circulating blood volume with its capacitance function. The role of these three sections of the vasculature (large capacitance arteries, resistance vessels and veins) in regulating blood circulation is represented in Figure 1.2.

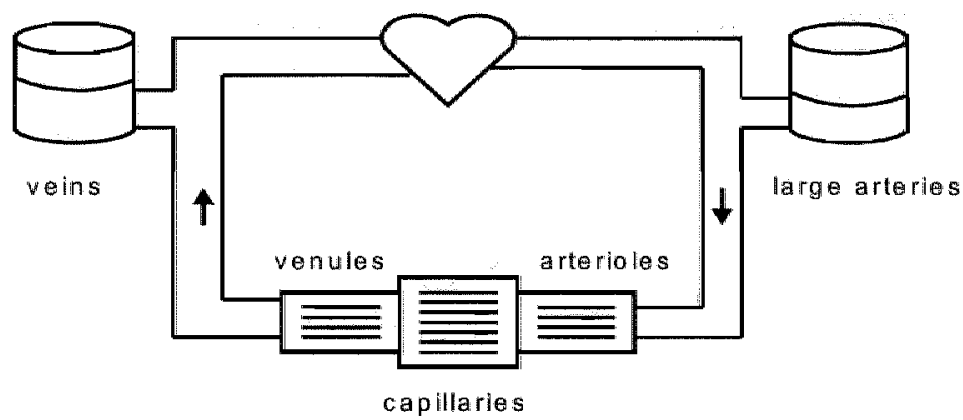

Figure 1.2

Schematic representation of the left circulation. Large arteries are represented by a capacitance chamber, which ensures a smoothing of flow. Small arteries and arterioles function to modulate flow distribution by regulating resistance. Veins are also capacitance wessels which regulate circulating blood volume.

By distending during the systolic phase of the cardiac cycle, large arteries "store" volume energy which is released during the diastolic phase to create a more continuous flow throughout the heart cycle. As such, the large arteries function as an hydraulic filter. Filtering reduces the work load of the heart since more work (work = pressure $\mathrm{x}$ volume) is required to pump a flow intermittently than steadily. Consider the following example, pumping a constant flow of $100 \mathrm{ml} / \mathrm{s}$ through a system with a resistance of $1 \mathrm{mmHg} / \mathrm{ml} / \mathrm{s}$ generates a pressure of $100 \mathrm{mmHg}$. 
The work done in one second is thus $10,000 \mathrm{mmHg} . \mathrm{ml}$. In contrast a pump that pumps the same flow intermittently, e.g., $200 \mathrm{ml} / \mathrm{s}$ for 0.5 second and $0 \mathrm{ml} / \mathrm{s}$ for 0.5 second through the same resistance generates a pressure of $200 \mathrm{mmHg}$ and does $20,000 \mathrm{mmHg} . \mathrm{ml}$ work in one second. By stabilizing flow, large vessels dampen pulse pressure (the difference between diastolic and systolic pressure), and the ease with which a vessel distends during systole determines to what degree the pulse pressure is dampened. At a given stroke volume, the work load of the heart can be deduced from the diastolic and pulse pressures, which at a given systemic resistance, is thus dependent on the elasticity of the vascular wall. In this manner large artery mechanics are important in influencing cardiac function. Indeed, reductions in arterial buffering capacity adversely affect myocardial energetic efficiency and may contribute to the elevated risk of ischemic cardiac diseases noted with ageing, hypertension and diabetes (Kannel et al. 1971; Kannel \& McGee, 1979; Randall et al. 1984; van Merode et al. 1988; Isnard et al. 1989).

The buffering capacity of an arterial system is termed compliance and is denoted by the absolute change in volume for a given pressure change, or $\Delta V / \Delta P$. Compliance can be measured at several levels. Systemic compliance is an index for the compliance of the entire arterial system; the ratio stroke volume I pulse pressure is generally used as an indication of systemic compliance (Kannel et al. 1971). Local compliance can be measured at the level of a given artery with the help of ultrasound to quantify the distention of the arterial wall during the cardiac cycle. This technique assumes that a change in volume is due to a change in lumen cross-section, thus making it possible to calculate compliance from changes in lumen area during the cardiac cycle (Reneman et al. 1996). Summing up,

$$
C C \approx \Delta A / \Delta P \approx \pi\left(D_{\text {dia }}+\Delta D\right) /(4 \Delta P)
$$

where $\mathrm{CC}$ is the compliance coefficient; $\Delta \mathrm{V}$ : change in arterial volume during the cardiac cycle; $\triangle \mathrm{A}$; change in lumen cross-sectional area; $\Delta \mathrm{D}$ : change in lumen diameter; $\Delta \mathrm{P}$ : pulse pressure; $\mathrm{D}_{\mathrm{dla}}$ : end-diastolic diameter.

The buffering capacity of an artery (compliance) is determined by arterial distensibility and arterial lumen volume. Arterial lumen volume is determined by arterial length and diameter, and it is obvious that a larger artery can more easily accept an oncoming pulse since it walls have to distend relatively less than those of a smaller artery to generate the same change in volume. Arterial distensibility is the relative change in volume for a given increase in pressure, or $(\Delta V / V) / \Delta P$. Analogous to the equations used for calculating compliance, the distensibility coefficient (DC) can be calculated from changes in lumen area during the cardiac cycle (Reneman et al. 1996): 


$$
D C \approx \Delta A /\left(A_{\text {diat }} \Delta P\right)
$$

Compliance and distensibility have a static and a dynamic component. Static mechanical properties are purely elastic and predominantly due to pressure distention. The vascular wall of large arteries is primarily composed of vascular smooth muscle cells and the connective tissue proteins elastin and collagen. It is generally accepted that a shift in the reliance on elastin and collagen fibers to support wall tension induces changes in static mechanics (Roach \& Burton, 1957; Bergel, 1961b; Wolinsky \& Glagov, 1964; Berry \& Greenwald, 1976). Cylindrical wall tension as defined by Laplace is the product of pressure and radius. At low values of wall strain, wall tension is primarily absorbed by elastin fibers (Roach \& Burton, 1957; Bergel, 1961b; Wolinsky \& Glagov, 1964; Berry \& Greenwald, 1976). As strain increases, collagen fibers are sequentially recruited (Roach \& Burton, 1957; Bergel, 1961b; Wolinsky \& Glagov, 1964; Berry \& Greenwald, 1976). Since collagen fibers are more rigid than elastin fibers, vascular elasticity demonstrates non-linear behavior under tonic conditions, i.e., the volume-pressure curve is sigmoidal (Figure 1.3) (Roach \& Burton, 1957; Bergel, 1961b; Wolinsky \& Glagov, 1964; Lee et al. 1993). Nonetheless, an arterial wall is not subjected to steady but to pulsatile forces. Pressure pulsatility constitutes the difference between static and dynamic mechanics. The vascular wall demonstrates viscoelastic behavior when subjected to pulsatile stress. The viscous behavior of the wall dampens the wall's compliance, i.e., the vascular wall absorbs a portion of the imposed stress. Viscoelastic behavior is frequency dependent; dynamic behavior is stiffer than static because the frequency of the pulsatile stress restricts the vascular wall from distending to its maximal capacity (Bergel, 1961a; Glaser et al. 1995). Although in vivo viscoelastic, or frequencydependent, behavior of arteries has been shown (Bergel, 1961a), little attention has been given to discerning between static and dynamic mechanical behavior in vivo.

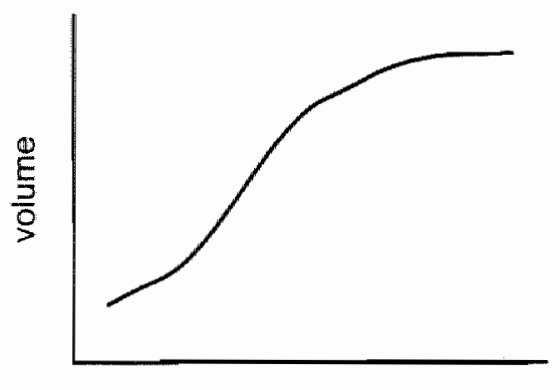

Figure 1.3

Non-linear relationship between pressure and large vessel volume.

pressure 
Not only vascular wall components, but the geometry of their arrangement may be important in influencing mechanical properties. While distensibility gives an indication of the behavior of the arterial wall as determined by its components and their arrangement, it does not characterize the elastic properties of the material itself. The Young"s incremental elastic modulus is a parameter better suited for describing material elasticity. As a material property, the Young's modulus ( $E_{\text {inc }}$ ) is characteristic of a given substance and is not affected by the geometry of a components arrangement. The Young's modulus corrects for the effects of wall geometry on distensibility as can be seen from the equation:

$$
E_{i n c}=D_{d i a} /(M t \cdot D C)
$$

For example, although the distensibility of a cylindrical shell may be reduced due to thicker walls, which require more energy to be displaced, the Young's modulus may not be altered indicating that the change in distensibility is not due to a change in the nature of the vascular wall components but due soley to an increase in its mass.

\section{Perspective}

Although diastolic lumen diameter, vascular wall structure, smooth muscle contractility distending pressure and pressure pulsatility are presumed to be involved in determining compliance, the exact contribution and interplay of these factors are not entirely clear. Although several recent studies suggest that distending pressure is the primary determinant of compliance (Hayoz et al. 1992; Laurent et al. 1993, 1994a), others point to the importance of vascular tone (Dobrin \&

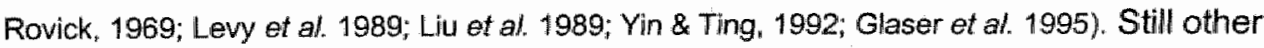
studies in experimental models of hypertension demonstrate that compliance decreases can be precluded by preventing structural changes (Levy et al. 1988; Benetos et al. 1992; Cabrera Fischer et al. 1993).

Although from these data, it is clear that vascular mechanics are influenced by a variety of hemodynamic, functional and structural parameters, evidence is surmounting to suggest that, at least initially, large arteries adapt their structure and geometry to alterations in hemodynamics in an attempt to maintain compliance. For example, in hypertension, the target pathology for most compliance research, vascular hypertrophy of large vessels is considered characteristic (Folkow, 1982; Devereux et al. 1994; Mulvany, 1994) and initially serves to normalize wall stress. Despite the increased media-to-lumen ratio, studies in hypertensive humans show that isobaric compliance and distensibility are not reduced (Hayoz et al. 1992; Laurent et al. 1993, 1994a, b; Laurent, 1995). This suggests that the elasticity of the wall in- 
creases, at least initially, to temper the effects of hypertrophy on compliance (Mulvany, 1992a; Laurent et al. 1994b; Weber et al. 1996).

Finally, when considering the interaction between large and small vessel hemodynamics, pulse pressure may be an important factor in influencing small artery structure since a positive correlation between pulse pressure reduction and small artery media-to-lumen ratio reduction has been described (Baumbach, 1991; Christensen; 1991). In turn, pulse pressure at a given point in the vascular tree is determined by both large vessel compliance and small vessel resistance, since peripheral resistance acts as a reflector for the pressure wave.

\section{Small artery mechanics: factors influencing resistance}

Arterial tone and function: While large vessels function to dampen pulse pressure, small arteries and arterioles regulate the distribution of flow by modifying resistance. The resistance of a vessel or vascular bed can be dramatically altered via vasodilator and vasocontrictor modulation of vessel lumen diameters as can be seen from the Hagen-Poiseuille equation:

$$
R=\frac{8 \pi I}{\pi r^{4}}
$$

where $R$ represents resistance, $\eta$ the viscosity of blood, I vessel length, and $r$ the radius of the vessel. For vessels in series, the total resistance is the sum of the individual resistances. For vessels in parallel, the reciprocal of the total resistance is equal to the sum of the reciprocals of the individual resistances.

The lumen diameter of a vessel can be regulated by local and remote mechanisms. Local mechanisms include auto- and paracrine factors secreted by the endothelium or vascular smooth muscle, mechanical stresses due to flow and pressure, electrical transmission between cells (Duling of al. 1991), and lastly metabolic end-products (Verhaeghe et al. 1978). Sympathetic nervous control and circulating hormones constitute the remote regulatory mechanisms.

In terms of local control mechanisms, the importance of the endothelium in regulating vascular tone can be deduced from the variety of vasoactive factors that it releases, including nitric oxide, prostaglandins, endothelium-derived hyperpolarizing factor, and endothelin (Lüscher ot al. 1992; Busse et al. 1993; Vanhoutte, 1993). Moncada and Palmer (1987) were the first to identify nitric oxide as the relaxing factor responsible for the endothelium-dependent vasodilation noted by Furgchott and Zawadski (1980) Nitric oxide is synthesized from L-arginine by the enzyme nitric oxide synthase. One isoform of this enzyme is constituitively expressed in endothelial cells; it has a basal activity that can be enhanced by increases in intracellular calcium. Additionally, there are an inducible and a 
neuronal isoform of nitric oxide synthase (Forstermann et at. 1994; Sessa; 1994). Inducible nitric oxide synthase is expressed in a variety of cells under pathological conditions. This isoform is not calcium-dependent and produces large quantities of nitric oxide without receptor stimulation (Forstermann et al. 1994; Sessa, 1994). The neuronal isoform is constituitively expressed in sympathetic nerve endings, and its activity tempers catecholamine release (Forstermann et al. 1994; Sessa, 1994). Nitric oxide is short-lived, but it can diffuse through the endothelial and smooth muscle cell membranes to activate soluble guanylate cyclase to produce cyclic GMP and induce smooth muscle relaxation (Moncada et al. 1991; Busse et al. 1993). As such, nitric oxide has been shown to play an important role in the regulation of blood flow and arterial pressure (Umans \& Levi, 1995). Nonetheless, while nitric oxide has been shown to play an important role in regulating tone in large vessels, endothelium-derived hyperpolarizing factor seems to gain importance as the vessel size gets smaller (Garland et al. 1995). Although endothelium-derived hyperpolarizing factor is as of yet unidentified, data suggest that it is a product of arachidonic acid metabolism that hyperpolarizes and relaxes the smooth muscle via calcium-dependent potassium channels (Komori \& Vanhoutte, 1990; Cohen \& Vanhoutte, 1995). Both vasodilator and vasoconstrictor prostaglandins are synthesized by cyclooxygenase and lipoxygenase in the endothelium. Prostacyclin relaxes vascular smooth muscle via cyclic AMP (Vanhoutte, 1993). Thromboxane $\mathrm{A}_{2}$ and prostaglandin $\mathrm{H}_{2}$ are the major vasoconstrictor products of cyclooxygenase (Lüscher et al. 1992; Vanhoutte, 1993). Endothelin-1 was first identifed by Yanagisawa and is now understood to be a family of three proteins that induce both vasoconstriction, via $E T_{A}$ receptors, and vasodilation, via $E T_{B}$ receptors (Yanagiswa et al. 1988; Battistini et al. 1993). While the release of these endotheliumderived vasoactive factors may be induced by pathways consequent to agonist activation of cell surface receptors, surmounting evidence suggests that also physical forces may activate the release of these factors (Davies et al. 1992; Nerem, 1993). As such, the endothelium plays an important role in vascular myogenic tone and flow-induced dilation (Rubanyi et al. 1990; Lamontagne et al. 1992; Bevan \& Henrion, 1994). .

Remote control of vascular reactivity originiating from the luminal side of the vessel comes from plasma spillover of neurohormones, such as angiotensin II from the lungs and catecholamines from the adrenal gland and the sympathetic nervous system. Stimulation of angiotensin $\|$ type $1\left(A T_{1}\right)$ receptors and $\alpha_{1}$ adrenoceptors induces vasoconstriction via a calcium-mobilizing cascade (Vanhoutte et al. 1981; Rogers \& Lokula, 1994). After binding of the agonists to their respective receptors, phospholipase $C$ is activated to hydrolyze phosphotidylinositol-biphosphate into inositol triphosphate and diacylglycerol (Berridge \& Invine, 1984; Hathaway ef al. 1989). Inositol triphososphate mobilizes calcium from intracellular stores, while diacylglycerol sensitizes the contractile 
appartus for calcium via protein kinase C (Berridge \& Irvine, 1984; Hathaway er al: 1989). Intracellular calcium levels may also be elevated from a, -adrenoceptor-mediated opening of voltage-operated calcium channels (Boonen \& De Mey 1990 ).

From the abluminal side of the vessel, vascular smooth muscle function is regulated by sympathetic and peptidergic nerves. Upon stimulation, sympathetic nerves release norepinephrine and the co-transmitters adenosine triphosphate and neuropeptide $Y$ into the synaptic cleft (Hirst \& Edwards, 1989). Norepinephrine binds post-junctionally to $\alpha_{1}$ - and $\alpha_{2}$-adrenergic receptors to induce vasoconstriction, and prejunctionally to $\alpha_{2}$-adrenoceptors to enhance neuronal uptake and inhibit further norepinephrine release (Bevan, 1978" Vanhoutte et al. 1981: Mulvany \& Aalkjaer, 1990). As mentioned above, norepinephrine induces calcium mobilization via the phosphoinositol cascade. While adenosine triphosphate and neuropeptide $Y$ also bind to post-junctional receptors to induce vasoconstriction, the peptidergic transmitters released from sensory motor nerves, e.g., calcitonin gene related peptide and substance $P$, stimulate vascular relaxation (Mulvany \& Aalkjaer, 1990; Lundberg et al. 1991).

Elevation of intracellullar calcium levels leads to the activation of myosin light chain kinase via calcium-bound calmodulin (Hathaway et al. 1989). Once the myosin light chain is phosphorylated, it binds with high affinity to actin. Contractile force ils generated by the hinging action of the myosin heads which slide the myosin filament relative to the actin fillament (cross-bridge formation). Phosphorylated cross-bridges can rapidly recycle and are thus important in initial and rapid force generation. A population of unphosphorylated cross-bridges, termed latch bridges, detach more slowly and contribute to the sustained maintenance of tension (Gerthoffer \& Murphy, 1983; Hathaway et al. 1989). Measurements have shown that the force per area, or stress, development capability of vascular smooth muscle cells from different vessels is similar under equal activation at non-pathological conditions (Mulvany, 1991). Thus, smooth muscle quantity and geometric rearrangement are likewise important in influencing the ability of a given vessel to generate force. For example, a vessel with a larger smooth muscle mass is able to produce more force than a vessel with a smaller muscle compartment. Furthermore, concerning vessels with the same muscular mass but different media-to-lumen ratios, the vessel with the greatest media-to-lumen ratio will generate the greatest force.

Arterial structure: Chronic hemodynamic and neurohormonal changes lead to alterations in vascular structure and geometry. As early as the 1950 's, Folkow and co-workers postulated and later experimentally demonstrated that changes in vascular media-to-lumen ratios may lead to the development and maintenance of hypertension (Folkow et al. 1958, 1970; Folkow \& Sivertsson, 1968). Since then, the concept of vascular remodelling has received much attention in the literature. Heagerty and coworkers (1993) were the first to coin the term remodelling to 
describe the rearrangement of a given amount of vascular material around a smaller lumen. Over the years, remodelling has come to mean any cardiac or vascular geometric change. In an attempt to clarify the multitude of vascular geometric changes, Mulvany et al. (1996) have proposed a classification scheme based on the change in lumen diameter paired with changes in media crosssectional area. This scheme is convenient for reference when describing the geometric changes induced by alterations in hemodynamic and neurohormonal factors.

Vascular remodelling is associated with pressure- and flow-dependent mechanisms. Pressure-dependent mechanisms seem to be synonymous with adaptations to increases in circumferential wall stress, calculated from the law of Laplace:

$$
\sigma=\frac{P \cdot r}{M t}
$$

where $\sigma$ is wall stress, $P$ arterial pressure, $r$ arterial radius and $M t$ media thickness. On the other hand, flow-dependent mechanisms normalize shear stress:

$$
T=\frac{4 n Q}{\pi r^{3}}
$$

where $\mathrm{T}$ represents shear stress, $\mathrm{\eta}$ blood viscosity, $\mathrm{Q}$ blood flow and $\mathrm{r}$ vessel radius. Changes in flow initially cause changes in lumen diameter to normalize shear stress. Once shear stress is normalized, vascular wall mass adapts to altered circumferential wall stress if the change in flow is chronic. Thus, flowinduced structural changes result in proportional adaptations without a change in media-to-lumen ratio as shown in Figure 1.4 (Langille, 1993; Mulvany et al. 1996). If increased pressure is the initial perturbing factor, structural alterations tend to lead to disproportional hypertrophy, an increase in media-to-lumen ratio, and normalized wall stress (Mulvany, 1992b; Langille, 1993). Treatments to reduce hypertension lead to exaggerated reductions in media-to-lumen ratio, as briefly summarized by Mulvany et al. (1996) These pressure-induced changes in mediato-lumen ratio are also demonstrated schematically in Figure 1.4. 

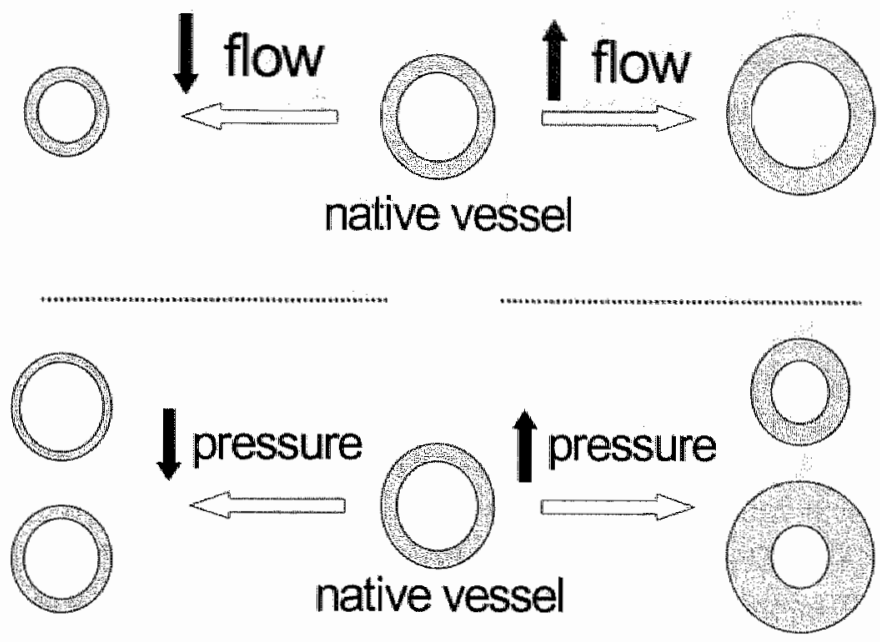

\section{Figure 1.4}

Diagram adapted from the proposition by Mulvany et al. (1996) to classify the types of arterial remodelling. This schematic shows the effect of hemodynamic changes on vascular geometry. Alterations in flow lead to proportional changes in vascular structure, $i . e_{.}$, without a change in media-to-lumen ratio. Alterations in pressure induce changes in media-to-lumen ratio. Increases in pressure result in decreased lumen diameters surrounded by either unchanged or increased media mass. Decreases in pressure result in larger diameters surrounded by unchanged or reduced media mass.

Whether supplementary to or divergent from hemodynamic-induced structural changes, a bulk of evidence exists to implicate the role of neurohormones in vascular structural changes. Vascular wall structure is determined by a balance of growth-stimulating and growth-antagonizing (or death-stimulating) factors. Current understanding supports the dual role of vasodilators as growth inhibitors and vasoconstrictors as growth promoters (Hahn ot al. 1993; Adams ot al. 1995; Duff et al. 1995; Mathew et al. 1996) in settings in which blood flow is not drastically changed. Indeed recent studies have shown that atrial natriuretic peptide inhibits growth (itoh et al. 1990; Appel, 1992), that nitric oxide stimulates apoptosis and furthermore that nitric oxide-induced apoptosis can be inhibited by angiotensin II via AT, receptors (Fukuo et al. 1996; Messmer et al. 1996; Pollman et al. 1996). On the other hand, vasoconstrictors such as endothelin, angiotensin $\|$ and catecholamines have been shown to induce vascular smooth muscle cell growth (Blaes \& Boissel, 1983; Hirata et al. 1989; Griffin et al. 1991; Chua et al. 1992; Schiffers ef al. 1993; Morbidelli et al. 1996; Yu et al. 1996). Although this is partially pressuredependent, pressure-independent mechanisms are also active. 
Compelling evidence substantiates the role of angiotensin 11 in inducing vascular smooth muscle hypertrophy, both in vitro and in vivo (Griffin et al. 1991; Boonen et al. 1993; Schiffers et al. 1993; Wiener et al. 1996). The effectiveness of angiotensin converting enzyme inhibitors in retarding or regressing hypertrophy in hypertensive models lends supplemental support to this tenet (Heagerty, 1991; Lee $t$ al. 1991). While angiotensin II has been shown to stimulate smooth muscle growth via AT, receptors (Koh et al. 1994. Sung et al. 1994), recent findings endorse the functional antagonism of $A T_{1}$ and $A T_{2}$ receptors (Itoh et al. 1993; Hein et al. 1995; Ichiki et al. 1995; Munzenmaier \& Greene, 1996; Yamada et al. 1996). As activation of AT receptors inhibits $A T_{1}$-mediated effects and vice versa, it seems that the proportion of receptor subtypes defines the ultimate response.

Catecholamines have likewise been shown to induce vascular smooth muscle growth, again both in vitro and in vivo (Blaes Boissel; 1983; de Blois et al. 1996; Schiffers et al. 1996). Intervention studies in young spontaneously hypertensive rats have additionally shown that antagonizing nerve development by sympathectomy or anti-nerve growth factor antibodies can partially prevent vascular remodelling (Lee et al. 1987; Korner et al. 1993).

Network structure: Hemodynamic and neurohormonal forces do not only affect the structure and geometry of individual vessels but also that of vascular networks. Relative increases in resistance may be achieved not only through changes in the structure and geometry of individual vessels but also through network architectural alterations (Hutchins \& Darnell, 1974; Chen et al. 1981; Le Noble et al. 1990). The length, diameter and branching pattern of vessels contribute to the minimal vascular resistance of a vascular bed. The importance of vascular networks in determining resistance was underlined in hypertension research where rarefaction, a reduction in the number of microvessels, has been found (Hutchins \& Damell, 1974; Chen et al. 1981; Prewitt et al. 1982: Le Noble et al. 1990). Rarefaction may be functional (vessels are not perfused under resting conditions) or structural (vessels are actively degraded) in nature (Hutchins \& Darnell, 1974; Prewitt et al. 1991). These network changes are already present in the early stages of development in spontaneously hypertensive rats, which suggests that they may be the cause and not the consequence of hemodynamic alterations (Struijker Boudier et al. 1990, 1992). Nonetheless, it has been shown that increased arterial pressure results in a reduction in the number of arterioles (Prewitt et al. 1991). Although wall stress adaptation may play a role in this phenomenon, other factors such as metabolic end-products, oxygen tension and blood flow are also likely to play a role (Price \& Skalak, 1994). 


\section{Arterial vasculature: structure and function in heart failure}

\section{Large artery mechanics: heart fallure}

Several studies in humans with heart failure suggest that systemic compliance is reduced and to a degree which correlates with ejection fraction (Pepine et al. 1978; Babalis et al. 1984). Although this reduction in systemic compliance is not always found (Laskey et al. 1990), local compliance has generally been found to be reduced (Hirai et al. 1989; Mohiaddin et al. 1989; Malcolm et al. 1991; Giannattasio et al. 1995). Several of these studies also demonstrate a clear relationship between aortic and coronary arteriosclerosis (Hirai et al. 1989; Mohiaddin et al. 1989), and it has been suggested that changes in stiffness of large arteries can be used as an early marker for coronary artery disease (Hiral et al. 1989). As such, decreased compliance in heart failure patients, if indeed due to atherosclerosis, is more likely a contributory factor in heart failure than a result of ensuing hemodynamic and neurohormonal changes.

Nonetheless, little attention has been directed to aortic mechanical properties in experimental heart failure models in which atherosclerosis is not present. Gaballa and coworkers (1995) report increased passive carotid artery stiffness in conjunction with increased collagen content in rats at six weeks after myocardial infarction. However, a recent study in our laboratory demonstrated no changes in the extracellular matrix protein content of the thoracic aorta up to three months after myocardial infarction (Heeneman et al. 1995).

\section{Small artery mechanics: heart failure}

\section{Arterial tone and function}

Vasodilator function: In contrast to the relatively sparse attention given to large artery mechanics, considerable attention has been spent on vasodilator function in heart failure. Reduced arterial vasodilator function may restrict biood flow to peripheral organs. After numerous clinical studies have demonstrated diminished acetylcholine-induced relaxations (Kubo et al. 1991; Drexler et al. 1992b; Katz et al. 1992, 1993; Hayoz et al. 1993), endothelial dysfunction is generally accepted as being characteristic of heart failure, but questions still remain as to which vasodilator or vasoconstrictive factors are responsible for this abnormality.

In experimental heart failure, numerous studies in the myocardially-infarcted rat have reported depressed acetylcholine-induced relaxation in isolated aortae (Ontkean et al. 1991; Lindsay et al. 1992; Buikema et al. 1993; Teerlink et al. 1993). Although this was sometimes an endothelium-dependent phenomenon (Lindsay et al. 1992; Teerlink et al. 1993), coincident decreases in endothelium-independent dilator responses have also been found (Ontkean et al. 1991; Buikema et al. 1993). Since impaired non-specific vasodilatory capability has also been found in human heart failure (Imaizumi et al. 1985; Katz et al. 1992, 1993), the assessment of endothelial versus aspecific vasodilator dysfunction should be differentiated. 
Furthermore, acefylcholine-induced relaxations are often assumed to be synonymous with stimulated nitric oxide release. However, acetylcholine also stimulates the release of prostaglandins and endothelium-derived hyperpolarizing factor in addition to nitric oxide. Indeed in the femoral artery of dogs with pacinginduced heart failure, Kaiser and co-workers (1989) demonstrated that diminished acetylcholine responses could be normalized with indomethacin. Increased vasoconstrictive prostaglandin levels have likewise been demonstrated in human heart failure (Katz et al. 1993).

While the majority of heart failure studies have investigated vasodilator function in large vessels, surmounting evidence suggests that, while nitric oxide is the primary endothelium-derived relaxing factor in large vessels, endothelium-derived hyperpolarizing factor gains importance in resistance beds (Garland et al. 1995). A recent study by Baggia and coworkers (1997) finds endothelial dysfunction in large but not in resistance arteries and suggests that endothelium-dependent relaxation is only reduced in vessels in which nitric oxide-induced relaxation plays a substantial role. However, since two other groups present data supporting the development of endothelial dysfunction in the resistance vasculature in experimental heart failure (Drexler \& Lu, 1992; Mulder et at. 1996), it is possible that endothelium-derived hyperpolarizing factor production is also abnormal in heart failure.

Any consensus in the aberrance of acetylcholine-induced responses in heart failure is countered by the divergency in reports on basal nitric oxide release. The basal activity of nitric oxide synthase has been estimated from contractions resulting from blockade of the enzyme or from plasma nitrate levels. Habib and co-workers (1994) showed that the increase in resistance in response to nitric oxide synthase blockade was greatest in heart failure patients with the highest systemic vascular resistance. Kubo et al. (1994) failed to find abnormal contractions to nitric oxide synthase inhibition in the forearms of heart failure patients in which local vascular resistance was not increased compared to controls. Furthermore, preserved contractions to nitric oxide synthase blockade was found in virtually all peripheral vascular beds of rats with heart failure induced by myocardial infarction (Drexler \& Lu, 1992; Drexler et al. 1992a). As baseline vascular resistance was not increased in the aforementioned studies, many observed alterations in basal nitric oxide synthase activity in heart failure may be more the consequence of differences in the level of vascular resistance than differences in the intrinsic activity of the enzyme.

Plasma nitrate concentrations are also often taken as indicative of basal nitric oxide synthase activity. In the case of septic shock, the massive amounts of nitric oxide produced by the inducible nitric oxide synthase isoform are reflected in plasma nitrate levels (Tracey et al. 1995). However, under normal conditions or in pathologies in which inducible nitric oxide synthase is not systemically upregu- 
lated, possible limitations in the use of plasma nitrate values have been brought forth (Ohyanagi et al. 1992). Indeed, although Winlaw et al. (1994) reported increased plasma nitrate levels in heart failure patients compared to volunteers, patients taking nitrate-containing medication were not found to have higher nitrate levels than those patients not receiving such medication.

Thus, all in all, agonist-stimulated vasodilator capacity seems to be reduced in patients with heart failure. This may impede organ blood flow recruitment. However, since vascular tone is the sum of vasodilator and vasoconstrictor influences, examining contractile function is also necessary.

Vasoconstrictor function: The importance of a balance in dilator and contractile input in modulating vascular function can be derived from pathologies such as hypertension and atherosclerosis in which a disbalance in these factors has been shown to induce vascular dysfunction (Lüscher et al. 1993). Several studies suggest that such a shift also occurs in heart failure (Main et al. 1991; Teerlink et al. 1994; Okumura et al. 1996). While Teerlink et al. (1994) and Okumura et al. (1996) suggest that decreased endothelium-derived relaxing factors contribute to vascular hyperreactivity in large vessels, Main et al. (1991) suggests that increased $\alpha_{2}$ mediated nitric oxide release may mitigate adrenoceptor-mediated vasoconstriction in coronary arteries. Heart failure is hallmarked by an increase in total peripheral resistance, which leads to decreased blood flow to major peripheral beds (Drexler et al. 1986; Leier, 1992). While this may be the result of reduced vasodilator capacity, increased vascular tone or exaggerated contractile properties may also be involved. Circulating levels of both angiotensin II and endothelin have been demonstrated in heart failure (Svengaard et al. 1993; Wei et al. 1994; Galatius-Jensen et at. 1996). Furthermore, increased plasma levels of catecholamines have been shown to stem not only from reduced plasma clearance, but also from elevated plasma spillover (Hasking of al. 1986, 1988; Leimbach ef al. 1986; Kaye et al. 1994).

Although contractile responsiveness to $\alpha$-adrenergic stimulation has been reported to be enhanced in dorsal pedal arteries of dogs with pacing-induced heart failure (Forster et al. 1989), various studies report reduced instead of exaggerated constrictor capacity (Angus et al. 1993; Kiuchi et al. 1993; Stassen et al. 1997a). Teerlink and coworkers (1993) recently demonstrated hyporeactivity to $\alpha$ adrenergic stimuli and potassium in denuded thoracic aortas of rats at one week after myocardial infarction. Stassen et al. found no alteration in rat thoracic aorta responsiveness five weeks after myocardial infarction (1997a) and a hyporeactivity to vasoconstrictors in mesenteric resistance arteries which was most pronounced during $\alpha_{1}$-adrenoceptor stimulation $\left(1997 a_{n}\right.$ b) In subcutaneous resistance arteries from patients with heart failure, Angus and coworkers (1993) similarly demonstrated diminished contractile reactivity. Diminished contractile function may subserve the "viscious cycle" of heart failure by perpetuating the need for 
additional vasoconstrictor neurohormones to maintain perfusion pressures. Furthermore, failure to generate resistance in a vascular bed may enthance edema formation by increasing capillary pressures. These chronic alterations in hemodynamics and neurohormone levels may ultimately induce structural changes in peripheral arteries.

Vessel and network structure: Peripheral resistance can be increased functionally or structurally. Given that heart failure is characterized by systemic and local neurohormone activation and that vasoconstrictors can function as growth factors (Berk \& Alexander, 1989; Schunkert et al. 1993; Svengaard et al. 1993; Dzau et al. 1994; Adams et al. 1995), structural adaptations in heart failure warrant examination. As early as 1970, Zelis and coworkers suggested that increased arterial sodium content may help contribute to increased arterial stiffness. Both the groups of Longhurst (1975) and Lindsay (1994) reported microcirculatory abnormalities such as thickened capillary basement membranes, which may reduce oxygen diffusion. While the latter found no reduction in total capillary cross-sectional area from these skeletal muscle biopsies (Lindsay et al. 1994), Duprez et al. (1996) recently reported increased capillary diameters but decreased hyperemic responses in the nailfold capillary bed. In the resistance vasculature, increased media thicknesses in intramuscular arterioles have been reported at one year after myocardial infarction in rats (Schieffer et al. 1995). In accordance with these results, Wroblewski et al. (1992) demonstrated increased minimal vascular resistance in heart failure patients. Several studies by us and others however failed to demonstrate structural alterations in rat mesenteric resistance vasculature from five weeks to one year after myocardial infarction (Heeneman et al. 1995; Mulder et al. 1996; Stassen et al. 1997a). Only recently have studies been carried out to examine large vessel structure during heart failure. Gaballa and coworkers (1995) report smaller media cross-sectional areas in rat carotid arteries at six weeks after myocardial infarcthon. In a comprehensive study, Heeneman et al. (1995) examined the time course for the development of structural alterations in various large vessels in the coronary artery ligated-rat. Reductions in media cross-sectional area of the abdominal aorta, and the carotid and renal artery, were noted at five weeks after myocardial infarction. At twelve weeks post-myocardial infarction, reduced media cross-sectional areas of the thoracic and abdominal aorta, superior mesenteric, renal and carotid arteries were observed. This corresponded with smaller lumen diameters in the thoracic aorta, superior mesenteric artery and renal artery and with smaller media-to-lumen ratios in the abdominal aorta and and carotid artery. 


\section{Skeletal muscle and respiratory alterations in heart failure}

Prominent symptoms in heart failure patients which limit mobility and impair quality of life are fatigue and breathlessness. Although it has classically been taught that fatigue results from insufficient oxygen delivery due to reduced cardiac pumping capability and the corresponding build-up of by-products of anaerobic metabolism, the lack of correlation between fatigue and cardiac function in heart failure patients suggests that pathological changes in the periphery contribute to the quickened fatigue response (Zelis et al. 1974; Franciosa et al. 1981; Szalchcic et al. 1985; Lipkin \& Poole-Wilson, 1986). Nonetheless, deterioration in respiratory function may also intensify symptoms. Pulmonary and ventilatory abnormalities are also thought to be responsible for dyspnea, or breathlessness.

Support for the role of peripheral mechanisms in perception of fatigue stems from studies in which augmenting blood flow during exercise does not reduce the symptoms of fatigue (Wilson et al. 1983; Mancini et al. 1990). Indeed, patients with relatively normal blood flow responses to exercise still demonstrated symptoms of exercise intolerance and fatigue (Wilson et al. 1993). Although skeletal muscle blood flow is often impaired in heart failure (Sullivan et al. 1989; Musch \& Terrell, 1992), possibly due to excessive sympathetic-mediated constriction or diminished vasodilatory capacity (Hasking et al. 1986; Le Jemtel et al. 1986), this does not seem to be the sole reason for heightened fatigue in heart failure patients.

On the other hand, while these changes in blood flow may not be directly responsible for exertional fatigue, they may indirectly lead to intrinsic skeletal muscle alterations. Numerous studies in humans and experimental animal models report diminished activity of aerobic enzymes, which are involved in the aerobic transfer of energy from foodstuffs to the high-energy phosphate bonds of ATP (Sullivan et al. 1990, 1991; Ralston et al. 1991; Drexler ot al. 1992c; Thompson ot al. 1994; Schaueiberger et al. 1996). Ultra-structural abnormalites in mitochondria, the organelles in which metabolic processes such as the citric acid cycle, oxidative phosphorylation, and fatty acid oxidation occur, have also been described (Drexler et al. 1992c). Taken together, these findings suggest that the capacity of skeletal muscle for aerobic metabolic processes is reduced in heart failure. Additional support for this hypothesis comes from reports of reduced maximal oxygen consumption (Sullivan et al. 1990; Drexler et al. 1992c; Schauelberger et al. 1996), which furthermore correlates with the noted reduction in enzyme activities (Drexler, 1992; Drexler et al. 1992c). Impaired oxygen utilization leads to quickened depletion of energy stores. In fast-twitch (type II) skeletal muscle, adenosine triphosphate levels suffice to sustain contractile activity for less than a second, and high-energy phopsphoryl groups are transferred from phosphocreatine to adenosine diphosphate to regenerate the triphosphate compound. Accelerated phosphocreatine depletion, depressed adenosine triphosphate recycling and increased intracellular acidosis have concordantly been observed in heart failure 
during exercise (Massie et al. 1987; Arnolda et al. 1991; Mancini et al. 1992b; Chati et al. 1994; Thompson et al. 1995; Kemp et al: 1996) and also during rest (Mancini et al. 1989; Bernocchi et al. 1996). Figure 1.5 presents a schematic representation of the metabolic processes generating energy in skeletal muscle cells and indicates which processes have been shown to be aberrant in experimental or clinical heart failure. As slow twitch (type I) muscle fibers utilize aerobic metabolism and fast twitch glycolytic metabolism; it is perhaps not surprising that several studies report a shift from type I to type II fibers, both from histological observations (Sullivan et al. 1990; Drexler et al. 1992c; Sabbah et al. 1993; Simonini et al. 1996) and molecular biology studies (Simonini et al. 1996).

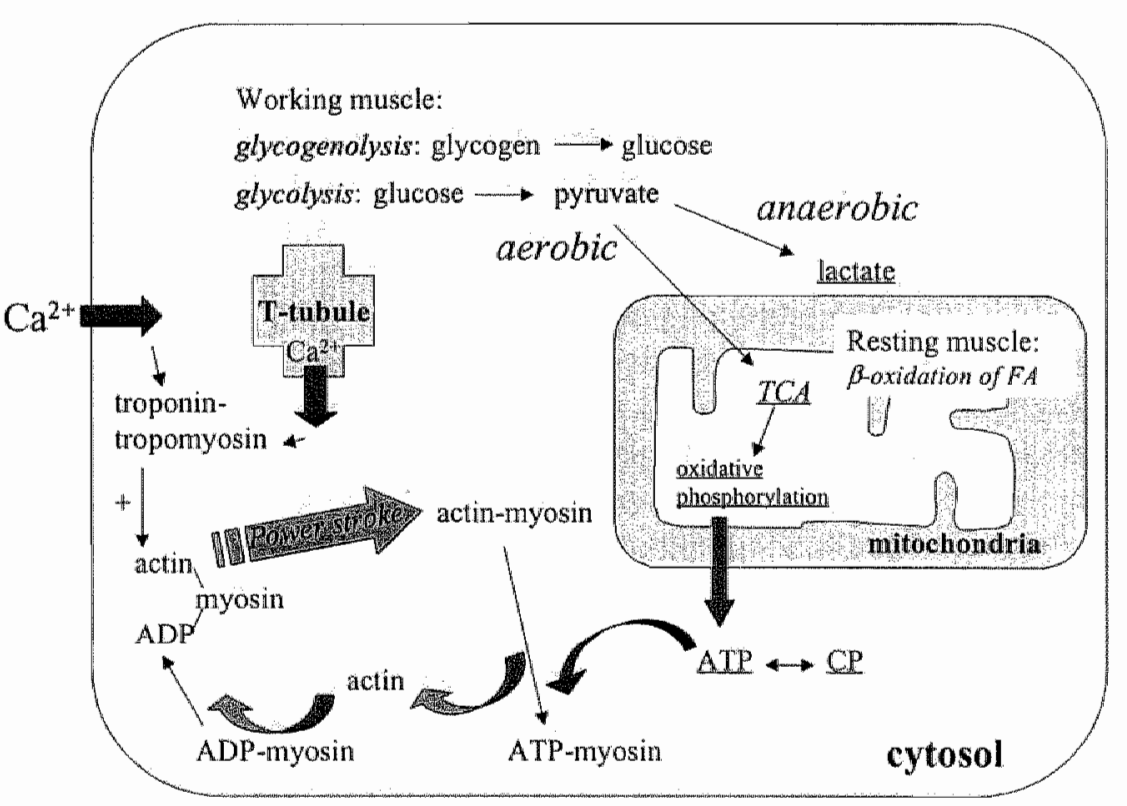

\section{Figure 1.5}

Schematic representation of the comparmentalization of skeletal muscle metabolic pathways which supply energy for contraction. Underlining denotes documented abnormalities in heart fallure. AT(D)P: adenosine tri(di) phosphate; CP: creatine phosphate; TCA: tricarboxylic acid cycle; FA: fatty acids.

Despite the fact that muscle atrophy has been demonstrated in patients with heart failure, muscle wasting does not seem to be the cause of exercise intolerance (Mancini et al. 1992b). Since the force generation per muscular mass is retained, it has been suggested that fatigue is due to intrinsic alterations in the 
endurance capacity of the muscle (Minotti et al. 1993). Also along these lines, skeletal muscle metabolic abnormalities seem not to be due to malnutrition (Broquist et al. 1994).

While, as discussed above, exercise capacity correlates poorly with hemodynamic indices of heart failure, reductions in peak oxygen consumption correlate with ventilatory abnormalities (Buller \& Poole-Wilson, 1990; Davies et al. 1991). Pulmonary dysfunction in heart failure arises from lung compression, pulmonary venous hypertension and low cardiac output. Cardiac enlargement and pleural effusion reduce the intrathoracic space; the resulting lung compression is referred to as a restrictive defect. Pulmonary venous hypertension arises as a consequence of retrograde transmission of increased left atrial pressures. Heightened pulmonary capillary bed pressures lead to an accumulation of fluid in the interstitial space. When sufficient fluid can not be drained away by lymphatic vessels and the pressure in the interstitial space exceeds alveolar pressure, pulmonary edema ensues. Chronic pulmonary venous hypertension leads to interstitial fibrosis which, although a protective mechanism against further edema formation, reduces lung compliance.

Pulmonary edema induces both restrictive and obstructive, i.e., restricting airway flow, defects in respiratory function. Furthermore, pulmonary edema contributes to reduced pulmonary diffusion capacity (Clark \& Coats, 1994b). Studies have shown that the ventilatory response, expressed as ventilation per unit carbon dioxide production, is enhanced in heart failure patients but that blood gasses are retained at normal levels (Rubin ot al. 1982; Clark \& Coats, 1994a). Although this suggests that pulmonary diffusion capacity may be decreased, i.e., more ventilation is necessary to achieve normal blood gases, this has not been consistently demonstrated. On the other hand, it has been demonstrated that patients ventilate more because of an increase in pulmonary dead space (Sullivan et al. 1988; Metra et al. 1992). Increases in pulmonary dead space are the result of ventilation-perfusion mismatching. Ventilation-perfusion mismatching occurs even in normal individuals due to the effects of hydrostatic pressure; the upper lobes are poorly ventilated and perfused compared to the lower lobes. In heart failure, ventilation is reduced by bronchial edema as mentioned above, and pulmonary hypoperfusion results from decreased cardiac output. Furthermore, expiratory muscle weakness, which leads to decreased expiratory pressure, is another mechanism by which pulmonary dead space is increased and has been demonstrated in heart failure (Hammond et al. 1990; Mancini et al. 1992a: McParland et al. 1992; Chua et al. 1995). Thus, increased pulmonary dead space may be a mechanism for the increased ventilatory response. Besides expiratory muscle weakness, decreased inspiratory pressures have also been shown (Hammond et al. 1990; Mancini et al. 1992a; Chua et al. 1995), and it is suggested that this is due to reductions in the strength and fatiguability of the diaphragm (Lecarpentier ot al. 1993; 
Supinski at al. 1994). Nonetheless, Mancini et al. (1992a) demonstrated that diaphragmatic work is drastically increased in heart fallure patients, probably due to increased bronchial resistance and decreased lung compliance (Light \& George, 1983; Peterman et al. 1987). All in all, increased bronchial resistance, lung stiffness, and ventilation-perfusion mismatching, especially in light of abnormalities in diaphragm function, undermine respiratory function. Such mechanisms undoubtedly contribute to enhanced perceptions of breathlessness and fatigue and the progression of heart failure.

Briefly summarizing, the growing incidence of heart failure is alarming, especially in light of the frightening morbidity and mortality rates. Not only the variance of etiologies, but also the fact that heart failure is a "whole body" disease make it a challenge for cardiovascular researchers as well as clinicians. Evidence abounds to show that hemodynamic and neurohormonal changes lead to alterations in cardiac, vascular, pulmonary and muscular function and that these changes feed upon each other in a negative spiral. Despite these observations, many of the mechanisms and complex interactions contributing to this disease remain unresolved.

\section{This thesis}

\section{The model}

Ligation of the left coronary artery in the rat leads to infarction of the left ventricle and results in hemodynamic alterations comparable to those characterizing clinical heart failure. Acute cardiac depression with decreased cardiac output and stroke volume (Schoemaker et al. 1990b) is followed by a period of circulatory compensation which deteriorates into overt heart failure characterized by elevated left ventricular end diastolic pressures, increased total peripheral resistance, left ventricular hypertrophy, and pulmonary congestion (Pfeffer et al. 1985; Drexler et al. 1986; Bech et al. 1989; DeFelice et al. 1989; Schoemaker et al. 1990a). As such, this model shares features analogous to those seen in clinical heart failure. Due to the extent of the surgical procedure, control experiments are performed in animals which have undergone a sham surgery in which the ligature is placed superificially in the left ventricular wall near the coronary artery and not securely tied.

In addition to the study of hemodynamic changes after myocardial infarction, this model has been utilized to investigate the development of cardiac structural changes, including structural remodelling of the left ventricle (Pfeffer \& Braunwald, 1990; Anversa et al. 1993; Smits et al. 1995), cellular changes in surviving myocytes (Schwarz et al. 1993; Neubauer et al. 1995; Pieruzzi et al. 1995; Blankesteijn et al. 1996), fibrotic and necrotic changes in the infarcted area (Jalil et al. 1989; Brilla, 1994; Smits et al. 1995) and vascular growth in remnant myocardium (Olivetti et al. 1989; NelissenVrancken et al. 1996). Furthermore, aspects of vascular contractile and dilator 
function (Drexler \& Lu, 1992; Teerlink et al. 1994, Stassen of al 1997a, b) as well as skeletal muscle alterations (Musch et al. 1990; Thompson et al. 1994, 1995; Simonin et al: 1996) have been addressed. Lastly, intervention studies have been applied to consider mechanisms conferring the beneficial effects of angiotensin converting enzyme inhibitors in heart failure treatment. Angiotensin converting enzyme inhibitors have been shown to improve systemic hemodynamics (Plieffer et al. 1985; Schoemaker et al. 1991), retard left ventricle hypertrophy and fibrosis (Pfeffer et al. 1985; Smits et al. 1995), and prevent vascular endothelial dysfunction (Thuillez et al. 1995; Mulder et al. 1996; Okumura et al: 1996). All in all, this model has been sufficiently characterized and proven to exhibit many of the symptoms seen in climical heart failure.

\section{The hypothesis}

This thesis is based on the hypothesis that the progression of heart fallure is due to a negative spiral in which adaptive processes that serve to maintain homeostasis on a short-term basis ultimately contribute to the progression of the disease. We postulate that chronic changes in hemodynamics and neurohormonal levels induce functional and structural changes in the vasculature the respiratory system and the skeletal muscles. In turn, the changes in these organ systems undermine heart function and consequently affect hemodynamics and neurohormonal activation, thus further perpetuating the downward spiral. Also, since many of the symptoms of heart failure, such as edema, dyspnea and fatigue, arise from peripheral adaptation mechanisms, it is interesting to examine these peripheral adaptive mechanisms in more detail. This thesis specifically investigates the development of peripheral vascular adaptations in experimental heart failure and speculatively attempts to piece them into the puzzle of the progression from compensatory to decompensatory heart failure.

\section{The experiments}

In Chapter 2, we expanded the hemodynamic characterization of heart failure progression in rats with time-related changes in systemic neurohormonal levels. Chapters 3,4 , and 5 investigate factors affecting aortic compliance and mechanics. Chapter 3 deals with the influence of angiotensin II-induced increases in vascular wall mass on isobaric compliance. Chapter 4 delves more into detail by assessing the nature of the static and dynamic mechanical behavior of the aorta and the modulatory role of angiotensin-II induced increases in wall mass and tone therein. $A T_{1}$ and $A T_{2}$ receptor antagonism was utilized in Chapter 5 to investigate angiotensin $\|$-mediated effects on aortic compliance and ellasticity in sham-operated and myocardially infarcted rats.

Chapters 6,7 and 8 are concerned with factors influencing resistance in the hindlimb vascular bed of rats. As discussed above, acetylcholine-induced 
dilatations are often utilized to assess endothelium function in heart failure, but the lack of consensus concerning the contribution of nitric oxide to these responses motivated us to examine the components of this response in the hindimb vasculature in Chapter 6 . As possible alterations in basal nitric oxide synthesis and local angiotensin $1 /$ production in this model were not excluded from the neurohormonal findings of Chapters 2 and may be relevant in human heart failure, we chose to examine the effects of chronically elevating angiotenin II plasma levels and chronically inhibiting nitric oxide production on hindlimb arterial structure and contractile responsiveness as described in Chapter 7. Lastly, in Chapter 8 , we characterized the dilatory and contractile responsiveness of the perfused hindlimb at various time points in the progression of heart failure. Although endothelium-dependent dilator dysfunction did not develop in three months after myocardial infarction in this model, contractile dysfunction was noted. Since, from the findings of Chapter 7, NO and/or angiotensin II might be involved in the development of this abnormality, we tested the effects of intervention with the NO synthase inhibitor L-NAME and the angiotensin converting enzyme inhibitor captopril on vasoconstrictor reactivity after myocardial infarction.

The last chapter, Chapter 9 , the coherence of these findings is discussed, especially in terms of their relationship to the progression of heart failure and their relevance to the clinical situation.

\section{References}

AdAMS MA, THOMPSON KE, BANTING JD, MADIGAN MA \& FRIBERg P (1995). Evidence for in vivo induction of cardiovascular growth processes by vasoconstrictor systems. Blood. Press. Suppl. 2, 61-67.

ANGUS JA, FERRIER CP, SUdHR K, KAYE DM \& JENnINGS GL (1993). Impaired contraction and relaxation in skin resistance arteries from patients with congestive heart failure. Cardiovasc. Res. 27, 204-210.

ANVERSA P, LI P, ZHANG X, OLIVETTI G \& CAPASSO JM (1993). Ischaemic myocardial injury and ventricular remodeling. Cardiovasc. Res. 27, 145-157.

APPEL RG (1992). Growth-regulatory properties of atrial natriuretic factor. Am. J. Physiol. 262, F911-F918.

ARAI M MATSUI H \& PERISSAMY M (1994). Sarcoplasmic reticulum gene expression in cardiac hypertrophy and heart failure. Circ. Res. 74, 555-562.

ARnolda L, Brosnan J, Rajagopalan B \& RAdDA GK (1991). Skeletal muscle metabolism in heart failure in rats. Am. J. Physiol. 261, H434-H442. 
BABALIS D; LEVY BI, AZANCOTI, MASQUET C \& BEAUFILS P (1984). Ventricular function and arterial compliance in patients with congestive cardiomyopathy: Int. $J$. Cardiol. 5 ; 361-364.

BAGGIA S, PERKINS K \& GREENBERG B (1997). Endathelium-dependent relaxation is not uniformly impaired in chronic heart fallure. J. Cardiovasc. Pharmacol. 29, 389-396.

BAKER KM, CHERNIN MI" WIXSON SK \& ACETO JF (1990). Renin-angiotensin system involvement in pressure-overload cardiac hypertrophy in rats. Am. J Physiol. 259, H324-H332.

BATTISTINI B, D'ORLEANS-JUSTE P \& SIROIS P (1993). Endothelins: circulating plasma levels and presence in other biologic fluids. Lab. Invest. 68, 600-628.

BAUMBACH GL (1991). Is pulse pressure a stimulus for altered vascular structure in chronic hypertension? Hypertension 18, 728-729.

BECH OM, KaHR O, Diamant B \& Steiness E (1989). Time course of functional deterioration after coronary artery ligation in rats. Cardiovasc. Res. 23, 649-654.

Benietos A, Bouaziz H, Albaladejo P, Levy BI \& Safar ME (1992). Physiological and pharmacological changes in the carotid artery pressure-volume curve in situ in rats. $J$ Hypertens, 11(Suppl. 6), S127-S131.

BERGEL DH (1961a). The dynamic elastic properties of the arterial wall. Journal of Physiology - London 156, 458-469.

BERGEL DH (1961b). The static elastic properties of the arterial wall. Journal of Physiology - London 156, 445-457.

BERK BC \& ALEXANDER RW (1989). Vasoactive effects of growth factors. Biochem. Pharmacol. 38, 219-225.

Bernocchi P, Ceconi C, Pedersini P, Pasini E, Curello $S$ \& Ferrari R (1996). Skeletal muscle metabolism in experimental heart failure. J. Mol. Cell. Cardiol. 28, 22632273.

BERRIDGE MJ \& IRVINE RF (1984). Inositol triphosphate: a novel second messenger in cellular signal transduction. Nature 312, 315-321.

BERRY CL \& GREENWALD SE (1976). Effects of hypertension on the static mechanical properties and chemical composition of the rat aorta. Cardiovasc. Res. 10, 437-451.

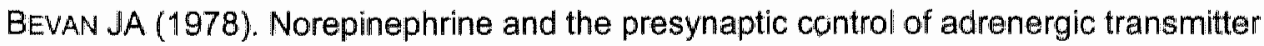
release. Fed. Proc. 37, 187-202. 
BEVAN JA \& HENRION D (1994). Pharmacological implications of the flow-dependence of vascular smooth muscle torre. Ann. Rev. Pharmacol. Toxicol. 34, 173-190.

BLAES N \& BOISSEL. JP (1983), Growth-stimulating effect of catecholamines on rat aortic smooth muscle cells in culture, $J$ Cell. Physiol. 116, 167-172.

BLANKESTEIJN WM, ESSERS-JANSSEN Y, ULRICH MMW \& SMITS JFM (1996). Increased expression of a homologue of drosophila tissue polarity gene "frizzled" in left ventricular hypertrophy in the rat, as identified by subtractive hybridization. J. Mol. Cell. Cardiol. 28, 1187-1191.

DE BLOIS D, SCHWARTZ SM, VAN KLEEF EM, SU JE, GRIFFIN KA, BIDANI AK, DAEMEN MJ \& LOMBARDI DM (1996). Chronic $\alpha_{1}$-adrenoceptor stimulation increases DNA synthesis in rat arterial wall. Modulation of responsiveness after vascular injury. Arterioscl. Thromb. Vasc. Biol. 16, 1122-1129.

BOHELER KR \& SCHWARTZ K (1992). Gene expression in cardiac hypertrophy. Trends Cardiovasc. Med. 2, 176-182.

BONNEUX L, BARENDREgt J, MEester K, BONSEL GJ \& VAN DER MAAS PJ (1994). Estimating clinical morbidity due to ischemic heart disease and congestive heart failure. Am. J. Public Health 84, 20-28.

BOONEN HCM \& DE MEY JGR (1990). Increased calcium sensitivity in isolated resistance arteries from spontaneously hypertensive rats: effects of dihydropyridines. Eur. J. Pharmacol. 179, 403-412.

BoONen HCM, DAEMEN MJAP, Eerdmans PHA, FAZZI GE, VAN KLeEF EM, SCHIfFers PMH \& DE MEY JGR (1993). Mesenteric small artery changes after vasoconstrictor infusion in young rats. J. Cardiovasc. Pharmacol. 22, 388-395.

BRILLA CG (1994). The candiac structure-function relationship and the renin-angiotensinaldosterone system in hypertension and heart failure. Curr. Opin. Cardiol. 9(Suppl. 1), S2-\$11.

Bristow MR, Ginsburg $R$, Minobe $W$, Cubicciotti $S$, SAgeman WS, Lurie K, BILLINGHAM ME, HARRISON DC \& STINSON EB (1982). Decreased catecholamine sensitivity and $\beta$-adrenergic-receptor density in failing human hearts. N. Engl. J. Med. $307,205-211$

Bristow MR, Ginsburg R, Umans $V$, Fowler M, Minobe W, RAsmussen R, Zera P, MENLOVE R, SHAW P, JAMIESON S \& STINSON EB (1986). $\beta 1$-and $\beta 2$-adrenergic receptor subpopulations in non-failing and failing human ventricular myocardium: coupling of both receptor subtypes to muscle contraction and selective $\beta 1$-receptor down regulation in heart fallure. Circ. Res. 59, 297-309. 
BROOVIST M, ARNOVIST H, DAHLSTROM U, LARSSON J, NYLANDER E \& PERMERT J (1994). Nutritional assessment and muscle energy metabolism in severe chronic congestive heart failure - effects of long-term dietary supplementation. Eur. Heart. J. 15, 1641-1650.

BUIKEMA H, VAN GILST WH, VAN VELDHUISEN DJ, DE SMET BJGL, SCHOLtens E, LIE KI \& WESSELING $H$ (1993). Endothelium dependent relaxation in two different models of chronic heart failure and the effect of ibopamine. Cardiovasc. Res. 27, 2118-2124.

BULLER NP \& POOLE-WILSON PA (1990). Mechanism of the increased ventilatory response to exercise in patiients with chronic heart failure. Br. Heart J.63, 281-283.

Busse R, MÜLCH A, FLEMING I \& HeCKER M (1993). Mechanisms of nitric oxide release from the vascular endothelium. Circulation 87(Suppl. 5), V18-V25.

Cabrera Fischer El, Levenson J, Barra JG, Armentano Rl, Pichel RH \& Simon A (1993). Preventive effect of chronic converting enzyme inhibition on aortic stiffening induced by renovascular hypertension in conscious dogs. Cardiovasc. Res. 27, 10391044.

Chati Z, Zannad F, Robin-Lherbier B, Escanye J-M, Jeandel C, Rogert J \& Aliot E (1994). Contribution of specific skeletal muscle metabolic abnormalities to limitation of exercise capacity in patients with chronic heart failure: A phosphorous 31 nuclear magnetic resonance study. Am. Heart J. 128, 781-792.

CHATTERJEE K (1996). Heart failure therapy in evolution. Circulation 94, 2689-2693.

CHEN II, PREWITT RL \& DOWELL RF (1981). Microvascular rarefaction in spontaneousiy hypertensive rat cremaster muscle. Am. J. Physiol, 241 "H306-H310.

CHRISTENSEN KL (1991). Reducing pulse pressure in hypertension may normalize small artery structure. Hypertension 18, 722-727.

CHUA BHL, KREBS CJ, CHUA CC \& DIGLIO CA (1992). Endothelin stimulates protein synthesis in smooth muscle cells. Am. J. Physiol. 262, E412-E416.

CHUA TP, ANKER SD, HARRINGTON D \& COATS AJS (1995). Inspiratory muscle strength is a determinant of maximum oxygen consumption in chronic heart failure. Br. Heart $J$. 74, 381-385.

CLARK AL \& COATS AJS (1994a). Lessons from arterial blood gas estimations during exercise in patients with chronic heart failure. Br. Heart J. 71, 528-530.

CLARK A \& COATS A (1994b). Mechanisms of exercise intolerance in cardiac failure: abnormalities of skeletal muscle and pulmonary function. Curr. Opin. Cardiol. 9, 305314. 
Clayell AF, STINGO A, MARgulies K, LERMAN A, UNDERWOOD D \& BURNETT JC (1993). Physiological significance of endothelin: its role in congestive heart failure. Circulation 87(Suppl. 5), V45-V50.

CLELAND JGF \& DUTKA DP (1994). Optimising heart failure pharmacotherapy: The ideal combination. Br. Heart J. 72, 73-79.

COHEN RA \& VANHOUTTE PM (1995). Endothelium-dependent hyperpolarization: beyond nitric oxide and cyclic GMP. Circulation 92, 3337-3349.

COHN JN (1990). Neuroendocrine activation after acute myocardial infarction. Am. J. Cardiol. 65, 281-311.

COHN JN, LeVIne TB, Olivari MT, Garberg V, LuRA D, Francis GS, Simon AB \& RECTOR T (1984). Plasma norepinephrine as a guide to prognosis in patients with chronic congestive heart failure. N. Engl. J. Med. 311, 819-823.

COHN JN, JOHNSON G, ZIESCHE S, COBB F, FRANCIS G, TRISTANI F, SMITH R, DUNKMAN WB, LOEB H, WONG M, BHAT G, GOLdMAN S, FLETCHER RD, DOHERTY J, HUGHES $V$, CARSON P. CINTRON G, SHABETAI R \& HAAKENSON C (1991). A comparison of enalapril with hydralazine-isosorbide dinitrate in the treatment of chronic congestive heart failure. N. Engl. J. Med. 325, 303-310.

DARGIE HJ, MEMURRAY JJV \& POOLE-WILSON PA, eds. (1996). Managing heart failure in primary care. London: Blackwell Healthcare Communications.

Davies PF, RobotewskyJ A, GRIEM ML, DULL RO \& POLACEK DC (1992). Hemodynamics forces and cell communication in arteries. Arch. Pathol. Lab. Med. 116, 1301-1306.

DAVIES SW, EMERY TM, WATLING MIL, WANNAMETHEE G \& LIPKIN DP (1991). A critical threshold of exercise capacity in the ventilatory response ito exercise in heart failure. $\mathrm{Br}$. Heart J. 65, 179-183.

DEFELICE A, FRERING R \& HoRAN P (1989). Time course of hemodynamic changes in rats with healed severe myocardial infarction. Am. J. Physiol. 257, H289-H296.

DEPARTMENT OF HEALTH. (1992). The health of the nation. London: HMSO.

Devereux RB, Roman M, Ganau A, de Simone G, Okin PM \& Kligfield P (1994). Cardiac and arterial hypertrophy and atherosclerosis in hypertension. Hypertension 23, 802-809.

DOBRIN PB \& ROvick AA (1969). Influence of vascullar smooth muscle on contractile mechanics and elasticity of arteries. Am. J. Physiol. 217, 1644-1651. 
DREXLER H (1992). Effects of angiotensin-converting enzyme inhibitors on the peripheral circulation in heart fallure. Am. J. Cardiol. 70, 50C-54C.

DREXLER H \& LU W (1992). Endothelial dysfunction of hindquarter resistance vessels in experimental heart failure. Am. J. Physiol. 262, $\mathrm{H} 1640-\mathrm{H} 1645$.

Drexler H, TOGgart EJ, Glick MR, HeAld J, Flaim SF \& ZELIS R (1986). Regional vascular adjustments during recovery from myocardial infarction in rats. 4 . Am. Coll. Cardiol. 8, 134-142.

DREXLER H HABLAWETZ E, LU W, RIEDE U \& CHRISTES A (1992a). Effects of inhibition of nitric oxide formation on regional blood flow in experimental myocardial infarction. Circulation 86, 255-262.

DREXLER H, HAYOZ D, MUNZEL T, HORNig B, JUST H, BRUNNeR HR \& ZELIS R (1992b). Endothelial function in congestive heart failure. Am. J. Cardiol. 69, 1596-1601.

DREXLER H, RIEde U, MÜNZEL T, KONIG H. FUnKE E \& JUST H (1992c). Alterations of skeletall muscle in chronic heart failure. Circulation 85, 1751-1759.

Duff JL, Marrero MB, PAXton WG, Schieffer B, Bernstein KE \& BERK BC (1995). Angiotensin II signal transduction and the mitogen-activated protein kinase pathway. Cardiovasc. Res. 30, 511-517.

DULING BR, MATSUKI T \& SEGAL SS. (1991). Conduction in the resistance vessel wall. In The resistance vasculature (ed. J. A. Bevan, W. Halpern \& M. J. Mulvany), pp. 193216. Totowa, NJi: Humana Press.

Duprez D, De Buyzere M, DhONDT E \& Clemen DL (1996). Impaired microcirculation in heart failure. Int. J. Microcirc. 16, 137-142.

DZAU VJ, PRATT R \& GIBBONS GH (1994). Angiotensin as local modulating factor in ventricular dysfunction and failure due to coronary artery disease. Drugs 47, 1-13.

ERIKKSON H (1995). Heart failure: a growing public health problem. I. Int. Med. 237, 135141.

FoLkow B (1982). Physiological aspects of primary hypertension. Physiol. Rev. 62, 347504.

FOLKOW B \& SIVERTSSON R (1968). Adaptive changes in "reactivity" in wall/lumen ratio in cat blood vessels exposed to prolonged transmural pressure difference. Life Sci. 7 , $1283-1289$.

FOLKOW B, GRIMBY G \& THULESIUS O (1958). Adaptive structural changes of the vascular walls in hypertension and their relation to the control of peripheral resistance. Acta Physiol. Scand, 44, 255-272. 
FOLKOW B, HALLBACK M, LUNDGREN Y \& WEISS L (1970). Background of increased flow resistance and vascular reactivity in spontaneously hypertensive rats. Acta Physiol. Scand. 80, 93-106.

FORSTER C, CARTER S \& ARMSTRONG P (1989). Vascular smooth muscle responsiveness to noradrenaline and phenylephrine following experimental heart failure in dogs. Can. J. Physiol. Pharmacol. 23, 489-497.

Forstermann U, Closs El, Pollock JS, Nakane M, Schwarz P, Gath I \& KLeinert H (1994). Nitric oxide synthase isozymes - characterization, purification, molecular cloning, and functions. Hypertension 23, 1121-1131.

FRANCIOSA JR, PARK M \& LEVINE TB (1981). Lack of correlation between exercise capacity and indexes of resting left ventricular performance in heart failure. $A m . J$. Cardiol. 47, 33-39.

Francis GS, Benedict C, Johnstone DE, KIRLIN PC, NiCKLAS J, Liang C-S, Kubo SH, RUDIN-TORETSKY E, YUSUF S \& FOR THE SOLVD INVESTIGATORS (1990). Comparison of neuroendocrine activation in patients with left ventricular dysfunction with and without congestive heart failure. A substudy of the Studies of Left Ventricular Dysfunction (SOLVD). Circulation 82, 1724-1729.

FRANCIS GS, COHN JN, JOHNSON G, RECTOR TS, GoldMAN S, SIMON A \& FOR THE VHEFT COOPERATIVE STUdies GROUP (1993). Plasma norepinephrine, plasma renin activity, and congestive heart failure: relations to survival and the effects of therapy in V-HeFT II. Circulation 87(Suppl. 6), VI40-VI48.

FUKUO K, SUHARA T, NAKAHASHI T, SHINTO $Y$, TSUJIMOTO $Y$, MORIMOTO $S \&$ OgIHARA T (1996). Nitric oxide induces upregulation of Fas and apoptosis in vascular smooth muscle. Hypertension 27, 823-826.

FURCHOTT RF \& ZAWADSKI JV (1980). The obligatory role of endothelial cells in the relaxation of arterial smooth muscle by acetylcholine. Nature 288, 373-376.

GABALLA MA, RAYA TE \& GOLDMAN S (1995). Large artery remodeling after myocardial infarction. Am. J. Physiol. 268, H2092-H2103.

Galatuds-Jensen S, Wroblewski $H_{*}$ Emmeluth C, Bie P, Haunso S \& Kastrup J (1996) Plasma endothelin in cardiac failure: a predictor of cardiac death? J. Card. Fail. 2, 7176.

GARLAND CJ, PLANE F, KEMP BK \& COCKS TM (1995). Endothelium-dependent hyperpolarization: a role in the control of vascular tone. TIPS 16, 23-30.

GAUDRON P, EILES C, ERTL G \& KOCHSIEK K (1993). Adaptation to cardiac dysfunction after myocardial infarction. Circulation 87(Suppl. 4), IV83-IV89. 
GERTHOFFER WT \& MURPHY RA (1983). Ca ${ }^{2 *}$, myosin phosphorylation, and relaxation of arterial smooth muscle. Am. J. Physiol. 245, C271-C277.

GHALI JK, COOPER R \& FORD E (1990). Trends in hospitalization rates for heart failure in the United States, 1973-1986. Arch. Int. Med. 150, 769-773.

Giannattasio C, Failla M, Stella ML, Mangoni Aa, Carugo S, PozZi M, Grassi g \& MANCIA $G$ (1995). Alterations of radial artery compliance in patients with congestive heart failure. Am. J. Cardiol. 76, 381-385.

Glaser E, lacolley P, Boutouyrie P, Sacunha R, Lucet B, Safar ME \& Laurent S (1995). Dynamic versus static compliance of the carotid artery in living Wistar-Kyoto rats. J. Vasc. Res. 32, 254-265.

GRIfFIn SA, BROWN WCB, MACPHERSON F, MCGRATH JC, WILSON VG, KorsgaARD $\mathbb{N}_{\text {, }}$ MULVANY MJ \& LEVER AF (1991). Angiotensin II causes vascular hypertrophy in part by a non-pressor mechanism. Hypertension 17, 626-635.

GROSSMAN W \& LORELL BH (1993). Hemadynamic aspects of left ventricular remodeling after myocardial infarction. Circulation 87 (Suppl. 4), IV28-IV30.

GROSSMAN W, JONES D \& MCLAURIN LD (1975). Wall stress and patterns of hypertrophy in the human left ventricle. J. Clin. Invest. 56, 56-64.

HaBiB H, DUTKA D, CROSSMAN D, OAKELY CM \& CLELAND JGF (1994). Enhanced basal nitric oxide production in heart failure: another failed regulatory mechanism? Lancet $344,371-373$.

HAHN AWA, RESINK TJ, KERN F \& BÜHLER FR (1993). Peptide vasoconstrictors, vessel structure, and vascular smooth-muscle proliferation. J. Cardiovasc. Pharmacol. 22(Supp|. 5). S37-S43.

HAMMOND MD, BAUER KA, SHARP JT \& ROCHA RD (1990). Respiratory muscle strength in congestive heast failure. Chest $98,1091-1094$.

HASking GJ, EsLer MD, JenNings GL, BURTON D \& Korner PI (1986). Norepinephrine spillpver to plamsa in patients with congestive heart failure: evidence of increased overall and cardiorenal sympathetic nervous activity. Circulation 73, 615-621.

HASkING GJ, ESLER MD, JENnINGS GL, DewAR E \& LAMBERT G (1988). Norepinephrine spillover to plasma during steady-state supine bicycle exercise: comparison of patients with congestive heart failure and normal subjects. Circulation 78, 516-521.

HATHAWAY DR, MARCH KL, LASH JA, ADAM LP \& WILENSKY RL (1989). Vascular smooth muscle. A review of the molecular basis of contractility. Circulation 80, 219-233. 


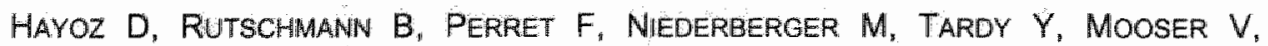
NUSSBERGER J. WAEBER B \& BRLINNER HR (1992). Conduit artery compliance and distensibility are not necessarily reduced in hypertension. Hypertension 20, 1-6.

HAYOZ D, DREXLER H, MONZEL T, HORNIG B, ZEIHER AM, JUST H, BRUNNER HR \& ZELIS $R$ (1993). Flow-mediated arterial dilation is abnormal in congestive heart failure. Circulation 87 (Suppl. 7), VII92-V1196.

HEAGERTY AM (1991). Functional and structural aspects of ACE inhibitors on the cardiovascular system. Cardiology 79(Suppl. 1), 3-9.

HEAGERTY AM, ARLKJAER C, BUnD SJ, KoRsgaARd N \& Mulvany MJ (1993). Small artery structure in hypertension. Dual processes of remodeling and growth. Hypertension 21, $391-397$.

HEENEMAN S, LEENDERS PJA, AARTS PJJW, SMITS JFM, ARENDS JW \& DAEMEN MJAP (1995). Peripheral vascular alterations during experimental heart failure in the rat: do they exist? Arterioscl. Thromb. Vasc. Biol. 15, 1503-1511.

HEIN L, BARSH GS, PRATT RE, DZAU VJ \& KoBILKA BK (1995). Behavioural and cardiovascular effects of disrupting the angiotensin II type-2 receptor in mice. Nature 377, 744-747.

HIRAI T, SaSAYAMA S, KaWASAKI T \& YAGI S-i (1989). Stiffness of systemic arteries in patients with myocardial infarction: a noninvasive method to predict severity of coronary atherosclerosis. Circulation 80, 78-86.

HiRATA $Y$, TAKAGI $Y$, FuKUDA $Y$ \& MARUMO $F(1989)$. Endothelin is a potent mitogen for rat vascular smooth muscle cells. Arterioscl. 78, 225-228.

HIRST GDS \& EDWARDS FR (1989). Sympathetic neuroeffector transmission in arteries and arterioles. Physiol. Rev. 69, 546-604.

HUTCHNSS PM \& DARNELL AE (1974), Observation of a decreased number of small arterioles in spontaneously hypertensive rats. Circ. Res. 34/35(Suppl. 1). 161-165.

ICHIKi T, LABOSKY PA, SHIOTA C, OKuYAMa S, ImAGAWA Y. Foga A, NimuRA F, ICHIKAWA I. HOGAN BLM \& INAGAMII T (1995). Effects on blood pressure and exploratory behavior of mice lacking angiotensin II type-2 receptor. Nature $377,748-750$.

IMAIZUMI T, TAKESHITA A, ASHIHARA T \& NAKAMURA M (1985). The effects of sublingually administered nitroglycerin on forearm vascullar resistance in patients with heart failure and in normal subjects. Circulation 72, 747-752.

ISNARD RN, PANniler BM, LAURENT S, London GM, Diebold B \& SAFAR ME (1989). Pulsatile diameter and elastic modulus of the aortic arch in essential hypertension: a noninvasive study. J. Am. Coll. Cardiol. 13, 399-405. 
ITOH H, PRATT RE \& DZAU VJ (1990). Atrial natriuretic polypeptide inhibits hypertrophy

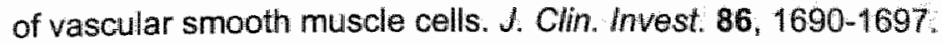

Itoh H, Mukoyama M, Pratt RE, Gibbons GH \& Dzau VJ (1993). Multiple autocrine growth factors modulate vascular smooth muscle cell growth response to angiotensin II. J. Clin. Invest. 91, 2268-2274.

JALIL JE, DOERING CW, JANICKI JS, OACK R, SHROFF SG \& WEBER KT (1989). Fibrillar collagen and myocardial stiffness in the intact hypertrophied rat left ventricle. Circ. Res. 64, $1041-1050$.

KAISER L, SPICKARD RC \& OLIVIER NB (1989). Heart failure depresses endotheliumdependent responses in canine femoral artery. Am. J. Physial. 256, H962-H967.

KALON KL, PINSKY JL, KANNEL WB \& LEVY D (1993). The epidemiology of heart failure: the Framingham study. J. Am. Coll. Cardiol. 22(Suppl. A), 6A-13A.

KANNEL WB \& MCGEE DL (1979). Diabetes and cardiovascular disease. The Framingham study. JAMA 241, 2035-2038.

KANNEL W, GORDON T \& SCHWARTZ MJ (1971). Systolic versus diastolic blood pressure and the risk of coronary heart disease. The Framingham Study. Am. U. Cardiol. 27, 335* 346 .

Katz S, Biasucci L, Sabba C, Strom JA, Jondeau G, Galvao M, Solomon S, Nikolic SD, FORMAN R \& LEJEMTEL TH (1992). Impaired endothelium-mediated vasodilation in the peripheral vasculature of patients with congestive heart failure. J. Am. Coll. Cardiol. $19,918-925$.

KATZ SD, SCHWARZ M, YUEN J \& LEJEMTEL TH (1993). Impaired acetylcholine-mediated vasodilation in patients with congestive heart failure: role of endothelium-derived vasodilating and vasoconstricting factors. Circulation 88, 55-61.

KAye D, LAMBERT GW, LefKovits J, MORRIS M, JeNnings G \& ESLER M (1994). Neurochemical evidence of cardiac sympathetic activation and increased central nervous system norepinephrine turnover in severe congestive heart failure. $J$. Am. Coll. Cardiol. 23, 570-578.

KEMP GJ, THOMPSON CH, STRATTON JR, BRUNOTTE F, CONWAY M, ADAMOPOULOS S, ARNOLDA L, RADDA GK \& RAJAGOPALAN B (1996). Abnormalities in exercising skeletal muscle in congestive heart failure can be explained in terms of decreased mitochondrial ATP synthesis, reduced metabolic efficiency, and increased glycogenolysis. Heart 76 , 35-41.

KIUChI K, Sato $\mathbb{N}$, Shannon RP, Vatner DE, MORgan K \& VATNeR SF (1993). Depressed $\beta$-adrenergic receptor-and endothelium-mediated vasodilation in conscious dogs with heart failure. Circ. Res. 73, 1013-1023. 
KOH E, MORMMOTO S, TOMTA J, RAKUG H, JIANG B, INOUE T, NABATA T, FUKUO K \& OGHARA $T$ (1994). Effects of an angiotensin II receptor antagonist, $C V-11974$, on angiotensin II-induced increases in cytosolic free calcium concentration, hyperplasia and hypertrophy of cultured vascular smooth muscle cells. J. Cardiovasc. Phamacol. $23,175-179$.

KOMORI K \& VANHOUTTE PM (1990). Endothelium-derived hyperpolarizing factor. Blood Vessels 27, 238-245.

KONSTAM M, DRACUP K, BAKER D, ET AL. (1994). Heart failure: evaluation and care of patients with left-ventricular systolic dysfunction. Clinical practical guidelines No. 11. AHCPR Publication No. 94-0612. Rockville,MD,USA: US Department of Health and Human Services.

KORNER P, BOBIK A, ODDIE C \& FRIBERG P (1993). Sympathoadrenal system is critical for structural changes in genetic hypertension. Hypertension 22, 243-252.

Kubo SH, RECTOR TS, BANK AJ, Williams RE \& HEIFETZ SM (1991). Endotheliumdependent vasodilation is attenuated in patients with heart failure. Circulation $84,1589-$ 1596.

KuBO SH, Rector TS, BANK AJ, RAIJ L, KRAEMER MD, TADros P. BEARdsLeE M \& GaRR MD (1994). Lack of contribution of nitric oxide to basal vasomotor the in theart failure. Am. J. Cardiol. 74, 1133-1136.

LAMONTAGNE D, POHL U \& BUSSE R (1992). Mechanical deformation of vessel wall and shear stress determine the basal release of endothellum-derived relaxing factor in the intact rabbit coronary vascular bed. Circ. Res. 70, 123-130.

LANGILLE BL (1993). Remodeling of developing and mature arteries: endothelium, smooth muscle, and matrix. J. Cardiovasc. Pharmacol. 21(Suppl. 1), S11-s17.

LASKEY WK, PARKER HG, FERRARI VA, KUSSMAUL WG \& NOORDERGRAAF A (1990). Estimation of totoal systemic arterial compliance in humans. J. Appl. Physiol. 69, 112119.

LAURENT S (1995). Arterial wall hypertrophy and stiffness in essential hypertensive patients. Hypertension 26, 355-362.

LaURENT S, HAYOZ D, TRAZZI S, BOUtOUYRIE P, WAEBER B, OMBONI S, BRUNNER HR, MANCIA G \& SAFAR M (1993). Isobaric compliance of the radial artery is increased in patients with essential hypertension. J Hypertens. 11, 89-98.

laurent $S$, Caviezel B, Beck L, Gierd X, Billaud E, Boutouyrie $P$, hoeks A \& Safar $M(1994 a)$. Carotid artery distensibility and distending pressure in hypertensive humans. Hypertension 23, 878-883. 


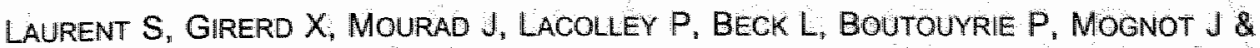
SAFAR M (1994b). Elastic modulus of the radial artery wall material is not increased in patients with essential hypertension. Arterioscl. Thromb. 14, 1223-1231.

Lecarpentier $Y$, Pery $N$, Coirault $C$, Scalbert E, Desche P, Suaro I, lambert F \& CHEMLA D (1993). Intrinsic alterations of diaphragm muscle in experimental cardiomyopathy. Am. Heart J. 126, 770-776.

LEE MA, BOHM M, PAUL M \& GANTEN D (1993). Tissue renin-angiotensin systems: their role in cardiovascular disease. Circulation 87(Suppl. 4), IV7-IV13.

Lee RMKW, Triggle CR, Cheung DWT \& Coughlin MD (1987). Structural and functional consequences of neonatal sympathectomy on the blood vessels of spontaneously hypertensive rats. Hypertension 10, 328-338.

Lee RM, BeRECeK KH, TSOPORIS J, MCKenzie R \& TRIGgLe CR (1991). Prevention of hypertension and vascular changes by captopril treatment. Hypertension 17, 141-150.

LEIER CV (1992). Regional blood flow in human congestive heart failure. Am. Heart J. 124, 726-735.

LEIMBACH WN, WALLIN BG, VICTOR RG, SuINDLOF G \& MARK AL (1986). Direct evidence from intraneural recordings for increased central sympathetic outflow in patients with heart failure. Circulation 73, 913-919.

LEJEMTEL TH \& SONNENBLICK EH (1993). Heart failure: adaptive and maladaptive process. Circulation 87(Suppl. 7), VII1-VII4.

LEJEMTEL TH, MASKIN CS, LUCIDO D \& CHADWICK BJ (1986). Failure to augment maximal limb blood flow in response to one-leg versus two-leg exercise in patients with severe heart failure. Circulation 74, 245-251.

LE NOBle JLML, TANGELder GJ, SLAAF DW, VAN EsSEN H, RENEMAN RS \& STRUIJKER BOUDIER HAJ (1990). A functional morphometric study of the cremaster muscle microcirculation in young spontaneously hypertensive rats. J Hypertens. 8, 741-748.

Levy BI, Michel J-B, Salzmann J-L, AzIZI M, PoItevin P, SAfar M \& Camilleri J-P (1988). Effects of chronic inhibition of converting enzyme on mechanical and structural properties of arteries in rat renovascular hypertension. Circ. Res. 63, 227-239.

LEVY BI, CURMI P, POITEVIN P \& SAFAR ME (1989). Modifications of the arterial mechanical properties of normotensive and hypertensive rats without arterial pressure changes. J. Cardiovasc. Pharmacol. 14, 2533-259.

LIGHT RM \& GEORGE RB (1983). Serial pulmonary function in patients with acute heart failure. Arch. Int. Med. 143, 429-433. 
LINDSAY DC, JIANG O BRUNOTTE F, ADAMOPOULOS $S$, COATS AJS, RAJAGOPALAN B, POOLEWLSON PA \& COLLINS P (1992). Impairment of endothelium dependent responses in a rat model of chronic heart failure: effects of an exercise training protocol. Circ. Res. 26, 694-697.

LINDSAY DC, ANAND IS, BENNETT JG, PEPPER JR, YACOUB MH, ROTHERY SM, SEVERS NJ \& POOLE-WILSON PA (1994). Ultrastructural analysis of skeletal muscle: microvascular dimensions and basement membrane thickness in chronic heart failure. Eur. Heart. $\mathrm{J}$. $15,1470-1476$.

LIPKIN DP \& POOLE-WILSON PA (1986). Symptoms limiting exercise in chronic heart failure. Br. Med. J. 292, 1030-1031.

LIU Z, TING C, ZHU S \& YIN FCP (1989). Aortic compliance in human hypertension. Hypertension 14, 129-136.

LOMPRE A-M. AMGER M \& LEVITSKY D (1994). Sarco(endo)plasmic reticulum calcium pumps in the cardiovascular system: function and gene expression. J. Mol. Cell. Cardiol. 26, $1109-1121$.

LONGHURST J, CAPONE R.J \& ZELIS R (1975). Evaluation of skeletal muscle capillary basement membrane thickness in congestive heart failure. Chest $67,195-198$.

LUSCHER TF, BOULANGER CM, DOHI Y \& YANG Z (1992). Endothelium-derived contracting factors. Hypertension 19, 117-130.

LÜSCHER TF, BOULANGER CM, YANG Z, NOLL G \& DOHI Y (1993). Interactions between endothelium-derived relaxing factors in health and cardiovascular disease. Circulation 87(Suppl. 5), V36-V/4.

LundBerg JM, Franco-Cereceda A, LAcroIX JS \& Pernow J (1991). Release of vasoactive peptides from autonomic and sensory nerves. Blood Vesse/s 28, 27-34.

MAIN JS, FORSTER C \& ARMSTRONG PW (1991). Inhibitory role of the coronary arterial endothelium to $\alpha$-adrenergic stimulation in experimental heart failure. Circ. Res. $68,940-$ 946.

Malcolm J, Arnold O, MARchiori GE, ImRIE JR, Burton GL, PFlugfelder PW \& KosTuk WJ (1991). Large artery function in patients with chronic heart failure: studies of brachial artery diameter and hemodynamics. Circulation 84, 2418-2425.

MANCINI DM, COYLE E, COGgan A, BELTZ J. FERRARO N, MOUTAIN S \& WILSON JR (1989). Contribution of intrinsic skeletal muscle changes to ${ }^{31} \mathrm{P}$ NMR skeletal muscle abnormalities in patients with chronic heart failure. Circulation $80,1338-1346$. 
MANCINI DM, SCHWARTZ M, FERRARO N, SEEstedt R, CHANCE B \& WLLSON JR (1990). Effect of dobutamine on skeletal muscle metabolism in patients with congestive heart failure: Am. J. Cardiol. 65, 1121-1126.

MANCINI DM, HENSON D, LAMANCA J \& LEVINE S (1992a). Respiratory musde function and dyspnea in patients with chronic congestive heart fallure. Circulation 86, 909-918.

MANGINI DM, WALTER G, REICHEK N, LENKINSKI R, MCGULLY KK, MULLEN JL \& WILSON JR (1992b). Contribution of skeletal muscle atrophy to exercise intolerance and altered muscle metabollism in heart failure. Circulation 85, 1364-1373.

Massie B, Conway M, Yonge R, Frostick S, LedINGHAM J, SLEIGHT P, RAddA G \& RAJAGOPALAN B (1987). Skeletal muscle metabolism in patients with congestive heart failure: relation to clinical severity and blood flow. Cinculation 76, 1009-1019.

MATHEW V, HASDAI D \& LERMAN A (1996). The role of endothelin in coronary atherosclerosis. Mayo Clinic Proceedings 71, 769-777.

MCPARLAND C, KRISHMAN B, WANG $Y$ \& GALLAGHER CG (1992). Inspiratory muscle weakness and dyspnea in chronic heart fallure. Am. Rev. Respir. Dis. 146, 467-472.

VAN MERODE T, HICK PJJ, HOEKS APG, RAHN KH \& RENEMAN RS (1988), Carotid artery wall properties in normotensive and borderline hypertensive subjects of various ages. Utrasound Med. Biol. 14, 563-569.

MESSMER UK, REED LIK \& BRUNE B (1996). Bcl-2 protects macrophages from nitric oxide-induced apoptosis. J. Biol. Chem. 271, $20192-20197$.

METRA M, DEI CAS L, PANINA G \& VISIOLI O (1992). Exercise hyperventilation, chronic congestive heart failure, and its relation to functional capacity and hemodynamics. Am. J. Cardiol. 70, 622-628.

MINOTTI JR, PILLAY P, OKA R, WELLS L, CHRISTOPH I \& MAsSiE BM (1993). Skeletal muscle size." relationship to muscle function in heart failure. $\int$. Appl. Physiol. 75, 373381 .

MOHIADDIN RH, UNDERWOOD SR, BOGREN HG, FIRMIN DN, KLIPSTEIN RH, REES RSO \& LONGMORE DB (1989). Regional aortic compliance studied by magnetic resonance imaging: the effects of age, training, and coronary artery disease. Br. Heart J. 62, 90-96.

MONCADA S, PALMER RMJ \& HIGGS EA (1991). Nitric oxide: physiology, pathophysiology, and pharmacology. Pharmacol. Rev. 43, 109-142.

Morbidelli L, Chang CH, Douglas JG, Granger HJ, Ledda F \& ZiciHe M (1996). Nitric oxide mediates mitogenic effect of VEGF on coronary venular endothelium. Am. J. Physiol. 270, H411-H415. 


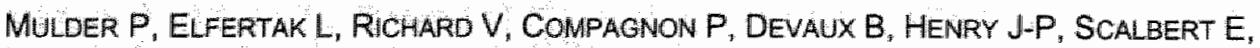
DESCHE P, MACE B \& THULLEZ C (1996). Peripheral aitery structure and endothelial function in heart fallure: effect of ACE inhibition. Am. J. Physiol. 271, H469-H477.

MULVANY MJ. (1991), Geometry, structure, and mechanics of resistance arteries. In The resistance vesculature (ed. J. A. Bevan), p. 127. Totowa,New Jersey: Humana Press.

MULVANY MJ (1992a). A reduced elastic modulus of vascular wall components in hypertension? Hypertension $20,7-9$.

MULVANY MJ (1992b). Vascular growth in hypertension. J. Cardiovasc. Pharmacol. 20(Suppl. 1), S7-S11.

Mulvany MJ (1994). Control of vascular structure. Am. J. Med. 94(Suppl. 4A), 20-23.

MULVANY MJ \& AALKJAER C (1990). Structure and function of small arteries. Physiol. Rev. 70, 921-961.

Mulvany MJ, BAUMBACH GL, AALKJAER C \& HEAGERTY AM (1996). Vascular remodeling. Hypertension 28, 505-506.

MUNZENMAIER DH \& GREENE AS (1996). Opposing actions of angiotensin II on microvascular growth and blood pressure. Hypertension 27, 760-765.

MUSCH TI \& TERRELL JA (1992). Skeletal muscle blood flow abnormalities in rats with a chironic myocardial infarction: rest and exercise. Am. J. Physiol. 262, H411-H419.

MUSCH TI, GHAUL MR, TRANChITELLA V \& ZELIS R (1990). Skeletal muscle glycogen depletion during submaximal exercise in rats with chronic heart failure. Basic Res. Cardial. 85, 606-618.

NELISSEN-VRANCKEN HJMG, DEBETS JJM, SNOECKX LHEH, DAEMEN MJAAP \& SMITS JFM (1996). Time-related normalization of miximal coronary fiow in isolated perfused hearts of rats with myocardial infarction. Circulation 93, 349-355.

NEREM RM (1993). Hemodynamics and the vascular endothelium. J. Biomed. Eng. 115, $510-514$

Neubauer S, HORn M, NAumann A, Tian R, HU K, LASER M, FRiedrich J, Gaudron P, SCHNACKERZ K, INGWALL JS \& ERTI G (1995). Impairment of energy metabolism in intact residual myocardium of rat hearts with chronic myocardial infarction. \&. Clin. Invest. 95, $1092-1100$.

OHYANAGI M, NISHIGAKI K \& FABER JE (1992). Interaction between microvascular $\alpha_{1}$ and $\alpha_{2}$ adrenoceptors and endothelium-derived relaxing factor. Circ. Res. 71, 188-200. 
OKUMURA $Y$, NASA $Y$, SANBE A, TOGA W \& TAKEO S (1996). Effects of long-term treatment with trandolapril on augmented vasoconstriction in rats with chronic heart failure. J. Card. Fail. 2, 301-310.

OLIVETTI G, LAGRASTA C, RICCI R, SONNEBLICK EH, CAPASSO JM \& ANVERSA P (1989). Long term pressure induced cardiac hypertrophy: capillary and mast cell production. Am. J. Physiol. 257, H1766-H1772.

OMLAND T, AARSLAND T, AAKVAAG A, LIE RT \& DicKSTEIN K (1993). Prognostic value of plasma atrial natriuretic factor, norephinephrine, and epinephrine in acute myocardial infarction. Am. J. Cardiol. 72, 255-259.

ONTKEAN M, GAY R \& GREENBERG B (1991). Diminished endothelium-derived factor activity in an experimental model of chronic heart failure. Circ. Res. 69, 1088-1096.

PACKER M (1992). The neurohormonal hypothesis: a theory to explain the mechanism of disease progression in heart failure. J. Am. Coll. Cardiol. 20, 248-254.

PALMER.RM, FERRINGE AG \& MONCADA S (1987). Nitric oxide release accounts for the biological activity of endothelium-derived relaxing factor. Nature 327, 524-526.

PEPINE CJ, NICHOLS WW \& CONTI CR (1978). Aortic input impedance in heart failure. Circulation 58, 460-465.

PETERMAN W, BARTH J \& ENTZIAN P (1987). Heart failure and airways obstruction. Int. J. Cardiol. 17, 207-209.

PFefFer JM, PfEFfer MA \& BRAUNWALd E (1985). Influence of chronic captopril therapy on the infarcted left ventricle of the rat. Circ. Res. 57, 84-95.

PFEFFER MA \& BRAUNWALD E (1990). Ventricular remodeling after myocardial infarction: experimental observations and clinical implications. Circulation 81, 1161-1172.

PIERUZZI F, ABASSI ZA \& KEISER HR (1995). Expression of renin-angiotensin system components in the heart, kidneys, and lungs of rats with experimental heart failure. Circulation 92, 3105-3112.

POLlman MJ, YAMADA T, HoRIUCHI M \& GibBons GH (1996). Vasoactive substances regulate vascular smooth muscle apoptosis: countervaling influences of nitric oxide and angiotensin II. Circ. Res. 79, 748-756.

PREWITT RL, CHEN H \& DOWELL R (1982). Development of microvascular rarefaction in the spontaneously hypertensive rat. Am. J. Physiol. 243, H243-H251.

PREWITT RL, WANG DH, NAKAMURA T \& SMITH EG. (1991). Growth and modification in number of resistance vessels. In The resistance vasculature (ed. J. A. Bevan, W. Halpern \& M. J. Mulvany), pp. 127-142. Totowa, NJ: Humana Press. 
PFICE RJ \& SKALAK TC (1994). Circumferential wall stress as a mechanism for arteriolar rarefaction and proliferation in a network model. Microvasc. Res. 47, 188-202.

RALSTON MA, MEROLA Aw \& LEIER CV (1991). Depressed aerobic enzyme activity of skeletal muscle in severe chronic heart falure. J. Lab. Clin. Med. 117, 370-372.

RANDALL OS, VAN DEN BOS GC \& WESTERHOF N (1984), Systemic compliance: does it play a role in the genesis of hypertension? Cardiovasc. Res. 18, 455-462.

RENEMAN RS; HOEKS APG \& WESTERHOFF N (1996). Non-invasive assessment of artery wall properties in humans - methods and interpretation. J. Vasc. Invest. 2, 53-64.

ROACH MR \& BURTON AC (1957). The reason for the shape of the distensibility curve of arteries. Can. J. Biochem. Physiol. 35, 681-690.

ROBERTS JT \& WEARN JT (1941). Quantitative changes in the capillary-muscle relationship in human hearts during normal growth and hypertrophy. 21, 617-633.

ROGERS TB \& LOKUTA AJ (1994). Angiotensin II signal transduction pathways in the cardiovascular system. Trends Cardiovasc. Med. 4, 110-116.

Rouleau IL, Moye LA, de Champlain J, KLEIN M, Bichet D, Packer M, Dagenais G, Sussex B, ARnOld JM, SEstier F, PARKER JO, MCEWAN MMP, BERnstein V, CuddY TE, Delage F, nadeau C, lamas Ga, Gottlieb SS, McCans J \& Pfeffer MA (1991). Activation of neurohormonal systems following acute myocardial infarction. Am. $J$. Cardiol. 68, 80D-86D.

Rouleau Jl, de Champlain J, Klein M, Bichet D al, Moye L, Packer M, Dagenais gR, Sussex B, ARnOld JM, Sestier F, PARKer JO, MCEWAN P, BERnstein $V$, Cuddy E, Lamas G, Gottllieb SS, McCans J, Nadeau C, Delage F, Hamm P \& Pfeffer MA (1993). Activation of neurohormonal systems in postinfarction left ventricullar dysfunction. J. Am. Coll. Cardial: 24, 581-591.

Roulleau Jl, Packer M, Moye L, de Champlain J, Bichet D, KLein M, Rouleau JR, Sussex $B$, ARnOld JM, SEstier F, PARKER JO, MCEWAN P, BERnstein $V$, Cuddy TE, lamas G, Gotitlieb SS, McCans J, Nadeau C, Delage F, Wun CCC \& Pfeffer MA (1994). Prognostic value of neurohumoral activation in patients with an acute myocardial infarction: effect of captopril. J. Am. Coll. Cardiol. 24, 390-398.

RUBANYI GM, FrEAY AD, KAUSER K, JOHNS A \& HARDER DR (1990). Mechanoreception by the endothelium: mediators and mechanisms of pressure- and flow- induced vascular responses. Blood Vessels $27,246-257$.

RUBIN SA, BROWN HV \& SWAN HJC (1982). Arterial oxygenation and arterial oxygen transport in chronic myocardial failure at rest, during exercise and after hydralazine treatment. Circulation 66, 143-148. 
SABBAH HN, HANSEN-SMITH F, SHARON VG, KONO T, LESCH M, GENGO PJ, STEFFEN RP, LEVINE TB \& GOLDSTEIN S (1993). Decreased proportion of type I myofibers in skeletal muscle of dogs with chronic heart failure. Circulation 87, 1729-1737.

SABBAH HN, SHAROV VG, LESCH M \& GOLDSTEIN S (1995). Progression of heart fallure: a role for interstitial fibrosis. Mol. Cell. Biochem. 147, 29-34.

SARNOFF SJ, MITCHELL JH, GLLMORE JP \& REMENSNYDER JP (1960). Homeometric autoregulation of the heart. Circ. Res. 8, 1077-1091.

SChauelberger M, ERIKSSOM BO, Held P \& Swedberg K (1996). Skeletal muscle metabolism during exercise in patients with chronic heart failure. Heart 76, 29-34.

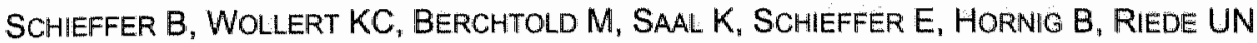
\& DREXLER H (1995). Development and prevention of skeletal muscle structural alterations after experimental myocardial infarction. Am. J. Physiol. 269, H1507-H1513.

SCHIFFERS PMH, VAN DER HEIJDEN HAMD, FAZZI GE, STRUIJKER BOUDIER HAJ \& DE MEY JGR (1993). Tonic tone in arteries exposed continuously to angiotensin II in vitro. J. Pharmacol. Exp. Ther. 266, 1520-1527.

SCHIFFERS PMH, FAZZI GE \& DE MEY JGR (1996). Heterogeneity of growth responses in the arterial system of young rats during vascoconstrictor infusion. J Hypertens. 14(Suppl. 1), S14.

SCHOEMAKER RG, DEBETS JJM, STRUIJKER BOUdER HAJ \& SMITS JFM (1990a). Beneficial hemodynamics effects of two weeks' milrinone treatment in conscious rats with heart failure. Eur. J. Pharmacol. 182, 527-535.

SCHOEMAKER RG, URQUHART J, DEBETS JJM, STRUIJKER BOUDIER HAJ \& SMITS JFM (1990b). Acute hemodynamic effects of coronary artery ligation in conscious rats. Basic Ros. Cardiol. $85,9-20$.

SCHOEMAKER RG, Degets JJM, STRUIJKER BOUdIER HAJ \& SMITS JFM (1991). Delayed but not immediate captopril therapy improves cardiac function in conscious rats, following myocardial infarction. J. Mol. Cell. Cardiol. 23, 187-197.

SCHUNKERT H, TANG S-S, LITWIN SE, DIAMANT D, RIEGGER G, DZAU VJ \& INGELFINGER JR (1993). Regulation of intrarenal and circulating renin-anglotensin systems in severe heart failure in the rat. Cardiovasc. Res. 27, 731-735.

SCHWARTZ K, CHASSAGNE C \& BOHELER KR (1993). The molecular biology of heart failure. J. Am. Coll. Cardiol. 22, 30A-33A.

SCHWARTZ K, CARRIER L, MERCADIER J J, LOMPRE A-M \& BOHELER KR (1993). Molecular phenotype of the hypertrophied failing myocardium. Circulation 87(Suppll. 7), VII5-VII10. 
SESSA WC (1994). The nitric oxide synthase family of proteins. J. Vasc. Res. 31, 131143.

SIGURDSSON A \& SWEDBERG K(1994). Is neurohormonal activation a major determinant of the response to $\mathrm{ACE}$ inhibition in left ventricular dysfunction and heart failure? $\mathrm{Br}$. Heart J. 72(Suppl.), 75-80.

SIGURDSSON A, HELD P \& SWEDBERG K (1993). Short- and long-term neurohormonal activation following acute myocardial infarction. Am. Heart J. 126, 1068-1076.

SigurdsSON A, Amtorp O, Gundersen T, Nilsson B, Remes J \& SWEdBerg K (1994). Neurohormonal activation in patients with mild or moderately severe congestive heart failure and effects of ramipri. The ramipril trial study group. Br. Heart J. 72, 422-427.

Simonini A, Long CS, Dudley GA, Yue P, McElhinny J \& Massie bM (1996). Heart failure in rats causes changes in skeletal muscle morphology and gene expression that are not explained by reduced activity. Circ. Res. 79, 128-136.

SMITS JFM \& DAEMEN MJAP (1994); Insights from animal models of myocardial infarction: do ACE inhibitors limit the structural response? Br. Heart J. 72(Suppl.), 61-64.

SMITS JFM, PASSIER RCJJ; NELISSEN-VRANCKEN HJMG, KUIZINGa MC \& DAEMEN MJAP (1995). Does ACE inhibition limit structural changes in the heart following myocardial infarction? Eur. Heart. J. 16(Suppl. N), 46-51.

STASSEN FRM, FAZZI GE, LEENDERS PJA, SMITS JFM \& DE MEY JGR (1997a). Coronary artery hyperreactivity and mesenteric arterial hyporeactivity after myocardial infarction in the rat. J. Cardiovasc. Pharmacol. 29, 780-788.

STASSEN FRM, WILLEMSEN MJJMF, JANSSEN GMJ, FAZZI GE, SCHIFFERS PMH, SMUTS JFM \& DE MEY JGR (1997b). Reduced responsiveness of rat mesenteric artery smooth muscle to phenylephrine and calcium following myocardial infarction. $\mathrm{Br}$. J. Pharmacol. $120,1506-1512$.

STEWART AL, GREenfield S, HAYS RD, Wells K, Rogers WH, BERRY SD, MCGLYNN EA \& WARE JE Jr (1989). Functional status and well being of patients with chronic conditions. JAMA 262, 907-913.

STRUIJJKER BOUDIER HAJ, VAN BORTEL. LMAB \& DE MEY JGR (1990). Remodeling of the vascular tree in hypertension: drug effects. TiPS 11, 240-244.

StruIJKER Boudier HAJ, Le Noble JLML, Messing MWJ, HiJberts MSP, Le NOBLE FAC \& VAN ESSEN H (1992). The microcirculation and hypertension. J Hypertens. 10(Suppl. 7), S147-S157. 
SLLLIVAN MJ, HIGGINBOTHAM MB \& COBB FR (1988). Increased exercise ventilation in patients with chronic heart failure: intact ventilatory control despite hemodynamic and pullmonary abnormalities. Circulation $77,552-559$.

SULLIVAN MJ, KNIGHT JD, HIGGINBOTHAM MB \& COBB FR (1989). Relation between central aand peripheral hemodynamics during exercise in patients with chronic heart failure. Muscle blood flow is reduced with maintenance of arterial perfusion pressure. Circulation 80, 769-781.

SulLIVAN MJ, GREen HJ \& COBB FR (1990). Skeletal muscle biochemistry and histology in ambulatory patients with ling-term heart failure. Circulation 81, 518-527.

SULLIVAN MJ, GREEN HJ \& COBB FR (1991). Altered skeletal muscle metabolic response to exercise in chronic heart failure: relation to skeletal muscle aerobic enzyme activity. Circulation 84, 1597-1607.

SUNG CP, ARLETH AJ, STORER BL \& OHLSTEIN EH (1994). Angiotensin type 1 receptors mediate smooth muscle proliferation and endothelin biosynthesis in rat vascular smooth muscle. J. Pharmacol. Exp. Ther. 271, 429-437.

SUPINSKI G, DIMARCO A \& DIBNER-DUNLAP M (1994). Alterations in diaphragm strength and fatiguability in congestive heart failure. J. Appl. Physiol. 76, 2702-2713.

SVEngaARD J, ANGelo-NIElsen K \& PINDBORG T (1992). Plasma concentration of atrial natriuretic peptide at admission and risk of cardiac death in patients with acute myocardial infarction. Br. Heart J. 68, 38-42.

SVEngaARD J, JOHANSEN JB, Thaysisen P \& HAghfELT T (1993). Neurohormonal systems during progression of heart failure: a review. Cardiology 83, 21-29.

SWEDBERG K, ENEROTH P, KJEKHUS J, WILHELMSEN L FOR THE CONSENSUS TRIAL STUDY GROUP (1990a). Hormones regulating cardiovascular function, hemodynamic indexes, and plasma hormones in untreated congestive cardiac failure. Circulation $\mathbf{8 2}, 1730$ 1736.

SWEDBERG K, ENEROTH P, KJEKSHUS J, SNAPINN S FOR THE CONSENSUS TRIAL STUDY GRoUP (1990b). Effect of enalapril and neuroendocrine activation on prognosis in severe congestive heart failure (follow-up of the CONSENSUS trial) Am. J. Cardiol. 66, 40D$45 \mathrm{D}$.

SzALChCIC J, MAssie BM, KRAMER BL, TOPIC N \& TUbau J (1985). Correlates and prognostic implication of exercise capacity in chronic congestive heart fallure. Am. $J$. Cardiol. 55, 1037-1042.

TEERLINK JR (1996). Neurohormonal mechanisms in heart failure: a central role for the renin-angiotensin system. J. Cardiovasc. Pharmacol. 27(Suppl. 2), S1-S8. 
TEERLINK JR, CLOZEL M, FISCHU W \& CLOZEL JP (1993). Temporal evolution of endothelial dysfunction in a rat model of chronic heart failure. J. Am. Coll. Cardiol. 22, $615-620$.

TEERLINK JR, GRAY GA, CLOZEL M \& CLOZEL J-P (1994). Increased vascullar responsiveness to norepinephrine in rats with heart fallure is endothelium dependent: dissociation of basal and stimulated nitric oxide release. Circulation $\mathbf{8 9}, 393-401$.

THOMPSON CH, KEMP GJ, RAJAGOPALAN B \& RADOA GK (1994). Metabolic abnormalities in skeletall muscle after myocardial infarction in the rat. Clinical Science 87, 403-406.

THOMPSON CH. KEMP GJ, RAJAGOPALAN B \& RADDA GK (1995). Abnormal ATP turnover in rat leg muscle during exercise and recovery following myocardial infarction. Cardiovasc. Res. 29, 344-349.

Thuillez C, Mulcer P, Elfertak L, Blaysat G, Compagnon P, Henry J-P, Richard V, SCALBERT E \& DESCHE P (1995). Prevention of endothelial dysfunction in small and large arteries in a model of chronic heart failure: effect of angiotensin converting enzyme inhibition. Am. J. Hypertens. 8, 7S-12S.

TRACEY WR, TSE J \& CARTER G (1995). Lipopolysaccharide-induced changes in plasma nitrate in rats and mice: pharmacological evaluation of nitric oxide synthase inhibitors. J. Pharmacol. Exp. Ther. 272, 1011-1015.

UMANS JG \& LEVI R (1995). Nitric oxide in the regulation of blood flow and arterial pressure. Ann. Rev. Physiol. 57, 771-790.

UNGERER M, BOHM ME E \& LOHSE MJE JS (1993). Altered expression of $\beta$-adrenergic receptor kinase and b1-adrenergic receptors in the failing human heart. Circulation 87 , 454-463.

VANHOUTTE PM (1993). Other endothelium-derived vasoactive factors. Circulation 87(Suppl. 5), V9-V17.

VANHOUTTE PM; VERBEUREN TJ \& WEBB RC (1981). Local modulation of adrenergic neuroeffector interaction in the blood vessel wall. Physiol. Rev. 61, 151-218.

VANKERL \& SCHWARTZ K (1995). Calcium transport proteins in the nonfailing and failing heart: gene expression and function. J. Mol. Med. 73, 487-496.

VATNER SF, SHANNON R \& HITTINGER L (1990). Reduced subendocardial coronary reserve, a potential mechanism for impaired diastolic function in the hypertrophied and failing heart. Circulation 81(Suppl. 2), III8- 1114 .

VERHAEGHE RH, LORENZ RR, MCGRATH MA, SHEPHERD JT \& VANHOUTTE PM (1978). Metabolic modulation of neurotransmitter release - adenosine, adenine nucleotides, potassium, hyperosmolarity, and hydrogen ion. Fed. Proc. 37, $208-211$. 
VOLDERS PGA, WILLEMS IEMG, CleUTJENS JPM, ARENDS JW, HAVENITH MG \& DAEMEN MJAP (1993). Interstitial collagen is increased in the non-infarcted myocardium after myocardial infarction. J. Mol. Cell. Cardiol. 25, 1317-1323.

WEBER R, STERIOPULOS N, BRUNNER HR \& HAYOZ D (1996). Contributions of vascular tone and structure to elastic properties of a medium-sized artery. Hypentension 27, 816822.

We CM, LERMAN A, RODEHEFFER RJ, MCGREgor CG, BRANDT RR, WRIGHT S, HEUbleIN DM, KAO PC, EDWARDS WD \& BURNETT J JC (1994). Endothelin in human congestive heart failure. Circulation $\mathbf{8 9}, 1580-1586$.

WIENER J, LOMBARDI DM, SU JE \& SCHWARTZ SM (1996). Immunohistochemical and molecular characterization of the differential response of the rat microvasculature to angiotensin-II infusion. J. Vasc. Res. 33, 195-208.

WILSON JR, MARTIN JL, FERRARO N \& WEBER KT (1983). Effect of hydralazine on perfusion and metabolism in the lug during up-right bicycle exercise in patients with heart failure. Circulation $68,425-432$.

WILSON JR, MANCINI DM \& DUNKMAN WB (1993). Exertional fatigue dule to skeletal muscle dysfunction in patinets with heart failure. Circulation $87,470-475$.

WINLAW DS, SMYTHE GA, KEOGH AM, SCHYVENIS CG, SPRATT PM \& MACDONALd PS (1994). Increased nitric oxide production in heart failure. Lancet 344, 373-374.

WOLINSKY H \& GLAGOV S (1964). Structural basis for the static mechanical properties of the aortic media. Circ. Res. 14, 400-413.

Wroblewski H, Kastrup J, NørgaArd T, MORTEnsen S-A \& Haun of increased microvascular resistance and arteriolar hyalinosis in skin in congestive heart failure secondary to idiopathic dilated cardiomyopathy. Am. J. Cardiol. 69, 769774.

YAMADA T, HORIUCHI M \& DZAU VJ (1996). Angiotensin II type 2 receptor mediates programmed cell death. Proc. Natl. Acad. Sci. USA. 93, 156-160.

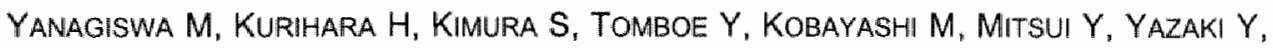
GOTO K \& MASAKI T (1988). A novel potent vasoconstrictor peptide produced by vascular endotheliall cells. Nature $332,411-415$.

$Y^{\prime} \mid N$ FCP \& TING C (1992). Compliance changes in physiological and pathological states. J Hypertens. 10(Suppl. 6), S31-S33.

YU S-M, TSAI S-Y, GUH J-H, KO F-N, TENG C-M \& OU JT (1996). Mechanism of catecholamine-induced proliferation of vascular smooth muiscle cells. Circulation $\mathbf{9 4}$, 547-554. 
ZELIS R, DELEA CS, COLEMAN HN \& MASON DT (1970). Arterial sodium content in experimental congestive heart failure. Circulation 16, 213-216.

ZELIS RJ, LONGHURST RJ, CAPONE RJ \& MASON DT (1974). A comparison of regional blood flow and oxygen utilization during dynamic forearm exercise in normal subjects and patients with congestive heart failure. Circulation $50,137-143$.

Zelis R, Sinoway L, Leenberger U, Clemson BS \& Davis D (1991). Time-constant adaptations in heart fallure. Eur. Heart. J. 12(Suppl. C), 2-7. 


\section{Time-related adaptations in plasma neurohormone levels and hemodynamics after myocardial infarction in the rat}

D.L. Ceiler

H.J.M.G. Nelissen-Vrancken

J.G.R. De Mey

J.F.M. Smits

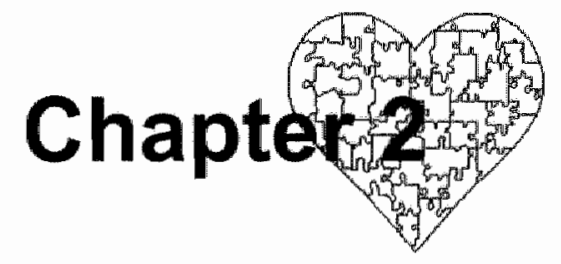




\section{Abstract}

Neurohormonal activation plays an important role in the progression of heart failure. In this study, we investigated the progression of neurohormonal activation in conjunction with the hemodynamic status of the rat after myocardial infarction (MI). Male Wistar rats were subjected to sham or MIl surgery. At 1, 3,5, and 13 weeks after surgery, cardiac output (CO), mean arterial pressure (MAP) and total peripheral resistance (TPR) were measured. In separate groups of rats, blood was sampled at 1,5 and 13 weeks after surgery and analyzed for various neurohormones. At one week after surgery, $\mathrm{CO}$ and TPR were not altered in MI rats, but plasma neurohormonal levels were elevated. At three and five weeks after surgery, reduced $\mathrm{CO}$, increased TPR and normal MAP were measured in MI rats compared to sham rats, but only endothelin levels were elevated. At thirteen weeks after surgery. MAP was reduced in MI rats and CO and TPR comparable between groups. Neurohormonall activation was again apparent in MI rats. Myocardial infarction in the rat induces early neurohormonal activation which normalizes hemodynamic parameters. A compensatory phase follows. At thirteen weeks post-MI, plasma concentrations of neurohormones are again elevated, perhaps as a sign of a transition to decompensation. 


\section{Introduction}

Improved survival after myocardial infarction (MI) and the ageing of the population are surely contributary to the increased prevalence of congestive heart failure (Erikkson, 1995). In the United States alone, heart failure affects four million people and contributes to more than a quarter of a million deaths yearly (Teerlink, 1996). Although heart failure is often approached from a hemodynamic point of view, mounting evidence suggests that neurohormonal factors play an important role in the progression of heart failure independent of their hemodynamic actions (Packer, 1992; Sigurdsson \& Swedberg, 1994; Teerlink, 1996).

Neurohormonal activation ensues in the early stages after myocardial infarction (Cohn, 1990; Rouleau et al. 1991; Sigurdsson et al. 1993). Heightened levels of these factors undoubtedly help to compensate for the reduction of myocardial mass by increasing cardiac contractility and vascular resistance to maintain organ perfusion. In patients without symptoms of heart failure, neurohormonal levels normalize within a few days (Rouleau et al. 1991; Sigurdsson et al. 1993). Nonetheless, in post MI patients with severe left ventricular dysfunction, neurohormonal activation persists (Francis et al. 1990; Rouleau et al. 1994). In overt heart failure, plasma levels of neurohormones are again found to be elevated (Francis et al. 1990; Swedberg et al. 1990a), and concentrations of endothelin (ET), atrial natriuretic peptide (ANP) and catecholamines have been shown to positively correlate with mortality rates (Cohn et al. 1984; Svengaard et al. 1992; Galatius-Jensen et al. 1996). Additional compelling evidence for the role of neurohormones in the progression of heart failure comes from studies showing that the efficacy of angiotensin converting enzyme inhibition is dependent on the level of neurohormonal activation (The CONSENSUS trial study group, 1987; Swedberg et al. 1990b). Although significant advancements have been made in the treatment of heart failure, a better understanding of neurohormonal mechanisms in heart fallure and the interaction of neurohormonal and hemodynamic factors in this disease is necessary to develop better, more effective therapies.

Ligation of the left coronary artery in the rat leads to infarction of the left ventricle and results in hemodynamic alterations indicative of heart failure. Acute cardiac depression with decreased cardiac output and stroke volume (Schoemaker et al. 1990b) is followed by a period of circulatory compensation which deteriorates into overt heart failure characterized by elevated left ventricular end diastolic pressures, increased total peripheral resistance, left ventricular hypertrophy, and pulmonary congestion (Pfeffer et al. 1985; Drexler et al. 1986; Bech et al. 1989; DeFelice et al. 1989; Schoemaker et al. 1990a). Although this model exhibits hemodynamic characteristics analogous to those seen in clinical heart failure, little data are present concerning the time course of neurohormonal activation in this model.

This study was undertaken to examine the time course and nature of 
neurohormonal activation in the MI model of heart failure in the rat in conjunction with the hemodynamic progression of the disease. Accordingly, plasma samples taken from $\mathrm{Ml}$ and sham rats at various time points after surgery were analyzed for angiotensin \| (ANG II), ANP, ET, epinephrine (EPI) and norepinephrine (NE). Furthermore, hemodynamic parameters were measured at similar time intervals in conscious, instrumented rats under basal conditions and following rapid volume loading.

\section{Methods}

Animals and myocardial infarction study

Male Wistar rats (280-320 g, Iffa Credo, Someren, the Netherlands) were housed under standard conditions $\left(20^{\circ} \mathrm{C}, 12\right.$-hour light/dark cycle) and given free access to standard chow (Hope Farms, Woerden, the Netherlands) and tap water. The experimental procedures were performed according to institutional guidelines and approved by the Ethical Committee for the Use of Experimental Animals of the Universiteit Maastricht (the Netherlands).

Rats were randomly selected to undergo $\mathrm{Ml}$ or sham surgery (sham). MI was induced by permanent ligation of the left coronary artery, as described previously (Schoemaker et al. 1991). Briefly, animals were anesthetized (pentobarbital; $60 \mathrm{mg} / \mathrm{kg}$ i.p.), intubated, and respirated (room air; 60 strokes/min; tidal volume $3 \mathrm{ml}$ ). Following thoracotomy in the fourth left intercostal space, the heart was exteriorized and a 6-0 silk suture looped around the proximal left coronary artery. After the heart had been returned to its normal position, the suture was securely ligated in the MI group. In sham rats, a superficial ligature was placed in the left ventricle wall near the left coronary artery and loosely tied. The thorax was closed with 3-0 silk under negative pressure. Sham and $\mathrm{Ml}$ rats were randomly divided for inclusion in either the hemodynamic or the neurohormonal study. Surgery did not have an effect on body weight at any time point investigated.

\section{Hemodynamic study}

Implantation of electromagnetic flow probes: Cardiac output (CO) was measured with an ellectromagnetic (EM) flow probe (Smith et al. 1979; Smits et al. 1982). Under pentobarbital anesthesia ( $60 \mathrm{mg} / \mathrm{kg}$ i.p.), the animals were respirated with room air ( 60 strokes/min, tidal volume $3 \mathrm{ml}$ ) after intubation of the trachea. Under aseptic conditions, a thoracotomy was performed in the third right intercostal space, and the aorta was dissected from surrounding tissue. An EM flow probe ( $2.7 \mathrm{~mm}$; Skalar, Delft, the Netherlands) was then placed on the ascending aorta. The ribs were tied together, and the muscles and skin were sutured separately. Thoracic pressure was restored by application of a negative pressure of $10 \mathrm{~cm}$ $\mathrm{H}_{2} \mathrm{O}$. The flow probe cable was guided to the neck, where the connector was fixed 
to the skin. The animals were allowed to recover for 3-6 days before implantation of arterial and venous catheters.

Implantation of catheters: Catheters were implanted under light ether anesthesia at least 1 day before measurements. The catheters were implanted through the femoral vessels into the inferior vena cava (PE 10 heat-sealed to PE 50; Clay Adlams, Parsippany, $N J$, USA) for $i . v$. injections and into the abdominal aorta (PE 10 heat-sealed to PE 50) for blood pressure measurements. Another catheter (Silastic 602-175 connected to PE 50; Dow Corning, Midland, MI, USA) was implanted through a femoral vein into the thoracic vena cava near the right atrium for measurements of central venous pressure. All catheters were guided to the neck, filled with saline, and closed with metal plugs.

Hemodynamic measurements: Hemodynamic parameters were measured at 7 , 21,35 , and 90 days after surgery in different groups of MI $(n=20,25,20$ and 16 per time point, respectively) and sham rats $(n=9,8,13$ and 8 respectively). Mean arterial pressure (MAP) and central venous pressure (CVP) were measured using a pressure transducer (150PC flow-thru pressure sensor, Micro Switch, Freeport, III, USA), and aortic flow was measured using a sine-wave EM flow meter (Transflow 601 system, type MDL400; Skalar, Delft, the Netherlands). Heart rate (HR), CO and stroke volume (SV) were obtained from the aortic flow signal. Total peripheral resistance (TPR) was computed as TPR $=($ MAP - CVP)/CO. All hemodynamic variables were continuously monitored and/or calculated on-line by a computer.

Baseline values were obtained in all animals by averaging the values of all variables for 10-20 min after an equilibration period of 45-60 min. Thereafter, a rapid volume loading was given by $i . v$. infusion of $12 \mathrm{ml}$ of a warm $\left(37^{\circ} \mathrm{C}\right.$ ) Ringer's solution ( $\mathrm{mM}: \mathrm{NaCl}, 154 ; \mathrm{KCl}, 2.7 ; \mathrm{CaCl}_{2}, 1.8 ; \mathrm{NaHCO}_{3}, 1.2 ; \mathrm{pH} 7.4$ ) in 60 s. Maximal cardiac performance was determined by averaging the values of cardiac output $\left(\mathrm{CO}_{\mathrm{VL}}\right)$ and stroke volume $\left(\mathrm{SV}_{\mathrm{VL}}\right)$ during the last $10 \mathrm{~s}$ of the volume loading (Schoemaker et al. 1990a).

\section{Neurohormonal study: surgery and blood sampling}

Blood was sampled for neurohormonal determination in sham and MI rats at 1 ( $n=28$ and 23 respectively), 5 ( $n=18$ and 13 respectively), and $13(n=12$ and 14 respectively) weeks after surgery. Several days before the end of the experimental period, rats were anesthetized with pentobarbital $(60 \mathrm{mg} / \mathrm{kg}$ i.p. $)$ and an arterial catheter was implanted under aseptic conditions and advanced from the femorall artery into the abdominal aorta. The saline-filled catheter was guided subcutaneously to the base of the neck, exteriorized, and sealed with a metal plug.

Blood was sampled from quietly resting rats beginning on the day after 
cannulation. A maximum of $2 \mathrm{ml}$ blood was sampled on a given day (and care was taken to ensure that catheters were rinsed with an insignificant amount $(<100$ $\mu l)$ of saline). Only one blood sample was taken from rats at 7 days after surgery. At 5 weeks after surgery, blood was sampled on two consequetive days and randomly divided in tubes for neurohormonal measurements. In the twelfth week after surgery, blood was sampled on three days with a rest day between sampling days. Sampling was routinely done in the morning hours. Sampled blood was divided into chilled tubes. Tubes for ANG II determination contained EDTA supplemented with $3.6 \mathrm{mM}$ enalaprilate, $1.25 \mathrm{mM}$ o-phenanthroline, $2 \%$ ethanol and $2 \mathrm{mg} / \mathrm{ml}$ neomycin; tubes for ANP determination contained EDTA supplemented with trasylol $(50 \mathrm{KIU} / \mathrm{ml}$ blood); tubes for $E T$ determination contained EDTA; tubes for catecholamine determination contained glutathion and heparin. The blood samples were centrifuged at $3000 \mathrm{~g}$ for 15 minutes, and plasma was stored at $-20^{\circ} \mathrm{C}$.

\section{Measurement of neurohormones in plasma}

Following extraction with ethanol from plasma, ANG II was determined by radioimmunoassay performed with ANG II standard and rabbit antibody (Stassen et al. 1997). Separation was performed with goat anti-rabbit secondary antibodies. Rat plasma ANP and ET were quantified by radioimmunoassay with commercial kits (Nichols Institute Diagnostics BV., Wychen, the Netherlands). Catecholamines were determined by fluorescence high performance liquid chromatography as described earlier (van der Hoorn et al. 1989).

\section{Determination of myocardial infarction size}

After experimentation, hearts were excised and washed in saline. Following removal of the atria, the ventricles were cut into transverse sices of $1-2 \mathrm{~mm}$, resulting in 5-6 slices. The mid-ventricular slice was fixed in $4 \%$ formaldehyde and embedded in paraffin, whereafter transverse sections $(4 \mu \mathrm{m})$ were stained according to the modified AZAN technique (van Krimpen et al. 1991). Infarct size was determined by planimetry and expressed as percentage of left ventricle circumference, calculated as the average of infarct sizes of endocardial and epicardial surfaces (Passier et al. 1995). Only rats with myocardial infarct sizes $>21 \%$ were used in the MI groups, as smaller infarcts do not have detectable hemodynamic consequences in vivo (Schoemaker et al. 1991). Ml sizes averaged 40 $-45 \%$ in all groups.

\section{Materials}

Inorganic salts for Ringer's solution glutathion and EDTA were otained from Merck (Amsterdam, the Netherlands); enalaprilate, o-phenanthroline, neomycin, and trasylol from Sigma (St. Louis, MO, USA); heparin from Leo Pharmaceuticals 
(Weesp, the Netherlands).

Data analysis

Hemodynamic parameters in sham and MI animals were compared at single time points by a Student's t-test. Neurohormonal parameters were compared by a nonparametric Mann Whitney U-test for unpaired observations. All data are expressed as mean \pm S.E.M. Differences were considered statistically significantly at a value of $p<0.05$

\section{Results}

As shown in Figure 2.1, at one week after myocardial infarction, baseline CO $(92 \pm 2$ vs. $99 \pm 1 \mathrm{ml} / \mathrm{min})$ and SV $(174 \pm 6$ vs. $181 \pm 7 \mu \mathrm{l})$ were not reduced. Although TPR was also not different between sham and MI rats (Figure 2.2b), MAP was reduced in MI rats (Figure $2.2 \mathrm{a} ; 92 \pm 2$ vs. $99_{ \pm} 1 \mathrm{mmHg}$ ). Maximal $\mathrm{CO}_{\mathrm{VL}}(89 \pm 3$ vs. $107 \pm 5 \mathrm{ml} / \mathrm{min}$ ) and $S V_{\mathrm{VL}}(224 \pm 6$ vs. $261 \pm 11 \mu \mathrm{l})$ were reduced in MI rats (Figure 2.1), which evidences reduced cardiac funtion. At this time point, plasma concentrations of ANG II, ANP and EPI were increased (Table 2.1).

Three weeks after surgery, baseline $C O\left(70_{ \pm} 2 \mathrm{vs} .86 \pm 3 \mathrm{ml} / \mathrm{min}\right)$ was decreased but MAP was not significantly reduced in $M \|$ rats due to an increase in TPR $\left(1.39_{ \pm} 0.07\right.$ vs. $1.15_{ \pm} 0.05 \mathrm{mmHg} / \mathrm{min} / \mathrm{ml}$ ) (Figures $2.1 \mathrm{a}$ and $2.2 \mathrm{a}$ and b). Similar to the hemodynamic status at three weeks after surgery, reduced baseline $\mathrm{CO}$ ( $79 \pm 2$ vs. $93 \pm 4 \mathrm{ml} / \mathrm{min})$, increased TPR $(1.21 \pm 0.04$ vs. $1.06 \pm 0.05 \mathrm{mmHg} . \mathrm{min} / \mathrm{ml})$ and unaltered MAP were measured in MI compared to sham rats at five weeks after surgery (Figures $2.1 \mathrm{a}$ and $2.2 \mathrm{a}$ and $\mathrm{b}$ ). SV was significantly smaller in MI rats at both time points ( 3 weeks: $189 \pm 7$ vs. $246 \pm 10 \mu$; 5 weeks: $217 \pm 5$ vs. $268 \pm 9 \mu$; Figure 2.1b). As shown in Figure 2.1, $\mathrm{CO}_{\mathrm{VL}}$ and $\mathrm{SV}_{\mathrm{wL}}$ were also decreased in $\mathrm{MI}$ rats at both time points ( 3 weeks: $105 \pm 3$ vs. $139 \pm 4 \mathrm{ml} / \mathrm{min}$ and $259_{ \pm} 8 \mathrm{vs} .351 \pm 10$ $\mu \mathrm{l}$, respectively; 5 weeks: $112 \pm 2$ vs. $150 \pm 3 \mathrm{ml} / \mathrm{min}$ and $289 \pm 6$ vs. $373_{\Perp} 14 \mu \mathrm{l}$, respectively). As seen in Table 2.1, only plasma ET levels were elevated five weeks after surgery in $\mathrm{MI}$ rats. 

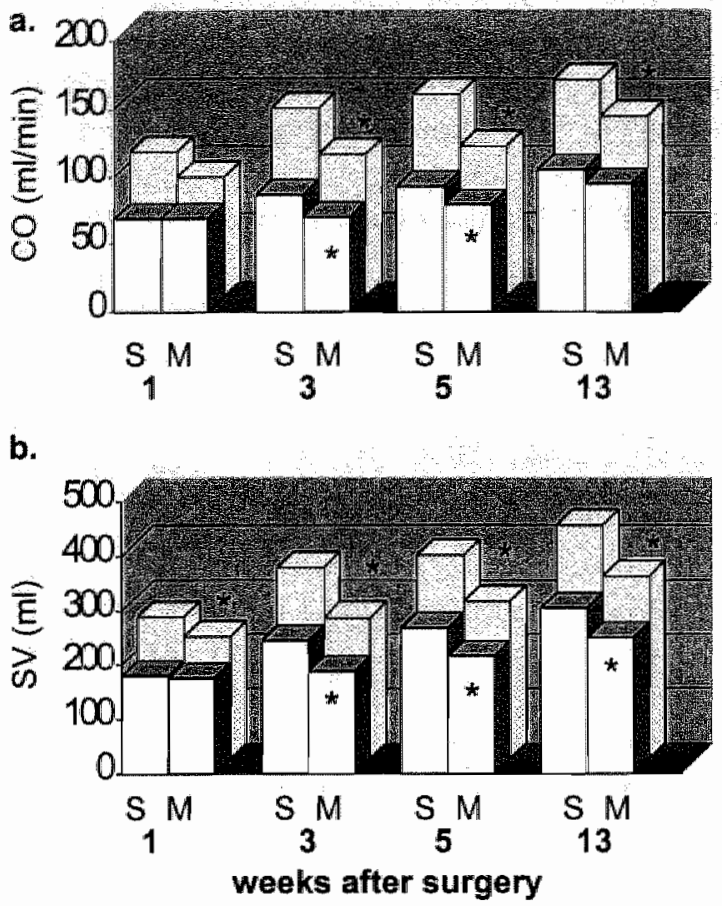

Figure 2.1

Panel a: Baseline (open bars) and maximal cardiac output (closed bars) in sham (S) and myocardially infarcted $(M)$ rats at various time points after surgery. Panel b: Baseline (open bars) and maximal stroke volumes (closed bars) of sham (S) and myocardially infarcted (M) rats at various time points after surgery. " $p<0.05 \mathrm{vs}$. sham; see text for $n$.

At thirteen weeks after surgery, MI rats became tachycardic ( $378 \pm 8$ vs. $347 \pm 7$ beats $/ \mathrm{min}$ ) (Figure $2.2 \mathrm{c}$ ). This enabled them to generate a relatively normal baseline $\mathrm{CO}\left(95_{ \pm} 3 \mathrm{vs} .105 \pm 6 \mathrm{~m} / \mathrm{min}\right)$ despite reduced stroke volumes $(251 \pm 9 \mathrm{vs}$. $303 \pm 17 \mu l)$ (Figure 2.1). TPR was not elevated and consequently MAP $(86 \pm 2$ vs. $100 \pm 2 \mathrm{mmHg}$ ) was reduced compared to sham rats (Figure $2.2 \mathrm{a}$ and $\mathrm{b}$ ). Various neurohormonal systems were again activated at this time; plasma levels of ANP, ET, NA and EPI were elevated in MI rats compared to their sham counterparts (Table 2.1). Depressed cardiac function was apparent from the difference in maximal $\mathrm{CO}_{\mathrm{VL}}$ and $S \mathrm{~V}_{\mathrm{VL}}$ between sham and $\mathrm{Ml}$ rats $\left(133_{ \pm} 6 \mathrm{vs} .160_{ \pm} 7 \mathrm{ml} / \mathrm{min}\right.$; $337 \pm 11$ vs. $429 \pm 25 \mu$, respectively; Figure 2.1). 


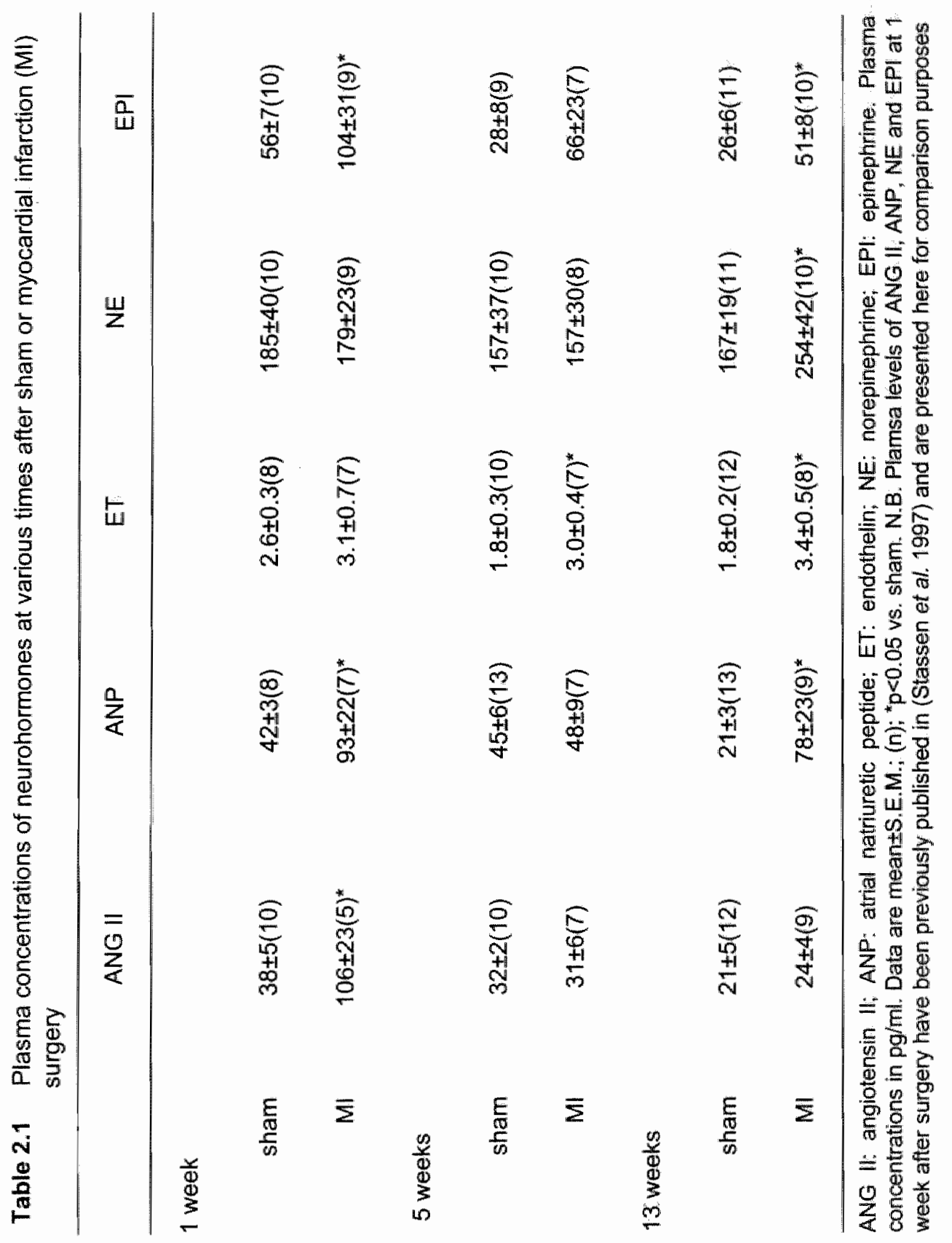


a.

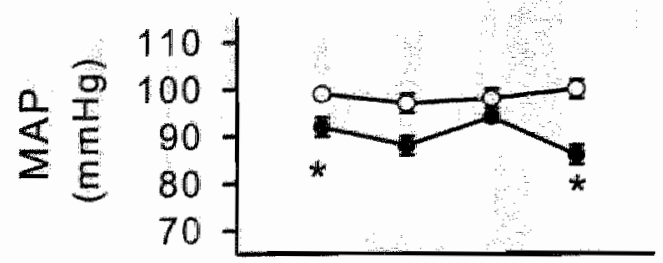

b.

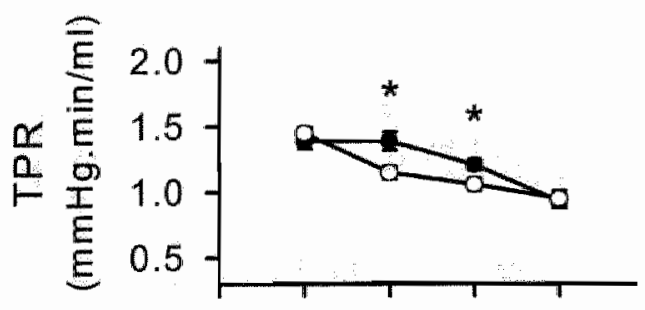

c.

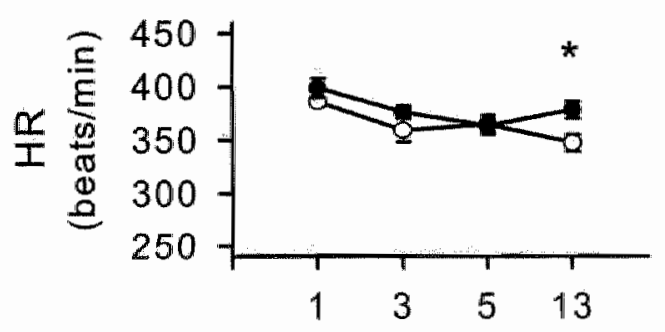

weeks after surgery

\section{Figure 2.2}

Mean arterial pressure (MAP; panel a), total peripheral resistance (TPR; panel b), and heart rate (HR; panel c) in myocardially infarcted rats (closed circles) and sham rats (open circles) at various time points after surgery. Data are mean $\pm S . E . M$; see text for $n$. ${ }^{*} p<0.05$ vs. sham.

\section{Discussion}

This study demonstrates that myocardial infarction in the rat induces severe left ventricular dysfunction concomitant with early neurohormonal activation. This phase is succeeded by a compensatory phase, in which neurohormonal levels normalize. Further reductions in maximal cardiac function and re-activation of various neurohormonal systems are signs of a transition into decompensation which become eminent at three months after the myocardial insult.

Although $\mathrm{M}$ l induced by coronary artery ligation in rats is an established model for studying the hemodynamic and cardiac structural changes during the 
development of heart failure (Pfeffer et al. 1979; Smits et al. 1995), little information is available on the neurohormonal status of this model. In the light of clinically-based hypotheses suggesting that chronic activation of neurohormonal systems induces adverse effects on cardiac function independent of the induced hemodynamic alterations (Packer, 1992; Sigurdsson \& Swedberg, 1994; Teerlink, 1996), the present study reports neurohumoral characteristics in this model, in relation to the associated hemodynamic changes.

At one week after $\mathrm{MI}, \mathrm{CO}_{\mathrm{VL}}$ and $\mathrm{SV}_{\mathrm{VL}}$ were significantly reduced in $\mathrm{MI}$ rats, indicating left ventricular dysfunction (Pfeffer et al. 1979; Schoemaker of al. 1991). Despite this, baseline CO was normal in MI rats. The observed elevation in ANG II and EPI levels may have contributed to compensation for the reduction of myocardial mass by increasing cardiac contractility (Kobayashi et al. 1978). Although baseline $\mathrm{CO}$ and TPR were not significantly altered, MAP was still slightly reduced. One may speculate that neurohormonal activation was of a sufficient degree to maintain $\mathrm{CO}$ and that, although perfusion pressure was reduced, it was adequate for supporting organ function.

At three and five weeks after surgery, increased TPR maintained MAP despite, and perhaps contributing to, reduced $\mathrm{CO}$ in $\mathrm{MI}$ rats. Nonetheless, elevated plasma levels of neurohormones were not detected. The apparent paradox of increased TPR in conjunction with normal neurohormonal levels may be due to normalization of ANP levels between one and five weeks. Although ANP primarily affects volume balance, it does also function as a vasodilator (Shen et al. 1991; Nishikimi et al. 1994). While other vasoconstrictor hormonal systems such as vasopressin and several prostaglandins may have been activated, these results may also point towards the importance of local neurohormonal systems. Endothelin is realized as primarily an autocrine / paracrine effector (Battistini et at. 1993), and local production of ANG II has also been shown to play an important role in cardiovascular homeostasis (Dzau et al. 1994; Pinto et al. 1995). Additionally, it is possible that basal nitric oxide release is reduced during the compensatory period, and the resulting decrease in vasodilator tone contributes to the increased peripheral resistance (Lüscher et al. 1993). During this period, cardiac function is undermined by the increased resistance against which the heart must pump.

At three and five weeks, the MI rats are most likely still in a phase of cardiac compensation in which continued dilatation of the left ventricle helps to maintain sufficient cardiac function (Pfeffer \& Braunwald, 1990). Increased cavity volumes have been demonstrated to be compensatory in the early phases after myocardial infarction in humans by restoring stroke volume (Pfeffer \& Braunwald, 1990; Gaudron et al. 1993). Dilatation causes increased wall stress, due to increased diastolic volume and pressure, which is a stimulus for myocyte hypertrophy (Grossman et al. 1975). Local hormones, especially ANG II, have also been shown to induce growth in both the myocyte and non-myocyte compartment (Baker et al. 1990; Smits et al. 
1995). Initially, hypertrophy also compensates for reduced myocardial mass.

Nonetheless, although left ventricle dilatation is initially compensatory, it eventually becomes non-compensatory since cardiac reserve plummets and since it increases the burden on the weakened heart (Pfeffer \& Braunwald, 1990; Gaudron et al 1993). Furthermore, ANG II activates fibroblast secretion of collagen (Smits ef al. 1995). Excessive hypertrophy, with unparalleled vessel growth and collagen deposition, ultimately lead to decreased subendocardial perfusion and increased myocardial stiffness as has been demonstrated in this model (Anversa et al. 1985; Vatner et al. 1990; Brilla, 1994; Nelissen-Vrancken et al. 1996), along with increased heart weights (Heeneman et al. 1995).

At thirteen weeks after myocardial infarction, stimulated stroke volumes are severely reduced suggesting that cardiac reserve is near minimum. At this time point, increased plasma levels of neurohormones are again prevalent and may contribute to maintaining baseline cardiac output by inducing tachycardia. These indications may be a sign of a transition into decompensation, as pulmonary congestion has also been noted in Ml rats during this time frame (Heeneman et al. 1995). While local and cardiac compensatory mechanisms may have been sufficient to maintain perfusion pressure between three and five weeks after myocardial infarction, excessive neurohormonal activation, as reflected in elevated plasma concentrations, becomes necessary at thirteen weeks to achieve hemodynamic sufficiency.

Like the hemodynamic alterations, neurohormonal alterations characteristic of this model have important similarities with the clinical situation. Neurohormonal activation is present acutely in post-MI patients (Cohn, 1990; Rouleau et al. 1991; Sigurdsson et al. 1993), but returns to normal levels in patients in which severe left ventricular dysfunction is not found (Rouleau et al. 1991; Sigurdsson et al. 1993). It must be noted that in patients with asymptomatic heart failure, but severe left ventricular dysfunction, neurohormonal activation persists (Francis et al. 1990; Rouleau at al. 1994). Symptomatic heart failure is likewise characterized by neurohormonal activation (Francis et al. 1990; Swedberg et al. 1990a). Although the time course of neurohormonal activation in the rat model parallels the human pathology in many ways, the absence of heightened plasma ANG II levels in the late phases after $\mathrm{MII}$ in the rat is noteworthy, especially since the renin-angiotensin system has been shown to play an important role in the structural and functional adaptations of the cardiovascular system of this model (Pfeffer et al. 1985, 1995; Schoemaker et al. 1991; Smits et al. 1995). Although the evidence from the present study is only circumstantial, it supports the importance of local renin-angiotensin systems (Pfeffer et al. 1995; Smits et al. 1995).

From these results, we conclude that left ventricular dysfunction after $\mathrm{Ml}$ in rats induces early neurohormonal activation. A compensatory phase follows in which cardiac structural changes supplemented by local vasoconstrictor hormone 
activation or vasodilator hormone reductions are compensatory and sufficient for adequate systemic hemodynamics. Later re-elevation of plasma neurohormone concentrations and further reductions in maximal cardiac function are suggestive of a transition into decompensation.

\section{References}

ANVERSA P, BEGHII C, KIKKAWA Y \& OLIVETTI G (1985). Myocardial response to infarction in the rat. Morphometric measurement of infarct size and myocyte cellular hypertrophy. Am. J. Pathol. 118, 484-492.

BAKER KM, CHERNIN MI, WIXSON SK \& ACETO JF (1990). Renin-angiotensin system involvement in pressure-overload cardiac hypertrophy in rats. Am. J. Physiol. 259, H324-H332.

BATTISTINI B, D'ORLEANS-JUSTE P \& SIROIS P (1993). Endothelins: circulating plasma levels and presence in other biologic fluids. Lab. Invest. 68, 600-628.

Bech OM, KahR O, Diamant B \& Steiness E (1989). Time course of functional deterioration after coronary artery ligation in rats. Cardiovasc. Res. 23, 649-654.

BRILLA CG (1994). The cardiac structure-function relationship and the renin-angiotensinaldosterone system in hypertension and heart failure. Curr. Opin. Cardiol. 9(Suppl. 1), S2-S11.

COHN JN (1990). Neuroendocrine activation after acute myocardial infarction. Am. J. Cardiol. 65, 28I-311.

COHN JN, Levine TB, Olivari MT, Garberg V, LuRa D, Francis GS, Simon aB \& RECTOR T (1984). Plasma norepinephrine as a guide to prognosis in patients with chronic congestive heart failure. N. Engl. J. Med. 311, 819-823.

THE CONSENSUS TRIAL STUDY GROUP (1987). Effects of enalapril on mortality in severe congestive heart failure: Results of the Cooperative North Scandanavian Enalapril Survival Study (CONSENSUS). N. Engl. J. Med. 316, 1429-1435.

DEFELICE A, FRERING R \& HORAN P (1989). Time course of hemodynamic changes in rats with healed severe myocardial infarction. Am. J. Physiol. 257, H289-H296.

Drexler H. Toggart EJ, Glick MR, Heald J, Flaim SF \& Zelis R (1986). Regional vascular adjustments during recovery from myocardial infarction in rats. J. Am. Coll. Cardiol. 8, 134-142.

DZAU VJ, PRATT R \& GIBBONS GH (1994). Angiotensin as local modulating factor in ventricular dysfunction and failure due to coronary artery disease. Drugs 47, 1-13. 
ERIKKSON H (1995): Heart failure: a growing public health problem. J. Int. Med. 237, 135141.

FRANCIS GS, BENEDICT C, JOHNSTONE DE, KIRLIN PC, NICKLAS J, LIANG C-S, KUBO SH, RUDIN-TORETSKY E, YUSUF S FOR THE SOLVD INVESTIGATORS (1990). Comparison of neuroendocrine activation in patients with left ventricular dysfunction with and without congestive heart failure. A substudy of the Studies of Left Ventricular Dysfunction (SOLVD). Circulation 82, 1724-1729.

Galatius-Jensen S, Wroblewski H, Emmeluth C, Bie P, Haunso S \& Kastrup J (1996). Plasma endothelin in cardiac failure: a predictor of cardiac death? J. Card. Fail. 2, 7176.

GAUDRON P, EILES C, ERTL G \& KOCHSIEK K (1993), Adaptation to cardiac dysfunction after myocardial infarction. Circulation 87(Suppl. 4), IV83-IV89.

GROSSMAN W, JONES D \& MCLAURIN LD (1975). Wall stress and patterns of hypertrophy in the human left ventricle. J. Clin. Invest. 56, 56-64.

HeEnEMAN S, LEENDERS PJA, AARTS PJJW, SMITS JFM, ARENDS JW \& DAEMEN MJAP (1995). Peripheral vascular alterations during experimental heart failure in the rat: do they exist? Arterioscl. Thromb. Vasc. Biol. 15, 1503-1511.

VAN deR HOORn FA, Boomsma F, MAN-IN-'T-Veld AJ \& SchalekAMp MA (1989). Determination of catecholamines in human plasma by high-performance liquid chromatography: comparison between a new method with fluorescent detection and an established method with electrochemical detection. J. Chromatogr. 487, 17-28.

KOBAYASHI M, FURUKAWA Y \& CHIBA S (1978). Positive chrontropic and inotropic effects of angiotensin II in the dog heart. Eur. J. Pharmacol. 50, 17-25.

VAN KRIMPEN C, SMITS JFM, CLEUTJENS JPM, DEBETS JJM, SCHOEMAKER RG, STRUIJKER BOUDIER HAJ, BOSMAN FT \& DAEMEN MJAP (1991). DNA synthesis in the non-infarcted cardiac interstitium after left coronary artery ligation in the rat: effects of captopril. J. Mol. Cell. Cardiol. 23, 1245-1253.

LÜSCHER TF, BOULANGER CM, YANG Z, NOLL G \& DOHI Y (1993). Interactions between endothelium-derived relaxing factors in health and cardiovascular disease. Circulation 87(Suppl. 5), V36-V44.

NELISSEN-VRANCKEN HJMG, DEBETS JJM, SNOECKX LHEH, DAEMEN MJAP \& SMITS JFM (1996). Time-related normalization of miximal coronary flow in isolated perfused hearts of rats with myocardial infarction. Circulation 93, 349-355.

NishIKIMI T, MIURA K, MINAMINo N, TAKEUCHI K \& TAKEDA T (1994). Role of endogenous atrial natriuretic peptide on systemic and renal hemodynamics in heart failure rats. Am. 
J. Physiol. 267, H182-H186.

PACKER M (1992). The neurohormonal hypothesis: a theory to explain the mechanism of disease progression in heart failure. J. Am. Coll. Cardiol. 20, 248-254.

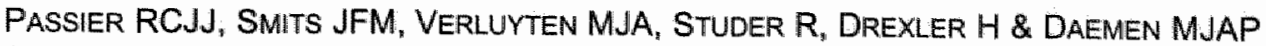
(1995). Activation of angiotensin-converting enzyme expression in infarct zone following myocardial infarction. Am. J. Physiol. 269, H1268-H1276.

PfefFer JM, PFefFer MA \& BRAunwald E (1985). Influence of chronic captopril therapy on the infarcted left ventricle of the rat. Circ. Res. 57, 84-95.

Pfiffer JM, FISCHER TA \& PFEFfer MA (1995). Angiotensin-converting enzyme inhibition and ventricular remodeling after myocardial infarction. Ann. Rev. Physiol. 57, 805-826.

PFEFFER MA \& BRAUNWALD E (1990). Ventricular remodeling after myocardial infarction: experimental observations and clinical implications. Circulation 81„1161-1172.

Pfeffer MA, Pfeffer JM, Fishbein MC, Fletcher PJ, Spadaro J, Koner RA \& BRAUNWALD E (1979). Myocardial infarct size and ventricular function in rats. Circ. Res. 44, 503-512.

PINTO YM. BUIKEMA H \& VAN GILST WH (1995). Hyperactive tissue renin-angiotensin systems in cardiovascular dysfunction: experimental evidence and clinical hypotheses. Clin. Exp. Hypertension 17, 441-468.

Rouleau Jl, Moyé La, de Champlain J, KLein M, Bichet D, Packer M, Dagenais G, SUSSEX B, ARNOLD JM, SEstIER F, PARKER JO, MCEWAN MMP, BERNSTEIN V, CUDDY TE, Delage F, Nadeau C, lamas GA, GotTlieb SS, McCans J \& Pfeffer MA (1991). Activation of neurohormonal systems following acute myocardial infarction. Am. J. Cardiol. 68, 80D-86D.

Rouleau Jl, Packer M, MOYe L, De Champlain J, Bichet D, KLein M, Rouleau JR, SusseX B, ARNOLd JM, SEstier F, PARKER JO, MCEWAN P, BERNSTEIN V, CUdDY TE, lamas G, Gottlieb SS, mcCans J, Nadeau C, Delage F, wun CCC \& Pfeffer Ma (1994). Prognostic value of neurohumoral activation in patients with an acute myocardial infarction: effect of captopril. J. Am. Coll. Cardiol. 24, 390-398.

SCHOEMAKER RG, DEBETS JJM, STRUIJKER BOUDIER HAJ \& SMITS JFM (1990a). Beneficial hemodynamics effects of two weeks' milrinone treatment in conscious rats with heart failure. Eur. J. Pharmacol. 182, 527-535.

SCHOEMAKER RG, URQUHART J, DEBETS JJM, STRUIJKER BOUDIER HAJ \& SMITS JFM (1990b). Acute hemodynamic effects of coronary artery ligation in conscious rats. Basic Res. Cardiol. 85, 9-20. 
SCHOEMAKER RG, DEBETS JJM, STRUIJKER BOUDIER HAJ \& SMITS JFM (1991). Delayed but not immediate captopril therapy improves cardiac function in conscious rats, following myocardial infarction. J. Mol. Cell. Cardiol. 23, 187-197.

SHEN Y-T, GRAHAM RM \& VATMER SF (1991). Effects of atrial natriuretic factor on blood flow distribution and vascular resistance in conscious dogs. Am. J. Physiol. 260, H1893H1902.

SIGURDSSON A \& SWEDBERG K (1994). Is neurohormonal activation a major determinant of the response to ACE inhibition in left ventricular dysfunction and heart failure? $\mathrm{Br}$. Heart J. 72 (Suppl.) ) 75-80.

SiguRdSSON A, HELD P \& SWEDBERG K (1993). Short- and long-term neurohormonal activation following acute myocardial infarction. Am. Heart J. 126, 1068-1076.

SMITH TL \& HUTCHINS PM (1979). Central hemodynamics in the developmental stage of spontaneous hypertension in the unanesthetized rat. Hypertension 1, 508-517.

SMITS JFM, COLEMAN TG, SMITH TL, KASBERgEN CM, VAN ESSEN H \& STRUIJKER BOUdIER HAJ (1982). Antihypertensive effect of propanolol in conscious spontaneously hypertensive rats: central hemodynamics, plasma volume and renal function during beta-blockade with propanolol. J. Cardiovasc. Pharmacol. 4, 903-914.

Smits JFM, PASSiER RCJJ, Nelissen-VRANCKEN HJMG, KUIZINGA MC \& DAEMEN MJAP (1995). Does ACE inhibition limit structural changes in the heart following myocardial infarction? Eur. Heart. J. 16(Suppl. N), 46-51.

STASSEN FRM, WILLEMSEN MJJMF, JANSSEN GMJ, FAZZI GE, SCHIFFERS PMH, SMITS JFM \& DE MEY JGR (1997). Reduced responsiveness of rat mesenteric artery smooth muscle to phenylephrine and calcium following myocardial infarction. Br. J. Pharmacol. $120,1506-1512$.

SVENGAARD J, ANGELO-NIELSEN K \& PINDBORG T (1992). Plasma concentration of atrial natriuretic peptide at admission and risk of cardiac death in patients with acute myocardial infarction. Br. Heart J. 68, 38-42.

SWEDBERG K, ENEROTH P, KJEKHUS J, WILHELMSEN L FOR THE CONSENSUS TRIAL STUDY GROUP (1990a). Hormones regulating cardiovascular function "hemodynamic indexes, and plasma hormones in untreated congestive cardiac failure. Circulation 82, 17301736 .

SWEdBERg K, ENEROTH P, KJeKSHUS J, SNAPINN S FOR THE CONSENSUS TRIAL STUdY GROUP (1990b). Effect of enalapril and neuroendocrine activation on prognosis in severe congestive heart failure (follow-up of the CONSENSUS trial). Am. J. Cardiol. 66, 40D$45 \mathrm{D}$. 
TEERLINK JR (1996). Neurohormonal mechanisms in heart failure: a central role for the renin-angiotensin system. J. Cardiovasc. Pharmacol. 27(Suppl. 2), S1-S8.

VATNER SF, SHANNON R \& HITTINGER L (1990). Reduced subendocardial coronary reserve. a potential mechanism for impaired diastolic function in the hypertrophied and failing heart. Circulation 81(Suppl. 2), III8-1I14. 


\section{The influence of angiotensin II-induced increase in aortic wall mass on compliance in rats in vivo}

\section{D.L. Ceiler}

H.J.M.G. Nelissen-Vrancken

J.F.M. Smits

J.G.R. De Mey

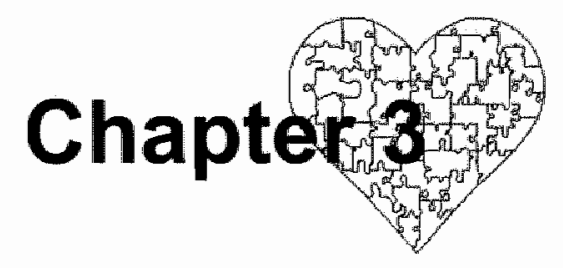




\section{Abstract}

This study was undertaken to examine the effects of angiotensin II-induced structural changes in the aortic wall on the dynamic mechanical properties of the vessel in the rat. Wistar rats were infused s.C. with $250 \mathrm{ng} / \mathrm{kg} / \mathrm{min}$ angiotensin II (ANG II) for 14 days (ANG). Both ANG and control rats (CON) were equipped with an arterial catheter for measurement of arterial blood pressure. Thoracic aorta diameter, compliance coefficient (CC), and distensibility coefficient (DC) were determined non-invasively in pentobarbital anesthetized animals using a B-mode imager attached to a vessel wall tracking system. After sacrifice, medial cross sectional area (CSA), and elastin and collagen densities were determined by morphometry on cross sections. Media thickness (Mt) and mediato-lumen ratio $(\mathrm{M} / \mathrm{L})$ were subsequently calculated. ANG II infusion significantly increased mean arterial blood pressure in conscious rats ( $122 \pm 3 \mathrm{mmHg}$ CON vs. $157 \pm 4$ $\mathrm{mmHg}$ ANG). This was normalized when the rats were anesthetized, thus making it possible to determine CC and DC under isobaric conditions where the diastolic diameters were also similar. Two-week infusion of ANG II induced a significant increase in CSA from $0.48 \pm 0.02 \mathrm{~mm}^{2}$ in CON to $0.61 \pm 0.03 \mathrm{~mm}^{2}$. Mt and $\mathrm{M} / \mathrm{L}$ were likewise increased, but collagen and elastin densities remained unchanged. CC and DC were not affected by this increase in aortic wall mass (CC: $0.143 \pm 0.009$ CON, $0.147 \pm 0.014$ $\mathrm{mm}^{2} / \mathrm{kPa}$ ANG; DC: $\left.0.052 \pm 0.005 \mathrm{CON}, 0.051 \pm 0.004 \mathrm{kPa}^{-4} \mathrm{ANG}\right)$. An increase in aortic wall mass resulting from chronic infusion of ANG $\|$ does not alter the dynamic compliance of the vessel under isobaric conditions. 


\section{Introduction}

The compliance of large arteries determines to what extent they can distend to absorb volume energy during the systolic phase of the heart cycle and is thus an important determinant of cardiac work load. Reductions in arterial compliance adversely affect myocardial energetic efficiency and may contribute to the elevated risk of "ischemic cardiac diseases noted with ageing, hypertension and diabetes (Kannel et al. 1971; Kannel \& McGee, 1979; Randall et al. 1984; van Merode et al. 1988).

Although a reduced compliance has been demonstrated in these states (Messerli et al. 1985; Kawasaki et al. 1987; Lehman et al. 1992), the factors behind this decrease are still controversial. Diastolic lumen diameter, vascular wall structure, smooth muscle contractility and distending pressure are most likely involved in determining compliance, but the contribution and interplay of these factors remain largely unknown. While several recent studies suggest that increased distending pressure is a primary determinant of decreased compliance (Hayoz et al. 1992; Laurent et al. 1993, 1994a), others point to the importance of vascular tone (Levy et al. 1989; Safar ef al. 1990). Still other studies in rat models of hypertension demonstrate that compliance decreases can be precluded by preventing structural changes (Levy et al. 1988; Benetos et al. 1992). As these factors are interrelated, deciphering their contributory role remains difficult.

With current ultrasound techniques accurate measurement of large artery diameter and compliance in humans is now possible (Safar \& Frohlich, 1995), but histological data on the structure of the vascular wall are often lacking. Furthermore, for methodologic reasons, non-invasive compliance measurements in clinical studies are restricted to either the carotid artery (an elastic artery) or to the radial and brachial artery (muscular arteries). Nonetheless, systemic arterial compliance resides largely in the aorta (Westerhof at al. 1969). With a recently described wall tracking system, it is possible to use ultrasound techniques to study the elastic characteristics of the aorta in intact laboratory animals, such as rats, in various physiological and pathological states (van Gorp et al. 1996). By utililizing this technique in combination with histology, it is possible to examine the relationship between geometric, cellular and molecular changes in the arterial wall on one hand and dynamic functional changes on the other.

This study was undertaken to examine the relationship between aortic wall geometry and compliance in anesthetized animals in vivo. To this end, we utilized angiotensin II to induce structural changes in the aorta. Angiotensin II, infused chronically, has been reported to induce arterial wall hypertrophy in rats (Daemen et al. 1991; Griffin et al. 1991; Lever et al. 1992; Boonen et al. 1993). Since the experiments occurred under isobaric and isometric conditions, the effects of aortic structure 
and geometry on dynamic in vivo compliance could be discerned without interference from confounding physical parameters.

\section{Methods}

\section{Animals}

Male Wistar rats (280-320 g, Iffa Credo, Someren, the Netherlands) were housed under standard conditions $\left(20^{\circ} \mathrm{C}, 12\right.$-hour light/dark cycle) and given free acces to standard chow (Hope Farms, Woerden, the Netherlands) and tap water. The experimental procedures were performed according to institutional guidelines and approved by the Ethical Committee for the Use of Experimental Animals of the Universiteit Maastricht (the Netherlands).

\section{Treatment}

Animals were randomly placed in either a control group (CON) or a treatment group (ANG) receiving $250 \mathrm{ng} / \mathrm{kg} / \mathrm{min}$ angiotensin $\|$ (ANG II, [Val'] $]$-angiotensin II, Saxon Blochemicals $\mathrm{GmbH}$, Hannover, Germany) s.c. for two weeks. ANG II was administered via an osmotic mini-pump (Alzet 2002, Alza Co, Palo Alto, CA, USA) implanted s.c. in the neck under ether anesthesia.

\section{Functional studies}

Ultrasound assessment of aorta diameter and wall movement: On the thirteenth day of ANG II infusion, the rats were anesthetized with pentobarbital $(60 \mathrm{mg} / \mathrm{kg}$ i.p.) and equipped with an arterial catheter (PE 50) implanted in the left carotid artery and aimed to terminate at the junction with the aortic arch. The catheter was guided under the skin and exteriorized at the base of the neck. Thereafter, blood pressure (monitored via a CP-01 low volume displacement pressure transducer, Century Technology Co, inglewood, CA, USA) and body temperature (maintained at $38^{\circ} \mathrm{C}$ by a rectal temperature probe and infrared heating lamp) were allowed to stabilize before aortic mechanical wall properties were determined non-invasively by ultrasound.

Accordingly, thoracic aorta diameter and wall movement during the cardiac cycle were assessed as recently described (van Gorp et al. 1996) using a vessel wall tracking system (WTS) attached to a conventional B-mode ultrasound system (Ple480, 7.5 MHz linear array, Pie Medical, Maastricht, the Netherlands). With the ultrasound probe positioned on the thorax, the thoracic aorta was first visualized in $\mathrm{B}$-mode ( $\mathrm{B}$ : brightness) before setting an $\mathrm{M}$-line ( $\mathrm{M}$ : motion) perpendicular to the vessel walls approximately $10 \mathrm{~mm}$ cranially from the diaphragm. Upon switching to $\mathrm{M}$-mode, ultrasound is emitted and received along the selected line of sight at a programmable emission trigger frequency (see below) to enable determination of dynamic parameters. 
The concept of the WTS has been described elsewhere (van Gorp et al. 1996). It is based on a data acquisition system capable of capturing the received and amplified radio frequency (RF) signals synchronously with the emission trigger at programmable sample frequencies (up to $30 \mathrm{MHz}$ ). Reference signals, such as blood pressure, are likewise synchronously sampled with the emission trigger. At an emission frequency of $1653 \mathrm{~Hz}$, the $1 \mathrm{MB}$ memory will hold $2.5 \mathrm{sec}$ of data, corresponding to approximately 16 cardiac (and 4 respiration cycles) under the current experimental conditions.

Upon completion of acquisition, the data are transferred to a PC. The first RF line acquired is graphically presented on a display to allow manual identification of the anterior and posterior wall boundaries by two markers, which represent the sample windows for data processing. To extract the change in position of either anterior or posterior wall averaged over a few RF lines, an approach based on the cross correlation model for corresponding segments of subsequent RF lines was applied (Hoeks et al. 1993). The estimates for the cross correlation coefficients are based on a running average over a programmable number of RF lines (data window in time) to enhance stability of the estimate for the mean displacement. The difference between the displacement signal of the posterior and anterior wall yields the change in diameter as a function of time. From the observed distention wave form, together with the initial distance between the sample windows, the end diastolic diameter, the peak-to-peak change in diameter, and the length of the cardiac cycle can be extracted for each cardiac cycle. In each animal, six $2.5 \mathrm{sec}$ recordings were performed, and the data obtained during these sessions were averaged.

Measurement of blood pressure in conscious rats: Mean arterial pressure (MAP) and heart rate (HR) were measured in quietly resting rats on day 14 via a pressure transducer (CP-01, Century Technology $\mathrm{Co}$.) in conjunction with an online monitoring computer program (Hemodynamic Data Acquisition Systems, Instrumental Services, Universiteit Maastricht).

Calculation of compliance and distensibility: Arterial compliance is defined as the absolute increase in volume $(\Delta V)$ for a given increase in arterial blood pressure (pulse pressure $=\Delta P$ ). Distensibility, on the other hand, is the relative increase in volume $(\Delta V / N)$ for a given $\Delta \mathrm{P}$. Assuming that a volumetric increase is due to vascular distention (radial) rather than (axial) elongation (Reneman et al. 1986) and that the vascular cross-section is perfectly circular, compliance (CC) and distensibility (DC) can be approached as follows:

$$
C C \approx \Delta A / \Delta P \approx \pi\left(D_{d f a}+\Delta D\right) /(4 \Delta P)
$$




$$
D C=\triangle A /\left(A_{\text {dia }} \Delta P\right)
$$

where $D_{\text {dia }}$ and $A_{\text {did }}$ stand for the end-diastolic diameter and area respectively; $\Delta D$ and $\triangle A$ represent, respectively, the change in diameter and lumen ares during the cardiac cycle.

\section{Structural measurements}

After conscious MAP measurements, the rats were euthanized with ether. A 10 $\mathrm{mm}$ segment of the thoracic aorta was isolated beginning at the third pair of intercostal arteries. The extent of longitudinal retraction upon isolation was assessed by pre- (Li) and post- (Le) excision measurements of the segment length. Retraction was in the order of $25 \%$ and did not differ significantly between ANG and CON. The excised vessel was fixed by immersion in $4 \%$ phosphatebuffered formalin at room temperature before being imbedded in paraffin.

Media cross-sectional area (CSAe), defined as the area between the internal and external elastica laminae was determined by semi-automated morphometry (JAVA 1.21, Jandel Scientific, Corte Madera, CA, USA) on $4 \mathrm{~mm}$ sections stained with Lawson's solution, a classic elastin stain. This value was converted to the expected in vivo CSA (CSA) by accounting for vascular retraction upon isolation, i.e.,

$$
C S A i=C S A e \cdot L e / L i
$$

CSAi and $D_{d i a}$ were used to calculate media thickness (Mt) (4) and media-tolumen ratio $(\mathrm{M} / \mathrm{L})(5)$ according to

$$
\begin{gathered}
M t=-\frac{D_{\text {dia }}}{2}+\sqrt{\left[\frac{D_{\text {dia }}}{2}\right]^{2}+\frac{C S A i}{\pi}} \\
M I L=\frac{2 \cdot M t}{D_{\text {dia }}}
\end{gathered}
$$

Furthermore, the incremental elastic modulus $\left(E_{\text {inc }}\right)$, was calculated as 


$$
E_{\text {inc }}=D_{\text {dia }} /(M t \cdot D C)
$$

Collagen and elastin densities were measured with a computerized morphometric system (Quantimet 570, Leica) on $4 \mathrm{~mm}$ sections stained with Sirius Red and Lawson's solution (Boom B.V., Meppel, the Netherlands), respectively. At least six fields of the media area per vessel cross-section were analyzed at $400 \mathrm{x}$, and the percentage of the total tissue area occupied by collagen or elastin was calculated. The analyses were performed in a blinded fashion.

\section{Statistics}

Data are expressed as mean \pm S.E.M. Differences between the experimental groups were compared by unpaired Student's t-test and considered to be statistically different at a value of $p<0.05$.

\section{Results}

The effects of chronic ANG II infusion on MAP and HR in awake and anesthetized rats are shown in Table 3.1. ANG II significantly increased MAP in awake animals but had no effect on HR. Pentobarbital anesthesia reduced MAP in ANG but not in CON such that the difference in MAP between groups was abolished. Again, there was no difference in HR between the groups. Nonetheless, HR in both groups was greater in the anesthetized as compared to the awake state.

Figure 3.1 is a typical example of thoracic aorta wall movement and distention measured in pentobarbital anesthetized rats with the described ultrasound/wall tracking system. The results of these measurements in the two groups are summarized in Table 3.2. Under anesthesia, diastolic pressure $\left(P_{\mathrm{dla}}\right)$ and pulse pressure $(\Delta P)$ as well as end-diastolic diameter $\left(D_{\text {dia }}\right)$ and aortic distention $(\Delta D)$ did not differ between ANG and CON. Consequently, chronic ANG II infusion had no effect on aortic mechanical properties under isobaric conditions (see equations 1 and 2 in Methods). As shown in Figure 3.2, both the compliance coefficient (CC) and the distensibility coefficient (DC) are similar for both groups (CC: $0.143 \pm 0.009$ CON, $0.147 \pm 0.014 \mathrm{~mm}^{2} / \mathrm{kPa}$ ANG; DC: $0.052 \pm 0.005 \mathrm{CON}, 0.05 \pm 10.004 \mathrm{kPa}^{-1}$ ANG). The incremental elastic modulus tended to be smaller in ANG, but the difference was not statistically significant (Figure 3.2). 
Table 3.1 General characteristics of control and angiotensin II-infused rats.

\begin{tabular}{|c|c|c|}
\hline & $\mathrm{CON}$ & ANG \\
\hline Body weight $(g)$ & $302 \pm 3$ & $303 \pm 4$ \\
\hline Conscious MAP $(\mathrm{mmHg})$ & $122 \pm 3$ & $157 \pm 4^{*}$ \\
\hline Anesthetized MAP & $120 \pm 6$ & $107 \pm 5$ \\
\hline Conscious HR (bpm) & $350 \pm 9$ & $351 \pm 25$ \\
\hline Anesthetized HR (bpm) & $422 \pm 9$ & $423 \pm 9$ \\
\hline
\end{tabular}

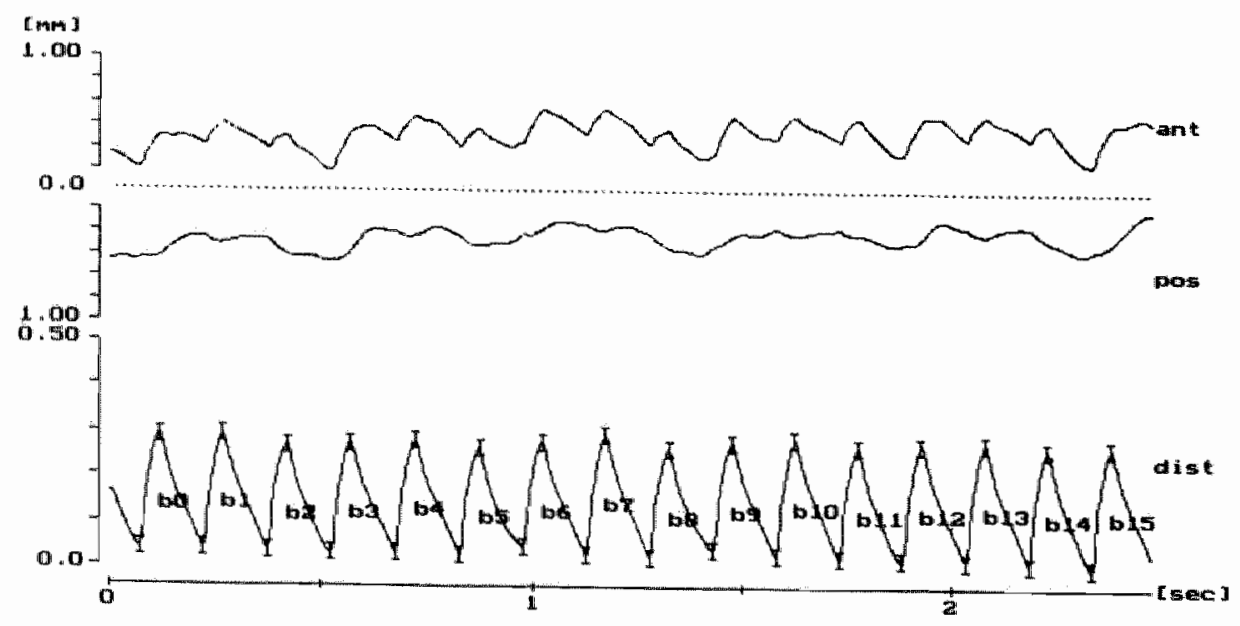

Figure 3.1

Typical example of anterior (ant) and posterior (pos) aortic wall displacement and the difference between both, distention (dis), during 16 consecutive cardiac cycles (b0-b15) as measured with ultrasound. 
a.

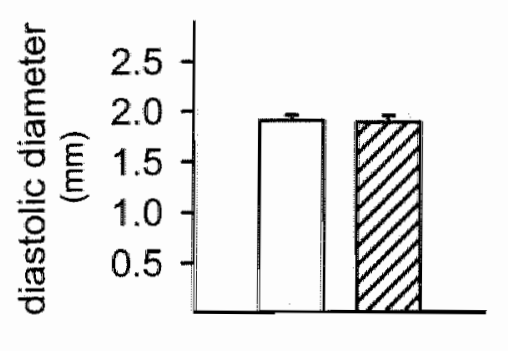

C.

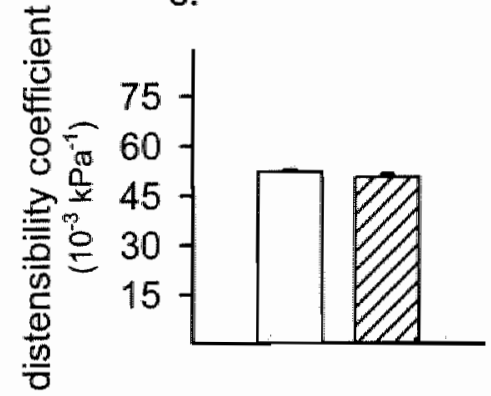

b.

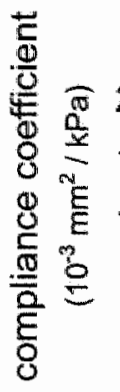

d.

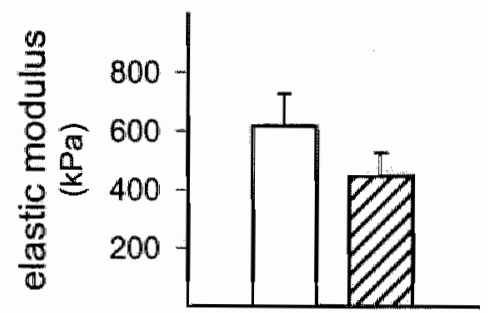

Figure 3.2

Effect of two-week angiotensin II infusion ( $250 \mathrm{ng} / \mathrm{kg} / \mathrm{min} \mathrm{s.c.)}$ on (a.) diastolic diameter, (b.) compliance coefficient, (c.) distensibility coefficient and (d.) incremental modulus in anesthetized rats at equivalent blood pressures. Open bars represent control animals; hatched bars, angiotensin II-treated rats. Data are presented as mean \pm S.E.M; $n=12$ for both groups.

Figure 3.3 summarizes the data on aortic wall geometry. Media cross-sectional area increased approximately $20 \%$ after two-week infusion of ANG II. Since diastolic diameter was comparable in ANG and CON under anesthesia, both media thickness and media-to-lumen ratio were consequently larger in ANG rats at comparable end-diastolic pressure. This increase in aortic wall mass noted after ANG II infusion appears to consist of a proportional increase in vascular wall components since neither elastin nor collagen volume fractions were modified (Figure 3.4). 
Table 3.2 Aortic pressure and distension in control and angiotensin II-infused rats.

CON ANG

n

$\mathrm{P}_{\text {dis }}(\mathrm{kPa})$

$\triangle \mathrm{P}(\mathrm{kPa})$

$\mathrm{D}_{\text {diat }}(\mathrm{mm})$
12

$14.5 \pm 0.8$

$4.17 \pm 0.17$

$1.91 \pm 0.05$
12

$12.8 \pm 0.7$

$4.38 \pm 0.36$

$1.90 \pm 0.06$

\section{$\Delta D(\mu \mathrm{m})$}

$185 \pm 10$

$188 \pm 12$

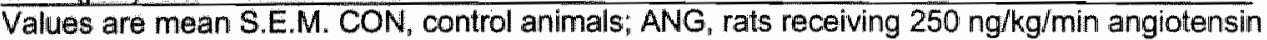
II s.c. for 2 weeks. $P_{\text {dial }}$ diastolic pressure; $\Delta P$, pulse pressure; $D_{\text {dia, }}$ lumen diamer at enddiastole; $\triangle D$, maximal change in lumen diameter during cardiac cycle. All data were derived as averages from six recordings of $2.5 \mathrm{sec}$ (approximately 16 cardiac cycles) per individual animal.

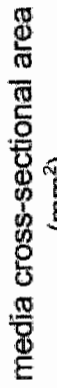

a.

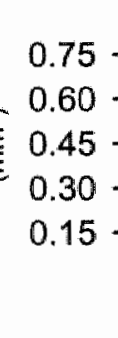

b.

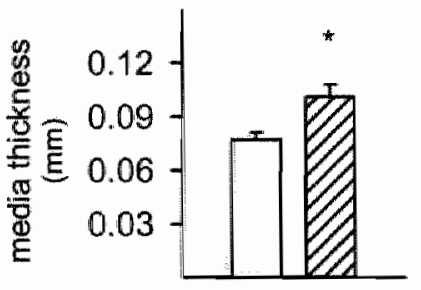

c.

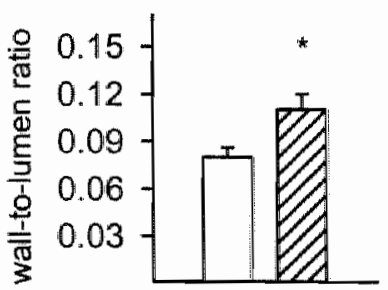

\section{Figure 3.3}

Aortic wall hypertrophy induced by two-week infusion of angiotensin II ( $250 \mathrm{ng} / \mathrm{kg} / \mathrm{min} \mathrm{s.c.)}$. Media cross-sectional area (panel a), media thickness (panel b) and media-to-lumen ratio (panel c) were all increased by treatment. Open bars represent control animals; hatched bars, angiotensin II-treated rats. Data are presented as mean \pm S.E.M; $n=12$ for both groups. " $p<0.05$ vs. control animals.

\section{Discussion}

In the present study, we examined the relationship between the structure (geometry and composition) of the thoracic aorta wall and the in vivo dynamic mechanical properties of the vessel in the rat. As the experiments were performed at similar pressures and diastolic diameters, we were able to examine the effect of increased wall mass on aortic mechanics without influence from these confounding factors. Although we confirm previous studies which demonstrate the 
a.

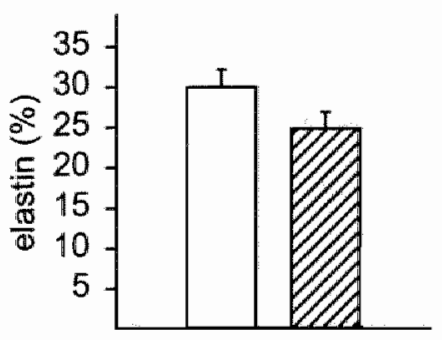

b.

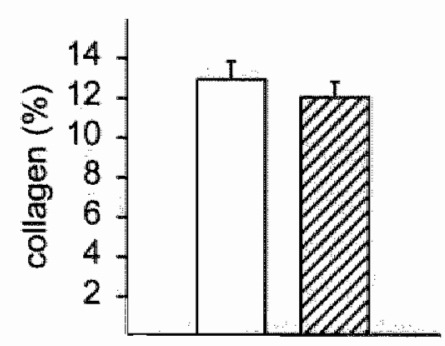

\section{Figure 3.4}

Effect of two-week angiotensin II infusion (250 ng/kg/min s.c.) on elastin (panel a) and collagen (panel b) density in rat thoracic aorta. Open bars represent control animals; hatched bars, angiotensin II-treated rats. Data are presented as mean $\pm S . E . M ; n=12$ for both groups.

growth effects of chronic ANG II administration (Daemen et al. 1991; Griffin et al. 1991; Lever et al. 1992; Boonen ot al. 1993), we find that this increase in aortic wall mass has no effect on compliance and distensibility under isobaric and isometric conditions.

Studies from our laboratory recently documented that B-mode vessel ultrasonography in combination with a wall tracking system can be applied in intact rats to accurately measure aortic lumen diameter and distention (van Gorp et al. 1996). These measurements together with the recorded pressure changes and the assumptions concerning vessel geometry are identical to those used in non-invasive human research and yield acceptable estimates of compliance and distensibility (Hoeks et al. 1990; Safar \& Frohlich, 1995). We subsequently related these in vivo mechanical properties to structural parameters measured histologically.

ANG II is known to be both a vasoconstrictor and growth factor. Besides having a direct effect on vascular tone, an ANG II has been described to enhance sympathetic tone via both central and peripheral mechanisms (Zimmerman et al. 1984; Story \& Ziogas, 1987; Wong et al. 1992). We observed that blood pressure was reduced by anesthesia in ANG II-infused rats but not in control rats, indicating that the effect of ANG II on sympathetic vasomotor tone is definitely considerable. 
Moreover, the peptide stimulates growth and proliferation of isolated arterial smooth muscle cells, stimulates the synthesis and deposition of extracellular matrix proteins, and promotes wall hypertrophy in isolated arteries (Daemen et al. 1991; Griffin et al. 1991; Kato et al. 1991; Lever et al. 1992; Boonen et al. 1993; Simon et al. 1995). In the present study, we utilized angiotensin II to induce changes in the structure of the aortic wall. We confirmed the chronic pressor effect and, at the level of the aorta, the growth-stimulatory effects of the peptide. Although we can not distinguish per se between smooth muscle hypertrophy, hyperplasia, or a combination of both, our data clearly demonstrate an increase in medial smooth muscle mass (increase in media cross-sectional area with proportional increases in collagen and elastin). The nature of the increase in muscular mass (hypertrophy or hyperplasia) does not effect the conclusions of this study. In contrast with earlier studies demonstrating ANG II-induced synthesis of elastin and collagen (Kato et al. 1991; Keeley et al. 1992), we did not find any changes in the densities of these extracellular matrix proteins. Nonetheless, even though the medial collagen and elastin fractions are not significantly altered, absolute amounts of collagen and elastin are undoubtedly increased due to the increase in cross-sectional area. It is possible that our two-week infusion protocol was too short to foster disproportional changes in matrix protein content, or since the stimulatory effect of ANG II on this process is more pronounced in young rats (Levy et al. 1988; Keeley et al. 1992), that the stimulus in the adult rats used in this study was insufficient to effect these changes.

Since anesthesia normalized the ANG 1 -induced increase in blood pressure in conscious rats, we were able to evaluate the effect of increased wall mass on aortic mechanical properties at nearly identical diastolic and pulse pressures. As the pressure-vollume relationship in large vessels has been shown to be clearly non-linear (Krafka, 1939; Roach \& Burton, 1957) (see Figure 1.3), compliance and distensibility change dramatically with variations in blood pressure, thus making it necessary to consider pressure as an important independent variable. Furthermore, diastolic diameter is also an important determinant of compliance since a larger initial lumen caliber can more readily absorb volume changes. In the present study, the diastolic lumen diameter was similar in treated and control rats under isobaric conditions. As the pulse pressure and the heart rate also did not differ between the anesthetized groups, we eliminated the possible contributions of rate-dependent phenomena, such as viscous wall properties. All in all, the isobaric and isometric conditions in anesthetized rats allowed the effects of aortic structure and geometry on dynamic in vivo compliance to be discerned without interference from physical parameters.

In contrast to passive changes in arterial compliance (due to pressure change), active changes in compliance can be induced by changes in smooth muscle tone (Dobrin \& Rovick, 1969). It is important to distinguish between systemic and local 
effects of tone. Whereas systemic changes in tone affect large artery diameter via pressure (i.e., increasing pressure induces a diameter increase), local changes have a direct effect on diameter. Although several in vitro studies have reported increased compliance after abolition of the vascular smooth muscle with potassium cyanide (Levy et al. 1988; Safar et al. 1990), in vivo studies using reactive hyperemia or nitroprusside to decrease smooth muscle tone have failed to note a clear effect of vascular tone on compliance (Isnard et al. 1989; Weber et al. 1996). In this study, no difference in aortic diameters was found in anesthetized animals at comparable pressures. This suggests that the circulating ANG II levels induced here, reported in similarly treated animals to be tripled (Griffin et al. 1991) " have little effect on aortic smooth muscle tone. It is unlikely that pentobarbital interferes with the direct (non-sympathetic-mediated) effects of angiotensin II since the pressor response to acute angiotensin $I \|$ injections in rats is not antagonized by pentobarbital (Le Noble et al. 1987).

Chronic infusion of ANG II induced a significant increase in media crosssectional area. As volume densities of elastin and collagen were unchanged, this suggests that ANG II induced a proportional increase in media components. Since both diastolic diameter and wall distention in anesthetized animals were comparable, this increase translates into not only an increased media thickness but also an increased media-to-lumen ratio in ANG II-treated rats. Yet, despite this change in aortic wall structure and geometry, compliance and distensibility were not modified. These results suggest that aortic compliance and distensibility are minimally affected by vascular wall mass, i.e., the increased mass does not hinder distention. Indeed, as a consequence of the change in aortic geometry, the incremental elastic modulus $\left(E_{\text {inc }}=D_{\text {dia }} /(M t . D C)\right)$ tends to be decreased in ANG Il-treated rats, suggesting that the thicker aorta wall is, if anything, more elastic (under isobaric conditions). This preposition is supported by recent studies in the carotid and radial arteries of hypertensive humans which suggest that an increased media thickness, as assessed with ultrasound, does not hinder vascular compliance (Laurent et al. 1994b; Laurent, 1995; Weber et al. 1996). Unfortunately, these studies lack histological data. Furthermore, the present study may clarify results in various rat models of hypertension (genetic, renovascular, and aging) in which chronic treatment with angiotensin converting enzyme inhibitors has been shown to prevent isobaric reductions in vascular compliance by preveriting both medial hypertrophy and collagen increase (Levy et al. 1988, 1993; Michel et al. 1994). Although these studies clearly demonstrated the importance of the structure of the vascular wall in determining compliance, the contributory role of hypertrophy as opposed to increased collagen content remained unclear. From the present study, it is tempting to conclude that dynamic vascular wall properties are more dependent on the relative composition of the vessel wall than on its absolute size and proportions. 
In conclusion, despite inducing a local increase in wall mass, chronic infusion of angiotensin II has no subsequent effect on either isobaric and isometric compliance or distensibility of the thoracic aorta. The present study further suggests that a proportional increase of aortic wall components is associated with the maintenance of the dynamic mechanical properties of the vessel.

\section{References}

Benetos A, Bouaziz H, Albaladejo P, Levy BI \& Safar ME (1992). Physiological and pharmacological changes in the carotid artery pressure-volume curve in situ in rats. $J$ Hypertens. 11(Suppl. 6), S127-S131.

BOONEN HCM, DAEMEN MJAP, EERDMANS PHA, FAZZI GE, VAN KLEef EM, SCHIFfERS PMH \& DE MEY JGR (1993). Mesenteric small artery changes after vasoconstrictor infusion in young rats. J. Cardiovasc. Pharmacol. 22, 388-395.

DAEMEN MJAP, LOMBAROI DM, BOSMAN FT \& SCHWARTZ SM (1991). Angiotensin II induces smooth muscle proliferation in the normal and injured rat arterial wall. Circ. Res. 68, 450-456.

DOBRIN PB \& RONICK AA (1969). Influence of vascular smooth muscle on contractile mechanics and elasticity of arteries. Am. J. Physiol. 217, 1644-1651.

VAN GORP A, VAN INGEN SCHENAU DS, WILLIGERS J, HOEKS APG, DE MEY JGR, STRUIJKER BOUDIER HAJ \& RENEMAN RS (1996). A technique to assess aortic distensibility and compliance in anesthetized and awake rats. Am. J. Physiol. 270, H780-H786.

GRIFFIN SA, BROWN WCB, MACPHERSON F, MCGRATH JC, WILSON VG, KORSGAARD N, MULVANY MJ \& LEVER AF (1991). Angiotensin II causes vascular hypertrophy in part by a non-pressor mechanism. Hypertension 17,626-635.

hayoz D, Rutschmann B, Perret $F$, Niederberger $M$, Tardy $Y$, Mooser $V$, NUSSBURGER J, WAEBER B \& BRUNNER HR (1992). Conduit artery compliance and distensibility are not necessarily reduced in hypertension. Hypertension 20, 1-6.

HoEkS APG, BRANDS PJ, SMeETS FAM \& RENEMAN RS (1990). Assessment of the distensibility of superficial arteries. Ultrasound Med. Biol. 16, 121-128.

HoEkS APG, ARTS TGJ, BRANDS PJ \& RENEMAN RS (1993). Comparison of the performance of the RF cross-correlation and Doppler autocorrelation technique to estimate the mean velocity of simulated ultrasound signals. Ultrasound Med. Biol. 19, 727-740.

ISNARD RN, PANnieR BM, LauRent S, London GM, Diebold B \& Safar ME (1989). Pulsatile diameter and elastic modulus of the aortic arch in essential hypertension: a noninvasive study. J. Am. Coll. Cardiol. 13, 399-405. 
KANNEL WB \& MCGEE DL (1979). Diabetes and cardiovascular disease. The Framingham study. JAMA 241, 2035-2038.

KANNEL W, GORDON T \& SCHWARTZ MJ (1971). Systolic versus diastolic blood pressure and the risk of coronary heart disease. The Framingham Study. Am. J. Cardiol. 27, 335346.

Kato $H$, suzuki H, Taulma $S$, ogata $Y$, Tominaga T, Sato a \& Saruta T (1991). Angiotensin II stimulates collagen synthesis in cultured vascular smooth muscle cells. J Hypertens. 9, 17-22.

KaWAsaki T, Sasayama S, Yagi S, Asakawa $T$ \& HIRAI $T$ (1987). Non-invasive assessment of the age related changes in stiffnes of major branches of human arteries. Cardiovasc. Res. 21, 678-687.

KeELEy FW, ELMOSELH A \& LeENEN FHH (1992). Enalapril suppresses normal accumulation of elastin and collagen in cardiovascular tissues of growing rats. Am. J. Physiol. 262, H1013-H1021.

KRAFKA J Jr (1939). Comparative study of the histo-physics of the aorta. Am. J. Physiol. $125,1-14$.

LAURENT S (1995). Arterial wall hypertrophy and stiffness in essential hypertensive patients. Hypertension 26, 355-362.

LAURENT S, HAYOZ D, TRAZZIS, BOUTOUYRIE P, WAEBer B, OMBONI S, BRUNNER HR, MANCIA G \& SAFAR M (1993). Isobaric compliance of the radial artery is increased in patients with essential hypertension. I Hypertens. 11, 89-98.

Laurent S, CAVIEzEl B, Beck L, Gierd X, Billaud E, Boutouyrie P, HoEks A \& SAfar $M(1994 a)$. Carotid artery distensibility and distending pressure in hypertensive humans. Hypertension 23, 878-883.

Laurent S, Girerd X Mourad J, Lacolley P, Beck L, Boutouyrie P, Mognot J \& SAFAR M (1994b). Elastic modulus of the radial artery wall material is not increased in patients with essential hypertension. Anterioscl. Thromb. 14, 1223-1231.

LEHMAN ED, GOSLING RG \& SNKSEN PH (1992). Arterial wall compliance in diabetes. Diabetic Med. 9, 114-119.

LE NOBLE JL, STRUIJKER BOUDIER HA \& SMITS JF (1987), Differential effects of general anesthetics on regional vasoconstrictor responses in the rat. Arch. int. Pharmacodyn. Ther. 289, 82-92. 
LEVER AF, LYALL F, MORTON JJ \& FOLKOW B (1992). Angiotensin II, vascular structure and blood pressure. Kidney Int. 41(Suppl. 37), S51-S55.

LEVY BI, MICHEL J-B, SALZMANN J-L, AZIZI M. POITEVIN P, SAFAR M \& CAMILLERI J-P (1988). Effects of chronic inhibition of converting enzyme on mechanical and structural properties of arteries in rat renovascular hypertension. Circ. Res. 63, 227-239.

LEVY BI, CURMI P, POITEVIN P \& SAFAR ME (1989). Modifications of the arterial mechanical properties of normotensive and hypertensive rats without arterial pressure changes. J. Cardiovasc. Pharmacol. 14, 253-259.

LeVy BI, Michel. JB, Salzmann Jl, Poitevin P, Devissaguet M, Scalbert E \& Safar ME (1993). Long-term effects of angiotensin-converting enzyme inhibition on the arterial wall of adult spontaneously hypertensive rats. Am. J. Cardiol. 71, 8E-16E.

VAN MERODE T, HICK PJJ, HOEKS APG, RAHN KH \& RENEMAN RS (1988). Carotid artery wall properties in normotensive and borderline hypertensive subjects of various ages. Uitrasound Med. Biol. 14, 563-569.

MESSERLI FH, FROHLICH ED \& VENTURA HO (1985). Arterial compliance in essential hypertension. J. Cardiovasc. Pharmacol. 7(Suppl. 2), S33-S35.

Michel JB, Heudes D, Michel O, Poitevin P, Philippe M, Scalbert E, Corman B \& LEVY BI (1994). Effect of chronic ANG I-converting enzyme inhibition on aging processes. Il. Large arteries. Am. J. Physiol. 267, R124-R135.

RANDALL OS, VAN DEN BOS GC \& WESTERHOF N (1984). Systemic compliance: does it play a role in the genesis of hypertension? Cardiovasc. Res. 18, 455-462.

Reneman RS, van Merode T, Hick P, Muytjens AMM \& Hoeks APG (1986). Agerelated changes in carotid artery wall properties in men. Ultrasound Med. Biol. 12, 465471.

ROACH MR \& BURTON AC (1957). The reason for the shape of the distensibility curve of arteries. Can. J. Biochem. Physiol. 35, 681-690.

SAFAR ME \& FROHLICH ED (1995). The arterial system in hypertension: a prospective view. Hypertension 26, 10-14.

SAFAR ME, LEVY BI, LAURENT S \& LONDON GM (1990). Hypertension and the arterial system: clinical and therapeutic aspects. J Hypertens. 8(Suppl. 7), S113-S119.

SIMON G, CSEREP G \& LIMAS C (1995). Development of structural vascular changes with subpressor angiotensin II administration in rats. Am. J. Hypertens. 8, 67-73. 
STORY DF \& ZIOGAS J (1987). Interaction of angiotensin with noradrenergic neuroeffector transmission. TIPS 8, 269-271.

WEBER R, STERIOPULOS N, BRUNNER HR \& HAYOZ D (1996). Contributions of vascular tone and structure to elastic properties of a medium-sized artery. Hypertension 27, 816822.

WESTERHOF N, BOSMAN F, DE VRIES CJ \& NOORDERGRAAF A (1969). Analog studies of the human systemic arterial tree. J. Biomechanics 2, 121-143.

WONG PC, BERNARD R \& TIMMERMANS PBMWM (1992). Effect of blocking angiotensin II receptor subtype on rat sympathetic nerve function. Hypertension 19, 663-667.

ZIMMERMAN BG, SYBERTZ EJ \& WONG PC (1984). Interaction between sympathetic and renin-angiotensin system. $J$ Hypertens. 2, 581-587 
Static and dynamic mechanical behavior of the intact rat aorta is influenced by pressure but not by angiotensin II-induced increases in wall mass or tone

D.L. Ceiler

H.J.M.G. Nelissen-Vrancken

J.F.M. Smits

J.G.R. De Mey

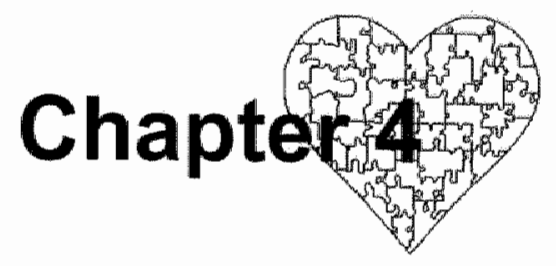




\section{Abstract}

The compliance of large blood vessels depends on blood pressure and its pulsatility. The first objective of our experiments was to discern between the static and dynamic components of aortic compliance over a large pressure range in vivo. Furthermore, both static and dynamic compliance may be modulated by changes in vascular wall mass or smooth muscle tone; the degree of this modulation may be pressure-dependent. Therefore, our second objective was to examine the effects of angiotensin II (ANG II)induced changes in vascular mass and smooth muscle tone on static and dynamic aortic properties.

Using ultrasound and wall tracking, aortic lumen area-pressure curves were generated in intact anesthetized rats over a broad range of pressures. Pressure was manipulated by altering blood volume. The slope of the pulsatile lumen area-pressure curve at a given mean pressure represents the dynamic compliance at that pressure. Static compliance was defined as the slope of the curve relating the diastolic lumen area to diastolic pressure for the entire set of pulsatile curves. To achieve our second objective, we performed these experiments in control rats and in rats treated acutely (500 $\mathrm{ng} / \mathrm{kg} / \mathrm{min} \mathrm{i.v}$.) or chronically ( $250 \mathrm{ng} / \mathrm{kg} / \mathrm{min}$ s.c. for two weeks) with ANG $\|$.

The dynamic compliance-pressure curve approximated a parabola. Maximal dynamic compliance $\left(0.272 \pm 0.026 \mathrm{~mm}^{2} / \mathrm{kPa}\right.$ in control rats) was achieved at near normotensive arterial pressure $( \pm 105 \mathrm{mmHg}$ ). The diastolic lumen area-pressure curve was fit best by an exponential equation; thus, the relationship between static compliance and diastolic pressure is also exponential within a physiological range $(30$ to $130 \mathrm{mmHg})$. ANG $\|-$ induced increases in aortic wall mass or smooth muscle tone did not modify the relationship between static or dynamic compliance and pressure.

These findings demonstrate that the static and dynamic mechanical properties of the rat thoracic aorta depend differently on blood pressure. Static compliance increases slightly with pressure in a physiological range, while dynamic compliance is regulated around normotensive arterial pressures. Furthermore, neither static nor dynamic compliance of the rat thoracic aortal are influenced by ANG II-induced increases in aortic wall mass or smooth muscle tone over a broad pressure range. 


\section{Introduction}

Recent clinical studies in both the elastic carotid artery and the muscular radial artery suggest that under isobaric conditions compliance and distensibility of these blood vessels are not reduced and may even be increased in hypertensive humans (Hayoz et al. 1992; Laurent et al. 1993, 1994a; Armentano et al. 1995). In these studies, media thickness could not be measured due to technical limitations, but under the assumption that media hypertrophy normalizes pressure-induced increases in wall stress, speculations were made that the elasticity of the arteries must be increased to maintain distensibility (Mulvany, 1992). These speculations were confirmed by Weber and coworkers (1996) and Laurent and coworkers (1994b) who noted decreased incremental elastic moduli $\left(E_{\text {inc }}\right)$ in hypertensive patients at a given pressure level. Similar adaptative processes seem also to be apparent in experimental hypertension as our group recently reported smaller $E_{\text {inc }}$ in spontaneously hypertensive rats which may have improved, though did not normalize, compliance (van Gorp et al. 1996a). Together, these results suggest that the arterial wall adapts to the prevailing blood pressure in order to normalize wall stress and maintain compliance.

From the aforementioned studies, it is clear that vascular mechanical and elastic properties are pressure dependent. Recent studies have therefore examined diameter-pressure and compliance-pressure relationships over the range covered by the prevailing systolic and diastolic pressures (Hayoz et al. 1992; Laurent et al. 1993, 1994b; Weber et al. 1996). Nonetheless, the overlap in the pressure ranges between hypertensive and normotensive subjects is often minimal in such an approach. Moreover, these representations can not dissociate between static and dynamic properties. Static properties depend upon the elastic response to pressure changes. Dynamic properties may be influenced by a viscous component which dampens the elastic behavior of the vessel during the cardiac cycle. Few studies have focussed on the static and dynamic properties of large vessels in vivo and how they might be influenced by pressure, vascular wall mass or smooth muscle tone. In the present experiments, our first objective was to discern the static and dynamic properties of the aorta in wivo. To do so, aortic lumen area-pressure curves were generated in intact anesthetized rats over a broad range of pressures with ultrasound. Pressure was manipulated by altering blood volume. The slope of the pulsatile lumen area-pressure curve at a given mean pressure represents the dynamic compliance at that pressure. Static compliance was defined as the slope of the curve relating the diastolic lumen area to diastolic pressure for the enitre set of pulsatile curves. Our second objective was to examine the effects of ANG II-induced changes in smooth muscle tone and ANG II-induced changes in vascular mass on static and dynamic aortic properties. We accordingly performed these experiments both in control rats and in rats 
treated acutely or chronically with ANG II. Thus, we were ultimately able to examine the effects of increased aortic smooth muscle tone (acute ANG II) and increased aortic media mass (chronic ANG II) on static and dynamic mechanics over a large pressure range.

\section{Methods}

\section{Animals, chronic treatment and surgery}

Male Wistar rats (280-320 g, Iffa Credo, Someren, the Netherlands) were housed under standard conditions $\left(20^{\circ} \mathrm{C}, 12\right.$-hour light/dark cycle) and given free acces to standard chow (Hope Farms, Woerden, the Netherlands) and tap water. The experimental procedures were performed according to institutional guidelines and approved by the Ethical Committee for the Use of Experimental Animals of the Universiteit Maastricht (the Netherlands).

A group of animals was randomly chosen to receive $250 \mathrm{ng} / \mathrm{kg} / \mathrm{min}$ angiotensin II ([Val ${ }^{5}$ ]-angiotensin II, Saxon Biochemicals GmbH, Hannover, Germany) s.c. for two weeks. ANG II was administered via an osmotic mini-pump (Alzet 2002, Alza Co, Palo Alto, CA, USA) implanted s.c. in the neck under ether anesthesia.

On treatment day 12 , the rats were anesthetized with pentobarbital $(60 \mathrm{mg} / \mathrm{kg}$ i.p.) and equipped with catheters under aseptic conditions. An arterial catheter was implanted through the femoral artery into the abdominal aorta (PE 10 heatsealed to PE 50; Clay Adams, Parsippany, $N J$, USA) for blood pressure measurements in conscious rats. One venous catheter was advanced from a femoral vein into the inferior vena cava (PE 10 heat-sealed to PE 50) for i.v. injections. The contra-lateral femoral vein was cannulated with another catheter (Silastic 602-175 connected to PE 50; Dow Corning, Midland, MI, USA) which was aimed to terminate above the ending of the other catheters. This catheter was used for administering and withdrawing blood. All saline-filled catheters were guided s.C. to the neck and closed with metal plugs.

Mean arterial pressure measurements in conscious rats Mean arterial pressure (MAP) was measured in all rats on day 14. Measurements were made in quietly resting rats via a pressure transducer (CP-01, Century Technology Co.. Inglewood, CA, USA) in conjunction with a data aquisition system on a personal computer (Hemodynamic Data Acquisition Systems, Instrumental Services, Universiteit Maastricht).

\section{Protocol for generating in vivo lumen area-pressure curve}

On day 14 after MAP measurements, control rats were randomly divided into two groups: those to receive no acute treament (CON) and those to receive 500 $\mathrm{ng} / \mathrm{min}$ i.V. ANG $\|$ (AC-ANG). This dose induced a rise in blood pressure 
comparable to that measured in conscious rats treated chronically with ANG II (CH-ANG).

Rats were then anesthetized with pentobarbital $(60 \mathrm{mg} / \mathrm{kg}$ i.p.). Rats were placed on a heating pad and body temperature was maintained at $38^{\circ} \mathrm{C}$ by a rectal temperature probe and infrared heating lamp. The left carotid artery was dissected free under a microscope taking care not to touch the surrounding nerves. A Millar Mikro-tip pressure transducer (SPC-320, 2F, Millar Instruments, Inc., Houston, TX, USA) was inserted via the left carotid artery and advanced into the thoracic aorta at the level of the heart. Blood pressure was allowed to stabilize before beginning experimentation.

Thoracic aorta diameter and distention were measured using a vessel wall tracking system (WTS) attached to a conventional B-mode ultrasound system (Pie480, 7.5 MHz linear array. Pie Medical, Maastricht, the Netherlands), as described in Chapter 3 and by van Gorp et al. (1996b). A typical example of thoracic aorta wall movement and distention measured in an anesthetized rat is presented in Figure 4.1. Measurements were first made under basal conditions. In AC-ANG, the infusions of ANG II was then started. Baseline measurements of the drug-induced effects were made after MAP stabilization ( $\sim 5 \mathrm{~min})$. Afterwards, blood was slowly removed from the venius catheter into a heparinized syringe to lower blood pressure and ultrasonic measurements were consequently made. Additional blood was removed to further lower pressure and ultrasound measurements were repeated. This process was repeated in steps of $\pm 10 \mathrm{mmHg}$ until blood pressure was approximately $40 \mathrm{mmHg}$. Blood was then slowly returned i.v. to elevate blood pressure and periodic ultrasound measurements were made. To achieve higher than basal pressures, additional warmed $\left(37^{\circ} \mathrm{C}\right)$, heparinized blood $(5 \mathrm{ml})$ from a litter mate was slowly administered, again with periodic ultrasound measurements. At each blood pressure interval, at least one recording of $2.5 \mathrm{sec}$ was made; this corresponds to approximately 16 cardiac cycles.

\section{Calculation of dynamic compliance}

Arterial compliance is defined as the absolute increase in volume $(\Delta V)$ for a given increase in arterial blood pressure $(\Delta P)$. Distensibility, on the other hand, is the relative increase in volume $(\Delta V / V)$ for a given $\triangle P$. Assuming that a volumetric increase is due to vascular distention (radial) rather than (axial) elongation (Reneman et al. 1986) and that the vascular cross-section is perfectly circular, compliance (CC) and distensibility (DC) can be approximated as follows:

$$
C C \approx \triangle A / \Delta P \approx \pi\left(D_{d i q}+\Delta D\right) /(4 \Delta P)
$$




$$
D C=\Delta A /\left(A_{\text {clia }} \Delta P\right)
$$

where $D_{\text {dia }}$ and $A_{\text {dia }}$ stand for the end-diastolic diameter and area respectively; $\Delta D$ and $\triangle \mathrm{A}$ represent, respectivey, the change in diameter and lumen area during the cardiac cycle.

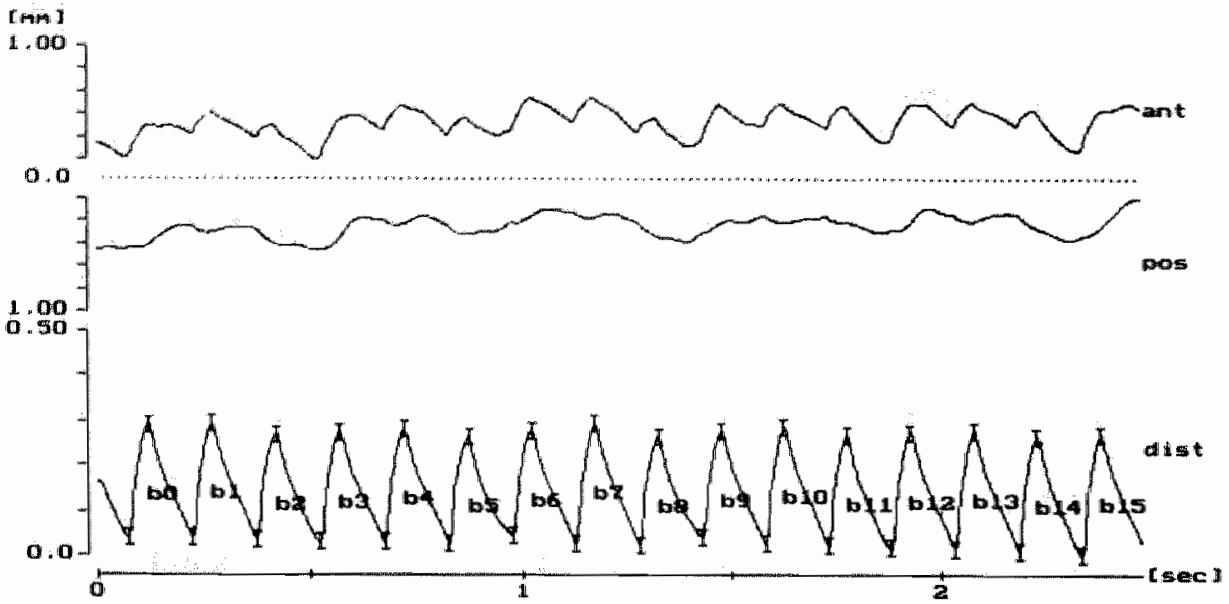

Figure 4.1

Typical example of anterior (ant) and posterior (pos) aortic wall displacement and the difference between both, distention (dis), during 16 consecutive cardiac cycles (ba-b15) as measured with ultrasound and wall tracking.

\section{Structural measurements}

Following in vivo mechanical measurements, rats were killed by an overdosis of ether anesthesia and a $10 \mathrm{~mm}$ segment of the thoracic aorta was isolated beginning at the third pair of intercostal arteries. The extent of longitudinal retraction upon isolation was assessed by pre- $(\mathbb{L} i)$ and post- $(L \theta)$ excision measurements of the segment length. Retraction was in the order of $25 \%$ and did not differ significantly between groups. The excised vessell was fixed by immersion in $4 \%$ phosphate-buffered formalin at room temperature before being imbedded in paraffin.

Media cross-sectional area (CSAe), defined as the area between the internal and external elastica laminae was determined by semi-automated morphometry (JAVA 1.21, Jandel Scientific, Corte Madera, CA, USA) on $4 \mathrm{~m}$ sections stained with Lawson s solution, a classic elastin stain. This value was converted to the expected in vivo CSA (CSAi), as described in Chapter 3 and by van Gorp et al. (1996a) by accounting for vascular retraction upon isolation, i.e., 
Other calculations

CSAi and $D_{\text {dia }}$ were used to calculate diastolic media thickness (Mt) according to

$$
M t=-\frac{D_{\text {dia }}}{2}+\sqrt{\left[\frac{D_{\text {dia }}}{2}\right]^{2}+\frac{C S A i}{\pi}}
$$

Furthermore, the incremental elastic modulus $\left(E_{\text {inc }}\right)$ and diastolic wall stress $\left(W S_{\text {dia }}\right)$ were calculated respectively as

$$
\begin{aligned}
& E_{\text {inc }}=D_{d i a} /(M t \cdot D C) \\
& W S_{d i a}=\left(P_{d i a} \cdot r_{d i a}\right) / M t
\end{aligned}
$$

Data analysis

The relationship between dynamic compliance and pressure was assessed by non-linear fit of individual CC vs. MAP curves (Graphpad Prism 1.00, San Diego, $C A$, USA). CC was calculated from ultrasound measurements at various blood pressures. MAP was determined by averaging all the (4100) sample points in a given 2.5 sec ultrasound recording. Data were fit per rat to a Gaussian distribution and a second order polynomial. Considering the entire group as a whole, dynamic compliance curves were best fit by a second order polynomial $\left(C C=a(M A P)^{2}+b(M A P)+c\right)$. Maximum $C C$ and its associated MAP were calculated from the first derivative of the individual polynomials and the steepness of the curve from the second derivative; the results were then averaged for the groups.

Static compliance (SC) was derived from the relationship between diastolic lumen area and pressure $\left(A_{\text {dia }}\right.$ and $P_{\text {dia }}$ respectively). Individual $A_{\text {dla }}$ vs. $P_{\text {dila }}$ curves were fit to linear, exponential growth and exponential association curves (Graphpad Prism 1.00), and an exponential growth curve (SC=A $A_{\text {star }} e^{\text {kstatP }}$ ) presented the best fit for the entire set of rats. The first derivative of the exponential area-pressure curves denotes the static compliance, and this was individually calculated and then averaged for the groups. 
Compliance is a hemodynamic parameter and thus does not describe the elastic characteristics of the vessel wall itself. Therefore, $E_{\text {inc, }}$ which is a material property was analyzed. Although $E_{\text {inc }}$ is a material property, it varies in arteries as a function of pressure since the arterial wall is anisotropic. For instance, elastin and collagen fibers may be differentially recruited at different pressures. To determine the effects of vascular mass and tone on elasticity, we examined the relationship between $E_{\text {inc }}$ and $W S_{\text {dila }}$. WS $S_{\text {dia }}$ was chosen instead of $P_{\text {dia }}$ since hypertrophy of the vessel wall lowers $W S_{\text {dia }}$ at a given $P_{\text {dia }}$ such that the vessel wall erroneously appears more elastic. The $E_{\text {inc }}$ and $W_{S_{\text {dia }}}$ relationship was fit by an exponential growth curve (Graphpad Prism1.00) and then averaged per group.

\section{Statistics}

Hemodynamic, histological and body weight data were compared by the nonparametric Kruskal Wallis test, as were all parameters describing mechanical curves. Differences were considered statistically significant at a value of $p<0.05$. Data are expressed as mean \pm S.E.M.

\section{Results}

As shown in Table 4.1, rats in the CH-ANG group weighed significantly less than those in the AC-ANG and CON groups. Chronic infusion of ANG II (250 $\mathrm{ng} / \mathrm{kg} / \mathrm{min}$ ) significantly increased conscious MAP; anesthesia however lowered MAP to control levels. Acute infusion of ANG II $(500 \mathrm{ng} / \mathrm{min})$ increased MAP in anesthetized animals to a similar degree as that seen in conscious rats treated chronically with ANG II (Table 4.1). Two week treatment with ANG II increased aortic media CSA by approximately $60 \%$ (Table 4.1 ).

\section{Static and dynamic compliance in untreated rats}

The dynamic compliance-pressure curve was best fit by a second order polynomial, or parabola $\left(\mathrm{CC}=\mathrm{a}(\mathrm{MAP})^{2}+\mathrm{b}(\mathrm{MAP})+\mathrm{c}\right)$ (Figure 4.2). The maximal $\mathrm{CC}$ was achieved at normotensive pressures (Table 4.2). Changes in heart rate with blood pressure did not influence the dynamic compliance-pressure relationship since their was no correlation in the relationship between heart rate and MAP $\left(r^{2}=0.02\right.$; Figure 4.3$)$.

Since the diastolic lumen area-pressure curve is exponential $\left(A_{\text {dila }}=a e^{k \text { Pdiar }}\right.$ ) (Figure 4.4a) within the range of diastolic pressures measured, the static compliance-pressure curve is also exponential (Figure 4.4b). Thus, while dynamic compliance peaks at normal pressures, static compliance gradually increases with increasing pressure (Figure 4.2 and 4.4 and Table 4.2). As expected, static compliance was larger than dynamic compliance over the pressure range examined (Figure 4.2 and 4.4 and Table 4.2). 
Table 4.1. General characteristics of experimental groups.

\begin{tabular}{lccc}
\hline & CON & AC-ANG & CH-ANG \\
\hline $\mathrm{n}$ & 8 & 6 & 10 \\
$\mathrm{BW}(\mathrm{g})$ & $301 \pm 2$ & $308 \pm 5$ & $280 \pm 5^{*}$ \\
$\mathrm{MAP}(\mathrm{mmHg})$ & $114 \pm 4$ & $105 \pm 2$ & $152 \pm 10^{*}$ \\
$\begin{array}{l}\text { (conscious) } \\
\text { MAP (mmHg) }\end{array}$ & $110 \pm 8$ & $99 \pm 4$ & $106 \pm 5$ \\
(basal,anesthetized) & & after ANG $11,148 \pm 4^{*}$ & \\
$\begin{array}{l}\text { HR (bpm) } \\
\text { (basal,anesthetized) }\end{array}$ & $384 \pm 54$ & $385 \pm 20$ & $408 \pm 8$ \\
CSA (mm ${ }^{2}$ ) & & after ANG $11,404 \pm 18$ & \\
\hline CON control & $0.432 \pm 0.046$ & $0.450 \pm 0.027$ & $0.774 \pm 0.183^{*}$ \\
\hline
\end{tabular}

CON: control rats; $A \bar{C}-A N G$ : rats acutely receiving $500 \mathrm{ng} / \mathrm{min}$ angiotensin $11 ; \mathrm{CH}-\mathrm{ANG}$; rats administered $250 \mathrm{ng} / \mathrm{kg} / \mathrm{min}$ angiotensin II s.c. for two weeks. BW: body weight; MAP: mean arterial pressure; HR: heart rate; CSA: aortic media cross-sectional area. Mean \pm S.E.M. " $p<0.05$ vs. CON.

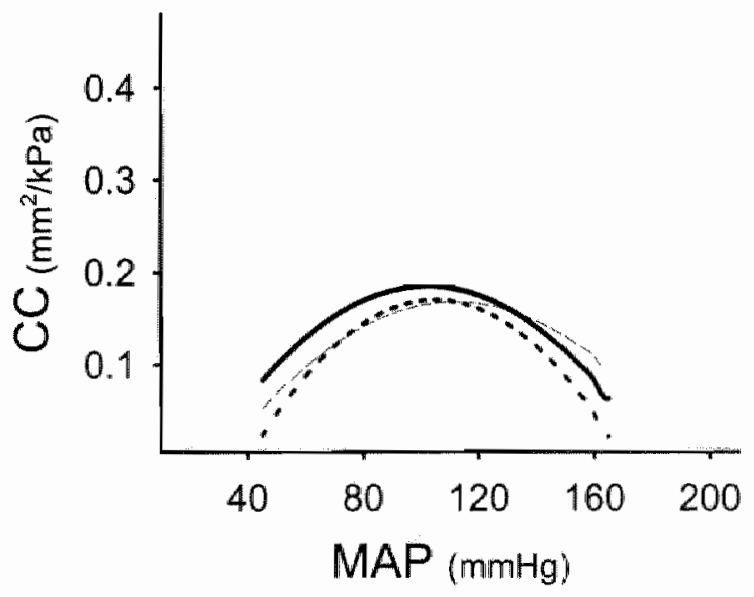

\section{Figure 4.2}

The relationship between dynamic compliance (CC) and mean arterial pressure (MAP) in the thoracic aorta of anesthetized rats under control conditions (solid line), during acute treatment with $500 \mathrm{ng} / \mathrm{min}$ angiotensin II (dotted line), or after chronic infusion of $250 \mathrm{ng} / \mathrm{kg} / \mathrm{min}$ angiotensin II for a period of two weeks (dashed line). Parameters for the curves with corresponding errors are noted in Table 4.2. 
Table 4.2 Curve-fitting parameters which describe aortic mechanics in anesthetized rats.

\begin{tabular}{|c|c|c|c|c|}
\hline & & CON & AC-ANG & $\mathrm{CH}-\mathrm{ANG}$ \\
\hline \multirow{3}{*}{$\begin{array}{l}\text { dynamic } \\
\text { compliance }\end{array}$} & $\mathrm{CC}_{\max }$ & $227 \pm 26$ & $179 \pm 18$ & $175 \pm 13$ \\
\hline & MAP $_{\operatorname{maxcC}}$ & $142 \pm 30$ & $106 \pm 3$ & $117 \pm 5$ \\
\hline & $y^{m}$ & $-3.56 \pm 1.19$ & $-4.64 \pm 0.62$ & $-2.88 \pm 0.57$ \\
\hline \multirow{2}{*}{$\begin{array}{l}\text { static } \\
\text { compliance }\end{array}$} & $\mathbb{K}_{\text {stat }}$ & $85.71 \pm 4.83$ & $86.59 \pm 4.58$ & $74.11 \pm 3.34$ \\
\hline & $\mathrm{A}_{\text {stat }}$ & $69 \pm 6$ & $73 \pm 6$ & $86 \pm 5$ \\
\hline \multirow[t]{2}{*}{$E_{\text {inc }} v s . W S_{\text {dia }}$} & $\mathrm{K}_{\text {Binc }}$ & $0.115 \pm 0.014$ & $0.158 \pm 0.024$ & $0.125 \pm 0.013$ \\
\hline & $A_{\text {Einc }}$ & $123 \pm 19$ & $140 \pm 49$ & $149 \pm 15$ \\
\hline
\end{tabular}
administered $250 \mathrm{ng} / \mathrm{kg} / \mathrm{min}$ angiotensin II s.c. for two weeks.

Dynamic compliance $(C C): C C=a(M A P)^{2}+b(M A P)+c ; C C_{\text {max }}$ : maximal dynamic compliance $\left(10^{-3}\right.$ $\left.\mathrm{mm}^{2} / \mathrm{kPa}\right) ; \mathrm{MAP}_{\max } \mathrm{Cc}^{:}$MAP at which $\mathrm{CC}_{\max }$ occurs $(\mathrm{mmHlg}) ; \mathrm{y}^{\mathrm{m}}$ : rate of change of slope of dynamic compliance curve $\left(10^{-3} \mathrm{~mm}^{2} /\left(\mathrm{kPa}^{3}\right)\right)$.

Static compliance $(\mathrm{SC}): \mathrm{SC}=\mathrm{A}_{\text {stat }} \mathrm{e}^{\mathrm{kstat}}$; $\mathrm{P}$ : diastolic pressure; $\mathrm{K}_{\text {stat }}$ growth coefficient of static compliance curve $\left(10^{-3} \mathrm{kPa} a^{-1}\right) ; A_{\text {stal }}$ i diastolic lumen area at negligible pressures $\left(10^{-3} \mathrm{~mm}^{2} / \mathrm{kPa}\right)$.

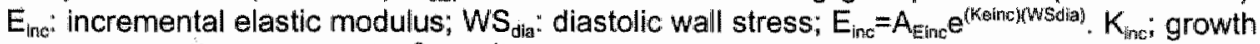
coefficient of $E_{i n c} v s$. W $S_{\text {dia }}\left(10^{-3} \mathrm{kPa}^{-4}\right) ; A_{\text {Einne }}: E_{\text {inc }}$ at negligible wall stress $(\mathrm{kPa})$.

Mean \pm S.E.M.

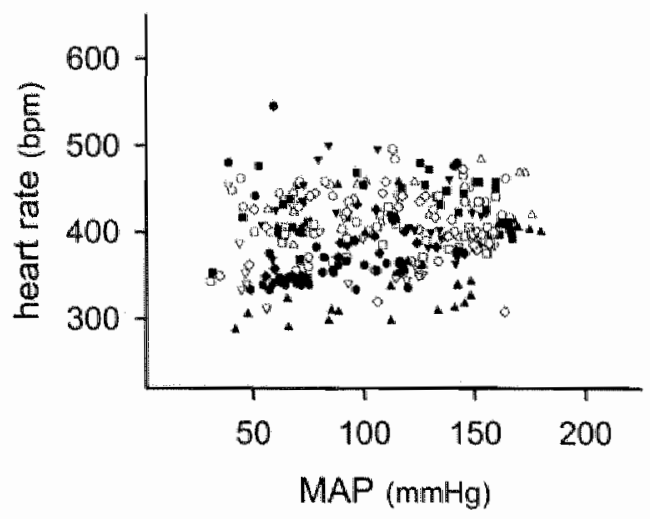

Figure 4.3

Lack of relationship between heart rate and mean arterial pressure (MAP) in rats under anesthesia. Different symbols represent individual experiments. 
a.

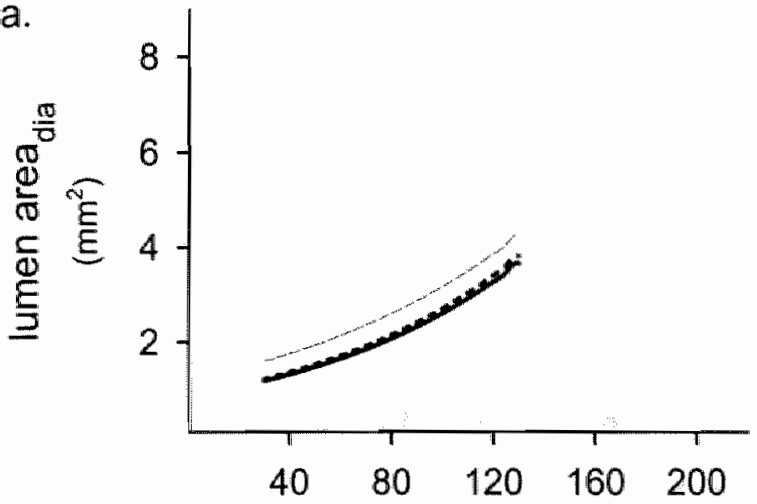

b.

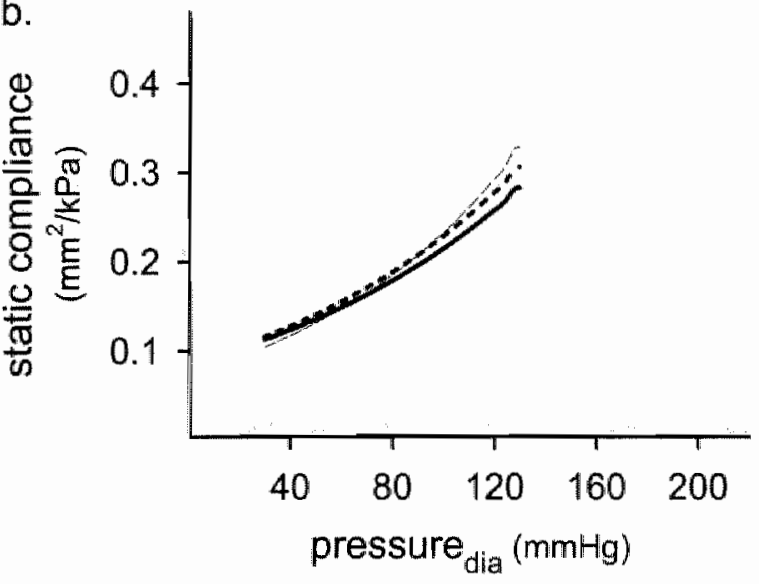

Figure 4.4

Panel a: Average diastolic lumen areapressure curves in anesthetized rats under control con-ditions (solid line), during acute treatment with 500 $\mathrm{ng} / \mathrm{min}$ angiotensin II (dotted line), or after chronic infusion of 250 $\mathrm{ng} / \mathrm{kg} / \mathrm{min}$ angiotensin II for a period of two weeks (dashed line). Panel b: The relationship between static compliance and diastolic pressure. The lines are defined as in the upper curve, and parameters with corresponding errors are noted in Table 4.2.

Effect of acute and chronic ANG // treament on aortic properties

Furthermore, baseline heart rates were not different between the groups (Table 4.1). Neither acute nor chronic ANG I| treatment influenced dynamic compliance. Maximum $\mathrm{CC}$ and the MAP at which it was achieved were not different between CON, CH-ANG and AC-ANG; likewise, the bredth of the curves, as indicated by the second derivative, were not altered (Table 4.2). Static compliance was likewise not altered by either ANG || treatment (Table 4.2). Furthermore, the elasticity of the aortic wall was not modified by acute or chronic ANG II infusions since $E_{\text {inc }}$ at a given $W S_{\text {dia }}$ did not differ between CON, CH-ANG and AC-ANG (Figure 4.5 and Table 4.2). 


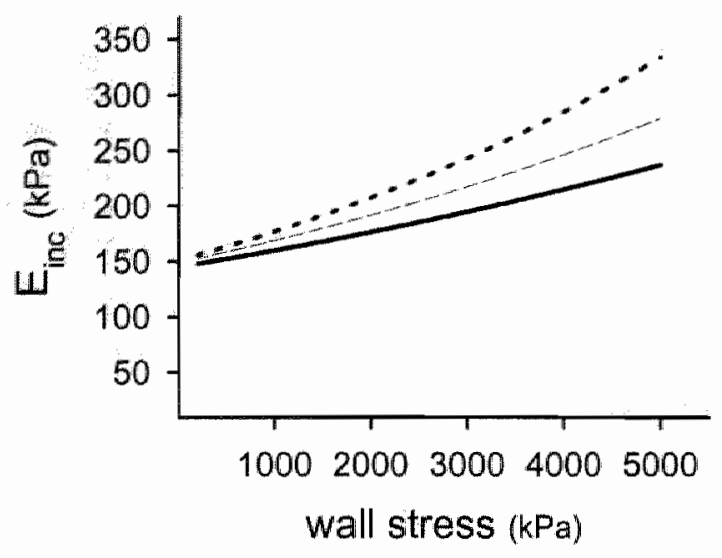

Figure 4.5

The incremental elastic modulus $\left(E_{\text {ins }}\right.$ ) exponentially increases with aortic wall stress in anesthetized rats under control conditions (solid line), during acute treatment with $500 \mathrm{ng} / \mathrm{min}$ angiotensin II (dotted líne), or after chronic infusion of $250 \mathrm{ng} / \mathrm{kg} / \mathrm{min}$ angiotensin II for a period of two weeks (dashed line). Parameters for the curves with corresponding errors are noted in Table 4.2.

\section{Discussion}

This study demonstrates that the mechanical function of the rat thoracic aorta varies with blood pressure. Static compliance increased slightly with pressure increases in a physiological range while compliance seemed to be maximal around normal arterial pressures. The present study also shows that the static and dynamic compliance of the rat thoracic aorta are not influenced by ANG IIinduced increases in aortic wall mass or smooth muscle tone over a broad pressure range.

Current hypertension research stresses the importance of examining wall mechanics over a range of pressures (Safar et al. 1990). This has traditionally been accomplished by fitting a diameter-pressure curve between diastolic and systolic pressures (Langewouters et al. 1984; Tardy et al. 1991). We expanded the pressure range for measurement since the pressure overlap between normo- and hypertensive states is often small. Furthermore, our methods allowed us to examine how area-pressure relations during the cardiac cycle, i.e., dynamic mechanics, vary with average pressure. To do so, we modified blood pressure by altering blood volume. Although we aspired to modify blood pressure nonpharmacologically, we realize that altering blood volume affects neurohormonal systems, such as the sympathetic system, the renin-angiotensin-aldosterone 
system and levels of atrial natriuretic factor. Activation of these factors most likely had, however, little bearing on our experiment. Pentobarbital anesthesia significantly impairs the activity of the sympathetic system as evidenced by the lack of a relationship between heart rate and MAP (Figure 4.3). The possible confounding influences of increased plasma levels of angiotensin II is ruled out by our demonstration that acute infusion of ANG II had no effect on aortic mechanical behavior. As will be further discussed below, it seems probable that vasoactive substances have a larger indirect effect on the aorta via resistance vessel-induced pressure changes than a direct effect on aortic smooth muscle.

\section{Compliance in relation to blood pressure}

It has been proposed that the mechanical behavior of the aortic wall is dependent on vascular geometry, wall composition, smooth muscle tone, operating pressure and pressure pulsatility. Our first objective was to ascertain the effects of pressure and its pulsatility on aortic distention during the cardiac cycle. We hypothesized that the behavior of the aortic wail is different under static, i.e., slowly changing pressure, and dynamic, i.e., pulsatile pressure, conditions since the vascular wall has less time to develop a maximal strain when the stress is oscillating. Differences between static and dynamic behavior have been clearly demonstrated in vitro (Bergel, 1961a, b), and recently in vivo in an elegant study by Glaser et al. (1995) In the present study, dynamic compliance during the cardiac cycle is represented by the compliance coefficient (CC). When an arterial wall displays viscous behavior, the compliance of the vessel will be smaller when subjected to pulsatility than when the pressure is constant. We approached static compliance by examining how the diastolic lumen area varies with changes in diastolic blood pressure and could therefore monitor the ability of the vascular wall to distend to tonic pressure changes.

In intact anesthetized rats, we observed that the relationship between dynamic compliance and mean arterial pressure was parabolic (Figure 4.2). Although similar findings have been obtained in Wistar Kyoto and spontaneously hypertensive rats (Benetos et al. 1992), studies in hypertensive humans have typically only demonstrated a negative relationship between arterial compliance and pressure in a smaller, but still overlapping pressure range (Hayoz et al. 1992; Laurent et al. 1994b; Bank et al. 1995; Weber et al. 1996). The discrepancy in these results may be due to differences in viscous behavior between the rat and human vessels. Decreased dynamic compliance at non-normotensive pressures suggests increased viscous behavior at these pressures. Although an exact explanation for this phenomenon is not known, the present results suggest that dynamic compliance is maximal around normotensive pressure.

On the other hand, static compliance increases gradually over a physiological pressure range. Logically, any vascular lumen area-pressure curve must 
eventually plateau as maximal diameters are approached. Thus, it appears that, in the diastolic pressure range which we studied, near maximal diameters were not achieved. Early in vitro studies have noted a sigmoidal relationship between area and static pressure development which plateaued at pressures greater than those studied here (Bergel; 1961b). Nonetheless, our objective was to examine a non-frequency dependent relationship between area and pressure. We thus chose to analyze the diastolic area-pressure relationship since the lumen diameter at any other point of the cardiac cycle may be influenced by the cyclic nature of pressure development. The slight rise in static compliance with increasing pressure in a traject in which near maximal diameters are not reached may be due to the fact that a more favorable link between smooth muscle crossbridges is achieved with increasing diameter.

By definition, static compliance is larger than dynamic compliance since the viscous components have more time to lengthen under tonic conditions. Our experimental findings are in agreement with this. At non-normotensive pressures, static compliance is clearly greater than dynamic compliance (Figure 4.2 and 4.4 and Table 4.2). At normotensive pressures, the curves approach each other as if viscous wall behavior is minimal at these pressures. If one assumes a pulse pressure of $30 \mathrm{mmHg}$, then the static compliance at a diastolic pressure of 90 $\mathrm{mmHg}$ does not significantly differ from the corresponding dynamic compliance at a normotensive pressure of $105 \mathrm{mmHg}$ (data not shown).

\section{Effects of vascular wall mass and tone on compliance}

The second objective of our study was to investigate the effects of smooth muscle tone and vascular media mass on compliance. To achieve this, rats were infused acutely with ANG II, to heighten arterial tone, and chronically, to induce vascular wall hypertrophy.

Although acute infusion of ANG II heightened aortic pressure, the relationship between pressure and either static or dynamic compliance was not different than that in control animals. Aortic wall elasticity at a given wall stress was also not modified with acute ANG II infusion. These findings suggest that any direct effects of ANG II on aortic smooth muscle tone are overweighed by the distal effects of ANG II on resistance vessels. Additionally, the fact that lumen diameters at a given pressure were not smaller during ANG II infusion may suggest that ANG II has only an insignificant effect on aortic smooth muscle tone. The relative unimportance of vasoconstrictor-induced tone compared to distally-generated pressure increases in affecting large artery diameter is supported by a similar study by Glaser et al. (1995).

In terms of chronic ANG II-induced hypertension, the increase in vascular wall mass after chronic ANG II treatment did not modify static or dynamic compliance. It is interesting to note that dynamic compliance in these chronically-treated 
animals was maximal around normotensive pressure and not around their conscious operating pressure. In contrast, in spontaneously hypertensive rats compliance was regulated around operating pressure (Benetos et al. 1992). In this case, increased smooth muscle tone may be an adaptive mechanism to maximize compliance since poisoning the smooth muscle with potassium cyanide shifted the compliance-pressure curve to peak around normotensive pressures (Benetos et al. 1992).

Furthermore, in the present study, there were no observable differences in aortic elasticity between chronic ANG II treated and control rats at a given wall stress. Due to the thicker aortic wall of the chronic ANG II-infused animais, a given wall stress is achieved at higher pressures in these animals. Thus, the increase in wall mass induced by ANG II seems to be adaptive; it normalizes wall stress but does not hinder wall mechanics. These results provide further support for the idea of the autoregulation of compliance, as advanced by Laurent (1995).

In summary, the present study demonstrates that the static and dynamic mechanical properties of the rat thoracic aorta are differently affected by blood pressure. Static compliance increases slightly with pressure increases in a physiological range, while dynamic compliance is maximal around normotensive arterial pressures. Furthermore, neither static nor dynamic compliance of the rat thoracic aorta is influenced by ANG II-induced increases in aortic wall mass or smooth muscle tone over a broad pressure range.

\section{References}

ARmentano R, MEgnien Jl, Simon A, Bellenfant F, BarRa J \& LeVenson J (1995). Effects of hypertension on viscoelasticity of carotid and femoral arteries in humans. Hypertension 26, 48-54.

BANK AJ, WILSON RF, KuBo SH, HOLTE JE, DRESING TJ \& WANG H (1995). Direct effects of smooth muscle relaxation and contraction on in wivo human brachial artery elastic properties. Circ. Res. 77, 1008-1016.

Benetos A, Bouaziz H, Albaladejo P, Levy BI \& Safar ME (1992). Physiological and pharmacological changes in the carotid artery pressure-volume curve in situ in rats. $J$ Hypertens. 11(Suppl. 6), S127-S131.

BERGEL DH (1961a). The dynamic elastic properties of the arterial wall. Journal of Physiology - London 156, 458-469.

BERGEL DH (1961b). The static elastic properties of the arterial wall. Journal of Physiology - London 156, 445-457.

Glaser E, Lacolley P, Boutouyrie P, Sacunha R, Lucet B, Safar ME \& Laurent S (1995). Dynamic versus static compliance of the carotid artery in living Wistar-Kyoto 
rats. J. Vasc. Res. 32, 254-265.

VAN GORP AW, VAN INGEN SCHENAU DS, HOEKS APG, STRUIJKER BOUdIER HAJ, RENEMAN RS \& DE MEY JGR (1996a). Aortic wall properties in 3 and 6 month old normotensive and spontaneously hypertensive rats at comparable operating pressures in vivo. Hypertension 26, 363-368.

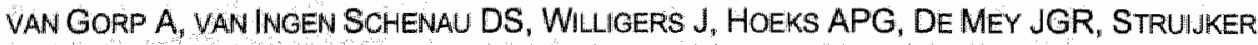
BOUDIER HAJ \& RENEMAN RS (1996b). A technique to assess aortic distensibility and compliance in anesthetized and awake rats. Am. J. Physiol. 270, H780-H786.

Hayoz $D$, Rutschmann $B$, Perret $F$, Niederberger $M_{*}$ Tardy $Y$, Mooser $V$, NUSSBERGER J, WAEBER B \& BRUINNER HR (1992). Conduit artery compliance and distensibility are not necessarily reduced in hypertension. Hypertension 20, 1-6.

LANGeWOUTERS GJ, WESSELING KH \& GoedHARD WJA (1984). The static elastic properties of 45 human thoracic and 20 abdominal aortas in vitro and the parameters of a new model. J. Biomechanics 17, 425-435.

LAURENT S (1995). Arterial wall hypertrophy and stiffness in essential hypertensive patients. Hypertension 26, 355-362.

Laurent S, hayoz D, Trazzi S, Boutouyrie P, Waeber B, Omboni S, Brunner HR, MANCIA G \& SAFAR M (1993). Isobaric compliance of the radial artery is increased in patients with essential hypertension. J Hypertens. 11, 89-98.

Laurent S, Caviezel B, Beck L, Gierd X, Billaud E, Boutouyrie P, hoeks A \& Safar $M$ (1994a). Carotid artery distensibility and distending pressure in hypertensive humans. Hypertension 23, 878-883.

Laurent S, Girerd X, Mourad J, Lacolley P, Beck L, Boutouyrie P. Mognot J \& SAFAR M (1994b). Elastic modulus of the radial artery wall material is not increased in patients with essential hypertension. Arterioscl. Thromb. 14, 1223-1231.

MULVANY MJ (1992). A reduced elastic modulus of vascular wall components in hypertension? Hypertension 20, 7-9.

Reneman RS, van Merode T. Hick P. Murtuens AMM \& Hoeks APG (1986). Agerelated changes in carotid artery wall properties in men. Ultrasound Med. Biol. 12, 465471.

SAFAR ME, LEVY BI, LAURENT S \& LONDON GM (1990). Hypertension and the arterial system: clinical and therapeutic aspects. J Hypertens. 8(Suppl. 7), S113-S119.

TARDY Y, MEISTER JJ, PERRET F, BRUNNER HR \& ARDITI M (1991). Non-invasive estimate of the mechanical properties of peripheral arteries from ultrasonic and 
photoplethysmographic measurements. Clin. Phys. Physiol Meas. 12, 39-54.

WEBER R, STERIOPULOS N, BRUNNER HR \& HAYOZ D (1996). Contributions of vascular tone and structure to elastic properties of a medium-sized artery. Hypertension 27, 816822. 
Effect of chronic blockade of angiotensin II receptor subtypes on aortic compliance in rats with myocardial infarction

D.L. Ceiler

H.J.M.G. Nelissen-Vrancken

J.G.R. De Mey

J.F.M. Smits

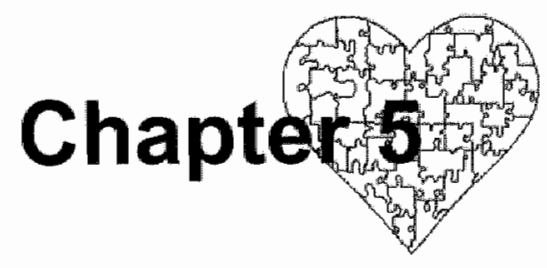




\section{Abstract}

This study was undertaken to investigate changes in aortic geometry and compliance after chronic blockade of $\mathrm{AT}_{1}$ and $\mathrm{AT}_{2}$ receptors under basal conditions and after myocardial infarction (MI). Sham-operated (sham) or MI rats received either: no treatment, $A T_{1}$ antagonist GR138950C (GR; 2 mg/kg/day i.v.) or $\mathrm{AT}_{2}$ antagonist PD123319 (PD; $3 \mathrm{mg} / \mathrm{kg} /$ day s.c.). After 3 weeks, mean arterial blood pressure (MAP) was measured. Thoracic aorta diastolic diameter $\left(D_{\text {dia }}\right)$, compliance coefficient $(C C)$ and distensibility coefficient (DC) were determined non-invasively in anesthetized rats using ultrasound and wall tracking. After sacrifice, histological measurements were made on aortic cross-sections.

In sham rats, MAP was lowered by GR treatment $(76 \pm 6$ vs $106 \pm 5 \mathrm{mmHg})$, but not by $P D$. $D_{\text {dila }}$ was reduced in both GR-treated $(1.74 \pm 0.08$ vs. $2.09 \pm 0.05 \mathrm{~mm}$ ) and PDtreated $(1.83 \pm 0.05$ vs. $2.09 \pm 0.05 \mathrm{~mm})$ sham rats. $C C$ and $D C$ were not modified by either treatment. Although media cross-sectional area was not affected by either $\mathrm{GR}$ or $P D$ treatment in sham rats, media thickness and media-lumen ratio were increased in both cases. Induction of MI had no effect on aortic structure, geometry or mechanics; however, treatment with either GR or PD improved DC versus untreated MI rats.

We conclude that $A T_{1}$ and $A T_{2}$ receptors are involved in angiotensin 11 -mediated effects on aortic geometry and mechanics under both basal conditions and after MI. Whereas blockade of $A T_{1}$ receptors most likely influences vascular properties via a depressor mechanism, $A T_{2}$ receptors induce pressure-independent remodelling. 


\section{Introduction}

Many studies have demonstrated the important modulatory role of angiotensin II in the cardiovascular system under basal conditions and in various pathologies, such as hypertension and heart failure (Lever, 1986; Schunkert et al. 1993; Luchner et al. 1996). Indeed, angiotensin II has been shown to induce both vascular smooth muscle hypertrophy and extracellular matrix protein synthesis in various animal models of hypertension (Daemen et al. 1991; Griffin et al. 1991; Keeley et al. 1992). Furthermore, this vasoactive peptide has been implicated in the development of cardiac hypertrophy and fibrosis after myocardial infarction in man as well as in animal models (Weber \& Janicki, 1989; Smits et al. 1995).

AT, receptors are involved in both the pressor and vascular and cardiac hypertrophic effects of the peptide (Timmermans et al. 1991; Smits et al. 1995). The functional significance of $A T_{2}$ receptors is only now becoming apparent. Several studies suggest that $A T_{1}$ and $A T_{2}$ receptors are functionally antagonistic (Hein of al. 1995; Nakajima et al. 1995; Munzenmaier \& Greene, 1996). Although a switch between AT receptor subtypes occurs during development, with the $\mathrm{AT}_{2}$ subtype being the most prevalent in fetal and neonatal stages (Viswanathan et al. 1991), Levi and colleagues have recently provided evidence conferring a role for $A T_{2}$ receptors in angiotensin II-induced structural changes in the adult rat aorta (Levy et al. 1996; Sabri et al. 1997).

This study was undertaken to investigate the role of $A T_{1}$ and $A T_{2}$ receptors in angiotensin II-induced effects on aortic geometry and mechanics under basal conditions and after myocardial infarction, a pathology in which the reninangiotensin system is known to be hyperactive (Schunkert et al. 1993; Luchner et al. 1996). Recent studies suggest that the proportion of $A T_{1}$ and $A T_{2}$ receptors is altered in failing hearts (De Gasparo et al. 1994b; Nio et al. 1995). A shift of receptor subtypes in the vasculature may either potentiate or abnegate the effects of enhanced angiotensin II activity. The present study was designed to unravel contributions of the two receptor populations to mechanical and structural properties of the aorta. This seems of importance in view of the development of specific $A T_{1}$ blockers and their potential application on the treatment of heart failure.

Accordingly, we administered selective $A T_{1}$ and $A T_{2}$ antagonists to rats for a period of three weeks. Thereafter, we utilized a recently described wall tracking system in which ultrasound techniques can be applied to study the elastic characteristics of the aorta in intact small laboratory animals, such as rats (van Gorp et al. 1996). By combining findings with post-mortem histological data, it was possible to examine the relationship between geometric and structural changes in the thoracic aortic wall and the resultant changes in the dynamic mechanical function of the vessel. 


\section{Methods}

\section{Animals}

Male Wistar rats (280-320 g, lffa Credo, Someren, the Netherlands) were housed under standard conditions $\left(20^{\circ} \mathrm{C}, 12\right.$-hour light/dark cycle) and given free acces to standard chow (Hope Farms, Woerden, the Netherlands) and tap water. The experimental procedures were performed according to institutional guidelines and approved by the Ethical Committee for the Use of Experimental Animals of Universiteit Maastricht (the Netherlands).

\section{Myocardial infarction surgery}

Rats were randomly selected to undergo myocardial infarction (MI) or sham surgery (sham). Myocardial infarction was induced by permanent ligation of the left coronary artery, as described previously (Schoemaker et al. 1991). Briefly, animals were anesthetized (pentobarbital; $60 \mathrm{mg} / \mathrm{kg}$ i.p.), intubated, and respirated (room air; 60 strokes/min; tidal volume $3 \mathrm{ml}$ ). Following thoracotomy in the fourth left intercostal space, the heart was exteriorized and a 6-0 silk suture looped around the proximal left coronary artery. After the heart had been returned to its normal position, the suture was securely ligated in the Ml group. In sham rats, a superficial ligature was placed in the left ventricle wall near the left coronary artery and loosely tied. The thorax was closed with 3-0 silk and negative pressure was restored.

\section{Treatment}

On the day of the Ml or sham surgery, the animals were further randomly subdivided into treatment groups. Control $\mathrm{Ml}$ and sham rats received no treatment. The remainder of the MI and sham were treated with either the AT, antagonist GR138950C or the $\mathrm{AT}_{2}$ antagonist PD123319. GR138950 (a generous gift of M. Drew, Glaxo, Stevenage, UK) was administered at $2 \mathrm{mg} / \mathrm{kg} /$ day i.v. via an osmotic mini-pump (2ML2 and 2ML1. Alzet, Alza Co, Palo Alto, CA, USA) to which a catheter had been attached. The catheter was inserted in the left jugular vein. PD123319 (a generous gift of $H$. van Ingen, Parke Davis, Hoofddorp, the Netherlands) was administered at $3 \mathrm{mg} / \mathrm{kg} /$ day s.c. (2ML2 and 2ML1 Alzet). Minipumps were implanted between the scapulae s.c. under ether anesthesia. Treatment lasted three weeks.

The dose of GR138950C was based upon results from pilot studies, in which $2 \mathrm{mg} / \mathrm{kg} /$ day induced a 20 -fold rightward shift of the angiotensin II pressorresponse curve. Infusion of PD123319 at a dose of $3 \mathrm{mg} / \mathrm{kg} /$ day in the rat results in plasma levels around $100 \mathrm{nM}$ (Marcari et al. 1994), which is sufficient to shift the dose response curve $1.8 \mathrm{log}$ units to the right $\left(\mathrm{pA}_{2} 8.5\right)$ and has been shown to specifically antagonize the $\mathrm{AT}_{2}$ receptor (De Gasparo et al. 1994a). 


\section{Functional studies}

Measurement of blood pressure in conscious rats: After 18-19 days, the rats were anesthetized with pentobarbital $(60 \mathrm{mg} / \mathrm{kg}$ i.p.) and equipped with an arterial catheter (PE10 heat-sealed to PE 50, Clay Adam, Parsippany, NJ, USA) which was advanced into the abdominal aorta via a femoral artery. Saline-filled catheters

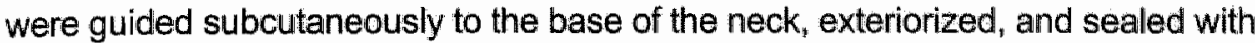
a metal plug. Rats were allowed to recover for at least one day.

Mean arterial pressure (MAP) was measured in quietly resting rats on day 20 or 21 via a pressure transducer (CP-01, Century Technology Co., Inglewood, CA, USA) in conjunction with an on-line monitoring computer program (Hemodynamic Data Acquisition Systems, Instrumental Services, Maastricht University).

Ultrasound assessment of aorta diameter and wall movement: On day 20 or 21 , aortic mechanical properties were measured in pentobarbital anesthetized rats. Blood pressure (monitored via a CP-01 low volume displacement pressure transducer) and body temperature (maintained at $38^{\circ} \mathrm{C}$ by an infrared heating lamp and a rectal temperature probe) were allowed to stabilize before beginning the experiments.

Thoracic aorta diameter and wall movement during the cardiac cycle were assessed as recently described (van Gorp ot al. 1996) using a vessel wall tracking system (WTS) attached to a conventional B-mode ultrasound system (Pie480, 7.5 $\mathrm{MHz}$ linear array, Pie Medical, Maastricht, the Netherlands). With the ultrasound probe positioned on the thorax, the thoracic aorta was first visualized in B-mode ( $B$ : brightness) before setting an $\mathrm{M}$-line ( $\mathrm{M}$ : motion) perpendicular to the vessel walls approximately $10 \mathrm{~mm}$ cranially from the diaphragm. Upon switching to $\mathrm{M}$ mode, ultrasound is emitted and received along the selected line of sight at a programmable emission trigger frequency to enable determination of dynamic parameters.

The concept of the WTS has been described elsewhere (Hoeks ot al. 1990). It is based on a data acquisition system capable of capturing the received and amplified radio frequency (RF) signals synchronously with the emission trigger at programmable sample frequencies (up to $30 \mathrm{MHz}$ ).

Upon completion of acquisition, the data are transferred to a PC. To extract the change in position of either anterior or posterior wall averaged over a few RF lines, an approach based on the cross correlation model for corresponding segments of subsequent RF lines was applied (Hoeks et al. 1993). The difference between the displacement signal of the posterior and anterior wall yields the change in diameter as a function of time. From the observed distention wave form, together with the initial distance between the sample windows, the end diastolic diameter, the peak-to-peak change in diameter, and the length of the cardiac cycle can be extracted for each cardiac cycle. A typical example of thoracic aorta wall movement and distention measured in an anesthetized rat is 
presented in Figure 5.1.

In each animal, six 2.5 second recordings, each of which comprises approximately 16 cardiac cycles, were performed, and the data obtained during these sessions were averaged. It has recently been demonstrated that this technique is reproducible and sensitive enough to detect the acute effects of pharmacological agents on aortic wall properties (van Gorp ef al. 1996).

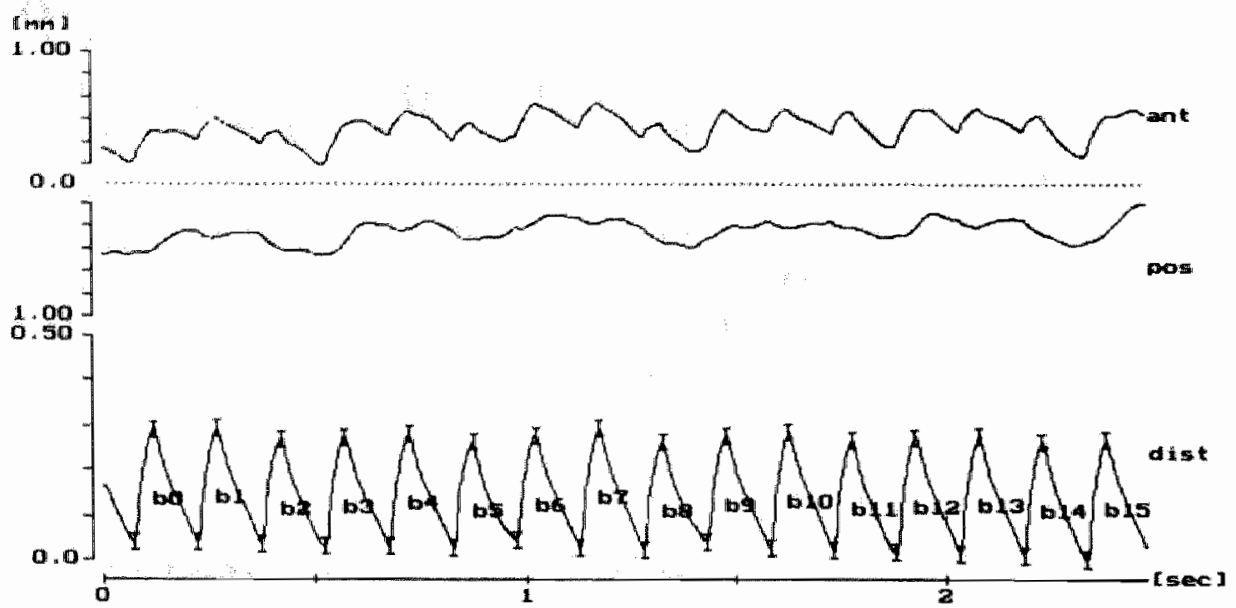

Figure 5.1

Typical example of anterior (ant) and posterior (pos) aortic wall displacement and the difference between both, distention (dis), during 16 consecutive cardiac cycles (b0-b15) as measured with ultrasound.

Calculation of compliance and distensibility: Arterial compliance is defined as the absolute increase in volume $(\Delta \mathrm{V})$ for a given increase in arterial blood pressure (pulse pressure $=\Delta P$ ). Distensibility, on the other hand, is the relative increase in volume $(\triangle V N)$ for a given $P$. Assuming that vascular volume increases only through radial distention (Reneman et al. 1986) and that the vascular cross-section is perfectly circular, compliance (CC) and distensibility (DC) can be approached as follows:

$$
C C \approx \Delta A / \Delta P=\pi\left(D_{d i \theta}+\Delta D\right) /(4 \Delta P)
$$

$$
D C=\Delta A /\left(A_{d i a} \Delta P\right)
$$


where $A_{\text {dia }}$ and $D_{\text {dia }}$ stand for the end-diastolic lumen area and diameter, respectively, and $\triangle \mathrm{A}$ and $\Delta \mathrm{D}$ for the corresponding change in lumen area and diameter during the cardiac cycle.

\section{Structural measurements}

Aortic histology: After animal sacrifice, a $10 \mathrm{~mm}$ segment of the thoracic aorta was isolated beginning at the third pair of intercostal arteries. The extent of longitudinal retraction upon isolation was assessed by pre- (Li) and post- (Le) excision measurements of the segment length as described in Chapter 3. Retraction was in the order of $25 \%$ and did not differ between experimental groups. The excised vessel was fixed by immersion in $4 \%$ phosphate-buffered formalin at room temperature before being embedded in paraffin.

Media cross-sectional area (CSAe), defined as the area between the internal and external elastica laminae was determined by semi-automated morphometry (JAVA 1.21, Jandel Scientific, Corte Madera, CA, USA) on $4 \mu \mathrm{m}$ cross-sections stained with Lawson's solution, a classic elastin stain. This value was converted to the expected in vivo CSA (CSAi) by accounting for vascular retraction upon isolation, i.e.,

$$
C S A i=C S A e \cdot L e / L i
$$

CSAi and $D_{\text {dia }}$ were used to calculate media thickness (Mt) (4) and media-tolumen ratio $(M / L)(5)$ according to

$$
\begin{gathered}
M t=-\frac{D_{\text {dia }}}{2}+\sqrt{\left[\frac{D_{\text {dia }}}{2}\right]^{2}+\frac{C S A i}{\pi}} \\
M / L=\frac{2 \cdot M t}{D_{\text {dia }}}
\end{gathered}
$$

Furthermore, the incremental elastic modulus $\left(E_{\mathrm{inc}}\right)(6)$ and the systolic medial wall stress $\left(\mathrm{WS}_{\mathrm{sys}}\right)$ (7) were calculated as 


$$
\begin{gathered}
E_{i n c}=D_{d i a} /(M t \cdot D C) \\
W S_{s y s}=\left(P_{s y s} \cdot r_{s y s}\right) / M t
\end{gathered}
$$

Medial collagen and elastin densities were measured with a computerized morphometric system (Quantimet 570, Leica, Cambridge, UK) on $4 \mu \mathrm{m}$ sections stained with Sirius Red and Lawson's solution (Boom B.V., Meppel, the Netherlands), respectively. At least six fields of the media area per vessel crosssection were analyzed at $400 x$ magnification, and the percentage of the media area occupied by collagen or elastin was calculated. The analyses were performed in a blinded fashion.

Myocardial infarct size determination: After animal sacrifice, hearts were excised and washed in saline. Following removal of the atria, the ventricles were cut into transverse sices of 1-2 mm, resulting in 5-6 slices. The mid-ventricular slice was fixed in $4 \%$ formaldehyde and embedded in paraffin, whereafter transverse sections $(4 \mu \mathrm{m})$ were stained according to the modified AZAN technique (van Krimpen et al. 1991). Infarct size was determined by planimetry and expressed in percentage of left ventricle circumference, calculated as the average of infarct sizes of endocardial and epicardial surfaces (Passier et al. 1995). Only hearts with infarct sizes $>21 \%$ were used in the Ml groups, as smaller infarcts do not have detectable hemodynamic consequences in vivo (Schoemaker et al. 1991).

\section{Statistics}

Data are expressed as mean \pm S.E.M. The effects of MI surgery and treatment were statistically tested non-parametrically with a Kruskal Wallis rank test with pairwise comparisons. Differences were regarded to be statistically significant at a value of $p<0.05$

\section{Results}

Effects of $A T$, receptor antagonism in sham rats

MAP was lowered in both the conscious and anesthetized state by treatment with the $\mathrm{AT}_{\text {q }}$ receptor antagonist, GR138950C (Table 5.1). The blood pressure lowering effect of GR138950C did not modify pulse pressure (Table 5.2). The reduction of diastolic pressure was associated with reduced diastolic aortic lumen diameter and increased vascular wall distention (Table 5.2). 
Media CSA was not modified by GR138950C (Table 5.3) Therefore, the reduction of diameter was accompanied by an increased Mt and $M / L$ (Table 5.3) Neither collagen nor elastin density, which averaged approximately $11 \%$ and $23 \%$, respectively, was affected by treatment (Figure 5.2 ).

Despite the treatment-induced changes in aortic pressure and aortic wall geometry, dynamic compliance and distensibility were not modified by three week administration of GR138950C (Figure 5.3 ; CC: $0.210 \pm 0.018$ vs. $0.246 \pm 0.026$ $\mathrm{mm}^{2} / \mathrm{kPa}$ ). Nonetheless, treatment with $\mathrm{GR} 138950 \mathrm{C}$ significantly reduced $E_{\text {inc }}$ $(291 \pm 53$ vs. $531 \pm 70 \mathrm{kPa})$ and $\mathrm{WS}_{\text {sys }}(196 \pm 29$ vs. $334 \pm 20 \mathrm{kPa})$, as shown in Figure 5.4.

Table 5.1 General characteristics of sham-operated (sham) and myocardially infarcted (MI) rats.

\begin{tabular}{|c|c|c|c|c|c|c|c|}
\hline & & $n$ & $\begin{array}{c}\text { body } \\
\text { weight } \\
\text { (g) }\end{array}$ & $\begin{array}{l}\text { heart } \\
\text { weight } \\
\text { (g) }\end{array}$ & $\begin{array}{c}\mathrm{MI} \\
\text { size } \\
(\%) \\
\end{array}$ & $\begin{array}{l}\text { conscious } \\
\text { MAP } \\
(\mathrm{mmHg})\end{array}$ & $\begin{array}{c}\text { anesthetized } \\
\text { MAP } \\
(\mathrm{mmHg})\end{array}$ \\
\hline & untreated & 9 & $339 \pm 7$ & $0.87 \pm 0.02$ & - & $114 \pm 2$ & $106 \pm 5$ \\
\hline \multirow{3}{*}{$\frac{E}{\frac{E}{\pi}}$} & GR138950C & 7 & $334 \pm 5$ & $0.84 \pm 0.02$ & - & $98 \pm 2^{*}$ & $76 \pm 6^{*}$ \\
\hline & PD123319 & 9 & $355 \pm 3^{*}$ & $0.92 \pm 0.01$ & - & $115 \pm 2$ & $97 \pm 5$ \\
\hline & untreated & 8 & $349 \pm 5$ & $0.94 \pm 0.02^{\dagger}$ & $41 \pm 4$ & $105 \pm 2^{\dagger}$ & $101 \pm 3$ \\
\hline \multirow[t]{2}{*}{$\bar{\Sigma}$} & GR138950C & 8 & $321 \pm 5^{\star}$ & $0.97 \pm 0.04^{\dagger}$ & $45 \pm 3$ & $85 \pm 3^{*}$ & $68 \pm 4^{*}$ \\
\hline & PD123319 & 6 & $346 \pm 7$ & $1.08 \pm 0.02^{* \dagger}$ & $37 \pm 3$ & $110 \pm 4^{*}$ & $101 \pm 4$ \\
\hline
\end{tabular}

values are mean \pm S.E.M. GR138950C, AT, antagonist was infused $2 \mathrm{mg} / \mathrm{kg} / \mathrm{day} i \mathrm{iv}$. for three weeks; PD123319, AT antagonist was infused $3 \mathrm{mg} / \mathrm{kg} / \mathrm{day}$ s.c. for three weeks; MAP, mean arterial pressure. ${ }^{*} p<0.05$ vs. untreated in same surgical category. ${ }^{1} p<0.05$ vs. comparablytreated sham.

Effects of $A T_{2}$ receptor antagonism in sham rats

Three week treatment with the $A T_{2}$ receptor antagonist, PD123319, did not influence mean arterial or pulse pressure in conscious or anesthetized sham rats (Tables 5.1 and 5.2), but significantly reduced diastolic diameter (Table 5.2). Absolute aortic distention during the cardiac cycle was not modified (Table 5.2). Media CSA, collagen density and elastin density were unaffected by treatment (Table 5.3, Figure 5.2). Mt and M/L were significantly larger in PD123319-treated rats due to the smaller lumen diameter (Table 5.3).

At similar pressures, the smaller lumen diameter in PD123319-treated compared to the untreated sham rats had no effect on dynamic mechanical 
parameters; both CC and DC were unaffected by treatment (Figure 5.3). Nonetheless, $E_{\text {inc }}(353 \pm 23$ vs. $531 \pm 70 \mathrm{kPa})$ and $W_{\text {sys }}(233 \pm 25$ vs. $334 \pm 20 \mathrm{kPa})$ were significantly reduced (Figure 5.4 ).

Table 5.2 Aortic pressure and distention in anesthetized rats.

\begin{tabular}{|c|c|c|c|c|c|c|}
\hline & & $\mathrm{n}$ & $\begin{array}{r}\mathbb{P}_{\text {glla }} \\
\text { (kPa) }\end{array}$ & $\begin{array}{c}\mathrm{AP} \\
(\mathrm{kPa})\end{array}$ & $\begin{array}{c}D_{\text {dia }} \\
(\mathrm{mm})\end{array}$ & $\begin{array}{l}\Delta \mathrm{DD} \\
(\mu \mathrm{m})\end{array}$ \\
\hline \multirow{4}{*}{ 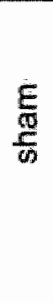 } & untreated & 9 & $13.02 \pm 0.63$ & $3.13 \pm 0.25$ & $2.09 \pm 0.05$ & $212 \pm 15$ \\
\hline & GR138950C & 7 & $8.99_{ \pm} 0.75^{\star}$ & $3.48 \pm 0.20$ & $1.74 \pm 0.08^{*}$ & $245_{ \pm} 10^{*}$ \\
\hline & PD123319 & 9 & $11.66 \pm 0.66$ & $3.58 \pm 0.18$ & $1.83 \pm 0.05^{*}$ & $220 \pm 11$ \\
\hline & untreated & 8 & $12.33 \pm 0.41$ & $3.48 \pm 0.19$ & $2.15 \pm 0.02$ & $209 \pm 5$ \\
\hline \multirow{2}{*}{$\bar{\Sigma}$} & GR138950C & 8 & $8.06 \pm 0.55^{*}$ & $2.85 \pm 0.22^{*}$ & $1.68 \pm 0.06^{*}$ & $245_{ \pm} 14^{*}$ \\
\hline & PD123319 & 6 & $12.90 \pm 0.34^{\dagger}$ & $3.10 \pm 0.19$ & $2.01 \pm 0.07^{\star \dagger}$ & $221 \pm 22$ \\
\hline
\end{tabular}

Values are mean \pm S.E.M. Sham, sham-operated; MI, myocardially infarcted; GR138950C, AT, antagonist was infused $2 \mathrm{mg} / \mathrm{kg} / \mathrm{day} / \mathrm{i}$. for three weeks; PD123319, $\mathrm{AT}_{2}$ antagonist was infused $3 \mathrm{mg} / \mathrm{kg} /$ day s.c. for three weeks; $P_{\text {dla }}$, diastolic presure; $\Delta P$, pulse pressure; $D_{\text {diar }}$ end-diastolic lumen diameter, $\Delta \mathrm{D}$, aortic wall distention during cardiac cycle. All data are derived from six recordings, each of $2.5 \mathrm{sec}$ (approximately 16 cardiac cycles) per individual animal. " $p<0.05$ vs. untreated in same surgical category. ${ }^{\dagger} p<0.05$ vs. comparably-treated sham.

\section{Effects of myocardial infarction}

As shown in Table 5.1, body weights were unaffected, but heart weights were significantly larger in MI rats compared to sham rats. In the conscious state, MAP was lower in MI than sham rats. This small but significant difference disappeared under anesthesia. Pulse pressure was also unchanged (Table 5.2). Additionally, thoracic aorta lumen diastolic diameter and wall distention were similar in sham and $\mathrm{MI}$ rats (Table 5.2). Under these isobaric and isometric conditions, aortic mechanical properties were not modified by MI. Both CC and DC were comparable in the untreated surgical groups, as illustrated in Figure 5.2. Furthermore, the histological characteristics of the vessel were not perturbed three weeks after MI. Media collagen and elastin content (Figure 5.2) as well as media CSA (Table 5.3) remained unchanged. The latter together with the comparable diastolic diameter indicates that neither Mt nor $\mathrm{M} / \mathrm{L}$ were modified by MI. Thus, myocardial infarction induced no changes in aortic mechanical or structural properties three weeks after surgery. 
Table 5.3 Histological data for sham-operated (sham) and myocardially infarcted (MI) rats.

\begin{tabular}{|c|c|c|c|c|c|}
\hline & & $n$ & $\begin{array}{c}\text { media CSA } \\
\left(\mathrm{mm}^{2}\right)\end{array}$ & $\begin{array}{l}\text { media thickness } \\
(\mu \mathrm{m})\end{array}$ & $\begin{array}{l}\text { media-to-lumen } \\
\text { ratio }\end{array}$ \\
\hline \multirow{3}{*}{$\frac{E}{\frac{E}{w}}$} & untreated & 9 & $0.414 \pm 0.011$ & $62 \pm 2$ & $0.059 \pm 0.003$ \\
\hline & GR138950C & 7 & $0.425 \pm 0.016$ & $75 \pm 4^{*}$ & $0.089 \pm 0.009^{*}$ \\
\hline & PD123319 & 9 & $0.422 \pm 0.019$ & $71 \pm 3^{4}$ & $0.078 \pm 0.005^{*}$ \\
\hline \multirow{3}{*}{$\bar{\Sigma}$} & untreated & 8 & $0.383 \pm 0.015$ & $57 \pm 2$ & $0.052+0.003$ \\
\hline & GR138950C & 8 & $0.378 \pm 0.009^{t}$ & $69 \pm 4^{*}$ & $0.085 \pm 0.006^{*}$ \\
\hline & PD123319 & 6 & $0.445 \pm 0.023^{*}$ & $69_{ \pm} 5^{*}$ & $0.070 .0 .008^{*}$ \\
\hline
\end{tabular}

Values are mean \pm S.E.M. GR138950C, AT, antagonist was infused $2 \mathrm{mg} / \mathrm{kg} / \mathrm{dlay} / \mathrm{iv}$. for three weeks; PD123319, AT 2 antagonist was infused $3 \mathrm{mg} / \mathrm{kg} /$ day s.c. for three weeks; CSA, crosssectional area. ${ }^{*} p<0.05$ vs. untreated in same surgical category. ${ }^{t} p<0.05$ vs. comparably-treated sham.

a.

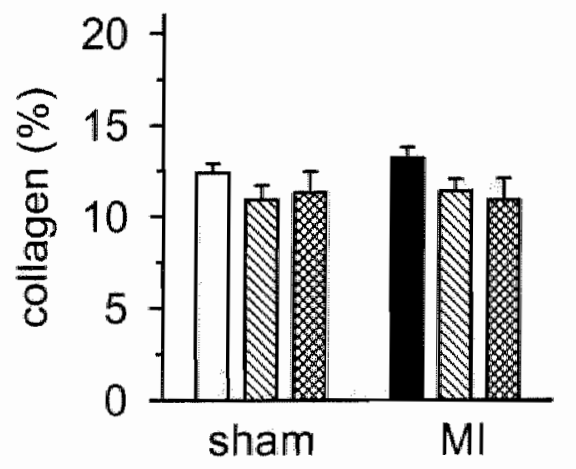

b.

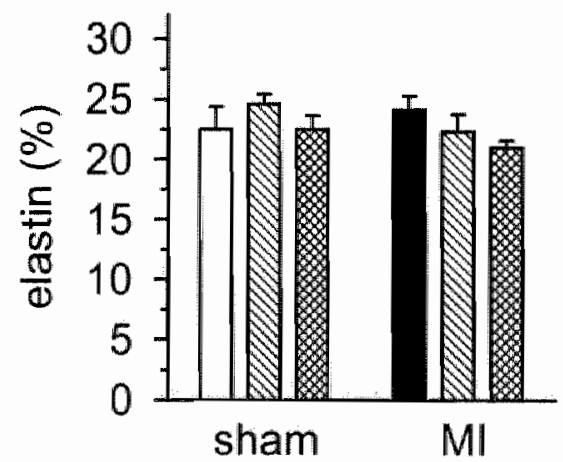

\section{Figure 5.2}

Effects of three-week treatment with the $A T_{1}$ antagonist, GR138950C, (2 mg/kg/day i.v.) (hatched bars) or the $\mathrm{AT}_{2}$ antagonist, PD123319, (3 mg/kg/day s.c.) (cross-hatched bars) on the media volume fraction of elastin (panel a) and collagen (panel b) of sham-operated (open bar) and myocardially-infarcted (filled bar) rats. Data show mean \pm S.E.M.; $n=6-9$. 
a.

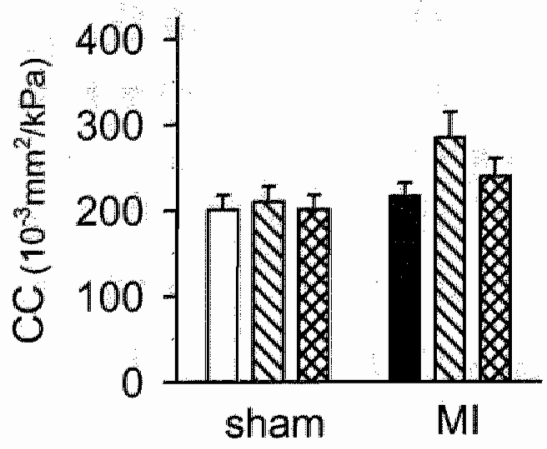

b.

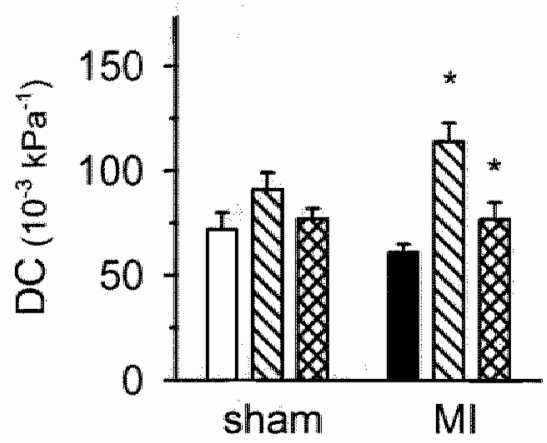

\section{Figure 5.3}

Effects of three-week treatment with the AT, antagonist, GR138950C, $(2 \mathrm{mg} / \mathrm{kg} /$ day i. v. $)$ (hatched bars) or the AT ${ }_{2}$ antagonist PD123319 ( $3 \mathrm{mg} / \mathrm{kg} / \mathrm{day}$ s.c.) (cross-hatched bars) on the compliance coefficient (CC) (panel a) and on the distensibility coefficient (DC) (panel b) of anesthetized sham-operated (open bar) and myocardially-infarcted (filled bar) rats. Data show mean $\pm S . E . M . ; n=6-9 * p<0.05$ vs. untreated in same surgical category.

a.

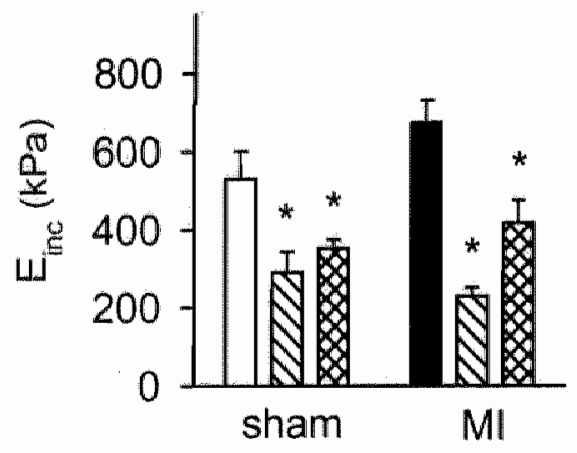

b.

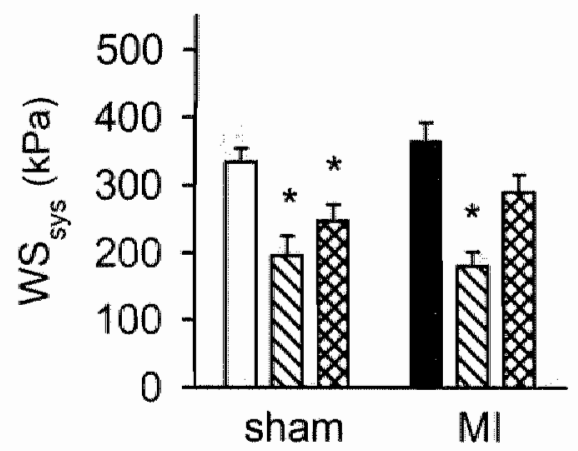

Figure 5.4

Effects of three-week treatment with the AT, antagonist, GR138950C, (2 mg/kg/day i.v.) (hatched bars) or the AT2 antagonist, PD123319. ( $3 \mathrm{mg} / \mathrm{kg} /$ day s.c.) (cross-hatched bars) on the incrementall elastic modulus $\left(E_{\text {inc }}\right.$ ) (panel a) and on systolic wall stress $\left(W S_{\text {sys }}\right)$ (panel b) of anesthetized sham-operated (open bar) and myocardially-infarcted (filled bar) rats. Data show mean $\pm S . E . M . ; n=6-9 . " ~ p<0.05$ vs. untreated in same surgical category. 
Effects of AT receptor antagonists in MI rats

Angiotensin receptor antagonism had largely similar effects in MI rats as in the sham animals: 1 . Conscious and anesthetized MAP was lowered by GR138950C but not by PD123319 (Table 5.1). 2. $D_{\text {dia }}$ was reduced by both treatments, and distention increased in GR138950C-treated MI rats (Table 5.2). 3. Mt and $\mathrm{M} / \mathrm{L}$ were likewise increased by both treatments (Table 5.3), 4. Collagen and elastin densities were similar irrespective of treatment (Figure 5.2). 5. CC was unaffected by either treatment (Figure 5.3).6. $E_{\text {inc }}$ was reduced by both treatments (Figure 5.4). Yet, unlike in the sham group in which no effect on distensibility was found, treatment with GR138950C as well as with PD123319 improved distensibility in MI rats (Figure 5.3) (untreated $0.061 \pm 0.004$, GR138950C-treated $0.114 \pm 0.009$, PD123319-treated $\left.0.077 \pm 0.008 \mathrm{kPa}^{-1}\right)$. Furthermore, although heart weight and aortic media CSA did not change with PD123319 treatment in sham rats, they increased significantly in Ml-treated counterparts (Tables 5.1 and 5.3).

\section{Discussion}

We examined the effect of chronic blockade of angiotensin II receptors on aortic structure and mechanical properties. From our results we conclude that angiotensin 11 plays an important role in determining aortic geometry and mechanics via both $A T_{1}$ and $A T_{2}$ receptors under basal conditions and after myocardial infarction.

\section{Effects of myocardial infarction}

Three weeks after myocardial infarction, we found no changes in aortic structure or geometric properties. These results are in agreement with a recent study from our group which shows that vascular structural changes develop only late (reaching significance by 3 months) after myocardial infarction (Heeneman et al. 1995). A recent study from Gaballa and coworkers (1995) reports structural changes in large vessels, which were accompanied by increased characteristic impedance and arterial stiffness. On one hand, the observed increase in collagen content in the aforementioned study, which we did not observe at three weeks post MI, may contribute to the increased arterial stiffness. On the other hand, impedance is determined by both a compliance and a resistance term. Thus, an increased resistance may contribute to the increased impedance. All in all, in the present study, the lack of alteration of aortic structure three weeks after MI was associated with preserved isobaric aortic mechanics.

Studies in humans with heart failure report either maintained or reduced values for compliance (Hirai et al. 1989; Mohiaddin et al. 1989; Laskey et al. 1990). Several of these studies also demonstrate a clear relationship between aortic and coronary atherosclerosis (Hirai et al. 1989; Mohiaddin et al. 1989). It has been suggested that changes in stiffness of large arteries can be used as an early marker for coronary 
artery disease (Hirai et al. 1989). As such, reduced systemic compliance, most likely due to atherosclerosis, in heart failure patients is more likely a cause of the pathology than a result of ensuing hemodynamic and neurohormonal changes.

\section{Effects of AT receptor antagonism in sham rats}

Treatment with the $A T$, receptor antagonist, GR138950C, reduced MAP, in accordance with earlier results indicating that angiotensin II participates in blood pressure regulation via $\mathrm{AT}_{1}$ receptors (Timmermans et al. 1991, 1993). Probably as a direct consequence, diastolic diameter was reduced. A smaller lumen diameter together with an unchanged media cross-sectional area resulted in increased media thickness and media-to-lumen ratio. Media elastin and collagen densities were not altered. Although angiotensin II has been implicated in vascular wall hypertrophy and extracellular matrix protein synthesis via $A T_{1}$ receptors (Timmermans et al. 1991, 1993), the lack of effect of AT, blockade in the sham animals in the present study corroborates with findings in other studies (Levy et al. 1988, 1996) where AT, blockade did not affect aortic mass in animals in which the renin-angiotensin system was not hyperactive.

Similar to the effects of $A T_{1}$ receptor antagonism on aortic geometry in sham rats, $\mathrm{AT}_{2}$ antagonism with $\mathrm{PD} 123319$ increased media-to-lumen ratio via a decrease in diastolic lumen diameter and a concomitant increase in media thickness without affecting media cross-sectional area or collagen and elastin density. Nonetheless, PD123319 induced these changes in aortic geometry in the absence of a pressure change, suggesting a direct effect on structure.

It is interesting to note that, although treatment with either antagonist in sham rats had an effect on aortic geometry, aortic compliance and distensibility were unchanged. In the case of the GR138950C-treated rats, compliance and distensibility were unaltered despite a reduction in blood pressure. It is thus tempting to speculate that compliance is closely regulated, i.e., lumen diameter and vascular wall structure (geometry and/or composition) adapt to maintain compliance. This posit is supported by surmounting data in hypertensive patients and animal models which demonstrate compensatory mechanisms which are activated when compliance is altered (Hayoz et al. 1992; Laurent et al. 1993, 1994).

Furthermore, in the present study, we found that the incremental elastic modulus, which describes the intrinsic elastic properties of the wall material, is reduced by three week treatment with either GR138950C or PD123319, indicating an increase in aortic wall elasticity. Possible reductions in aortic compliance due to reduced lumen diameters seem to be compensated by changes in vascular wall properties. 
Effect of $A T$ receptor antagonism in $M I$ rats

A major difference between the effects of the AT receptor blockade in sham and MI rats is that distensibility is improved with both GR138950C and PD123319 in MI rats. The latter result may be explained by the fact that, even though the reninangiotensin system is active in sham rats, as evidenced by $\mathrm{AT}_{4}$-antagonisminduced reductions in arterial pressure, the renin-angiotensin system is known to be hyperactive following MI (Schunkert et al. 1993; Luchner et al. 1996 .

Paradoxically, antagonism of $A T_{1}$-mediated hypertrophic effects did not lead to reductions in heart weight or aortic media cross-sectional area in MI rats. While $A T_{1}$ antagonism leads to a regression of cardiac hypertrophy in hypertensive models (Everett et al. 1994; Zierhut et al. 1996), such treatment has been shown to have no effect or even hypertrophic effects on cardiac mass after myocardial infarction (Raya et al. 1991; Casparro of al. 1994; Cheung, 1997). In terms of the aorta, media cross-sectional areas were, if anything, smaller in untreated $\mathrm{MI}$ rats compared to sham rats, and treatment with GR138950C had no further effect on medial area. $\mathrm{AT}_{1}$ and $\mathrm{AT}_{2}$ receptors have been shown to be functionally antagonistic in many respects (Hein et al. 1995; Nakajima et al. 1995; Munzenmaier \& Greene, 1996), such that the net effect of $A T_{1}$-induced growth and $A T_{2}$-induced apoptosis (Nakajima et al. 1995; Yamada et al. 1996) may depend on the proportion of receptor subtypes. The tendency towards apoptosis (smaller cross-sectional areas) and away from growth may stem from either an absolute or relative upregulation in vascular $\mathrm{AT}_{2}$ receptors, similar to changes in expression that have been reported in hearts from rats following $\mathrm{Ml}$ and from humans with chronic heart failure (De Gasparo et al. 1994b; Nio et al. 1995). Such a change in receptor populations may likewise be responsible for the increase in heart weight and aortic cross-sectional area in PD123319-treated MI rats.

In Chapter 3, we demonstrated that proportional changes in media mass do not per se affect vascular mechanics. In the present study, we were also unable to detect effects of AT-antagonism on medial extracellular collagen and elastin volume density. Nonetheless, the improvement in distensibility may have been due to an effect of angiotensin receptor antagonism on the development of aberrant collagen cross-linking, extracellular protein rearrangement and/or adventitial collagen differences in MI rats.

\section{Conclusion}

The most important conclusions of the present study are: (1) No changes in either aortic structure or mechanics develop three weeks after myocardial infarction in rats. (2) Antagonism of angiotensin receptors improves aortic distensibility in MI rats. (3) Angiotensin II plays an important role in determining aortic structure and mechanics via both $A T_{1}$ and $A T_{2}$ receptors under basal conditions. (4) While antagonism of $\mathrm{AT}_{1}$ receptors affects aortic geometry and mechanics by a 
depressor mechanism, $A T_{2}$ receptor antagonism seems to effect changes via remodelling.

\section{References}

CASPARRO JM, LI P, MEgGS LG, HERMAN MV \& ANVERSA P (1994). Efficacy of angiotensin-converting enzyme inhibition and $A T_{\text {, }}$ receptor blockade on cardiac performance after myocardial infarction in rats. J. Cardiovasc. Pharmacol. 23, 584-593.

CHEUNG B (1997): Increased left-ventricular mass after losartan treatment. Lancet 349, $1743-1744$.

DAEMEN MJAP, LOMBARDI DM, BOSMAN FT \& SCHWARTZ SM (1991). Angiotensin II induces smooth muscle proliferation in the normal and injured rat arterial wall. Circ. Res. 68, 450-456.

De Gasparo M, LeVens NR, Kamber B, Furet P, Whitebread S, Brechler V \& Bottarl SP. (1994a). The angiatensin II $A T_{2}$ receptor subtype. New York: Plenum Press.

De Gasparo M, Rogg $H$, Brink M, Wang L, Whitebread S, Bullock G \& Erne $P$ (1994b). Angiotensin II receptor subtypes and cardiac function. Eur. Heart. J. 15(Suppl. D), 98-103.

EVERETT AD, TUFRO-MCREDdie A, FISCHER A \& GOMEZ RA (1994). Angiotensín receptor regulated cardiac hypertrophy and transforming growth factor- $\beta_{1}$ expression. Hypertension 23, 587-592.

GABALLA MA, RAYA TE \& GOLDMAN S (1995). Large artery remodeling after myocardial infarction. Am. J. Physiol. 268, H2092-H2103.

VAN Gorp A, VAN INGEN SchenAu DS, Willigers J, HOEKS APG, DE MEY JGR, StRUIJKER BOUDIER HAJ \& RENEMAN RS (1996). A technique to assess aortic distensibility and compliance in anesthetized and awake rats. Am. J. Physiol. 270, H780-H786.

GRIFFIN SA, BROWN WCB, MACPHERSON F, MCGRATH JC, WILSON VG, KORSGAARD N, MULVANY MJ \& LEVER AF (1991). Angiotensin II causes vascular hypertrophy in part by a non-pressor mechanism. Hypertension 17, 626-635.

Hayoz D, Rutschmann B, Perret $F$, Niederberger $M$, Tardy $Y$, Mooser $V$, NUSSBURGER J. WAEBER B \& BRUNNER HR (1992). Conduit artery compliance and distensibility are not necessarily reduced in hypertension. Hypertension 20, 1-6.

HeEnEMAN S, LEENDERS PJA, AARTS PJJW, SMITS JFM, ARENDS JW \& DAEMEN MJAP (1995). Peripheral vascular alterations during experimental heart failure in the rat: do they exist? Arterioscl. Thromb. Vasc. Biol. 15, 1503-1511. 
HEIN L, BARSH GS, PRATT RE, DZAU VJ \& KOBILKA BK (1995). Behavioural and cardiovascular effects of disrupting the angiotens in II type-2 receptor in mice. Nature $377,744-747$.

HIRAI T, SASAYAMA S, KAWASAKI T \& YAGI S-i (1989). Stiffness of systemic arteries in patients with myocardial infarction: a noninvasive method to predict severity of coronary atherosclerosis. Circulation 80, 78-86.

HoEks APG, BRANDS PJ, SMeETS FAM \& RENEMAN RS (1990). Assessment of the distensibility of superficial arteries. Ultrasound Med. Biol. 16, 121-128.

HoEks APG, ARTS TGJ, BRANDS PJ \& RENEmAN RS (1993). Comparison of the performance of the RF cross-correlation and Doppler autocorrelation technique to estimate the mean velocity of simulated ultrasound signals. Ultrasound Med. Biol: 19, $727-740$.

KeELEY FW, ELMOSELHI A \& LEENEN FHH (1992). Enalapril suppresses normal accumulation of elastin and collagen in cardiovascular tissues of growing rats. $A m$. J. Physiol. 262, H1013-H1021.

VAN KRIMPEN C, SMITS JFM, CLEUTJENS JPM, DEBETS JJM, SCHOEMAKER RG, STRUIJKER BOUDIER HAJ, BOSMAN FT \& DAEMEN MJAP (1991). DNA synthesis in the non-infarcted cardiac interstitium after left coronary artery ligation in the rat: effects of captopril. $J$. Mol. Cell. Cardiol. 23, 1245-1253.

LASKEY WK, PARKer HG, FerRari VA, KussmaUl WG \& NOORDERgRAAF A (1990). Estimation of totoal systemic arterial compliance in humans. J. Appl. Physiol. 69, 112119.

Laurent S, hayoz D, TrazzI S, Boutouyrie P, Waeber B, Omboni S, Brunner HR, MANCIA G \& SAFAR M (1993). Isobaric compliance of the radial artery is increased in patients with essential hypertension. J Hypertens. 11, 89-98.

laurent S, Caviezel B, Beck L, Gierd X, Blllaud E, Boutouyrie P. Hoeks a \& Safar $M$ (1994). Carotid artery distensibility and distending pressure in hypertensive humans. Hypertension 23, 878-883.

LEVER AF (1986). Slow pressor mechansims in hypertension: a role for hypertrophy of resistance vessels? J Hypertens. 4, 515-524.

LeVy BI, Michel J-B, Salzmann J-L, AzIZI M, Poitevin P, Safar M \& Camilleri J-P (1988). Effects of chronic inhibition of converting enzyme on mechanical and structural properties of arteries in rat renovascular hypertension. Circ. Res. 63, 227-239.

Levy Bi, Benessiano J, Henrion D, Caputo L, Heymes C, Duriez M, Poitevin P \& SAMUEL JL (1996). Chronic blockade of AT2-subtype receptors prevents the effect of angiotensin II on the rat vascular structure. J. Clin. Invest. 98, 418-425. 
LUCHNER A, STEVENS TL, BORgESON DD, REDfield MM, BALLY JE, SANDberg SM, HEUBLEIN DM \& BURNET J JC (1996). Angiotensin II in the evolution of experimental heart failure. Hypertension $28,472-477$.

MARCARI D, WHITEBREAD S, CUMN F, DE GASPARO M \& LEVENS N (1994). Renal actions of the $\mathrm{AT}_{2}$ receptor ligands CGP42114 and PD123319 after blockade of the reninangiotensin system. Eur. J Pharmacol. 259, 27-36.

MOHIADDIN RH, UNDERWOOD SR, BOGREN HG, FIRMIN DN, KLIPSTEIN RH, REES RSO \& LONGMORE DB (1989). Regional aortic compliance studied by magnetic resonance imaging: the effects of age, training, and coronary artery disease. Br. Heart J. 62, 90-96.

MUNZENMAIER DH \& GREENE AS (1996). Opposing actions of angiotensin II on microvascular growth and blood pressure. Hypertension 27, 760-765.

NAKAJIMA M, HutCHINSON HG, FuJinaga F, HAYASHIDA W, MORISHITA R, ZHANG L, HORIUCHI M. PRATT RE \& DZAU VJ (1995). The angiotensin II type 2 (AT ${ }_{2}$ ) receptor antagonizes the growth effects of the $A T_{1}$ receptor: Gain-of-function study using gene transfer. Proc. Nall. Acad. Sci. USA. 92, 10663-10667.

Nio Y, Matsubara H. Murasawa S, Kanasaki M \& Inada M (1995). Regulation of gene transcription of angiotensin II receptor subtypes in myocardiall infarction. J. Clin. Invest. $95,46-54$.

PAssier RCJJ, SMITS JFM, VERLUYTEN MJA, Studer R, DREXLER H \& DAEMEN MJAP (1995). Activation of anglotensin-converting enzyme expression in infarct zone following myocardial infarction. Am. J. Physiol. 269, H1268-H1276.

RAYA TE, FONKEN SJ, LEe RW, DAUgheRtY $S$, GoldMAN $S$, WONG PC, TIMMERMANS PBMWM \& MORKIN E (1991). Hemodynamic effects of direct angiotensin II blockade compared to converting enzyme inhibition in rat model of heart fallure. Am. U. Hypertens: 4, $334 S-340$ s.

Reneman RS, VAN MERode T. Hick P, Muytjens AMM \& HoEks APG (1986). Agerelated changes in carotid artery wall properties in men. Ultrasound Med. Biol.' 12, 465471.

Sabri A, LeVy BI, Poitevin P, Caputo L, Faggin E, Marotte F, Rappaport L \& Samuel $\mathrm{JL}$ (1997). Differential roles of $A T_{1}$ and $A T_{2}$ receptor subtypes in vascular trophic and phenotypic changes in response to stimulation with angiotensin II. Arterioscl. Thromb. Vasc. Biol. 17, $257-264$.

SCHOEMAKER RG, DEBetS JJM, STRUIJKER BOUdIER HAJ \& SMITS JFM (1991). Dellayed but not immediate captopril therapy improves cardiac function in conscious rats following imyocardial infarction. J. Mol. Cell. Cardiol. 23, 187-197. 
SCHUNKERT H, TANG S-S, LITWIN SE, DIAMANT D, RIEGgeR G, DZAU VJ \& INGELFINGER JR (1993). Regulation of intrarenal and circulating renin-angiotensin systems in severe heart failure in the rat. Cardiovasc. Res. 27, 731-735.

SMITS JFM, PASSIER RCJJ, NelisSEN-VRANCKEN HJMG, KUIZINGA MC \& DAEMEN MJAP (1995). Does ACE inhibition limit structural changes in the heart following myocardial infarction? Eur. Heart. J. 16(Suppl. N), 46-51.

TimMermans PBMWM, WONG PC, CHIU AT \& Herblin WF (1991). Non-peptide angiotensin II receptor antagonists. TiPS 12, 55-62.

Timmermans PBMWM, Wong PC, Chiu AT, Herblin WF, Benfield P, CARINI DJ, LeE RJ, WEXLER RR, SAYE JM \& SMITH RD (1993). Angiotensin II receptors and angiotensin II receptor antagonists. Pharmacol. Rev. 45, 205-251.

VISWANATHAN M, TSUTSUMI K, CORRREA FMA \& SAAVEDRA JM (1991). Changes in expression of angiotensin receptor subtypes in the rat aorta during development. Biochem. Biophys. Res. Comm. 179, 1361-1367.

WEBER KT \& JANICKI JS (1989). Angiotensin and the remodeling of the myocardium. $\mathrm{Br}$. J. Clin. Pharmacol. 28, 141S-150S.

YAMADA T, HoRIUCHI M \& DZAU VJ (1996). Angiotensin II type 2 receptor mediates programmed cell death. Proc. Natl. Acad. Sci. USA. 93, 156-160.

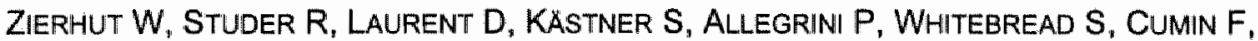
BAUM H-P, DE GASPARO M \& DREXLER H (1996). Left ventricular wall stress and sarcoplamic reticulum $\mathrm{Ca}^{2+}$-ATPase gene expression in renal hypertensive rats: dosedependent effects of ACE inhibition and AT,-receptor blockade. Cardiovasc. Res. 31, 758-768. 


\section{Effect of nitric oxide synthase inhibition on the acetylcholine response in the perfused hindlimbs of rats}

\section{D.L. Ceiler}

H.J.M.G. Nelissen-Vrancken

J.G.R. De Mey

J.F.M. Smits

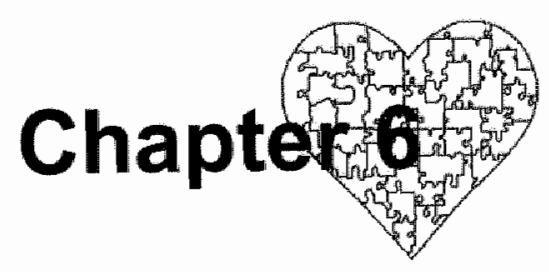




\section{Abstract}

The effect of nitric oxide (NO) synthase inhibition on acetylcholine-induced vasodilatation in the perfused rat hindlimb was investigated to find the contribution of NO to such dilator responses. Although NO synthase inhibition with $150 \mu \mathrm{g} \mathrm{L}-$ nitro-arginine increased vascular resistance considerably, from $7.28 \pm 0.29$ to $10.83 \pm 0.44 \mathrm{mmHg} \cdot \mathrm{min} / \mathrm{ml}(\mathrm{n}=7)$, the acetylcholine responses were not attenuated. Acetylcholine $(10 \mu \mathrm{g})$ induced a peak dilatation of $66 \pm 4 \%$ before, and $63 \pm 7 \%$ after L-nitro-arginine. The duration of the peak and total responses, examined in separate sets of animals $(n=12)$, was similar in both circumstances ( $61 \pm 4 \mathrm{~s}$ before vs. $53 \pm 5 \mathrm{~s}$ after, and $7.45 \pm 0.61 \mathrm{~min}$ before vs. $7.48 \pm 0.64 \mathrm{~min}$ after respectively). These results suggest that a non-NO factor is responsible for acetylcholine-stimulated dilatation in the rat hindlimb vascular bed. 


\section{Introduction}

Acetylcholine is routinely chosen for the assessment of endothelial function. Although acetylcholine responses are often equated with stimulated nitric oxide production, various vasoactive factors, including prostaglandins and an unidentified endothelium-derived hyperpolarizing factor (EDHF) are released concomitantly upon acetylcholine stimulation. The extent to which nitric oxide (NO) actually contributes to this response in various vessels and vascular beds is not clear. Recent studies have shown the role of NO to vary greatly, depending on agonist, vascular bed, and vessel size (Hwa et al. 1994; Vargas, F et al. 1994; Zygmunt et al. 1994; Garland et al. 1995).

The present study was undertaken to investigate the contribution of NO to acetylcholine-stimulated dilatation in the buffer-perfused hindlimb vascular bed of the rat at physiological flows by examining the effect of NO synthase inhibition on acetylcholine vasodilator responses.

\section{Methods}

Hindlimb perfusion

Male Wistar rats (Iffa Credo, the Netherlands), 305-320 g, were anaesthetized (sodium pentobarbital; $60 \mathrm{mg} / \mathrm{kg}$ i.p.) and subjected to hindlimb perfusion as described previously (Nelissen-Vrancken et al. 1992). Briefly, after cannulation of the abdominal aorta and vena cava, perfusion with an isotonic, oxygenated KrebsHenseleit buffer containing $10 \mu \mathrm{M}$ indomethacin was initiated. After the animal was killed (intracardiac injection of $\mathrm{KCl}$ ), the flow was adjusted to $7.5 \mathrm{ml} / \mathrm{min}$ (electromagnetic probe, Skalar, Delft, the Netherlands). An on-line monitoring program (Hemodynamic Data Acquisition Systems, Instrumental Services, Universiteit Maastricht) was utilized to monitor flow ( $F=\mathrm{ml} / \mathrm{min})$ and pressure $(P=m m H g)$ and subsequently calculate resistance $(R=P / F)$. The values were sampled at $10 \mathrm{msec}$ intervals and averaged over one second. Experiments were conducted at $37^{\circ} \mathrm{C}$. Mediators were added into the perfusion circuit proximal to a stirring chamber.

\section{Protocol}

The hindlimb was precontracted $(20 \mathrm{mmHg})$ by phenylephrine infusion $(7.5 \mu \mathrm{M})$. After a non-cumulative acetylcholine dose-response curve $(0.10 \mathrm{ng}-10 \mu \mathrm{g}) \mathrm{had}$ been made, NO synthase was inhibited with $150 \mu \mathrm{g}$ L-nitro-arginine, a dose higher than the $\mathrm{ED}_{50}$ (see Results). When this reaction plateaued, a submaximal dose of acetylcholine $(10 \mu \mathrm{g})$ was again administered.

A separate set of experiments $(n=12)$ served to test the effect of L-nitroarginine on the time course of the acetylcholine response. To this end, the peak percentage dilatation (the maximum relative change in resistance), the duration 
of the peak dilatation, and the duration of the total response were analyzed. The progression of the response was plotted by averaging the percent dilatation for the first ten seconds of every minute and subsequently averaging these values for the various experiments:

\section{Materials}

The Krebs-Henseleit buffer was of the following composition (mM): $111 \mathrm{NaCl}, 5$ $\mathrm{KCl}, 1.2 \mathrm{KH}_{2} \mathrm{PO}_{4}, 25 \mathrm{NaHCO}_{3}, 1.25 \mathrm{CaCl}_{2}, 11.1$ glucose, and $40 \mathrm{~g} / \mathrm{l}$ dextran-70, pH 7.4. All salts were purchased from Merck (Amsterdam, the Netherlands); dextran-70, indomethacin and phenylephrine from Sigma (St. Louis, MO, USA); L-nitro-arginine from Research Biomedicals International (Natick, MA, USA); acetylcholine from Ciba Vision Ophta (Breda, the Netherlands).

\section{Data analysis}

The data are expressed as mean \pm S.E.M. Half-maximal effective dose $\left(E D_{50}\right)$ and maximal response values were obtained from the non-linear regression of individual dose-response curves. The values for all parameters defining the response induced by $10 \mu \mathrm{g}$ acetylcholine before and during NO synthase inhibition were compared by means of the paired Student's t-test, and were considered statistically significantly different at a value of $p<0.05$.

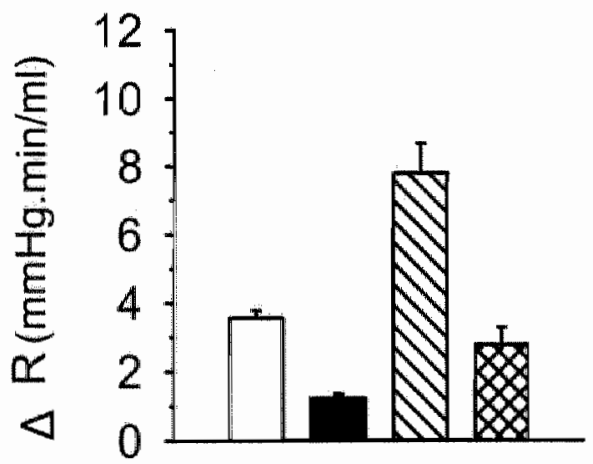

\section{Figure 6.1}

Vasodilator effect of $10 \mu \mathrm{gg}$ acetylcholine $(\mathrm{ACh})$ in the phenylephrine (Phe)-precontracted perfused rat hindlimb before and after $\mathrm{NO}$ synthase inhibition with $150 \mu \mathrm{g} \mathrm{L}$ nitro-arginine (L-NA). $\triangle R$ represents absolute changes in basal vascular resistance. Data are presented as mean S.E.M.; $n=7$.

\section{Results}

Perfusion of the rat hindlimb produced a low vascular tone $(3.53 \pm 0.15$ $\mathrm{mmHg} \cdot \mathrm{min} / \mathrm{ml}$ ) which was increased to $6.23 \pm 0.21 \mathrm{mmHg} . \mathrm{min} / \mathrm{ml}$ by infusion of 7.5 $\mu \mathrm{M}$ phenylephrine. Acetylcholine $(0.10 \mathrm{ng}-10 \mu \mathrm{g})$ dilated the phenylephrine- 
precontracted hindlimb in a dose-dependent manner with an $\mathrm{ED}_{50}$ of $8.2 \pm 2.2 \mathrm{ng}$ and a maximal dilatation of $71 \pm 2 \%(n=7)$.

Pilot experiments $(n=3)$ in which cumulative dose-response curves for L-nitroarginine were made, yielded a maximal increase in resistance of $9.98 \pm 1.31$ $\mathrm{mmHg} \cdot \mathrm{min} / \mathrm{ml}$ and an $\mathrm{ED}_{50}$ of $62 \pm 32 \mu \mathrm{g}$. The maximal contraction could be substantially reversed $(85 \pm 10 \%)$ with an infusion of excess of L-arginine $(10 \mu \mathrm{M})$.

Injection of $150 \mu \mathrm{g}$ L-nitro-arginine after completion of the acetylcholine curve induced a contraction which developed slowly over approximately 15 minutes and remained stable for the remainder of the experiment. Resistance increased by $3.67 \pm 0.39 \mathrm{mmHg} . \mathrm{min} / \mathrm{ml}$ (Figure 6.1).

As shown in Figure 6.1, acetylcholine $(10 \mu \mathrm{g})$ reduced the precontracted tone by $66 \pm 4 \%$ before NO synthase inhibition. Treatment with L-nitro-arginine had no effect on the peak response, as the subsequent injection of $10 \mu \mathrm{g}$ acetylcholine produced an unattenuated dilatation of $63 \pm 7 \%$.

In rats in which the time course of the acetylcholine dilatation was studied, the peak response was significantly increased after L-nitro-arginine $(77 \pm 3 \%$ vs. $84 \pm 3$ $\%$ respectively) (Figure 6.2 insert). The relative dilatation as a function of time was not significantly altered by NO synthase inhibition (Figure 6.2). The duration of the peak response and that of the total dilatation were similar, irrespective of NO synthase inhibition ( $61 \pm 4 \mathrm{~s}$ before vs. $53 \pm 5 \mathrm{~s}$ after, and $7.45 \pm 0.61 \mathrm{~min}$ before vs. $7.48 \pm 0.64 \mathrm{~min}$ after, respectively).

\section{Figure 6.2}

Effect of NO synthase inhibition with $150 \mu \mathrm{g} \mathrm{L}$ nitro-arginine on the time course of the acetycholine $(10 \mu \mathrm{g})$ response in the phenylephrineprecon-tracted perfused rat hindlimb. \% dilatation is the relative decrease in precontracted tone. Insert shows maximum percent dilatation. Data are presented as mean \pm S.E.M.; $n=7$. "p<0.05 compared to response before L-nitro arginine.

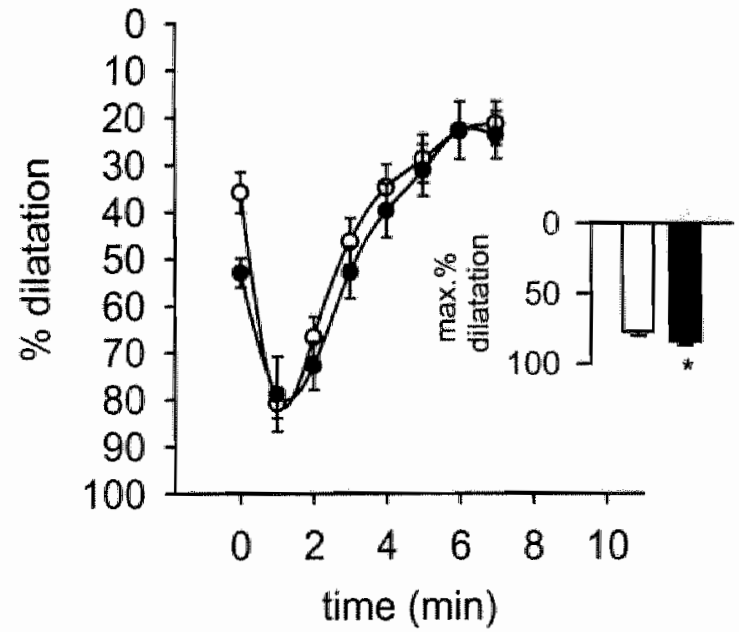




\section{Discussion}

In this study, the effect of NO synthase inhibition on vasodilator responses to acetylcholine in the perfused rat hindlimb was examined in order to find the contribution of NO to acetylcholine-stimulated dillatation in this vascular bed. Although NO synthase inhibition with L-nitro-arginine generated a considerable increase in vascular resistance, it had no effect on acetylcholine-induced responses.

The unaffected acetylcholine vasodilator capability during NO synthase inhibition that was now demonstrated is in agreement with results of several in vivo studies (Zambetis et al. 1991; Hu et al. 1994) and with the results of Mügge and co-workers (1991) for the blood-perfused hindlimb of the rabbit. In our preparation, however " possible interference from blood-borne substances or central effects could be avoided. Furthermore, our study supplements recent results in isolated vessels, which show a non-NO component of acetylcholine vasodilatation (Hwa et al: 1994; Zygmunt et al. 1994; Garland et al. 1995), by further demonstrating that NO plays only a minor role in these endothelium-dependent responses in an entire vascular bed at physiological flows.

Acetylcholine stimulates the release of several vasoactive agents including $\mathrm{NO}$, EDHF and prostaglandins. Although several studies have shown that prostacyclin contributes insignificantly to acetylcholine vasodilatation (Mügge et al. 1991; Vargas ef al. 1994), indomethacin was included in these experiments to avoid any interference from prostaglandins.

The production of NO has been shown to be specifically inhibited by L-arginine analogues, with L-nitro-arginine being one of the most potent (Vargas et al. 1991). As $L$-arginine was able to largely reverse the actions of $L$-nitro-arginine in our pilot experiments, it is most likely that specific inhibition of NO synthase occurred in this preparation. The incomplete irreversibility of the L-nitro-arginine-induced contraction and the large exceses of L-arginine required to attain it are probably due to the high affinity of L-nitro-arginine for NO synthase. These pilot experiments likewise demonstrated that the dose of L-nitro-arginine chosen was sufficient to ensure a considerable inhibition of NO synthase.

Nonetheless, the effects of NO synthase inhibition on the acetylcholine response might be tempered if an increased sensitivity to stimulated NO develops upon withdrawall of constitutively released NO. Although this has been noted by several authors (Mügge et al. 1991; Vargas et al. 1994), an inverse relationship between vasoconstrictor-induced tone and acetylcholine responsiveness has also been demonstrated (Dainty et al. 1990). In our preparation, although we observed a positive correlation between vascular tone and absolute changes in resistance, percentage changes remained unaffected. We cannot exclude the possibility that supersensitivity to NO contributed to the present findings, but the fact that L-nitro- 
arginine induced a considerable increase in resistance indicates that supersensitivity was not sufficient to outweigh the effects of inhibition.

It has been suggested that EDHF contributes to a transient component and NO to a longer-lasting component of the acetylcholine response (Hayashi et al. 1994; Vicaut et al. 1994). As such, NO synthase inhibition may only affect the duration and magnitude of the total response and have little effect on peak responses. In the present study, however, we found that NO synthase inhibition had no effect on the duration of either the total response or the peak response. Furthermore, the magnitude of the relative dilatation as a function of time remained unchanged. This suggests that NO plays a minor role in acetylcholine-stimulated dilatation in this preparation.

By default, our results suggest the importance of a non-NO, non-prostanoid component of endothelium-dependent dilatation in the rat hindlimb vasculature. Recent studies have suggested that EDHF, which is probably a cytochrome P450derived arachidonic acid metabolite (Bauersachs et al. 1994; Hecker ot al. 1994), plays a role in acetylcholine-induced vasodilatation in isolated vesseis and the perfused kidney (Hwa et al. 1994; Vargas et al. 1994; Zygmunt et al. 1994). Although NO appears to be the primary mediator of agonist-induced endothelium-dependent dilatation the aorta, it is becoming more apparent that its role is lessened as the periphery is approached (Zygmunt et al. 1994; Garland et al. 1995). Indeed, in isolated vessels of the rat mesentery. Hwa and co-workers (1994) have shown that, whereas acetylcholine-stimulated dilatation in the superior mesenteric arteries is largely due to NO, EDHF becomes the primary endothelium-dependent dilator in resistance vessels. As the total response of a vascular bed is primarily determined by resistance vessels, it seems likely that EDHF also participates in acetylcholineinduced vasodilatation of the perfused hindlimb.

in conclusion, the results of this study suggest that a non-NO, non-prostacyclin factor(s), such as EDHF, plays a major functional role in the acetylcholine vasodilator response of the non-blood-perfused rat hindlimb at physiological flows.

\section{References}

BAUERSACHS J, HECKER M \& BUSSE R (1994). Display of the characteristics of endothelium-derived hyperpolarizing factor by a cytochrome P450-derived arachidonic acid metabolite in the coronary microcirculation. Br. J. Pharmacol. 113, 1548-1553.

DAINTY IA, MCGRATH JC, SPEDding M \& TEMPLETON AGB (1990). The influence of the initial stretch and the agonist-induced tone on the effect of basal and stimulated release of EDRF. Br. J. Pharmacol. 100, 767-773.

Garland CJ, Plane F. Kemp BK \& COCKS TM (1995). Endothellum-dependent hyperpolarization: a role in the control of vascular tone. TIPS 16, 23-30. 
HAYASH K, LOUTZENHISER R, EPSTEIN M, SUZUKI H \& SARUTA T (1994). Multiple factors contribute to acetylcholine-finduced renal afferent arteriolar vasodilation during myogenic and norepinephrine- and $\mathrm{KCl}$-induced vasoconstriction - Studies in the isolated perfused hydronephrotic kidney. Circ. Res. $75,821-828$.

HECKER M, BARA AT, BAUERSACHS J \& BUSSE R (1994). Characterization of endotheliumderived hyperpolarizing factor as a cytochrome $\mathrm{P} 450$-derived arachidonic metabolite in mammals. J. Physiol $\mathbf{4 8 1 , 4 0 7 - 4 1 4 . ~}$

HU L, MANNING J RD \& BRANDS MW (1994). Long-term cardiovascular rolle of nitric oxide in conscious rats. Hypertension 23, 185-194.

HWA JJ, GHIBAUDI L, WILLIAMS P \& CHATTERJEE M (1994). Comparison of acetylcholinedependent relaxation in large and small arteries of rat mesenteric vascular bed. Am. J. Physiol. 266, H952-H958.

MUGge A, LOPEZ JAG, PIEGORS DJ, BREESE KR \& HEISTAD DD (1991). Acetylcholline induced vasodilation in rabbit hindlimb in vivo is not inhibited by analogues of L-arginine. Am. J. Physiol. 260, H242-H247.

NELISSEN-VRANCKEN HJMG, LEENDERS PJA, STRUIJKER BOUdIER HAJ \& SMITS JFM (1992). Increased responsiveness of the vascular bed to angiotensin I, angiotensin II and phenylephrine in acute and chronic ischemic hindlimbs in rats. J. Vasc. Res. 29, 359-366.

VARGAS F, SABIO JM \& DE DIOS LUNA J (1994). Contribution of endothelium-derived relaxing factors to acetylcholine induced vasodilation in the rat kidney. Cardiovasc. Res. $28,1373-1377$.

VARgas HM, Cuevas JM, IgnarRo LJ \& ChaudHuRI G (1991). Comparison of the inhibitory potencies of $\mathbb{N}^{G}$-methyl-, $\mathbb{N}^{G}$-nitro-and $\mathbb{N}^{\mathrm{G}}$-amino-L-arginine on EDRF function in the rat: evidence for continuous and basal EDRF release. J. Pharmacol. Exp. Ther. $257,12081215$.

VICAUT E, BAUDRY N \& HOU X (1994). Nitric oxide-independent response to acetylcholine by terminal arterioles in rat cremaster muscle. l. Appl. Physiol. 77, 526-533.

ZAMBETIS M, DUSTING GJ, RAJANAYAgam S \& WOODMAN OL (1991). Mechanism of the hypertension prodiuced by inhibition of nitric oxide biodsynthesis in rats. $J$. Cardiovasc. Pharmacol. 17(Suppl. 3). S191-S197.

ZYGMUNT PM, GRUNDEMAR L \& HOGESTATT ED (1994). Endothelium-dependent relaxation resistant to $\mathrm{N}^{\omega}$-nitro-L-arginine in the rat hepatic artery and aorta. Acta Physiol. Scand. 1994, 107-114. 


\title{
Effects of chronic infusion of L-NAME or angiotensin II on arterial structure and reactivity in the hindlimb of rats
}

\author{
D. L. Ceiler \\ H.J.M.G. Nelissen-Vrancken \\ J.G.R. De Mey \\ J.F.M. Smits
}

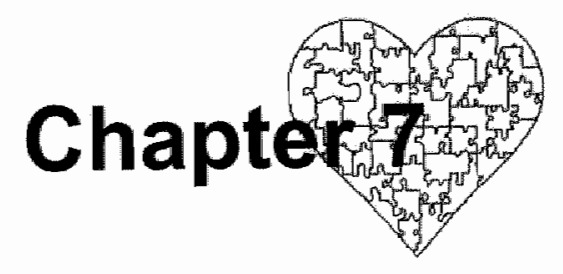




\section{Abstract}

This study was undertaken to assess the effect of chronic infusions of angiotensin II (ANG II) or an NO-synthase inhibitor (L-nitro-arginine methyl ester; L-NAME) on hindlimb vascular structure and reactivity. Wistar rats were infused s.c. with either ANG II (250 ng/ $/ \mathrm{kg} / \mathrm{min}$ ) or L-NAME ( $25 \mathrm{mg} / \mathrm{kg} /$ day) for two weeks, or received no treatment (CON). Thereafter, mean arterial pressure (MAP) was measured in resting rats, and the rats were subsequently subjected to hindlimb perfusion. Minimal vascular resistance following nitroprusside, responses to $35 \mathrm{mM}$ and $125 \mathrm{mM}$ potassium $\left(\mathrm{K}^{+}\right)$, and maximal resistance $\left(\Delta R_{\text {max }} ; 125 \mathrm{mM} \mathrm{K} K^{+}\right.$plus $3 \mathrm{mg}$ phenylephrine) were measured. In separate groups of rats, a resistance-sized side branch of the femoral artery was isolated and media cross-sectional area (CSA) was determined.

Chronic infusion of ANG $\|$ and L-NAME increased MAP to a similar extent (ANG \|: 156 18 ; L-NAME: $164 \pm 8$; CON: $121 \pm 3 \mathrm{mmHg}$ ). Neither infusion modified minimal resistance in the perfused hindlimb compared to CON. In ANG II rats, resistance responses to $35 \mathrm{mM} \mathrm{K}^{*}$ (ANG II: $3.4 \pm 0.3 ;$ CON: $7.3 \pm 0.7 \mathrm{mmHg} \cdot \mathrm{min} / \mathrm{ml}$ ) and $125 \mathrm{mM} \mathrm{K}{ }^{*}$ (ANG II: $17.5 \pm 1.0 \mathrm{CON}: 22.0 \pm 1.0 \mathrm{mmHg} \cdot \mathrm{min} / \mathrm{ml}$ ) were reduced, but $\Delta R_{\max }$ (ANG II: 29.1 $11.4 \mathrm{CON}: 27.9 \pm 1.7 \mathrm{mmHg} . \mathrm{min} / \mathrm{ml}$ ) was not modified. L-NAME infusion resulted in significantly decreased vasoconstrictor responses to $\mathrm{K}^{*}(35 \mathrm{mM}: 4.3 \pm 0.5 ; 125 \mathrm{mM}$ : $14.7 \pm 1.3 \mathrm{mmHg} \cdot \mathrm{min} / \mathrm{ml}$ respectively; $p<0.05)$, and in reduced $\Delta R_{\max }(17.5 \pm 1.3$

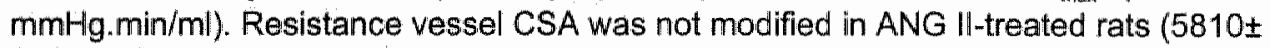
$\left.500 \mathrm{~mm}^{2}\right)$, but was significantly smaller in L-NAME-treated rats $\left(4140 \pm 600 \mathrm{~mm}^{2}\right)$ as compared to CON rats $\left(6280 \pm 300 \mathrm{~mm}^{2}\right)$.

We conclude that chronic infusion of ANG II induces a desensitization to depolarizing stimuli while maximal contractile ability is preserved. In contrast, chronic infusion of LNAME leads to a contractile hyporeactivity possibly due to a reduction in vascular smooth muscle mass. 


\section{Introduction}

Vasodilators and vasoconstrictors exert counter-regulatory influences on vascular tone, and this balance may be shifted in disease states such as hypertension and atherosclerosis (Lüscher et al. 1993). Vascular wall structure is similarly determined by the balance of growth-stimulating and growth-inhibiting (or death-stimulating) factors, and recent literature supports the role of some vasoconstrictor agents as growth promoters and vasodilator agents as growth inhibitors in settings in which blood flow is not drastically changed (Hahn at al. 1993; Adams et al: 1995; Duff et al. 1995; Mathew et al. 1996). We postulated that perturbing the vasodilator / vasoconstrictor balance may induce divergent effects on arterial structure and function independent of the pressure change. Thus, we intervened with two hormones thought to play an important role in the vasodilator/vasoconstrictor balance in hypertension, namely angiotensin II (ANG II) and nitric oxide (NO).

Experimental hypertension has been induced by chronic infusions of the vasoconstrictor peptide ANG II and chronic inhibition of basal NO production with NO synthase inhibitors. These two forms of experimental hypertension may display important common features. Chronic NO synthase inhibition with, for example, L-NAME has been shown to induce renal damage (Baylis ot al. 1992), increase plasma renin levels (Morton et al. 1993) and produce an ANG II-dependent form of hypertension (Pollock et al. 1993). Furthermore, both models have an important sympathetic component (Henegar et al: 1995; Sander et al. 1995).

Despite these similarities, both models display characteristic differences. Chronic infusion of ANG II has been shown to induce a slow rise in blood pressure (Griffin et al. 1991; Simon et al. 1995), and it has been suggested that this is due to vascular smooth muscle hypertrophy, in some but not all vessels (Griffin et al. 1991; Simon et al. 1995; Wiener et al. 1996; Stassen et al. 1997b). On the other hand, L-NAME administration does not consistently lead to vascular smooth muscle growth (Morton et al. 1993; Li \& Schriffin, 1994; Swentek et al. 1997). Furthermore, while ANG II infusions may result in a vascular hyper-reactivity due to increased vascular mass (Boonen et al. 1993; Stassen et al. 1997b), both vascular hyper- and hypo-reactivity have been demonstrated after chronic L-NAME administration (Li \& Schriffin, 1994; Dowell et al. 1996; Henrion et al. 1996).

Thus, the present study examines arterial structure and function under similar experimental settings after the vasodilator/vasoconstrictor balance has been altered by either tempering the influence of the vasodilator $\mathrm{NO}$ or enriching that of the vasoconstrictor ANG II. Accordingly, Wistar rats were therefore infused with ANG II or L-NAME for two weeks and thereafter subjected to hindlimb perfusion. Minimal vascular resistance of the hindlimb and media cross-sectional area of a resistance-sized artery were determined to assess vascular network and structure 
characteristics. Responses to potassium and maximal changes in resistance were measured as indicators of vascular contractile function.

\section{Methods}

\section{Animals and treatment}

Male Wistar rats $270-290 \mathrm{~g}$. Iffa Credo, Someren, the Netherlands) were housed under standard conditions $\left(20^{\circ} \mathrm{C}, 12\right.$-hour light/dark cycle) and given free access to standard chow (Hope Farms, Woerden, the Netherlands) and tap water. The experimental procedures were performed according to institutional guidelines and approved by the Ethical Committee for the Use of Experimental Animals of our university.

Animals were randomly chosen to receive treatment with angiotensin $\|$ (ANG II) or L-nitro-arginine-methyl-ester (L-NAME), or to serve as control (CON) animals. An osmotic mini-pump (2002, Alzet, Alza Co, Palo Alto, CA, USA) administering either $250 \mathrm{ng} / \mathrm{kg} / \mathrm{min}$ ANG $\|$ or $25 \mathrm{mg} / \mathrm{kg} /$ day L-NAME was implanted s.c. at the base of the neck under ether anesthesia. Treatment lasted for two weeks. CON animals were not treated.

\section{Measurement of blood pressure in conscious rats}

On treatment day 12, the rats were anesthetized with pentobarbital (60 mg/kg i.p.) and equipped with an arterial catheter (PE 50) implanted in the left carotid artery and aimed to terminate at the junction with the aortic arch. Saline-filled catheters were guilded subcutaneously to the base of the neck, exteriorized, and sealed with a metal plug.

Mean arterial pressure (MAP) was measured in quietly resting rats on day 14 via a pressure transducer (CP-01, Century Technology Co., Inglewood, CA, USA) in conjunction with an on-line monitoring computer program (Hemodynamic Data Acquisition Systems, Instrumental Services, Universiteit Maastricht).

\section{Hindimb perfusion}

Rats were anesthetized with sodium pentobarbital (60 mgikg i.p.) and subjected to hindlimb perfusion as described previously (Nelissen-Vrancken et al. 1992). Briefly, after opening the abdomen, all side branches of the aorta and vena cava distal to the kidneys and proximal of the iliac bifurcation were ligated. The caudal artery and the seminal vesicles were likewise ligated. Upon cannulation of the abdominal aorta, perfusion with an isotonic, oxygenated $\left(95 \% \mathrm{O}_{2} / 5 \% \mathrm{CO}_{2}\right)$ Krebs-Henseleit buffer via a wind kettle was initiated. Eluate was collected from a cannula implanted in the vena cava. The animals were killed (intracardiac injection of a saturated $\mathrm{KCl}$ solution), the flow adjusted to $7.5 \mathrm{ml} / \mathrm{min}$, and the hindlimbs flushed of all blood for approximately half an hour before starting experimentation. During 
this time, resistance in the hindlimb gradually dropped to a plateau level. The aforementioned on-line monitoring program was utilized to monitor flow $(F ; 1 \mathrm{~mm}$ diameter flow-through electromagnetic flow probe, Skalar, Delft, the Netherlands) and pressure (P; CP-01, Century Technology $\mathrm{Ca}$ ) and concurrently calculate resistance $(R=P / F)$. Drugs were administered proximal to a mixing chamber and experiments were performed at $37^{\circ} \mathrm{C}$.

\section{Experimental protocol}

Minimal resistance was induced by two subsequent injections of $500 \mathrm{mg}$ sodium nitroprusside (SNP). Afterwards, an infusion of a $\mathrm{KCl}$ solution was used to determine responses to $35 \mathrm{mM} \mathrm{K}^{+}$and $125 \mathrm{mM} \mathrm{K}^{*}$. Since flow pulsatility and rate fluctuations were eliminated by directing the perfusate through a wind kettle which had a volume of approximatley $80 \mathrm{ml}$, establishing equilibrium with new perfusates containing osmotically-balanced high potassium was practically impossible. Thus, high concentration $\mathrm{KCl}$ solutions were infused to achieve equilibrium concentrations of $35 \mathrm{mM}$ and $125 \mathrm{mM} \mathrm{K}^{+}$at the set flow rate 7.5 $\mathrm{ml} / \mathrm{min}$. Both control and treated animals were subjected to this hyperosmolarity, and the time required for establishing equilibrium with $35 \mathrm{mM}$ and $125 \mathrm{mM} \mathrm{K}^{+}$was not different between groups. A $3 \mathrm{mg}$ bolus injection of phenylephrine (Phe) was then administered on top of the $125 \mathrm{mM} \mathrm{K}$ response in order to determine maximal resistance $\left(R_{\max }\right)$. This dose of Phe is 100 times greater than the dose shown to induce a maximal $\alpha_{1}$-adrenergic vasoconstriction in a previous study (Nelissen-Vrancken et al. 1992).

\section{Contribution of sympathetic nerves}

In another group of rats, the contribution of the sympathetic varicosities to the contractile response upon depolarizing stimulation was determined. According to the method of Aprigliano and Hermsmeyer (1977), rats were sympathectomized with two i.p. injections of $50 \mathrm{mg} / \mathrm{kg} \mathrm{6-hydroxydopamine} \mathrm{three} \mathrm{hours} \mathrm{apart} \mathrm{and}$ subjected the next day to hindlimb perfusion as described above. Successful sympathectomy was indicated by the absence of glyoxylic acid staining of highly innervated mesenteric resistance vessels as described elsewhere (Stassen et al. 1997b). These vessels were chosen since hindlimb perfusion made it impossible to sampie vessels from this vascular bed.

\section{Histology}

In separate groups of rats, a resistance-sized side-branch (lumen diameter \pm 150 $\mathrm{mm}$ ) of the femoral artery, the arteria genu supreme, was isolated at atmospheric pressure at approximately $5 \mathrm{~mm}$ from its junction with the femoral artery (Bund ot al. 1991). The isolated vessel was immersion-fixed in $4 \%$ phosphate-buffered fomaldehyde before being processed for histological examination. Arterial 
segments were embedded in paraffin, and Lawson's solution (Boom B.V., Meppel, the Netherlands) was used to stain the internal and external elastic laminae in 4 $\mathrm{mm}$ cross-sections. The elastic lamina were visualized using a Zeiss Axioscope (Zeiss, Germany) and a standard CCD camera (Stemmer, Germany), and media cross-sectional area (CSA) was calculated by subtracting the area enclosed by the internal elastic lamina from the area enclosed by the media-adventitial border by using commercial software (JAVA 1.21, Jandel Scientific, Corte Madera, CA, USA), as described previously (Stassen et al. 1997a).

\section{Materials}

The Krebs-Henseleit buffer was of the following composition $(\mathrm{mM}): 111 \mathrm{NaCl}, 5$ $\mathrm{KCl}, 1.2 \mathrm{KH}_{2} \mathrm{PO}_{4}, 25 \mathrm{NaHCO}_{3}, 1.25 \mathrm{CaCl}_{2}, 11.1$ glucose, and $40 \mathrm{~g} / \mathrm{l}$ dextran-70, $\mathrm{pH} 7.4$. Dextran levels were limited to $4 \%$ to prevent electromagnetic flow probe drift. All inorganic salts were purchased from Merck (Amsterdam, the Netherlands); dextran-70, L-NAME, L-arginine, Phe and 6-hydroxydopamine from Sigma (St: Louis, MO, USA); [Val'5]-ANG II from Saxon Biochemicals (Hannover, Germany).

\section{Data analysis}

Constriction values are expressed as absolute changes in resistance. Groups were compared non-parametrically by a Kruskal Wallis test for multiple comparisons. Differences were considered to be statistically significant at a value of $p<0.05$. All data are expressed as mean $\pm S$.E.M.

Table 7.1 General characteristics of experimental groups.

\begin{tabular}{|c|c|c|c|}
\hline & $n$ & body weight $(g)$ & MAP $(\mathrm{mmHg})$ \\
\hline CON & 21 & $279 \pm 3$ & $121 \pm 3$ \\
\hline L-NAME & 14 & $277 \pm 5$ & $164 \pm 8^{*}$ \\
\hline ANG II & 17 & $257 \pm 8^{\star}$ & $156 \pm 5^{*}$ \\
\hline
\end{tabular}




\section{Results}

Chronic infusion of ANG II and L-NAME increased MAP compared to untreated rats (Table 7.1). The extent of MAP elevation was comparable for ANG $\|$ and the NO synthase inhibitor. ANG II-infused rats weighed significantly less than rats in the other two groups (Table 7.1). Basal tone in the perfused hindlimb was low as indicated by the low baseline resistances (CON: $3.6 \pm 0.2 \mathrm{mmHg} . \mathrm{min} / \mathrm{ml}$; L-NAME: $3.7 \pm 0.1 \mathrm{mmHg} \cdot \mathrm{min} / \mathrm{ml}$; ANG II: $3.7 \pm 0.1 \mathrm{mmHg} \cdot \mathrm{min} / \mathrm{ml}$ ), which corresponds to perfusion pressures around $25-30 \mathrm{mmHg}$. Consequently, nitroprusside induced only a $\pm 8 \%$ vasodilatation in the hindlimbs of both treated and control animals. Neither treatment had an effect on minimal vascular resistance (Figure 7.1, panel a). Histological findings are also presented in Figure 7.1. Media CSA of the resistance-sized side branch of the femoral artery was smaller in L-NAME treated rats than in CON rats $\left(4140 \pm 600 \mathrm{~mm}^{2}\right.$ vs. $\left.6280 \pm 300 \mathrm{~mm}^{2}\right)$; ANG II infusion was without effect $\left(5810 \pm 500 \mathrm{~mm}^{2}\right)$.

a.

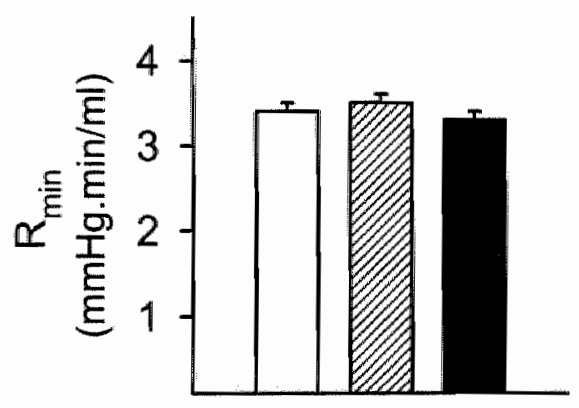

b.

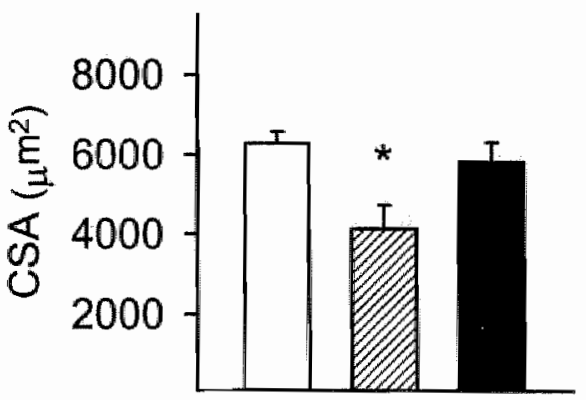

Figure 7.1

Effect of chronic infusions of L-NAME ( $25 \mathrm{mg} / \mathrm{kg} /$ day; hatched bars; $\mathrm{m}=7$ panel $a$; and $b$ ) or angiotensin II ( $250 \mathrm{ng} / \mathrm{kg} / \mathrm{min}$; closed bars; $n=7$ panel a; $n=10$ panel b) on minimal resistance $\left(\mathrm{R}_{\mathrm{min}}\right.$; panell a) and media cross-sectional area (CSA; panell b) of a resistance-sized side branch of the femoral artery. Open bars represent control rats ( $n=7$ panel $a ; n=12$ panel b). Drugs were infused s.c. via osmotic mini-pumps for two weeks. Mean \pm S.E.M. "p<0.05 vs. control.

As shown in Figure 7.2, the increase in resistance induced by $35 \mathrm{mM} \mathrm{K}$ was reduced following L-NAME $(4.3 \pm 0.5 \mathrm{mmHg} \cdot \mathrm{min} / \mathrm{ml})$ and ANG $\|(3.4 \pm 0.3$ $\mathrm{mmHg} \cdot \mathrm{min} / \mathrm{ml}$ ) versus CON rats $(7.1 \pm 0.9 \mathrm{mmHg} \cdot \mathrm{min} / \mathrm{ml})$. Likewise, responses to $125 \mathrm{mM} \mathrm{K}{ }^{+}$were smaller in L-NAME- and ANG $\|$infused rats $(14.7 \pm 0.5$ and $17.5 \pm 1.0 \mathrm{mmHg} . \mathrm{min} / \mathrm{ml}$ respectively vs. $21.6 \pm 1.2 \mathrm{mmHg} \cdot \mathrm{min} / \mathrm{ml}$; Figure 7.2). Although $\Delta \mathrm{R}_{\max }$, i.e., the response to $125 \mathrm{mM} \mathrm{K}^{+}$plus $3 \mathrm{mg}$ Phe was similar in 


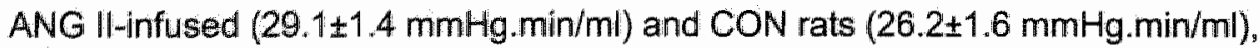
$\Delta R_{\text {riax }}$ was significantly lower in L-NAME-treated rats $(17.5 \pm 1.3 \mathrm{mmHg} . \mathrm{min} / \mathrm{ml}$; Figure 7.2),

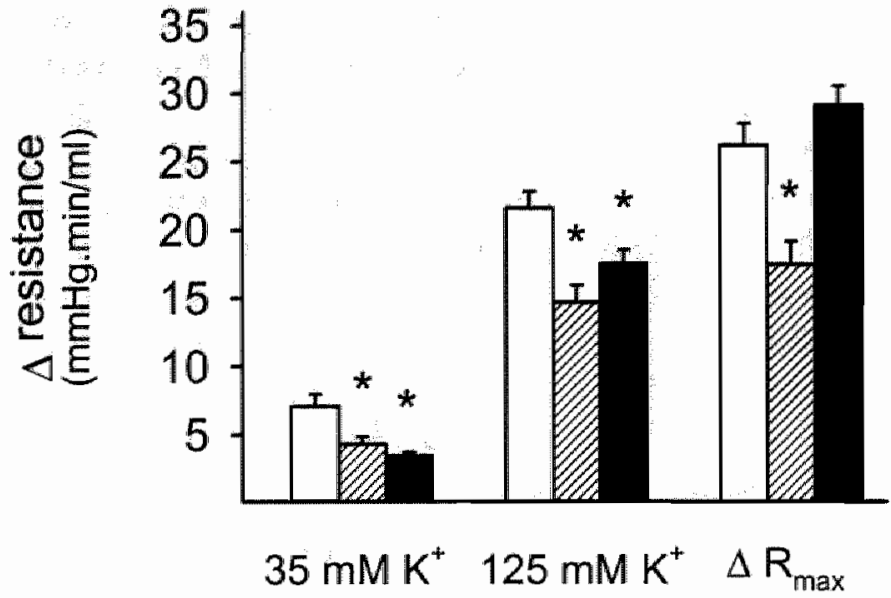

Figure 7.2

Absolute changes in resistance in the perfused hindlimb generated by the infusion of $35 \mathrm{mM} \mathrm{K}$ and $125 \mathrm{mM} \mathrm{K}^{*}$ and the induction of maximal resistance $\left(\Delta \mathrm{R}_{\mathrm{rnax}} ; 125 \mathrm{mM} \mathrm{K}^{*}\right.$ and subsequent 3 $\mathrm{mg}$ phenylephrine bolus) Open bars, control rats, $(n=7)$; hatched bars, rats receiving 25 $\mathrm{mg} / \mathrm{kg} /$ day L-NAME $(\mathrm{n}=7)$; closed bars, rats receiving $250 \mathrm{ng} / \mathrm{kg} / \mathrm{min}$ angiotensin $\|(\mathrm{n}=7)$. Drugs were infused s.c. via osmotic mini-pumps for two weeks. Mean $\pm S . E . M .{ }^{*} p<0.05$ vs. control.

The ratio of the $35 \mathrm{mM} \mathrm{K}^{+}$and the $125 \mathrm{mM} \mathrm{K}^{+}$responses was used as an indication of the sensitivity to potassium-induced constriction. Potassium sensitivity was reduced in ANG II-treated $(0.20 \pm 0.02)$, but not in L-NAME-treated rats $(0.31 \pm 0.06)$ compared to CON rats $(0.33 \pm 0.03$; Figure $7.3 a)$. The contribution of Phe to $\Delta R_{\max }$ was calculated as the resistance increase upon Phe injection relative to $\Delta R_{\max }$. As shown in Figure $7.3 \mathrm{~b}$, the Phe component of $\Delta R_{\max }$ was increased in the ANG II-infused rats $(0.40 \pm 0.02$ vs. $0.18 \pm 0.03$ in CON).

Sympathectomy reduced the response to $35 \mathrm{mM} \mathrm{K}^{+}(4.1 \pm 0.9 \mathrm{mmHg} \cdot \mathrm{min} / \mathrm{ml})$, and to $125 \mathrm{mM} \mathrm{K}(15.6 \pm 0.8 \mathrm{mmHg} \cdot \mathrm{min} / \mathrm{ml})$ as well as $\Delta R_{\max }(20.8 \pm 0.9$ $\mathrm{mmHg} \cdot \mathrm{min} / \mathrm{ml})$, but had no effect on potassium sensitivity $(0.26 \pm 0.06)$ or the relative Phe contribution $(0.25 \pm 0.03)$ versus $C O N$. 


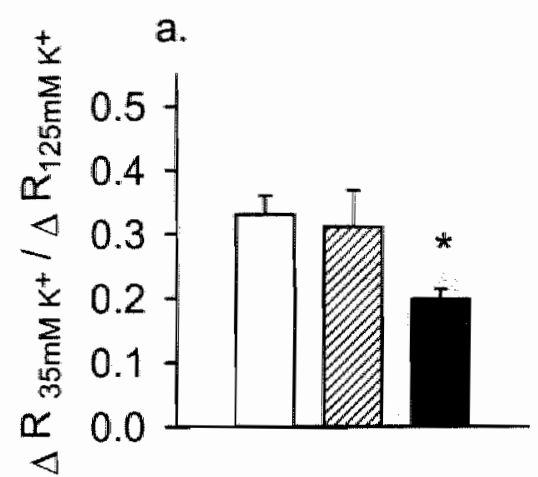

b.

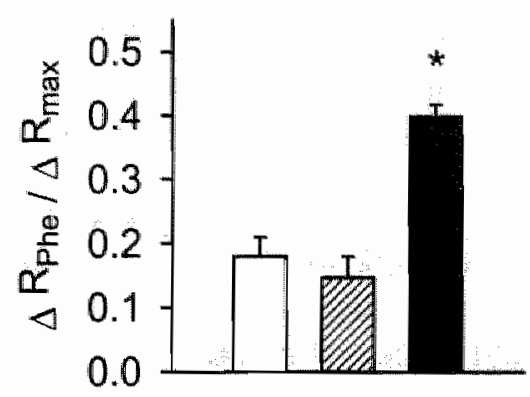

Figure 7.3

Effect of chronic infusion of L-NAME (25 mg/kg/day) or angiotensin II (ANG II; $250 \mathrm{ng} / \mathrm{kg} / \mathrm{min}$ ) on $\mathrm{K}^{*}$ sensitivity (panel a) and the contribution of phenylephrine (Phe) to maximal responses (panel $b$ ) in the perfused hindlimb. The ratio of the resistance change $(\Delta R)$ induced by $35 \mathrm{mM}$ and $125 \mathrm{mM} \mathrm{K}^{+}$is presented as an indication of potassium sensitivity. The contribution of Phe to the maximal resistance $\left(\Delta R_{\max }\right)$ response is calculated as the resistance increase after Phe injection $\left(\Delta R_{\text {pha }}\right)$ relative to $\Delta R_{\text {max }}$. Open bars, control rats $(n=7)$; hatched bars, $L-N A M E-$ treated rats $(n=7)$; closed bars, ANG ll-treated rats $(n=7)$. Drugs were infused s.c. via osmotic minipumps for two weeks. Mean \pm S.E.M. *p<0.05 vs. control.

\section{Discussion}

The results of the present study demonstrate that experimental hypertension induced by chronic infusion of ANG II or L-NAME have divergent effects on hindlimb vascular structure and function, suggesting that the agents have differential effects on vascular smooth muscle that are not solely related to the elevation in arterial pressure, which was similar in both models.

The administered dosage of ANG II generates plasma concentrations of approximately $140 \mathrm{pg} / \mathrm{ml}$ (Stassen et al. 1997b). This concentration is comparable to that seen at one week after myocardial infarction in rats (Stassen et al. 1997c) and in the developmental phase of two kidney-one clip hypertension (Von Thun et a/. 1994). Nonetheless, after the two-week ANG II infusion, rats were significantly lighter than their untreated counterparts. This weight loss may be due to the anorexigenic effects of ANG II through depression of circulating insulin growth factor I levels (Faggiano, 1994).

Despite the fact that several studies suggest that NO synthase inhibition induces an ANG II-dependent hypertension probably due to renal damage (Baylis et al. 1992; Pollock et al. 1993), other investigators in our group did not observe elevated plasma ANG II levels after two-week L-NAME infusion $14 \pm 8 \mathrm{pg}$ ANG $\mathrm{II} / \mathrm{ml}$ plasma in L-NAME-infused rats (personal communication S. Heeneman); $23 \pm 6 \mathrm{pg}$ 
ANG $1 / / \mathrm{ml}$ in CON; $138 \pm 49 \mathrm{pg}$ ANG $11 / \mathrm{ml}$ plasma in chronically ANG $\|$-infused rats (Stassen al 1997b)), which indicates that we studied two different forms of hypertension. Nonetheless, the degree of hypertension which was generated by the present interventions $( \pm 160 \mathrm{mmHg})$ is comparable to that seen in spontaneously hypertensive and renin transgenic rats (Struijker Boudier et al. 1996) and lower than that reported for renal hypertensive rats (Deng \& Schriffin, 1991).

\section{Hindlimb vascular structure and network characteristics}

Despite heightened mean arterial pressures, we failed to observe hypertrophy in a resistance-sized side-branch of the femoral artery with either treatment. On the contrary, resistance vessel hypotrophy was noted in L-NAME-infused rats. Although NO has been imputed as a possible anti-trophic and apoptotic agent (Fukuo et al. 1996; Messmer et al. 1996), it is possible that removal of the growthinhibiting actions of NO was insufficient to stimulate growth. On the other hand, hypotrophy of vessels is a phenomenon often observed after chronic reductions in blood flow. Since significantly decreased flows to the hindlimb have been reported during NO synthase inhibition (Gardiner et al. 1990), reduced flow may be responsible for the observed hypotrophic response after L-NAME administration.

On the other hand, we recently suggested that perivascular innervation is a prerequesite for pressure-independent ANG II-induced vascular hypertrophy (Stassen et al. 1997b). Although sympathetic nerves contribute to vascular tone in the hindlimb, as demonstrated by the effects of sympathectomy in this study, the femoral resistance vessel which we isolated is only sparsely innervated (Stassen et al. 1997b). This sparse innervation may explain our failure to find hypertrophy in this vessel.

Although analysis of one vessel is in no way characteristic of an entire vascular bed, minimal vascular resistance, which better describes vascular bed perfusion characteristics, was also not altered by chronic infusion of angiotensin II or LNAME. Combining the histological and minimal resistance data with the lack of increase in vascular constrictor responses implies that, in terms of the entire vascular bed, neither vascular wall mass nor media-to-lumen ratio were increased by either angiotensin II or L-NAME treatment in a two week period, as suggested by Folkow et al. (1970), Schriffin (1992), and Agabiti Rosei et al. (1995). Thus, the increased peripheral resistance (ascertained from mean arterial pressure) during the two week experimental period is purely functional in nature, neither being caused by nor causing peripheral vascualr hypertrophy.

Minimal vascular resistance is dependent on the length, maximal lumen diameter and branching pattern of vessels in a vascular bed and is thus an indication of total network characteristics. Folkow and coworkers demonstrated that increased minimal vascular resistance may be important in the development and maintenance of hypertension in spontaneously hypertensive (SHR) and renal 
hypertensive rats (Folkow \& Karlström, 1984; Folkow et al. 1992). Several aspects may account for the apparent paradox concerning the value of minimal resistance in experimental hypertension in the previous and the present work. First of all, the percentile difference in minimal resistance in young SHR and Wistar-Kyoto control rats used by Folkow and associates (1984) was already established before the onset of hypertension, suggesting that genetic factors may contribute to the aberrant vascular structure in the SHR. The differences between the ANG IIinfused rats in the present study and the aforementioned two-kidney, one-clip renal hypertensive rats (Folkow et al. 1992), which are also characterized by increased plasma levels of ANG II, are more difficult to resolve, but may lie in the nature of perfusate used. Folkow and coworkers (1992) perfused with a solution containing horse serum which may contain vasoconstrictors, such as serotonin (De Mey et al. 1989), and differentially affect the assessment of minimal resistance in control and hypertensive rats.

Additionally, since minimal vascular resistance is dependent on a multitude of factors, counteractive changes in the vascular network may occur. For instance, the effects of pressure-induced rarefaction might be nullified by ANG II-induced (Struijker Boudier et al. 1990; Le Noble et al. 1991) or NO-induced (Ziche et al. 1994; Morbidelli et al. 1996) angiogenesis. All in all, these results suggest that increased arterial pressure, per se, is not sufficient to induce changes in minimal vascular resistance.

\section{Hindlimb vasoconstrictor function}

Hypertension induced by chronic NO synthase inhibition has been shown to have a neural component due to the removal of the inhibitory actions of NO from neuronal nitric oxide synthase on sympathetic activity (Sander et al. 1995). Thus, the functional hyporeactivity induced by chronic L-NAME administation may share similarities with decreased vascular responsiveness seen after chronic catecholamine infusion (Johnson et al. 1991; Boonen et al. 1993). Nonetheless, the cellular mechanisms debilitating vascular responsiveness remain unclear. In two recent studies by the group of Michel (Dowell et al. 1996; Henrion ot al 1996), vasoconstrictor responses in the aorta and mesenteric resistance arteries to various agonists were reduced after chronic L-NAME treatment. However, these responses were not different from those in control rats when normalized to the decreased response to $125 \mathrm{mM}$ potassium, suggesting aspecific contractile dysfunction. An aspecific decrease in contractile responses suggests that dysfunction of the contractile apparatus contributes to vascular hyporeactivity after chronic inhibition of NO synthase. Furthermore, the aforementioned reduction in vascular wall mass may also contribute to general functional hyporeactivity. Interestingly, similar reductions in vascular wall mass and vascular contractile responsiveness have been observed after chronic reductions in blood flow, in 
which shear stress-induced NO release is also reduced (Pourageaud \& De Mey, 1997).

While L-NAME infusion lead to general contractile hyporeactivity, ANG II infusion resulted in hyposensittivity and hyporeactivity to potassium but enhanced responses to phenylephrine. Microvascular injury, as noted with ANG II in the mesenteric vascular bed (Wiener et al: 1996), seems not to be involved in these changes because the maximal constrictor responses were not altered in the hindquarter circulation. Reduced sensitivity to potassium may find its origin in the chronic effects of ANG II on cellular $\mathrm{Na}^{+}$handling. ANG II has been shown to stimulate the $\mathrm{Na}^{+}-\mathrm{H}^{+}$antiporter which leads to an activation of the electrogenic $\mathrm{Na}^{+}$ pump and thus cellular hyperpolarization (Smith, 1986; Simon, 1992).

Maximal constrictor responses to potassium result from depolarization of both vascular smooth muscle cells and perivascular sympathetic nerves. The contribution of a neurogenic component is confirmed by the observations following sympathectomy. Reduced responses to $125 \mathrm{mM}$ potassium after chronic ANG II infusion may thus be due to the prolonged stimulation of the sympathetic system by the peptide leading to sympathetic nerve depletion. This has been previously suggested for two kidney-one clip rats (Webb et al. 1983) and for rats with myocardial infarction (Stassen et al. 1997b, c), both of which are characterized by elevated circulating levels of ANG II. Reduced release of endogenous catecholamines may thus account for the elevated response to exogenously supplied phenylephrine in the presence of $125 \mathrm{mM}$ potassium. Clearly these suggestions will have to be verified in future dedicated experiments.

In conclusion, different models of drug-induced hypertension induce discrepant vascular functional and structural changes in the perfused rat hindiimb. While chronic L-NAME treatment leads to vascular hyporeactivity possibly due to hypotrophy, chronic ANG II infusions may lead to functional changes in the absence of structural alterations. It is interesting to consider these results in the scope of essential hypertension, in which treatment regimes have been known to have inconsistent effects within a population. Since the epidemiology of essential hypertension is multi-factorial, diverse structural and functional alterations may be prominent and relevant in the differing effectiveness of anti-hypertensive agents among patients.

\section{References}

ADAMS MA, THOMPSON KE, BANTING JD, MADIGAN MA \& FrIBERg P (1995). Evidence for in vivo induction of cardiovascular growth processes by vasoconstrictor systems. Blood. Press. Suppl. 2, 61-67.

Agabiti Rosel E, Rizzoni D, Castellano M, Porteri E, Zulli R, Muiesan ML, Bettoni G, SALVETTI M, MUIESAN P \& GIULINI SM (1995). Media:lumen ratio in human small 
resistance arteries is related to forearm minimal vascular resistance. $J$ Hypertens. 13 , $341-347$.

APRIGLIANO O \& HERMSMEYER K (1977). Trophic influence of the sympathetic nervous system on the rat portal vein. Circ. Res. 41, 198-206.

BAYLIS C, MITRUKA B \& DENG A (1992). Chronic blockade of nitric oxide synthesis in the rat produces systemic hypertension and glomerular damage. J. Clin. Invest. 90, 278281.

BoONen HCM, DAEMEN MJAP, EERDMANS PHA, FAZZI GE, VAN KLEEF EM, SCHIfFERS PMH \& DE MEY JGR (1993). Mesenteric small artery changes after vasoconstrictor infusion in young rats. J. Cardiovasc. Pharmacol. 22, 388-395.

BUND SJ, WEST KP \& HEAGERTY AM (1991). Effects of protection from pressure on resistance artery morphology and reactivity in spontaneous hypertensive and WistarKyoto rats. Circ. Res. $68,1230-1240$.

DE MEY JG, UITENDAAL MP, BOONEN HC, VRIJDAG MJ, DAEMEN MJ \& STRUIJKER BOUDIER $H A$ (1989). Acute and long-term effects of tissue culture on contractile reactivity in renal arteries of the rat. Circ. Res. 65, 1125-1135.

DENG LY \& SCHRIFFIN EL (1991). Morphological and functional alterations of mesenteric small resistance arteries in early renal hypertension in rats. Am. J. Physiol. 261, H1171. $\mathrm{H} 1177$.

DOWELL FJ, HENRION D, DURIEZ M \& MiCHEL J-B (1996). Vascular reactivity in mesenteric resistance arteries following chronic nitric oxide synthase inhibition in Wistar rats. $\mathrm{Br}$. $J$. Pharmacol. 117, 341-346.

DufF JL, MARRERo MB, PAXTON WG, SCHIEFFER B, BERNSTEIN KE \& BERK BC (1995). Angiotensin II signal transduction and the mitogen-activated protein kinase pathway. Cardiovasc. Res. 30, 511-517.

FAGGIANO P (1994). Abnormalities of pulmonary function in congestive heart failure. Int. J. Cardiol. 44, 1-8.

FOLKOW B \& KARLSTROM G (1984). Age- and pressure-dependent changes of systemic resistance vessels concerning the relationships between geometric design, wall distensibility, vascular reactivity and smooth muscle sensitivity. Acta Physiol. Scand. $122,17-33$.

FOLKOW B, HALLBACKK M, LUNDGREN Y \& WEISS L (1970). Background of increased flow resistance and vascular reactivity in spontaneously hypertensive rats. Acta Physiol. Scand. 80, 93-106. 
FOLKON B, ISAKSSON OGP, KARLSTROM G, LEVER AF \& NORDLANDER M (1992). Trophic effects of hypophyseal hormones on resistance vessels and the heart in normotensive and renal hypertensive rats. Acta Physiol. Scand, 144, 291-306.

FUKUO K, SUHARA T, NAKAHASHI T, SHINTO Y, TSUJIMOTO Y, MORIMOTO S \& OGIHARA T (1996). Nitric oxide induces upregulation of Fas and apoptosis in vascular smooth muscle. Hypertension 27, 823-826.

GARDINER SM, COMPTON AM, BENNETT T, PALMER RMJ \& MONCADA S (1990). Control of regional blood flow by endothelium-derived nitric oxide. Hypertension 15, 486-492.

Griffin SA, Brown WCB, MacPherson F, McGrath JC, WILson VG, Korsgatrd N, MULVANY MJ \& LEVER AF (1991). Angiotensin II causes vascular hypertrophy in part by a non-pressor mechanism. Hypertension 17, 626-635.

HAHN AWA, RESINK TJ, KERN F \& BÜHLER FR (1993). Peptide vasoconstrictors, vessel structure, and vascular smooth-muscle proliferation. J. Cardiovasc. Pharmacol. 22(Suppl. 5), S37-S43.

HENEGAR JR, BROUWER GL, KABOUR A \& JANICKI JS (1995). Catecholamine response to chronic ANG II infusion and its role in myocyte and coronary vascular damage. Am. J. Physiol. 269, $\mathrm{H} 1564-\mathrm{H} 1569$.

HENRION D, DOWELL FJ, LEVY BI \& MICHEL J-B (1996). In vitro alteration of aortic vascular reactivity in hypertension induced by chronic $\mathrm{N}^{\mathrm{G}}$-nitro-L-arginine methyl ester. Hypertension 23, 361-366.

JOHNSON MD, MCMILLIAN MK \& SCHANBERG SM (1991). Alterations on cardiovascular responsiveness and adrenoceptor binding during catecholamine infusion hypertension in rats. Proc. Soc. Exp. Biol. Med. 197, 67-73.

LANGILLE BL \& O'DONNELL F (1986). Reductions in arterial diameter produced by chronic reductions in blood flow are endothelium-dependent. Science 231, 405-407.

LE NOBLE FAC, HeKKING JWM, VAN STRAATEN HWM, SLAAF DW \& StRUIJKER BOUdier HAJ (1991). Angiotensin II stimulates angiogenesis in the chorio-allantoic membrane of the chick embryo. Eur. J. Pharmacol. 195, 305-306.

LI J-S \& SCHRIFFIN EL (1994). Resistance artery structure and neuroeffector mechanisms in hypertension induced by inhibition of nitric oxide synthase. $A m$. J. Hypertens. 7, 996-1004.

LÜSCHER TF, BOULANGER CM, YANG Z, NOLL G \& DOHI Y (1993). Interactions between endothelium-derived relaxing factors in health and cardiovascular disease. Circulation 87(Suppl. 5), V36-V44. 
MATHEW V, HASDAI D \& LERMAN A (1996). The role of endothellin in coronary atherosclerosis. Mayo Clinic Proceedings 71, 769-777.

MESSMER UK, REED UK \& BRUNE B (1996). BCl-2 protects macrophages from nitric oxide-induced apoptosis. J. Biol. Chem. 271, 20192-20197.

Morbidelli L, Chang CH, Douglas JG, Granger HJ, LEdda F \& ZiCHE M (1996). Nitric oxide mediates mitogenic effect of VEGF on coronary venular endothelium. $\mathrm{Am}$. $J$. Physial. 270, $\mathrm{H} 411-\mathrm{H} 415$.

MORTON JJ, BEATTIE EC. SPEIRS A \& GULLIVER F (1993). Persistent hypertension following inhibition of nitric oxide formation in the young Wistar rat: role of renin and vascular hypertrophy. I Hypertens. 11, 1083-1088.

NELISSEN-VRANCKEN HJIMG, LEENDERS PJA, STRUIJKER BOUdIER HAJ \& SMITS JFM (1992). Increased responsiveness of the vascullar bed to angiotensin I, angiotensin II and phenylephrine in acute and chronic ischemic hindlimbs in rats. J. Vasc. Res. 29, 359-366.

POLLOCK DM, POLAKOWSKI JS, DIVISH BJ \& OPGENORTH TJ (1993). Angiotensin blockade reverses hypertension during long-term nitric oxide synthesis inhibition. Hypertension 21, 660-666.

POURAGEAUD F \& DE MEY JGR (1997). Structural properties of rat mesenteric small arteries after four week exposure to elevated or reduced blood flow. Am. J. Physiol. 273, H1699-H1706.

SANDER M, HANSEN PG \& VICTOE RG (1995). Sympathetically mediated hypertension caused by chronic inhibition of nitric oxide. Hypertension 26, 691-695.

SCHRIFFIN E (1992). Reactivity of small blood vessels in hypertension: relation with structural changes. State of the art lecture. Hypertension 19(Suppl. 2), II1-II9.

SIMON G (1992). Stimulation of vascular Na-K pump with subpressor angiotensin II in rats. Proc. Soc. Exp. Biol. Med. 119, 424-431.

SIMON G, CSEREP G \& LIMAS C (1995). Development of structural vascular changes with subpressor angiotensin Ill administration in rats. Am. J. Hypertens. 8, 67-73.

SMTH JB (1986). Angiotensin-receptor signaling in cultured vascular smooth muscle cells. Am. J. Physiol. 250, F759-F769.

STASSEN FRM, FAZZI GE, LEENDERS PJA, SMITS JFM \& DE MEY JGR (1997a). Coronary artery hyperreactivity and mesenteric arterial hyporeactivity after myocardial infarction in the rat. 4 . Cardiovasc. Pharmacol. 29, 780-788. 
STASSEN FRM, RAAT NJH, BROUWERS-CEILER DL, FAZZI GE, SMITS JFM \& DE MEY JGR (1997b). Angiotensin II induces media hypertrophy and hyperreactivity of densely but not sparsely innervated small arteries of the rat. J. Vasc. Res. 34, 289-297.

STASSEN FRM, WHLLEMSEN MUJMF, JANSSEN GMJ, FAZZI GE, SCHIFFERS PMH, SMITS JFM \& DE MEY JGR $(1997 \mathrm{c})$. Reduced responsiveness of rat mesenteric artery smooth imuscle to phenylephrine and calcium following myocardial infarction. Br. J. Pharmacol. $120,1506-1512$.

STRUIJKER BOUDIER HAJ, VAN BORTEL LMAB \& DE MEY JGR (1990). Remodeling of the vascular tree in hypertension: drug effects. TiPS 11, 240-244.

STRUiJker Boudier HAJ, VAN Essen H, FAZZI G, DE MEy JGR, QIU HY \& LÉVY BI (1996). Disproportional arterial hypertrophy in hypertensive mRen-2 transgenic rats. Hypertension 28, 779-784.

SVENTEK P, TURGEON A \& SCHRIFFIN EL (1997). Vascular endothelin-1 gene expression and effect of blood pressure of chronic ETA endothelin receptor antagonism after nitric axide synthase inhibition with L-NAME in normal rats. Circulation 95, 240-244.

VON THUN AM, VARI RC, EL-DAHR SS \& NAVAR G (1994). Augmentation of intrarenal angiotensin II levels by chronic angiotensin II infusion. Am. J. Physiol. 266, F120-F128.

WEBB RC, JOHNSON JC \& BOHR DF (1983). Adrenergic neurotransmission in tail arteries from two-kidney, one-clip, renal hypertensive rats. Hypertension 5, 298-306.

WIENER J, LOMBARDI DM, SU JE \& SCHWARTZ SM (1996). Immunohistochemical and molecular characterization of the differential response of the rat microvasculature to anglotensin-II infusion. J. Vasc. Res. 33, 195-208.

Ziche M, Morbidelli L, Masinn E, Amerini S, Granger HJ, Maggi CA, Geppetti P \& LEDDA F (1994). Nitric oxide mediates angiogenesis in vivo and endothelial cell growth and migration in vitro promoted by substance P. J. Clin. Invest. 94, 2036-2044. 
Role of basal NO synthesis in vasoconstrictor hyporeactivity in the perfused rat hindlimb after myocardial infarction: Effect of captopril

D.L. Ceiler

H.J.M.G. Nelissen-Vrancken

J.G.R. De Mey

J.F.M. Smits

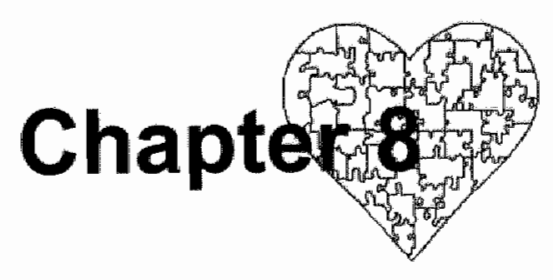




\section{Abstract}

Myocardial infarction (M) in the rat produces hemodynamic changes which mimic the development of clinical heart failure. We evaluated endothelial function, vascular contractile ability and the modulatory role of basal nitric oxide (NO) production therein in the rat hindlimb vascular bed after MI. Furthermore, we examined the effects of treatment with the angiotensin converting enzyme inhibitor captopril in this setting. MI was induced in male Wistar rats by ligation of the left coronary artery. Acetylcholineinduced dilatations were assessed in the ex vivo perfused hindlimb at various timepoints. At 14 and 35 days post-Ml, vascular contractile function was assessed from resistance changes induced by $35 \mathrm{mM}$ and $125 \mathrm{mM}$ potassium $\left(\mathrm{K}^{+}\right)$and the maximum increase in resistance $\left(\Delta R_{\text {max }}, 125 \mathrm{mM} \mathrm{K}\right.$ and $3 \mathrm{mg}$ phenylephrine). Basal NO synthesis was blocked for two weeks with L-NAME in sham and MI rats and similar contractility experiments were performed. The effect of captopril treatment on vasoconstrictor responses was also tested.

Acetylcholine-induced dilatations were not different between sham and MI rats. Vasoconstrictor responses to $\mathrm{K}^{*}$ and $\Delta \mathrm{R}_{\max }$ were reduced at 14 days after $\mathrm{MI}$. This reduction in vasoconstrictive ability was similar to that seen in L-NAME-treated sham rats, while L-NAME did not affect vasoconstrictor reactivity in MI rats. At 35 days after

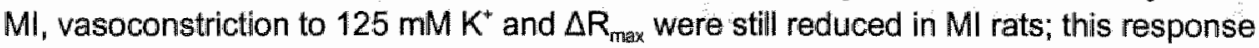
was however partially restored after captopril treatment.

In the rat hindlimb after MI, the development of vascular contractile hyporeactivity may be due to reduced basal NO production. Delayed treatment with captopril improves peripheral vascular contractile function in this setting. 


\section{Introduction}

Abnormal responsiveness of the peripheral vasculature may contribute to the common symptoms of fatigue and reduced execise tolerence in patients with heart failure. Reduced arterial dilator function may restrict blood flow to peripheral organs. Although clinical studies have demonstrated diminished endothelialdependent relaxations (Kubo et al. 1991; Katz et al. 1993), the basal production of the endothelium-dependent vasodilator, nitric oxide (NO) has been reported to be either increased or decreased (Kubo et al. 1991; Habib et al. 1994). In experimental animal models, acetylcholime (ACh)-induced responses have also generally been found to be reduced, but studies have largely centered on early time points and on large vessels (Kaiser et al. 1989; Ontkean et al. 1991). Studies with inhibitors of NO synthase generally suggest that systemic and regional basal NO production is unaltered in experimental heart failure (Drexler \& Lu, 1992; Drexler et al. 1992a). However as in vitro contractile hyperreactivity can be sometimes abolished by removal of the endothelium, evidence pointing towards decreased quantities of constituitively released endothelium-dependent dilators also exists (Teerlink et al. 1994; Okumura et al. 1996).

While a shift towards exaggerated arterial constriction would impede organ flow, reduced contractile function may result in inefficient cardiac output distribution. Angus and coworkers (1993) demonstrated such a diminished contractile reactivity in subcutaneous resistance arteries from patients with heart failure. In experimental heart failure, various authors have also demonstrated diminished vasoconstrictor capacity (Teerlink et ai. 1994; Stassen et al. 1997a). Teerlink and coworkers (1994) demonstrated hyporeactivity to $\alpha$-adrenergic stimuli and potassium $\left(\mathrm{K}^{+1}\right.$ in denuded thoracic aortas of rats at one week after myocardial infarction (MI). While Stassen et al. (1997a) found no alteration in rat thoracic aorta responsiveness five weeks after MII, they noted a non-selective hyporeactivity to vasoconstrictors in isolated mesenteric resistance arteries.

The aforementioned MI model in rats is an established model for studying the development and progression of heart failure (Pfeffer et al. 1985; Drexler et al. 1986; Schoemaker et al. 1991). In this model, acute hemodynamic adaptation deteriorates to overt heart failure, as characterized by increased left ventricular end-diastolic pressure, decreased cardiac index, and increased systemic vascular resistance (Drexler et al. 1986; Schoemaker et al. 1991). The MI rat has been used to investigate mechanisms conferring the beneficial effects of angiotensin converting enzyme (ACE) inhibitors in heart failure treatment. ACE inhibitors have been shown to improve systemic hemodynamics, retard left ventricle hypertrophy and fibrosis, and prevent endothelial dysfunction (Pfeffer et al. 1985; Schoemaker et al. 1991; Simits et al. 1995; Mulder et al. 1996). While immediate administration of ACE inhibitors may impede the wound healing process in the infarcted heart, delayed administration 
of these drugs seems to retard the progression of heart failure (Schoemaker et al. 1991; Smits et al. 1995).

In the present study, we examined vascular dilator and constrictor responses of a skeletal muscle vascular bed at physiological flows in the rat MI model. Accordingly, minimal vascular resistance and endothelial function were examined at various time points after MI to assess whether dilator capacity changes with the development of heart failure. In this light, we also measured plasma nitrate and nitrite $\left(\mathrm{NO}_{\mathrm{x}}\right)$ levels as an indicator of basal $\mathrm{NO}$ synthesis. Furthermore, vascular contractile function was evaluated at 14 and 35 days post-MI. We chose these time frames to facilitate comparison with earlier studies from our lab (Stassen et al. $1997 \mathrm{a}$, b). Since the hindlimb vascular bed demonstrated contractile dysfunction, we assessed the effects of late ACE inhibitor treatment with captopril on this abnormality.

\section{Methods}

Animals, surgery, and treatment

Male Wistar rats (280-320 g, lffa Credo, Someren, the Netherlands) were housed under standard conditions $\left(20^{\circ} \mathrm{C}, 12\right.$-hour light/dark cycle) and given free access to standard chow (Hope Farms, Woerden, the Netherlands) and tap water. The experimental procedures were performed according to institutional guidelines and approved by the Ethical Committee for the Use of Experimental Animals of the Universiteit Maastricht (the Netherlands).

Rats were randomly selected to undergo myocardial infarction (MII) or sham surgery (sham). MI was induced by permanent ligation of the left coronary artery, as described previously (Schoemaker et al. 1991). Briefly, animals were anesthetized (pentobarbital; $60 \mathrm{mg} / \mathrm{kg}$ i.p.), intubated, and respirated (room air; 60 strokes $/ \mathrm{min}$; tidal volume $3 \mathrm{ml}$ ). Following thoracotomy in the fourth left intercostal space, the heart was exteriorized and a 6-0 silk suture looped around the proximal left coronary artery. After the heart had been returned to its normal position, the suture was securely ligated in the MI group. In sham rats, a superficial ligature was placed in the left ventricular wall near the left coronary artery and loosely tied. The thorax was closed with 3-0 silk under negative pressure. The animals were allowed to recover for at least days.

On the day of surgery, sham and $\mathrm{MI}$ rats were randomly selected and equipped with an osmotic mini-pump (2002, Alzet, Alza Co, Palo Alto, CA, USA) administering $25 \mathrm{mg} / \mathrm{kg} /$ day L-nitro-arginine methyl ester (L-NAME) s.c. for two weeks. In separate groups of sham and MI rats, captopril was administered at 12 $\mathrm{mg} / \mathrm{kg} /$ day via osmotic mini-pumps (2ML2, Alzet) s.c. from days 21 - 35. Minipumps were implanted subcutaneously in the neck under ether anesthesia. 
Measurement of blood pressure in conscious rats treated chronically with L-NAME On treatment day 12, the rats were anesthetized with pentobarbital $(60 \mathrm{mg} / \mathrm{kg}$ i.p.) and equipped with an arterial catheter (PE 50) implanted in the left carotid artery and aimed to terminate at the junction with the aortic arch. Saline-filled catheters were guided subcutaneously to the base of the neck, exteriorized, and sealed with a metal plug.

Mean arterial pressure (MAP) was measured in quietly resting rats on day 14 via a pressure transducer (CP-01, Century Technology Co., Inglewood, CA, USA) in conjunction with an on-line monitoring computer program (Hemodynamic Data Acquisition Systems, Instrumental Services, Universiteit Maastricht).

\section{Hindlimb perfusion}

Rats were anesthetized with sodium pentobarbital (60 mg/kg i.p.) and subjected to hindlimb perfusion as described previously (Nelissen-Vrancken et al.1992). Briefly, after opening the abdomen, all side branches of the aorta and vena cava distal to the kidneys and proximal of the iliac bifurcation were ligated. The caudal artery and the seminal vesicles were likewise ligated. Upon cannulation of the abdominal aorta, perfusion with an isotonic, oxygenated $\left(95 \% \mathrm{O}_{2} / 5 \% \mathrm{CO}_{2}\right)$ Krebs-Henseleit buffer via a wind kettle was initiated. Flow was set to $7.5 \mathrm{ml} / \mathrm{min}$ for both sham and MI rats since we and others noted no differences in resting skeletal muscle blood flow between groups (Drexler \& Lu, 1992; Heeneman et al. 1995). Eluate was collected from a cannula implanted in the vena cava. The animal was killed (intracardiac injection of a saturated $\mathrm{KCl}$ solution) and the hindlimb flushed of all blood for approximately half an hour before starting experimentation. An on-line monitoring program (Hemodynamic Data Acquisition Systems) was utilized to monitor flow ( $F ; 1 \mathrm{~mm}$ diameter flow-through electromagnetic flow probe, Skalar, Delft, the Netherlands) and pressure (P; CP-01, Century Technology Co.) and concomitantly calculate resistance $(R=P / F)$. Drugs were administered proximal to a mixing chamber and experiments were conducted at $37^{\circ} \mathrm{C}$.

\section{Protocol}

Minimal resistance $\left(R_{\min }\right)$ and endothelial function in untreated sham and MI rats: At 7, 21, 35 and 90 days after surgery, randomly-selected untreated sham and $\mathrm{MI}$ rats were chosen to undergo a hindlimb perfusion protocol to examine $R_{\min }$ and endothelial function. For these experiments, the Krebs-Henseleit buffer was modified to include $10 \mathrm{mM}$ indomethacin to inhibit cyclooxygenase-induced prostaglandin synthesis. After initiating hindlimb perfusion as described above, two subsequent bolus injections of $500 \mathrm{mg}$ sodium nitroprusside (SNP) were injected to achieve $R_{\min }$.

To assess endothelial function, the hindlimb vascular bed was constricted by a resistance of $2.7 \mathrm{mmHg} \cdot \mathrm{min} / \mathrm{ml}$ via a phenylephrine (Phe) infusion 
(approximately $7.5 \mathrm{mM}$ ) and a non-cumulative $\mathrm{ACh}$ dose-response curve $(0.10 \mathrm{ng}$ - $10 \mathrm{mg}$ ) was generated. Thereafter, $150 \mathrm{mg}$ L-nitro-arginine (L-NA), an NO synthase inhibitor, was injected. This dose was chosen from pilot experiments in which the $E D_{50}$ for the constrictor effect of L-NA was determined to be approximately $60 \mathrm{mg}$ (Chapter 6). After blocking NO synthase, $10 \mathrm{mg}$ ACh was administered to assess the non- $\mathrm{NO}$, non-prostaglandin component of the $\mathrm{ACh}$ induced dilatation. Two subsequent $500 \mathrm{mg}$ doses of SNP were injected to assess endothelium-independent vasodilator function.

$R_{\min }$ and constrictor function in treated and untreated sham and MI rats: In separate groups of sham and $\mathrm{Ml}$ animals at 14 and 35 days after surgery, $R_{\min }$ was determined as mentioned above. Thereafter, an infusion of a $\mathrm{KCl}$ was used to determine responses to $35 \mathrm{mM} \mathrm{K}^{+}$and $125 \mathrm{mM} \mathrm{K}^{+}$. A $3 \mathrm{mg}$ bolus injection of Phe was administered on top of the $125 \mathrm{mM} \mathrm{K}$ response in order to determine the maximal increase in resistance $\left(\Delta \mathrm{R}_{\max }\right)$. The dose of Phe is 100 times greater than the dose shown to induce a maximal $\alpha_{1}$-adrenergic effect in a previous study (Nelissen-Vrancken et al. 1992).

\section{Plasma $\mathrm{NO}_{x}$ assay}

Plasma concentrations of $\mathrm{NO}_{x}\left(\mathrm{NO}_{3}+\mathrm{NO}_{2}\right)$ were determined by using the Griess reaction according to the method of Tracey (1995). Briefly, heparinized blood was sampled from sham and $\mathrm{Ml}$ rats at $7,14,21,35$, and 90 days after surgery. Blood was centrifuged for 5 minutes at $15,000 \mathrm{rpm}$ and the plasma collected. After deproteinizing the plasma with $1.5 \% \mathrm{ZnSO}_{4}$, plasma nitrate was reduced with nitrate reductase in microtiter plates. After reacting with the Griess reagent (1 volume $1 \%$ sulfanilamide in $5 \% \quad \mathrm{H}_{3} \mathrm{PO}_{4}: 1$ volume $0.1 \% \mathrm{~N}$-(1-naphyl) ethylenediamine), absorbance was read at $540 \mathrm{~nm}$ using a microplate reader and converted to $\mathrm{NO}_{x}$ concentrations by using a nitrate standard curve. Samples were measured in duplicate. Inter-assay variability was $0.02 \%$. As a control for the contribution of basal $\mathrm{NO}$ production to plasma $\mathrm{NO}_{\mathrm{x}}$ concentrations, plasma $\mathrm{NO}_{\mathrm{x}}$ was measured in sham rats in which NO synthase was blocked for 2 weeks with L-NAME (25 mg/kg/day s.C.).

\section{Determination of myocardial infarction size}

After experimentation, hearts were excised and washed in saline. Following removal of the atria, the ventricles were cut into transverse slices of 1-2 mm, resulting in 5-6 slices. The mid-ventricular slice was fixed in $3 \%$ formaldehyde and embedded in paraffin, whereafter transverse sections $(4 \mathrm{~mm})$ were stained according to the modified AZAN technique (van Krimpen et al. 1991). Infarct size was determined by planimetry and expressed in percentage of left ventricle circumference, calculated as the average of infarct sizes of endocardial and epicardial surfaces (Passier et al. 1995). Only hearts with infarct sizes $>21 \%$ were 
used in the Ml groups, as smaller infarcts do not have detectable hemodynamic consequences in vivo (Schoemaker et al: 1991).

\section{Materials}

The Krebs-Henseleit buffer had the following composition (mM): $111 \mathrm{NaCl}, 5 \mathrm{KCl}$, $1.2 \mathrm{KH}_{2} \mathrm{PO}_{4}, 25 \mathrm{NaHCO}_{3}, 1.25 \mathrm{CaCl}_{2}, 11.1$ glucose, and $40 \mathrm{~g} / \mathrm{l}$ dextran-70, $\mathrm{pH} 7.4$. All inorganic salts were purchased from Merck (Amsterdam, the Netherlands); dextran-70, captopril, indomethacin, phenylephrine, sulfanilamide, and $\mathrm{N}-(1-$ naphyl)ethylenediamine, and L-NAME from Sigma (St. Louis, MO, USA); sodium nitroprusside from Janssen Pharmaceutica (Beerse, Belgium); L-nitro-arginine from Research Biomedicals International (Natick, MA, USA); acetylcholine from Ciba Vision Ophta (Breda, the Netherlands); nitrate reductase from Boehringer Mannheim (Almere, the Netherlands); heparine from Leo Pharmaceuticals (Weesp, the Netherlands).

\section{Data analysis}

All dilatations are expressed as percent of the preconstriction. The half-maximal effective dose $\left(E D_{50}\right)$ and maximal response values for the $A C h$ dose-response curve were obtained from non-linear regression analysis of individual doseresponse curves according to the equation

$$
\Delta R \frac{\Delta R_{\max } D^{n}}{E D_{50}^{n} D^{n}}
$$

where $\Delta R$ is the change in resistance, $\Delta R_{\max }$ the maximal change in resistance, $D$ the dose of $A C h, n$ the Hill coefficient, and $E D_{50}$ the negative log of the dose inducing half maximal effect.

Minimal resistance, dilatation data and constrictor responses to L-NA for sham and $\mathrm{Ml}$ rats at the different time points were compared by means of a Mann Whitney U-test for unpaired observations. The contribution of the non-NO, nonprostaglandin component of ACh-induced dilatations was calculated as the response to $10 \mathrm{mg} \mathrm{ACh}$ after L-NA relative to that before L-NA.

Constrictions are expressed as absolute changes in resistance. $\mathrm{K}^{+}$sensitivity was assessed from the ratio of the resistance increases to $35 \mathrm{mM}$ and $125 \mathrm{mM}$ $\mathrm{K}^{+}$. The contribution of Phe to the maximal vasoconstrictor response was calculated as the resistance increase upon Phe injection relative to the maximal increase in resistance. The effect of MI surgery and L-NAME treatment on vascular function was assessed via the non-parametric Kruskal Wallis test. Similarly, the effect of MI surgery and captopril treatment on vascular function were also analyzed using the non-parametric Kruskal Wallis test. 
Values for plasma $\mathrm{NO}_{x}$ at the various time points were compared by Mann Whitney U-test for unpaired observations.

All data are expressed as mean \pm S.E.M. Differences were considered statistically significantly at a value of $p<0.05$.

\section{Results}

\section{General characteristics (Table 8.1)}

Although MI had no effect on body weights at $7,21,35$ or 90 days after surgery, heart weights were significantly increased at $7,14,35$ and 90 days after surgery. Heart-to-body weight ratios paralleled the heart weight data, except that this parameter was not significantly increased in MI rats at 14 days.

$R_{\min }$ in untreated rats

Vascular tone in the buffer-perfused rat hindlimb was low, such that at near physiological flows of $7.5 \mathrm{ml} / \mathrm{min}$, resistances of approximately $3.6 \mathrm{mmHg} . \mathrm{min} / \mathrm{ml}$ were noted and two subsequent bolus injections of $500 \mathrm{mg}$ sodium nitroprusside had little effect on resistance. Dilatations were in the order of a few percent and were not different between surgical groups at any time point. $R_{\min }$ was not altered in the rat hindlimb at 7,21,35 or 90 days after MI compared to sham rats (Figure 8.1).

Endothelial function and plasma $\mathrm{NO}_{x}$

ACh dilated the Phe-preconstricted hindlimb at all time points in a dosedependent manner as shown at 90 days after surgery in Figure 8.2. As shown in Table 8.2, neither the sensitivity " as indicated by the $E D_{50}$, nor the maximal dilator effect of ACh were altered after MI. Furthermore, the constriction induced by 150 mg L-NA was not different at any time point after surgery in MI-compared to sham rats (Table 8.2). L-NA did not inhibit the dilatation to $10 \mathrm{mg} \mathrm{ACh}$ at any time point in either sham or MI rats (Table 8.2). Maximal endothelium-independent vasodilator responses to sodium nitroprusside were approximately $90 \%$ of the preconstriction level and were not affected by the induction of $\mathrm{Ml}$ (data not shown).

As can be seen in Table 8.3, no differences in plasma $\mathrm{NO}_{x}$ values were detectable between sham and $\mathrm{Ml}$ rats at any time point. Average values in sham rats varied between 7 and $19 \mathrm{mM}$. Two week administration of L-NAME did not modify plasma $\mathrm{NO}_{\mathrm{x}}$ llevels in either sham or MI rats (Table 8.3). 
Table 8.1 General characteristics of sham- and myocardially infarcted (MI) rats used in reactivity studies.

\begin{tabular}{|c|c|c|c|c|c|c|}
\hline $\begin{array}{l}\text { days post- } \\
\text { operative }\end{array}$ & group & $n$ & $\mathrm{BW}(\mathrm{g})$ & $H W(g)$ & HWIBW & $\begin{array}{l}\text { MI } \\
(\%)\end{array}$ \\
\hline \multirow[t]{2}{*}{7} & sham : & 7 & $308 \pm 5$ & $0.91 \pm 0.02$ & $0.296 \pm 0.008$ & \\
\hline & MI & 8 & $294 \pm 6$ & $1.02 \pm 0.03^{*}$ & $0.348 \pm 0.011^{*}$ & $46 \pm 3$ \\
\hline \multirow[t]{4}{*}{14} & sham & 10 & $274 \pm 7$ & $0.77 \pm 0.05$ & $0.274 \pm 0.017$ & \\
\hline & sham+L-NAME & 7 & $277 \pm 5$ & $0.87 \pm 0.03$ & $0.314 \pm 0.012$ & \\
\hline & MI & 10 & $304 \pm 8^{*}$ & $0.87 \pm 0.03^{*}$ & $0.295 \pm 0.008$ & $41 \pm 4$ \\
\hline & $M I+L-N A M E$ & 7 & $263 \pm 8^{t}$ & $0.77 \pm 0.03$ & $0.298 \pm 0.024$ & $41 \pm 5$ \\
\hline \multirow[t]{2}{*}{21} & sham & 8 & $354 \pm 4$ & $1.05 \pm 0.02$ & $0.297 \pm 0.007$ & \\
\hline & $\mathrm{MI}$ & 8 & $358 \pm 9$ & $1.12 \pm 0.05$ & $0.312 \pm 0.014$ & $41 \pm 5$ \\
\hline \multirow[t]{4}{*}{35} & sham & 18 & $393 \pm 8$ & $1.07 \pm 0.04$ & $0.271 \pm 0.006$ & \\
\hline & sham + cap & 7 & $365 \pm 8^{*}$ & $0.90 \pm 0.02^{*}$ & $0.248 \pm 0.007$ & \\
\hline & MI & 19 & $387 \pm 10$ & $1.20 \pm 0.04^{*}$ & $0.312 \pm 0.012^{*}$ & $47 \pm 2$ \\
\hline & $\mathrm{Ml}+\mathrm{cap}$ & 9 & $324 \pm 11$ & $0.92 \pm 0.03^{\dagger}$ & $0.281 \pm 0.017$ & $43 \pm 3$ \\
\hline \multirow[t]{2}{*}{90} & sham & 17 & $447 \pm 11$ & $1.17 \pm 0.04$ & $0.261 \pm 0.006$ & \\
\hline & MI & 12 & $456 \pm 7$ & $1.50 \pm 0.05^{*}$ & $0.330 \pm 0.012^{*}$ & $40 \pm 3$ \\
\hline
\end{tabular}

L-NAME: $25 \mathrm{mg} / \mathrm{kg} / \mathrm{min}$ s. c. from day $0-14$. cap: $12 \mathrm{mg} / \mathrm{kg} / \mathrm{min}$ captopril s.c. from days $21-35$ post-operative; BW: body weight; HW: heart weight; HW/BW: heart-to-body weight ratio. Mean \pm S.E.M.; ${ }^{*} p<0.05$ vs untreated sham. ${ }^{*} p<0.05$ vs. untreated MI. 


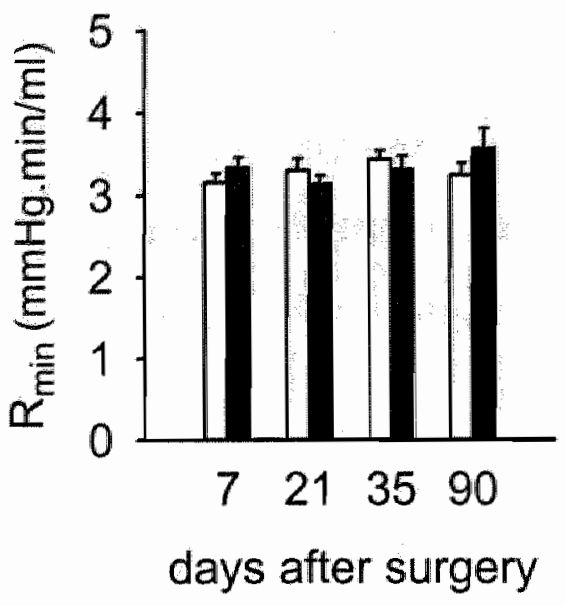

Figure 8.1

Minimal resistances $\left(R_{\text {min }}\right)$ in the perfused hindlimb of sham and myocardially infarcted (MI) rats. Open bars, sham rats; closed bars, Mi rats. MeantS.E.M.; see Table 8.2 for $n$.

Table 8.2 Endothelial function in the perfused hindlimb of sham and myocardially infarcted (MI) rats.

\begin{tabular}{|c|c|c|c|c|c|c|}
\hline $\begin{array}{l}\text { days post- } \\
\text { operative }\end{array}$ & group & $n$ & $\begin{array}{l}A C h E D_{50} \\
\text { (ng) }\end{array}$ & $\begin{array}{c}\mathrm{ACh}_{\max } \\
(\%)\end{array}$ & $\begin{array}{c}\Delta R_{\mathrm{L}-\mathrm{NA}} \\
(\mathrm{mmH} / \mathrm{min} / \mathrm{ml})\end{array}$ & $\begin{array}{l}A C h_{\text {post L-NA }} l \\
A C h_{\text {pre L-NA }}\end{array}$ \\
\hline \multirow[t]{2}{*}{7} & sham & 7 & $23 \pm 1$ & $77 \pm 4$ & $4.76 \pm 0.72$ & $1.10 \pm 0.03$ \\
\hline & MI & 8 & $14 \pm 3$ & $79 \pm 3$ & $5.63 \pm 1.11$ & $1.12 \pm 0.02$ \\
\hline \multirow[t]{2}{*}{21} & sham & 8 & $19 \pm 10$ & $82 \pm 3$ & $4.07 \pm 0.33$ & $1.05 \pm 0.03$ \\
\hline & MI & 8 & $25 \pm 7$ & $75 \pm 4$ & $4.90 \pm 0.80$ & $1.10 \pm 0.03$ \\
\hline \multirow[t]{2}{*}{35} & sham & 9 & $18 \pm 6$ & $72 \pm 4$ & $3.38 \pm 0.86$ & $1.02 \pm 0.03$ \\
\hline & MI & 11 & $22 \pm 5$ & $81 \pm 2$ & $4.34 \pm 0.81$ & $1.08 \pm 0.01$ \\
\hline \multirow[t]{2}{*}{90} & sham & 17 & $21 \pm 4$ & $65 \pm 4$ & $4.65 \pm 0.70$ & $1.12 \pm 0.04$ \\
\hline & MI & 12 & $15+3$ & $72 \pm 6$ & $4.26 \pm 0.46$ & $1.06+0.03$ \\
\hline
\end{tabular}

$A C h D_{50,4}$ half-maximal effective dosis for acetylcholine calculated from dose-response curves; $A C h_{\text {max }}$, maximal dilatation calculated from dose response curves; $\Delta R_{\mathrm{LNA} A}$, change in resistance induced by $150 \mathrm{mg}$ L-nitro-arginine; $A \mathrm{ACh}_{\text {post LNA }} / \mathrm{ACh}_{\text {prat-Na: }}$ non-NO component of $\mathrm{ACh}$ dilatation. MeantS.E.M. 
Figure 8.2

Acetylcholine dose response curve non-cumulatively generated in the perfused, phenylephrine-preconstricted hindlimb of sham and myocardially infarcted $(\mathrm{MI})$ rats 90 days after surgery. Open circles, sham rats; closed circles, MI rats. Mean \pm S.E.M.; see Table 8.2 for $n$.

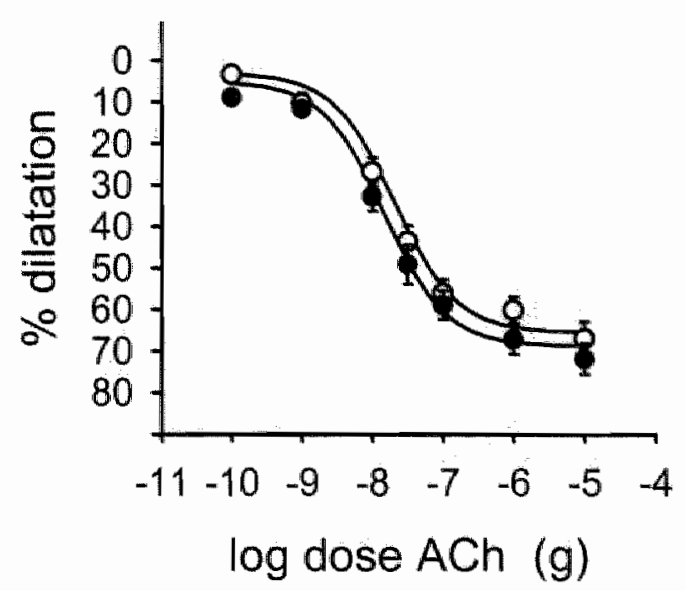

Table 8.3 Plasma $\mathrm{NO}_{\mathbf{x}}\left(\mathrm{NO}_{3}\right.$ and $\left.\mathrm{NO}_{2}\right)$ concentration from sham and myocardially infarcted (MI) rats at various days after surgery.

\begin{tabular}{cllcl}
\hline $\begin{array}{c}\text { days post- } \\
\text { operative }\end{array}$ & group & $n$ & $\begin{array}{c}\mathrm{Ml} \\
(\%)\end{array}$ & $\begin{array}{c}\mathrm{NO}_{x} \\
(\mathrm{mM})\end{array}$ \\
\hline \multirow{2}{*}{14} & sham & 7 & & $9.8 \pm 1.6$ \\
& sham+L-NAME & 7 & & $7.8 \pm 1.2$ \\
& MI & 7 & $43 \pm 5$ & $7.2 \pm 0.7$ \\
& MI+L-NAME & 6 & $41 \pm 5$ & $6.8 \pm 0.5$ \\
21 & sham & 9 & & $19.0 \pm 2.1$ \\
& MI & 13 & $45 \pm 3$ & $13.2 \pm 2.3$ \\
& sham & 20 & & $11.2 \pm 0.7$ \\
& MI & 14 & $44 \pm 3$ & $12.3 \pm 0.9$ \\
& sham & 13 & & $7.4 \pm 0.5$ \\
& MI & 11 & $42 \pm 3$ & $9.1 \pm 1.1$ \\
\hline
\end{tabular}

L-NAME: $25 \mathrm{mg} / \mathrm{kg} / \mathrm{min}$ s.C. from days 0-14; Data are mean士S.E.M. 


\section{Vesoconstrictor function}

Vascular contractile function in the perfused hindlimb was significantly reduced two weeks after Ml. As shown in Figure 8.3, the responses to $35 \mathrm{mM} \mathrm{K}^{*}(4.1 \pm 0.6$ $\mathrm{mmHg} \cdot \mathrm{min} / \mathrm{ml})$ and $125 \mathrm{mMl} \mathrm{K}{ }^{4}(15.7 \pm 1.0 \mathrm{mmHg} \cdot \mathrm{min} / \mathrm{ml})$, as well as $\Delta R_{\max }(22$. $\pm 21.3 \mathrm{mmHg} \mathrm{min} / \mathrm{ml}$ ) were reduced in $\mathrm{Ml}$ rats compared to sham rats $(7.4 \pm 0.7$, $21.9 \pm 0.9$, and $27.7 \pm 1.6 \mathrm{mmHg} . \mathrm{min} / \mathrm{ml}$, respectively). Furthermore, although the $\mathrm{K}^{*}$ sensitivity was significantly reduced in untreated $\mathrm{MI}$ rats versus the untreated sham counterparts, the contribution of phenylephrine to the maximal response was not altered (Table 8.4).

Unlike at two weeks after MI, neither the absolute change in resistance generated by $35 \mathrm{mM} \mathrm{K}^{+}$(Figure 8.4) nor the $\mathrm{K}^{+}$sensitivity (Table 8.4) was altered at five weeks after MI. Nonetheless, constrictor responses to $125 \mathrm{mM} \mathrm{K}{ }^{+}$and maximal contractile ability were still significantly reduced $\left(125 \mathrm{mM} \mathrm{K}^{+}: 15.7 \pm 0.73\right.$ vs. $19.3 \pm 0.9 \mathrm{mmHg} \cdot \mathrm{min} / \mathrm{ml} ; \Delta \mathrm{R}_{\max }: 21.7 \pm 1.4$ vs. $26.1 \pm 1.3 \mathrm{mmHg} \cdot \mathrm{min} / \mathrm{ml}$; Figure $8.4)$ in untreated $M I$ rats compared to their sham counterparts. This reduction in maximal vasoconstriction was not due to a decrease in the phenylephrine response (Table 8.4 ).

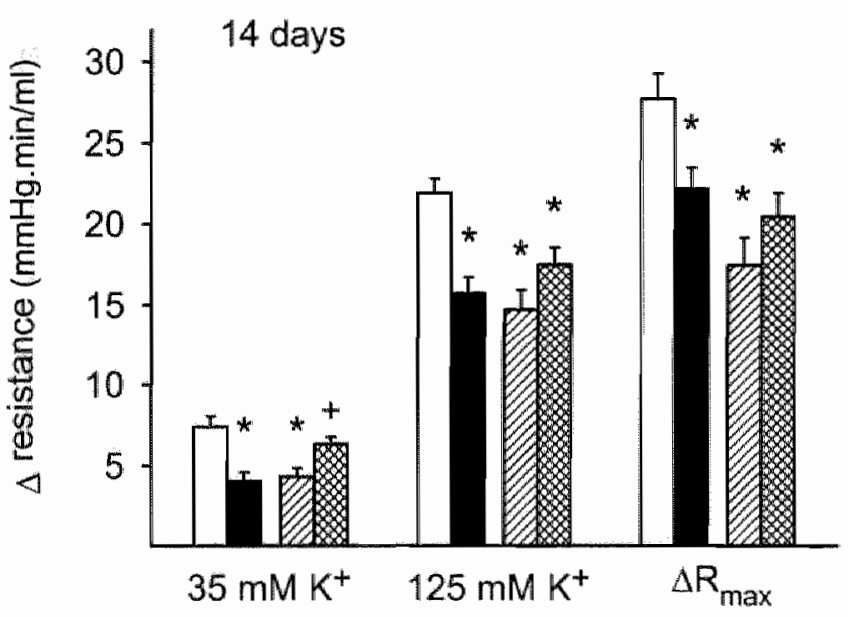

Figure 8.3

Effect of myocardial infarction (MI) surgery and L-NAME treatment on the resistance generated by $35 \mathrm{mM} \mathrm{K}^{*}, 125 \mathrm{mM} \mathrm{K}$ and $125 \mathrm{mM} \mathrm{K}$ plus $3 \mathrm{mg}$ phenylephrine $\left(\Delta R_{\max }\right)$ in the perfused hindlimb of sham and MI rats at two weeks after surgery. L-NAME was administered at 25 mg/kg/day from days 0-14. Open bars, sham rats; closed bars, MI rats; hatched bars, L-NAMEtreated sham rats; cross-hatched bars, L-NAME-treated MI rats. Mean \pm S.E.M.; see Table 8.4 for $n .{ }^{*} p<0.05$ ws. untreated sham. ${ }^{"} p<0.05$ ws, untreated Ml. 
Table 8.4 Effect of sham surgery and myocardial infarction (MI) on vasoconstrictor properties.

\begin{tabular}{clccc}
\hline $\begin{array}{c}\text { days post- } \\
\text { operative }\end{array}$ & \multicolumn{1}{c}{ group } & $\mathrm{n}$ & $\mathrm{K}^{*}$ sensitivity & $\Delta \mathrm{R}_{\text {pho }} / \Delta \mathrm{R}_{\text {max }}$ \\
\hline \multirow{2}{*}{14 days } & sham & 10 & $0.34 \pm 0.02$ & $0.20 \pm 0.03$ \\
& sham + L-NAME & 7 & $0.31 \pm 0.06$ & $0.15 \pm 0.03$ \\
& MI & 10 & $0.25 \pm 0.03^{*}$ & $0.29 \pm 0.04$ \\
& MI + L-NAME & 6 & $0.36 \pm 0.02^{\dagger}$ & $0.13 \pm 0.04^{\dagger}$ \\
& sham days & 8 & $0.28 \pm 0.03$ & $0.26 \pm 0.02$ \\
& sham + cap & 7 & $0.36 \pm 0.03$ & $0.30 \pm 0.02$ \\
& MI & 9 & $0.26 \pm 0.02$ & $0.26 \pm 0.03$ \\
& MI + cap & 9 & $0.35 \pm 0.09^{\dagger}$ & $0.23 \pm 0.02^{\ddagger}$ \\
\hline
\end{tabular}

L-NAME: $25 \mathrm{mg} / \mathrm{kg} / \mathrm{min}$ s.c. from days 0-14; cap: captopril $12 \mathrm{mg} / \mathrm{kg} \mathrm{s.c.} \mathrm{from} \mathrm{days} 21-35 ; \mathrm{K}^{4}$ sensitivity: ratio of the change in resistance induced by $35 \mathrm{mM}$ and $125 \mathrm{mM} \mathrm{K} ; \Delta R_{\mathrm{P}_{\mathrm{he}}} / \Delta \mathrm{R}_{\max }$ : contribution of phenylephrine $\left(\Delta R_{\mathrm{Pho}}\right)$ to maximal response $\left(\Delta R_{\text {max }}\right)$. Mean $\pm S . E . M . ;{ }^{*} p<0.05$ vs. untreated sham ${ }^{\dagger} p<0.05$ vs. untreated MI. ${ }^{\ddagger} p<0.05$ vs. treated sham.

\section{Effect of L-NAME treatment}

Body weight was significantly less in the L-NAME treated MI rats compared with untreated MI rats. (Table 8.1). Treatment with L-NAME had no effect on heart-tobody weight ratios in either sham or MI rats (Table 8.1). MI rats had significantly

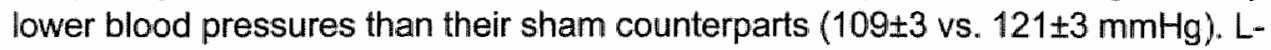
NAME induced hypertension in sham rats $(164 \pm 8 \mathrm{mmHg}$ ), and raised blood pressure (significantly) to normotensive levels in $\mathrm{MI}$ rats $(122 \pm 5 \mathrm{mmHg})$. The blood pressure rise in Ml rats was less than that in sham rats in both absolute (13 vs. $43 \mathrm{mmHg}$ ) and relative terms (12 vs. $36 \%$ ).

Two-week treatment with L-NAME did not alter $R_{\text {min }}$ in sham or MI rats $(3.4 \pm 0.1$ vs. $3.4 \pm 0.1 \mathrm{mmHg} . \mathrm{min} / \mathrm{ml}$ in sham rats and $3.3 \pm 0.1 \mathrm{vs} .3 .3 \pm 0.1 \mathrm{mmHg} \cdot \mathrm{min} / \mathrm{ml}$ in $\mathrm{Ml}$ rats). Vasoconstrictor responses to $\mathrm{K}^{+}$and $\triangle R_{\max }$ were reduced in L-NAMEtreated sham rats versus their untreated counterparts $(35 \mathrm{mM} \mathrm{K}: 4.3 \pm 0.5$ $\mathrm{mmHg} \cdot \mathrm{min} / \mathrm{ml} ; 125 \mathrm{mM} \quad \mathrm{K}^{+}: \quad 17.5 \pm 1.0 \mathrm{mmHg} \cdot \mathrm{min} / \mathrm{ml} ; \quad \Delta R_{\max }: \quad 20.4 \pm 1.5$ $\mathrm{mmHg} \cdot \mathrm{min} / \mathrm{ml}$; Figure 8.3). This reduction in vasoconstrictor ability was similar to that seen in untreated $\mathrm{Ml}$ rats at two weeks after MI. In MI rats, two week administration of L-NAME had virtually no effect on vasoconstrictor function in MI rats: vasoconstriction to $35 \mathrm{mM} \mathrm{K} \mathrm{K}^{+}$was significantly larger in treated $(6.3 \pm 0.5 \mathrm{mmHg} . \mathrm{min} / \mathrm{ml}$; Figure 8.3$)$ than untreated MI but still slightly, though not significantly, reduced compared to untreated sham rats. Responses to $125 \mathrm{mM}$ 
$K^{4}$ and $\Delta R_{\max }$ were not altered in L-NAME-treated MI compared to either untreated MI or L-NAME treated sham rats $\left(125 \mathrm{mM} \mathrm{K}: 17.5 \pm 1.0 \mathrm{mmHg} \cdot \mathrm{min} / \mathrm{ml} ; \Delta R_{\max }\right.$ : $20.4 \pm 1.5 \mathrm{mmHg} \cdot \mathrm{min} / \mathrm{ml}$; Figure 8.3). The increase in $35 \mathrm{mM} \mathrm{K}^{+}$vasoconstrictor responses was reflected in an increased $\mathrm{K}^{*}$ sensitivity in L-NAME-treated versus untreated $\mathrm{MI}$ rats (Table 8.4).

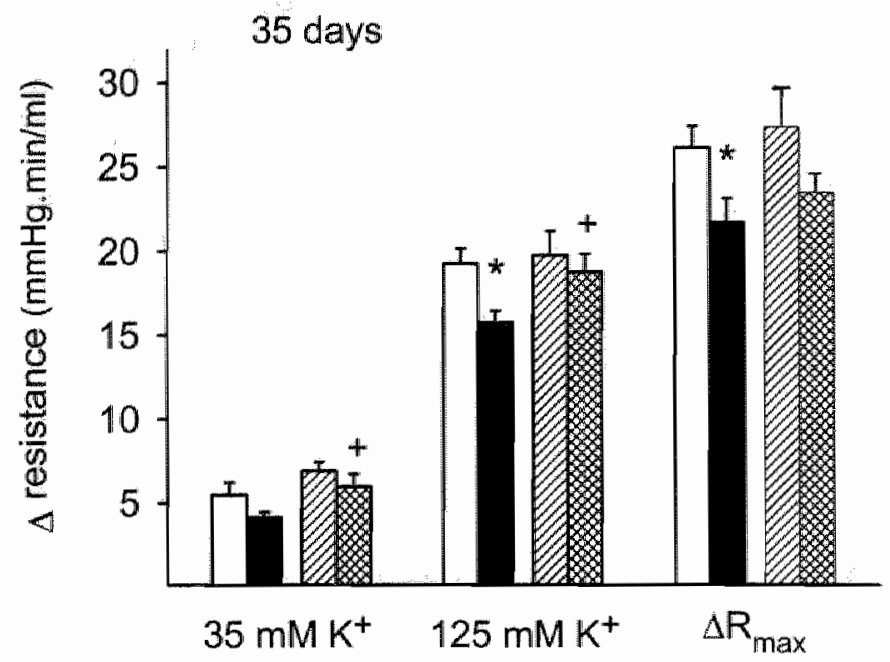

\section{Figure 8.4}

Effect of myocardial infarciton (MI) surgery and captopril treatment on the resistance generated by of $35 \mathrm{mM} \mathrm{K}^{*}, 125 \mathrm{mM} \mathrm{K}^{*}$ and $125 \mathrm{mM} \mathrm{K}^{*}$ plus $3 \mathrm{mg}$ phenylephrine $\left(\Delta \mathrm{R}_{\max }\right)$ in the perfused rat hindlimb five weeks after surgery. Captopril was administered at $12 \mathrm{mg} / \mathrm{kg} / \mathrm{day}$ s.c. from days 21-35. Open bars, sham rats; closed bars, MI rats; hatched bars, captopril-treated sham rats: cross-hatched bars, captopril-treated MI rats. Mean \pm S.E.M.; see Table 8.4 for $n$. ${ }^{*} p<0.05$ vs. untreated sham. " $p<0.05$ vs, untreated MI.

\section{Effect of captopril treatment}

Both sham and MI rats treated with captopril had lower body weights than their untreated counterparts (Table 8.1). This decrease in body weight was paralleled by a reduction in heart weight, as heart-to-body weight ratios were not changed. Furthermore, treatment with captopril did not modify $\mathrm{R}_{\min }$ (treated sham rats: $3.2 \pm 0.2 \mathrm{mmHg} . \mathrm{min} / \mathrm{ml}$; treated $\mathrm{Ml}$ rats: $3.1 \pm 0.1 \mathrm{mmHg} . \mathrm{min} / \mathrm{ml}$ ).

The response to $35 \mathrm{mM} \mathrm{K}$ was significantly increased in captopril-treated compared to untreated $\mathrm{MI}$ rats $(6.4 \pm 0.6$ vs. $4.1 \pm 0.3 \mathrm{mmHg} . \mathrm{min} / \mathrm{mll}$; Figure 8.4$)$, as was the sensitivity to $\mathrm{K}^{+}$(Table 8.4). Additionally, captopril restored the constrictor response to $125 \mathrm{mM} \mathrm{K}^{+}$( $p<0.05$ vs. untreated $\mathrm{Ml}$ rats and $p>0.1$ vs. treated and untreated sham rats; Figure 8.4). Treatment with captopril also slightly improved 
the maximal constrictor response in $M I$ rats; $\Delta R_{\text {max }}$ generated in treated-MI rats $(24.1 \pm .4 \mathrm{mmHg} . \mathrm{min} / \mathrm{ml})$ was not reduced compared to either treated $(27.4 \pm 2.3$ $\mathrm{mmHg} . \mathrm{min} / \mathrm{ml})$ or untreated $(26.1 \pm 1.3 \mathrm{mmHg} . \mathrm{min} / \mathrm{ml})$ sham rats. Nonetheless, the contribution of phenylephrine to the maximal response was not altered (Table 8.4).

\section{Discussion}

In the present study, we examined the dilator and constrictor function of a skeletal muscle vascular bed at physiological flows in the rat MI model. Acetylcholineinduced dilatations were not altered in the hindlimb vascular bed up to three months after myocardial infarction. Nonetheless, vasoconstrictor responses were reduced at both two and five weeks after $\mathrm{Ml}$. The reduction in vasoconstrictive ability at two weeks was similar to that seen in L-NAME-treated sham rats, while L-NAME had no effect on vasoconstrictor responsiveness in MI rats. Two week treatment with the angiotensin-converting enzyme inhibitor captopril from week three to five significantly improved peripheral vascular constrictor function in $\mathrm{MI}$ rats.

Ligation of the left coronary artery in the rat leads to infarction of the left ventricle and results in hemodynamic alterations analogous to those in clinical heart failure. Acute cardiac depression with decreased cardiac output and stroke volume (Schoemaker et al. 1990) is followed by a period of circulatory compensation which deteriorates into overt heart failure characterized by elevated left ventricular end diastolic pressures, increased total peripheral resistance, left ventricular hypertrophy, and pulmonary congestion (Pfeffer et al. 1985; Drexler et al. 1986; Schoemaker et al. 1991).

Chronic neurohormonal activation and peripheral vasoconstriction may ultimately lead to vascular structural changes, especially given the dual role of several vasoconstrictors as growth-promoting agents (Hahn et al, 1993; Adams et al: 1995). Indeed, a few early studies in heart failure patients suggest that structural alterations in microvessels may contribute to increased peripheral resistance (Wroblewski et al. 1992; Lindsay et al. 1994). Nonetheless, vascular network alterations having an effect on minimal resistance were not evident in the present model studied. Minimal vascular resistance is, however, a very sensitive technique for assessing the consequences of structurally-based changes in vascular networks. On one hand, it is possible that neurohormonal activation after myocardial infarction in the rat is not of sufficient magnitude or duration to induce structural changes. On the other, microvascular alterations may be solely of a functional and not of a structural nature. Indeed, studies from our lab failed to find structural alterations in resistance vessels of rats up to three months after MI (Heeneman et al. 1995; Stassen et al. 1997a). 
Despite the classic features of heart failure which characterize the present model, evidence for endothelium-dependent dilator dysfunction, a recurrent symptom of clínical heart failure (Kubo et al. 1991; Katz et al. 1993), was not found in the perfused hindlimb vascular bed in the present work. Nonetheless, several studies using the MI rat model have demonstrated depressed ACh-induced relaxation in isolated aortae (Ontkean et al. 1991; Lindsay et al. 1992; Buikema et al. 1993; Teerlink et al. 1993). Although these diminished responses were sometimes found to be endothelium-dependent (Lindsay et al. 1992; Teerlink et al. 1993), coincident decreases in endothelium-independent dilator responses were also found (Ontkean et al. 1991; Buikema of al. 1993). Since impaired non-specific vasodilatory capability has also been observed in human heart failure (Katz et al. 1993), care should be prescribed in the assessment of endothelium-dependent versus general vasodilator dysfunction.

In the femoral artery of dogs with pacing-induced heart failure, Kaiser and coworkers (1989) demonstrated that diminished ACh-induced responses were normalized in the presence of indomethacin suggesting a role for prostaglandins in the reduced ACh-induced dilatations seen in that model, Increased plasma levels of vasoconstrictor prostaglandins have likewise been demonstrated in human heart failure (Katz ot al. 1993). Thus, the inclusion of indomethacin in the perfusate in the present study may partially explain the discrepancy of our results with other studies.

The aforementioned studies strongly suggest that endothelial dilator capability is impaired in large vessels during heart failure; however, the situation in the resistance vasculature is less clear. Recent studies by Drexler et al (1992) and Mulder et al. (1996) support the development of endothelial dysfunction in resistance vascular beds after $\mathrm{MI}$ in rats. However, in line with the findings of the present study, Baggia and coworkers (1997) reported endothelial dysfunction in large, but not in resistance-sized, vessels. Whille NO seems to be the primary endothelium-derived relaxing factor in large vessels, surmounting evidence points towards the increased contribution of endothelium-derived hyperpolarizing factor (EDHF) in relaxation of resistance vascular beds (Garland et al. 1995 and Chapter 6). Indeed, in the present study as in Chapter 6, NO synthase inhibition failed to inhibit acetylcholine-induced dilatations in this preparation. Furthermore, the nonprostaglandin, non-NO component was not different between sham and MI rats. Stimulated NO production may be diminished in heart failure, and the demonstration of endothelial dysfunction may thus depend on the contribution of NO to agonist-induced dilatations in a given vessel or vascular bed.

Plasma nitrate or $\mathrm{NO}_{x}$ concentrations are often taken as indicative of basal $\mathrm{NO}$ synthase activity. In the case of lipopolysaccharide septic shock, the massive amounts of NO produced by the inducible NO synthase (iNOS) isoform are reflected in increased plasma nitrate levels (Tracey et al. 1995). However, under 
normal conditions or in pathologies in which iNOS is not systemically upregulated, limitations in the use of plasma nitrate values have been brought forth (Ohyanagi et al. 1992). In the present study, plasma $\mathrm{NO}_{\mathrm{x}}$ values showed considerable variability in sham rats, despite small inter-assay variability. Furthermore, chronic inhibition of NO synthase with L-NAME had little effect on $\mathrm{NO}_{x}$ plasma concentrations. Although we can only functionally assess the degree of NO synthase inhibition achieved with chronic L-NAME infusion, acute administration of additional L-NAME in the treated rats induced no further rise in the already elevated blood pressure (unpublished observation) suggesting that our dose of $L$ NAME inhibited basal NO synthase activity significantly. Thus, the applicability of plasma nitrate values in the assessment of basal NO synthesis may be questioned.

Potassium-induced constrictions were found to be diminished at both two and five weeks after myocardial infarction. Maximal vasoconstrictor responses were also diminished, but the fraction of the response due to potassium or phenylephrine was unaltered. This finding suggests that the noted vasoconstrictor dysfunction is not a receptor-specific phenomenon, but a general contractile defect. These results parallel work by Angus et al (1993) in skin resistance arteries from patients with heart failure and studies from our lab in isolated mesenteric resistance vessels of rats after MI (Stassem et al. 1997a, b). All in all, the reduction in depolarization-induced and maximal vasoconstrictor responses seems to indicate generalized vasoconstrictor dysfunction in the hindlimb of the MI rat.

Several lines of evidence from the present findings suggest that basal, nonacetylcholine-stimulated NO synthesis may be reduced after MI in the rat and that this may contribute to the development of vascular contractile dysfunction in the hindlimb vascular bed. To begin, vasoconstriction upon acute NO synthase inhibition was not different in sham and MI rats; if anything the values were slightly but not significantly higher in MI rats. Undiminished constrictions to blockade of NO synthase in MI rats in light of the aforementioned general vasocontractile dysfunction suggest that NO synthase inhibition withdrew a larger fraction of the total basal NO production in the MI rats, i.e., the "remaining" NO plays a greater role in inhibiting vascular tone in sham than MI rats. Furthermore, chronic NO synthase inhibition increased biood pressure to a much lesser degree in $\mathrm{Ml}$ rats. Lastly, two week administration of L-NAME reduiced vascular contractile ability in sham rats analogous to the vasoconstrictive dysfunction seen in MI rats two weeks after surgery, whereas L-NAME treatment did not alter vasoconstrictor responses in $\mathrm{Ml}$ rats. Thus, basal NO synthesis may be reduced after $\mathrm{MI}$. Additional support for reduced NO production in heart failure arises from studies demonstrating decreased expression of NO synthase (Comini at al. 1996; Smith et al. 1996) and increased plasma concentrations of endogenous NO synthase inhibitors (Usui et al. 1997). Furthermore, the availablity of L-arginine, the substrate for NO 
synthase may be limiting since it has been demonstrated that $L$-arginine infusions improve endothelial function in heart failure (Hirooka et al. 1994).

The deleterious effect of reduced basal NO levels on vascular contractile ability put forth in the present study is a phenomenon which has been previously observed (Dowell et al. 1996; Herrion et al. 1996). A recent study by Boerth et al. (1997) suggests that NO contributes to the maintenance of a contractile phenotype in vascular smooth muscle cells vila a cGMP-dependent kinase (PKG). Thus, it seems possible that a certain amount of NO is required for normal smooth muscle function.

Much attention has been given to the beneficial effects of angiotensin converting enzyme (ACE) inhibition on systemic hemodynamics, cardiac function, and endothelial function in a broad variety of pathological settings (Pfeffer et al. 1985; Konstam et al. 1992; Brilla \& Maisch. 1994; Drexler et al. 1995; Smits et al. 1995; Mulder et al. 1996). As clinical studies have demonstrated that chronic ACE inhibitor therapy improves skeletal muscle blood flow and oxygen consumption and that these improvements are paired with the reversal of intrinsic skeletal muscle alterations (Drexler et al. 1992b), treatment with ACE inhibitors may improve or limit exercise intolerance in heart failure patients.

The peripheral circulatory benefits of ACE inhibitors have been assumed to arise from their favorable effect on endothelium-dependent dilatation (Nakamura et al. 1994; Mulder ot al. 1996; Okumura et al. 1996). The present study suggests that, at least part of the peripheral effects of ACE inhibition post-MI may stem from the improvement of vasoconstrictor function via increased basal NO production. ACE inhibition augments basall NO levels through inhibition of bradykinin degradation (Mombouli et al. 1992). Thus, administration of ACE inhibitors after MI in the rat may increase basal NO synthesis and thereby improve reduced vasoconstrictor responses. Indeed, Henrion and coworkers (1996) recently reported that contractile hyporeactivity consequent to chronic NO synthase inhibition was prevented when an NO synthase and ACE inhibitor were administered concomittantly.

Okumura and coworkers (1996) have presented data which suggest that chronic ACE inhibitor treatment can prevent enhanced vasoconstrictor reactivity in the rat after Ml. At first glance, these findings seem contradictory to the results of the present study. However, the contractile hyperreactivity noted in large vessels was endothelium-dependent and perhaps also due to a reduction in basal NO production (Okumura et al. 1996). The divergence with the results of the present study may be due to the unequivocal role of $\mathrm{NO}$ in large and small vessels as discussed above. Additionally, similar to the beneficial effects of ACE inhibition noted in the present study, chronic ACE inhibitor administration prevented the development of vasoconstrictor abnormalities in the Okumura study possibly by enhancing basall NO synthesis (Okumura et al. 1996). Thus w both studies suggest 
that $A C E$ inhibitor treatment improves vasoconstrictor abnormalities by enhancing basal NO production.

Hyporesponsiveness to vasoconstrictors may contribute to the development of oedema and exercise intolerance in heart failure. If sufficient proximal resistance can not be generated in a vascular bed, the resulting increase in capillary pressure may exaggerate oedema formation. Furthermore, during exercise, sympathetic activation induces general vasoconstriction, such that blood flow is channeled to metabolite-dilated exercising muscles. If vasoconstrictor dysfunction results in reduced sympathetic-induced vasoconstriction, blood flow may be siphoned away from exercising muscles, leading to quickened fatigue. In addition to contributing to these major symptoms of heart failure, constrictor hyporesponsiveness may further the progression of the disease. Although vasoconstrictor dysfunction seems incongruous with the elevated peripheral resistance in heart failure since reduced vasoconstriction should improve peripheral perfusion, it may actually contribute to the viscious circle. As cardiac function deteriorates, neurohormonal systems are activated to maintain systemic perfusion pressure. The development and progression of constrictor hyporesponsiveness will perpetuate the need for additional vasoconstrictor neurohormones to generate the necessary resistance. This continued upregulation of neurohormonal activity may hinder cardiac function both indirectly and directly. Taken together, our results in rats suggest that vascular contractile dysfunction may contribute to the progression of heart failure.

From these results, we conclude that during the first three months after $\mathrm{MI}$ in the rat hindlimb vascular bed: 1) vascular network alterations having an effect on minimal resistance do not develop, 2) ACh-induced dilator responses are not reduced, 3) basal synthesis of NO may be reduced, 4) reduced arterial constrictor responses develop and 5) captopril treatment improves this dysfunction, possibly by enhancing basal NO production. As reduced vasocontractile responsiveness may perpetuate the progression of heart failure and has also been demonstrated in human heart failure (Angus et al. 1993), this finding may be of clinical relevance.

\section{References}

AdAMs MA, THOMPSON KE, BANTING JD, MADIGAN MA \& Friberg P (1995). Evidence for in vivo induction of cardiovascular growth processes by vasoconstrictor systems. Blood. Press. Suppl. 2, 61-67.

ANGUS JA, FERRIER CP, SUDHIR K, KAYE DM \& JENNINGS GL (1993). Impaired contraction and relaxation in skin resistance arteries from patients with congestive heart failure. Cardiovasc. Res. 27, 204-210.

BAGgIA S, PERKINS K \& GREenBERg B (1997). Endothelium-dependent relaxation is not uniformly impaired in chronic heart failure. J. Cardiovasc. Pharmacol. 29, 389-396. 
BOERTH NJ, DEY NB, CORNWELL TL \& LINCOLN TM (1997). Cyclic GMP-dependent protein kinase regulates vascular smooth muscle cell phenotype. J. Vasc. Res. 34, 245259.

BRILLA CG \& MAISCH B (1994). Regulation of the structural remodelling of the myocardium: from hypertrophy to heart failure. Eur. Heart. J. 15(SuppI. D), 45-52.

BUIKEMA H, VAN GILST WH, VAN VELDHUISEN DJ, DE SMET BJGL, SCHOLTENS E, LIE KI \& WESSELING H (1993). Endothelium dependent relaxation in two different models of chronic heart failure and the effect of ibopamine. Cardiovasc. Res. 27, 2118-2124.

Comini L, Bachetti T, Gaia G, Pasini E, Agnoletti L, Pepi P, Ceconi C, Curello $S$ \& FERRARI R (1996). Aorta and skeletal muscle NO synthase expression in experimental heart failure. J. Mol. Cell. Cardiol. 28, 2241-2248.

DOWELL FJ, HENRION D, DURIEZ M \& MICHEL J-B (1996). Vascular reactivity in mesenteric resistance arteries following chronic nitric oxide synthase inhibition in Wistar rats. $B r$. J. Pharmacol: 117, 341-346.

DREXLER H \& LU W (1992). Endothelial dysfunction of hindquarter resistance vessels in experimental heart failure. Am. J. Physiol. 262, H1640-H1645.

DREXLER H, TOggaRt EJ, GLICK MR, HEALD J, Flaim SF \& ZeLIS R (1986). Regional vascular adjustments during recovery from myocardial infarction in rats. $J$. Am. Colll. Cardiol. 8, 134-142.

DREXler H, Hablawetz E, Lu W, Riede U \& Christes A (1992a). Effects of inhibition of nitric oxide formation on regional blood flow in experimental myocardial infarction. Circulation 86, 255-262.

DREXLER H, RIEDE U, MÜnzel T, KÖNIG H, FUNKE E \& JUST H (1992b). Alterations of skeletal muscle in chronic heart failure. Circulation 85, 1751-1759.

DREXLER H, KURZ S, Jeserich M, MÜnzel T \& HORNIng B (1995). Effect of chronic angiotensin-converting enzyme inhibition on endothelial function in patients with chronic heart failure. Am. J. Cardiol. 76, 13E-18E.

Garland CJ, PLANe F, KemP BK \& COCKS TM (1995). Endothelium-dependent hyperpolarization: a role in the control of vascular tone. TiPS 16, 23-30.

HABiB H, DUTKA D, CROSSMAN D, OAKELY CM \& CLELAND JGF (1994). Enhanced basal nitric oxide production in heart failure: another falled regulatory mechanism? Lancet $344,371-373$.

HAHN AWA, RESINK TJ, KERN F \& BÜHLER FR (1993). Peptide vasoconstrictors, vessel structure, and vascular smoath-muscle proliferation. J. Cardiovasc. Pharmacol. 22(Suppl. 5), S37-S43. 
HEENEMAN S, LEENDERS PJA, AARTS PJJW, SMITS JFM, ARENDS JW \& DAEMEN MJAP (1995). Peripheral vascular alterations during experimental heart failure in the rat: do they exist? Anterioscl. Thromb. Vasc. Biol. 15, 1503-1511.

HENRION D, DOWELL FJ, LEVY BI \& MICHEL J-B (1996). In vitro alteration of aortic vascular reactivity in hypertension induced by chronic $\mathrm{N}^{6}$-nitro-L-arginine methyl ester. Hypertension 23, 361-366.

HIROOKA $Y$, IMAIZUMI T, TAGAWA T, SHIRAMOTO M; ENDO T, ANDO S-i \& TAKESHITA A (1994). Effects of L-arginine on impaired acetylcholine-induced and ischemic vasodilation of the forearm in patients with hear failure. Circulation 90, 658-668.

KAISER L, SPICKARD RC \& OLIVIER NB (1989). Heart failure depresses endotheliumdependent responses in canine femoral artery. Am. J. Physiol: 256, H962-H967.

KATZ SD, SCHWARZ M, YUEN J \& LEJEMTEL TH (1993). Impaired acetylcholine-mediated vasodilation in patients with congestive heart failure: role of endothelium-derived vasodilating and vasoconstricting factors. Circulation $\mathbf{8 8}, 55-61$.

Konstam MA, Rousseau MF, KRonenberg MW, Udelson JE, MELnin J STEWART D, DOLAN N, EDENS TR, AHN S, KINAN D \& FOR THE SOLVD INVESTIGATORS (1992). Effects of the angiotensin converting enzyme inhibitor enalapril on the long-term progression of left ventricular dysfunction in patients with heart failure. Circulation 86, 431-438.

VAN KRIMPEN C, SMITS JFM, CleUtJJENS JPM, DEBETS JJM, SchOEMAKER RG, STRUIJKER BOUDIER HAJ, BOSMAN FT \& DAEMEN MJAP (1991). DNA synthesis in the non-infarcted cardiac interstitium after left coronary artery ligation in the rat: effects of captopril. J. Mol. Cell. Cardiol. 23, 1245-1253.

KuBo SH, RECTOR TS, BANK AJ, WILlIAMS RE \& Heifetz SM (1991). Endotheliumdependent vasodilation is attenuated in patients with heart failure. Circulation 84,1589 1596.

LINDSAY DC, JIANG C, BRUNOTTE F, ADAMOPOLLIOS S, COATS AJS, Rajagopalan B, POOLE-WILSON PA \& COLLINS P (1992). Impairment of endothelium dependent responses in a rat model of chronic heart failure: effects of an exercise training protocol. Circ. Res. 26, 694-697.

Lindsay DC, ANand IS, Bennett JG, Pepper JR, YaCoub MH, Rotheriy SM, SEvers NJ \& POOLE-WLSON PA (1994). Uitrastructural analysis of skeletal muscle: microvascular dimensions and basement membrane thickness in chronic heart failure. Eur. Heart. $J$. $15,1470-1476$.

Mombouli J-V, Illiano S, Nagao T, Scott-Burden T \& Vanhoutte PM (1992). Potentiation of endothelium-dependent relaxations to bradykinin by angiotensin 1 converting enzyme inhibition inhibitors in canine coronary artery involves both endothelium-dependent relaxing and hyperpolarizing factors. Circ. Res. 71, 137-144. 
Mulder P, Elfertak L, RICHARd V, COMpagnon P, Devaux B, HENRY J-P. SCAlbert E, DESCHE P, MACE B \& THULLEZ C (1996). Peripheral artery structure and endothelial function in heart failure: effect of ACE inhibition. Am. J. Physiol. 271, H469-H477.

NakAMUIRA M, Funakoshi T, ARAKAWA N, YOSHIDA M, MAKITA S \& HIRAMORI K (1994). Effect of angiotensin-converting enzyme inhibitors on endothelium-dependent peripheral vasodilation in patients with chronic heart failure. J. Am. Coll. Cardiol. 24, 1321-1327.

NELISSEN-VRANCKEN HJMG, LEENDERS PJA, STRUIJKER BOUDIER HAJ \& SMITS JIFM (1992). Increased responsiveness of the vascular bed to angiotensin I, angiotensin II and phenylephrine in acute and chronic ischemic hindlimbs in rats. J. Vasc. Res. 29, 359-366.

OHYAMAGI M, NISHIGAKIK \& FABER JE (1992). Interaction between microvasicular $\alpha_{1}$ and $\alpha_{2}$ adrenoceptors and endothelium-derived relaxing factor. Circ. Res. 71, 188-200.

OKUMURA $Y$, NASA $Y$, SANBE $A$. TOGA W \& TAKEO $S$ (1996). Effects of long-term treatment with trandolapril on augmented vasoconstriction in rats with chronic heart failure. J. Card. Fail. 2, 301-310.

ONTKEAN M, GAY R \& GREEnBERG B (1991). Diminished endothelium-derived factor activity in an experimental model of chronic heart failure. Circ. Res. 69, 1088-1096.

PASSIER RCJJ, SMITS JFM, VERLUYTEN MJA, STUDER R, DREXLER H \& DAEMEN MJAP (1995). Activation of angiotensin-converting enzyme expression in infarct zone following myocardial infarction. Am. J. Physiol. 269, H1268-H1276.

Pfeffer JM. Pfeffer MA \& BRAunwald E (1985). Influence of chronic captopril therapy on the infarcted left ventricle of the rat. Circ. Res. 57, 84-95.

SCHOEMAKER RG, URQUHART J, DEBETS JJM, STRUIJKER BOUDIER HAJ \& SMITS JFM (1990). Aculte hemodynamic effects of coronary artery ligation in conscious rats. Basic Res. Cardiol. 85, 9-20.

SCHOEMAKER RG, DebetS JJM, STRUIJKER BOUdiER HAJ \& SMITS JFM (1991). Delayed but not immediate captopril therapy improves cardiac function in conscious rats, following myocardial infarction. J. Mol. Cell. Cardiol. 23, 187-197.

SMITH CJ, SUN D, HOEGLER C, ROTH BS, ZHANG $X, Z$ ZHO $G, X U X-B$, Kobari $Y$, PRITCHARD K Jr, SESSA WC \& HINTZE TH (1996). Reduced gene expression of vascular endothelial NO synthase and cyclooxygenase-1 in heart failure. Circ. Res. 78, 58-64. SMITS JFM, PASSIER RCJJ, NELISSEN-VRANCKEN HJMG, KUIZINGA MC \& DAEMEN M.JAP (1995). Does ACE inhibition limit structural changes in the heart following myocardial infarction? Eur. Heart. J. 16(Suppl. N), 46-51. 
STASSEN FRM, FAZZI GE, LEENDERS PJA, SMITS JFM \& DE MEY JGR (1997a), Coronary artery hyperreactivity and mesenteric arterial hyporeactivity after myocardial infarction in the rat. J. Cardiovasc. Pharmacol. 29, 780-788.

STASSEN FRM, WILLEMSEN MJJMF, JANSSEN GMJ, FAZZI GE, SCHIFFERS PMH, SMITS JFM \& DE MEY JGR (1997b). Reduced responsiveness of rat mesenteric artery smooth muscle to phenylephrine and calcium following myocardial infarction. Br. J. Pharmacol. $120,1506-1512$.

TEERLINK JR, ClOzEL M* FISCHLI W \& ClOzEL J-P (1993). Temporal evolution of endothelial dysfunction in a rat model of chronic heart failure. J. Am. Coll. Cardiol. 22, 615-620.

TEERLINK JR, GRAY GA, ClOzEL M \& CLOZEL J.P (1994). Increased vascular responsiveness to norepinephrine in rats with heart failure is endothelium dependent: dissociation of basal and stimulated nitric oxide release. Circulation 89, 393-401.

TRACEY WR, TSE J \& CARTER G (1995). Lipopolysaccharide-induced changes in plasma nitrate in rats and mice: pharmacological evaluation of nitric oxide synthase inhibitors. J. Pharmacol. Exp. Ther. 272, 1011-1015.

UsuI M, MATSUOKA H, MIYAZAKI H, OKUDA S \& IMAIZUMI T (1997). increased endogenous nitric oxide synthase inhibitor in patients with congestive heart failure. Hypertension 30 , 484.

WROBleWSKI H, KastRup J, NøRGaARD T, MORTEnSEN S-A \& Haung S (1992). Evidence of increased microvascular resistance and arteriolar hyalinosis in skin in congestive heart failure secondary to idiopathic dilated cardiomyopathy. Am. J. Cardiol. 69, 769774. 


\section{General discussion}

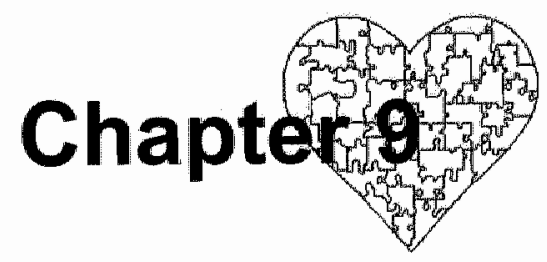


Congestive heart failure is a serious health problem - in terms of prevalence, morbidity and mortality. Heart failure afflicts $1-2 \%$ of the population in Europe and the United States, and its incidence is predicted to continue growing (Department of Health, 1992; Bonneux et al. 1994; Dargie et al. 1996). Patients suffering from heart failure succumb to edema, dyspnea and fatigue. Despite advances in treatment regimes, mortality rates remain high, being eight times that of the same-aged general population (Kalon et al. 1993; Konstam et al. 1994).

Initial diagnosis of heart failure is hindered by the broad scope of pathologies which may ultimately lead to the development of this syndrome. While ischemic heart disease has surpassed hypertension as the most occurrent primary cause, these etiologies are not necessarily mutually exclusive (Erikkson, 1995). The progression of the disease is similarly quite varied in terms of both the extent and time course of developing symptoms. Heart failure is not a static condition but a negative spiral of cardiac and peripheral compensatory mechanisms which ultimately become maladaptive. The development of more effective treatment regimes requires a better understanding of the mechanisms leading to compensatory maladaptation and better insight into factors leading to the disease's morbidity.

In this thesis, a number of factors which may influence both large and small artery function during the development and progression of heart failure were addressed. We hypothesized that chronic changes in hemodynamics and neurohormonal activity contribute to the progression of heart failure by inducing functional and structural changes in the vasculature. These alterations in the vasculature may then further undermine cardiac function, which in turn effects hemodynamic and neurohormonal changes to perpetuate the downward spiral that hallmarks heart failure.

\section{Hemodynamic and neurohormonal changes in the coronary artery ligated rat model of heart failure}

As presented and discussed in Chapter 2, the myocardially infarcted rat displays characteristics of left ventricular dysfunction and develops heart failure. Indeed, infarcted hearts responded poorly to volume loading over the entire experimental period, indicating that cardiac function was compromised. Although maximally stimulated cardiac output was consistently reduced, compensatory mechanisms were clearly capable of maintaining baseline hemodynamic function in the first phases after myocardial infarction. Acutely (at one week) post-myocardial infarction, activation of neurohormonal systems contributes to maintenance of baseline cardiac output probably by enhancing cardiac contractility since peripheral resistance was not increased. From three to five weeks after myocardial infarction, total peripheral resistance was increased, which sustains 
perfusion pressure. This increase in afterload may have contributed to the reduction in baseline cardiac output at that time. Peripheral resistance was increased despite normal levels of various neurohormones. This apparent paradox may be due to the importance of unmeasured neurohormones, local neurohormonal systems, or structural changes in the peripheral vasculature (Moncada et al. 1991; Wroblewski et al. 1992, 1995; Battistini et al. 1993; Dzau et al. 1994; Pinto et al. 1995; Schieffer et al. 1995). Thirteen weeks after myocardial infarction, increased plasma levels of neurohormones were again prevalent and contributed to normal baseline cardiac output by inducing tachycardia. These indications may be a sign of a transition into decompensation, as pulmonary congestion has previously been observed at this time point (Heeneman et al. 1995). While local and cardiac compensatory mechanisms were sufficient to maintain perfusion pressure between three and five weeks after myocardial infarction, excessive neurohormonal activation, as reflected in elevated plasma concentrations of various hormones, became necessary at thirteen weeks to achieve hemodynamic sufficiency.

Thus, the coronary artery ligated rat develops hemodynamic abnormalities consistent with heart failure, which corroborates data previously reported by us and others (Pfeffer et al. 1985; Drexler et al. 1986; Bech et al. 1989; DeFelice et al. 1989; Schoemaker et al. 1990). The present findings demonstrate that the hemodynamic changes develop simultaneously with systemic neurohormonal changes. Combining these observations with the abundant histological data concerning cardiac hypertrophy and pulmonary edema provides strong evidence for the development of heart failure in this model (Pfeffer \& Braunwald, 1990; Anversa et al. 1993; Heeneman et al. 1995; Smits et al. 1995). Nonetheless, it must be noted that coronary artery ligation was performed in otherwise healthy, young adult rats. This is not representative of the clinical heart failure situation, which primarily occurs in the elderly with asundry complicating pathologies. Although this may be considered as limitation, this model does allow the study of the development of heart failure after myocardial infarction without interference from other complicating diseases. More importantly, the observed hemodynamic and neurohormonal changes in rats display many similarities with the development of heart failure after myocardial infarction in man. In hemodynamic terms, left ventricular dysfunction in the early stages of clinical heart failure becomes apparent primarily during exercise (Zelis et al. 1991; Gaudron et al. 1993), which is comparable to the experimental data generated during volume-loading since both maneuvers put an extra demand on the heart. Furthermore, in both instances neurohormonal activation is observed acutely after myocardial infarction after which a compensatory period with normal neurohormonal levels follows (Cohn, 1990; Rouleau et al. 1991). During this time, left ventricular dilatation and increased wall stress lead to cardiac hypertrophy (Zelis et al. 1991; Lejemtel \& Sonnenblick، 1993). 
In the long run, neurohormonal systems are again activated (Francis et al. 1990 . 1993; Swedberg et al. 1990; Sigurdsson et al. 1994). Thus, this model is suitable for the study of peripheral adaptations in the development of heart failure post myocardial infarction.

\section{Factors affecting large artery mechanics}

During the development of heart fallure in the myocardially infarcted rat, increased peripheral resistance during the compensatory phases (Chapter 2) may undermine cardiac function and contribute to the progression of heart failure. However, cardiac workload is determined by both resistance and compliance, and thus ultimately depends on the function of both small resistance arteries and large elastic arteries. Studies in humans with heart failure report either maintained or reduced systemic arterial compliance (Hirai et al. 1989; Mohiaddin et al. 1989; Laskey et al. 1990). It remains unclear if reduced compliance in clinical heart failure is a result of the underlying pathologies leading to heart failure or a consequence of the disease itself.

In this thesis the mechanical behavior of large arteries after non-complicated myocardial infarction in the rat was investigated. Although it has been proposed that the mechanical behavior of the large arteries is determined by vascular geometry, vascular wall composition, smooth muscle tone, operating pressure and pressure pulsatility, the contribution of these factors to determining in vivo dynamic compliance remains largely unknown. Research concerning the role of these factors in compliance may advance the understanding of the causes for altered compliance in heart failure and its subsidiary pathologies. Although we recently reported that vascular structural changes develop only late (reaching statistical significance by 3 months) after myocardial infarction (Heeneman et al. 1995), hemodynamic abnormalities during heart failure may invoke changes in the dynamic behavior of arteries, just as neurohormonal alterations may affect smooth muscle tone.

In Chapters 3,4 and 5 of this thesis, various possible determinants of compliance, including media thickness, lumen diameter and pressure, were modified in control and myocardially infarcted rats. Many of these modifications were achieved by altering components of the renin-angiotensin system. As abundant evidence demonstrates the hypertrophic actions of angiotensin II in the vasculature (Daemen et al. 1991; Griffin et al. 1991; Lever et al. 1992; Boonen et al. 1993), it was a logical choice as a hypertrophic agent, especially in light of the fact that confounding influence of increased blood pressure was eliminated under anesthesia. In terms of heart failure, although plasma levels of angiotensin II appeared to be only transiently elevated in the myocardially infarcted rat, the importance of the (local) renin angiotensin system in both experimental and 
clinical heart failure has been generally acknowledged (Dzau ef al. 1994; Pinto et al, 1995), thus warranting both our chronic infusion of angiotensin II and our chronic blockade of AT receptors. Indeed, the possible shift in cardiac AT receptor subtypes populations during heart failure (De Gasparo et al. 1994; Nio et al. 1995) spurred us to examine the contributions of both receptor subtypes to the mechanical and structural properties of the aorta. This is of importance in view of the development of specific $\mathrm{AT}_{1}$ blockers and their potential application in the treatment of heart failure.

The results presented in Chapter 3 demonstrate that two week infusion of angiotensin II induces an increase in aortic wall mass without changing vascular wall composition and that this additional wall mass does not influence the mechanical function of the rat thoracic aorta under isobaric conditions. These findings are in agreement with recent studies in muscular arteries which suggest that isobaric compliance may not be reduced in hypertensive humans (Hayoz et al. 1992; Laurent et al. 1994a, $b$; Weber et al. 1996; Sumitani et al. 1997). All these findings together suggest compliance may be autoregulated. For instance, a change in wall stress leading to hypertrophy would lower compliance if it were not accompanied by increased wall elasticity.

To more thoroughly understand factors affecting compliance, static and dynamic compliances and their relationship to pressure, wall mass and tone were derived from in vivo lumen area-pressure curves (Chapter 4). From the findings of Chapter 4 , we conclude that any acute effect of angiotensin II on aortic smooth muscle tone is overweighed by the distal effects of the peptide on resistance vessels leading to increased arterial pressure. Secondly, mere increases in vascular wall mass do not modify the compliant or elastic properties of the thoracic aorta over a wide range of pressures. Nonetheless, since the results of Chapters 3 demonstrate that collagen and elastin densities were unchanged by two week angiotensin II infusion, it remains to be determined if and how vascular wall composition changes affect vascular mechanics.

Chapter 4 also presents novel results concerning the relationship between pressure and static and dynamic compliance. While static compliance increases with pressure (within a physiological range), dynamic compliance peaks at normotensive pressures. These results suggest that, while viscoelastic behavior is least apparent at normotensive pressures, purely elastic behavior increases in the same pressure range if sufficient time is given for strain development. Changes in viscoelastic behavior with pressure may be a possible mechanism for the autoregulation of dynamic compliance.

Possible autoregulation of dynamic compliance inherently suggests susceptibility to pharmacological modification. Chapters 3 and 4 clearly show that smooth muscle tone and vascular wall mass are not probable effectors of compliance. In Chapter 5, we examined if chronic antagonism of $A T_{1}$ and $A T_{2}$ 
receptors could modulate aortic mechanics. AT, receptor antagonism decreased mean arterial pressure in rats, while $\mathrm{AT}_{2}$ antagonism reduced lumen diameters without affecting pressure. Both effects may have been expected to reduce compliance. In terms of $\mathrm{AT}_{1}$ antagonism, a decrease in compliance with a reduction in blood pressure may be expected on the basis of the findings in Chapter 4. Likewise, a chronic reduction in lumen diameter with $A T_{2}$ antagonism would also imply a decreased compliance: Nonetheless, the expected decrease in dynamic compliance seems to have been offset by the increased elasticity $\left(E_{\text {inc }}\right)$ which was induced by both treatments. The increase in $E_{\text {inc }}$ following chronic $A T_{1}$ antagonism may be a direct consequence of a reduction in blood pressure since in Chapter 4 the incremental elastic modulus showed an exponential relationship with wall stress and thus also blood pressure. The mechanisms behind the improvement of aortic elasticity after $\mathrm{AT}_{2}$ receptor antagonism are less clear, but may involve changes in extracellular matrix protein interactions or the adventitia. It is interesting to consider the possibility that changes in dynamic compliance induced by AT receptor antagonism may have been counteracted by physiological compensation mechanisms. As summarized in Table 9.1, dynamic compliance could be altered by acute changes in blood pressure, but our attempts to chronically modulate dynamic compliance (Chapters 3,4 and 5) were unsuccessful. Changes in blood pressure acutely influence dynamic compliance in a manner that seems to depend on viscous arterial wall behavior. Thus, these results provide circumstantial evidence that dynamic compliance is sensed and autoregulated. While it seems possible that viscoelastic behavior may play a role herein, further research is needed to elucidate the structural components involved.

\section{Factors affecting large artery mechanics in heart failure}

As mentioned above, one of the objectives of this thesis was to investigate the mechanical behavior of large arteries after non-complicated myocardial infarction. Thus, the intervention studies of Chapter 5 were also conducted in coronary artery-ligated rats. In untreated rats three weeks after myocardial infarction, aortic mechanics were not different from those seen in sham-operated rats. Thus, during the compensatory phase of heart failure in which peripheral resistance is increased (Chapter 2), aberrant aortic mechanics do not seem to contribute to increased cardiac workload. If pressure is an important determinant of compliance as suggested in Chapter 4, normal aortic mechanical behavior after myocardial infarction in the rat is not surprising since arterial pressure was not altered in this model at the time of experimentation (Chapter 5). 
Table 9.1 Possible factors affecting dynamic compliance

\begin{tabular}{|c|c|c|c|c|}
\hline $\begin{array}{l}\text { Possible dynamic } \\
\text { compliance } \\
\text { regulators }\end{array}$ & Chapter & Effector & $\begin{array}{c}\text { Primary } \\
\text { effect }\end{array}$ & Result \\
\hline \multicolumn{5}{|l|}{ Acute } \\
\hline Tone & 4 & ANG $\|$ & distal $\Rightarrow \mid \mathrm{P}$ & $=C C=E_{i n o}$ \\
\hline Pressure & 4 & blood volume & I P & CC peaks at NTP \\
\hline \multicolumn{5}{|l|}{ Chronic } \\
\hline Geometry & 3,4 & ANG $\|$ & $\mathrm{Mt}$ & $=C C_{1}=E_{i n c}$ \\
\hline & 5 & $\mathrm{AT}_{2}$ antag. & Dia & $=C C, \mid E_{i n c}$ \\
\hline Composition & 3 & ANG ॥ & not achieved & $?$ \\
\hline Pressure & 5 & $\mathrm{AT}_{1}$ antag. & $\| P$ & $=C C_{1} \mid E_{\text {ino }}$ \\
\hline
\end{tabular}

ANG II: angiotensin II, treatment regime noted in the appropriate chapters; $A T_{1 / 2}$ antag.: AT receptor antagonism as noted in the appropriate chapter; $1:$ increased; $\|:$ decreased; $P$ : pressure; NT: normotensive; Mt: media thickness; Dia: lumen diameter; distal: affecting resistance vessels; $\mathrm{CC}$ : dynamic compliance coefficient; $\mathrm{E}_{\mathrm{inc}}$ : incremental elastic madulus.

A possible role for AT receptors in influencing aortic elasticity was described in Chapter 5, which is noteworthy if viscoelasticity affects compliance (Chapter 4). Since $A T_{1}$ and $A T_{2}$ receptor subtypes have been suggested to be functionally antagonistic (Hein et al. 1995; Nakajima et al. 1995; Munzenmaier \& Greene, 1996) and since recent studies indicate that the proportion of AT receptor subtypes may be altered in failing hearts (De Gasparo et al. 1994; Nio et al. 1995), angiotensin IImediated effects on aortic elasticity may be altered in heart failure. More specifically, a shift of receptor subtypes in the vasculature may either potentiate or abnegate the effects of enhanced (local) angiotensin II activity in heart failure (Schunkert et al. 1993; Luchner et al. 1996). Although AT receptor antagonism induced fairly similar effects in myocardially infarcted and sham rats, both $A T_{1}$ and $A T_{2}$ antagonism additionally improved the distensibility of the aorta in rats after myocardial infarction. The mechanisms behind this additional improvement are not clear, but such an improvement in aortic mechanics may be beneficial in the treatment of heart failure by reducing cardiac work load, and thus warrant additional research attention. 


\section{Factors affecting resistance arteries}

Total peripheral resistance is generally found to be increased in clinical heart failure (Drexler et al. 1986; Leier, 1992). In our model it was increased during the compensatory ( $3-5$ week) period in this model. This is generally assumed to be due to structural changes in the resistance vasculature (Wroblewski et al. 1992, 1995; Pinto et al. 1995; Schieffer et al. 1995\%, to an impaired dilatory capacity of peripheral vessels (Zelis et al. 1991; LeJemtel \& Sonnenblick, 1993; Drexler, 1994), or to enhanced peripheral vasoconstriction (Hasking et al. 1986, 1988; Wilson et al. 1988, 1989 . On the contrary, diminished contractile function has also been noted in both experimental and clinical heart failure (Angus et al. 1993; Stassen et al. 1997a, c). Chapters 6-8 address several factors influencing the generation of resistance in the rat hindlimb vascular bed.

The generation of resistance in a vascular bed is dependent on the geometry of the vascular network, the geometry of the contributory vessels themselves, the function of the vascular smooth muscle, and the balance between vasoconstrictor and vasodilator factors. In Chapter 8 , we noted that vascular network changes that have an effect on minimal resistance do not develop in the hindlimb within three months after myocardial infarction, suggesting that if enhanced resistance is generated in this vascular bed, it is soley of a functional nature, e.g., elevated supply of stimulus, increased function of the smooth muscle. These findings differ from those of Wroblewski et al. (1992) who demonstrated increased minimal vascular resistance in skin in patients with heart failure, but are in agreement with several studies which failed to demonstrate structural alterations in rat mesenteric resistance vasculature from five weeks to one year after myocardial infarction (Heeneman et al. 1995; Mulder et al. 1996; Stassen et al. 1997a). It thus seems that the neurohormonal and hemodynamic changes after myocardial infarction in the rat do not induce network structural changes which affect minimal resistance in the hindlimb vascular bed.

We initially hypothesized that chronic increases of vasoconstrictor neurohormones in heart failure might induce hypertrophy in the resistance vasculature. Nonetheless, systemic neurohormonal activation was only apparent at one and thirteen weeks in the rat (Chapter 2), making it possible that the magnitude and/or the duration of the hormonal inbalance was insufficient to induce vascular alterations. Furthermore, the exact role of local neurohormones is not known. To better understand the effects of chronic changes in the neurohormonal balance on vascular structure, we investigated the effects of tempering the influence of the endogenous endothelium-derived vasodilator NO with L-NAME and enriching that of the vasoconstrictor angiotensin II (Chapter 7). Chronic L-NAME treatment lead to vascular hypotrophy, probably due to a chronic reduction of blood flow (Langille \& O'Donnell, 1986; Gardiner et at. 1990; Pourageaud \& De 
Mey, 1997). Although chronic angiotensin $1 /$ infusion has been shown to induce hypertrophy in small arteries (Griffin et al. 1991; Simon et al. 1995; Stassen et al. 1997b), the media cross-sectional area of the resistance-sized vessel that we studied remained unchanged, possibly due to its lack of sympathetic innervation (Stassen et al. 1997b). Minimal vascular resistance was also not altered by chronic infusion of angiotensin I! or L-NAME. Based on findings by Folkow et al. (1970), Schriffin (1992), and Agabiti Rosei et al. (1995) concerning the relationship between vascular gemoetry and function, the lack of increase in vascular constrictor responses combined with the histological and minimal resistance data implies that, in terms of the entire vascular bed, neither vascular wall mass nor media-to-lumen ratio were increased over a two week period by either angiotensin II or L-NAME. Thus, the increased peripheral resistance (ascertained in Chapter 7 from mean arterial pressure) during the two week experimental period is purely functional in nature, neither being caused by nor causing peripheral vascular hypertrophy. On the contrary, chronically reduced NO synthesis seems to directly or indirectly lead to vascular hypotrophy.

While hindlimb vascular resistance is not elevated by structural network changes in the myocardially infarcted rat, we also did not find evidence for a contribution of impaired vasodilator capacity in this model. Normal acetylcholineinduced dilator responses were found in the perfused hindlimb vascular bed up to thirteen weeks after myocardial infarction (Chapter 8). Depressed endotheliumdependent dilatations in clinical and experimental heart failure are often associated with altered endothelium-independent relaxations (Ontkean et al. 1991; Buikema et al. 1993), which we failed to find, or with increased vasoconstrictior prostaglandin production (Katz et al. 1992, 1993) which we inhibited. Thus, we initially assumed that acetylcholine-stimulated NO production was not aberrant in our model. However, from the results of Chapter 6 , we noted that a non-NO, nonprostacyclin factor, which may be the yet unidentified endothelium-derived hyperpolarizing factor (EDHF) (Komori \& Vanhoutte, 1990; Cohen \& Vanhoutte, 1995), participates in acetylcholine-induced vasodilations in the rat hindlimb vascular bed. Indeed, while NO seems to be the primary endothelium-derived relaxing factor in large vessels, surmounting evidence points towards the increased contribution of EDHF in relaxation of resistance vascular beds (Garland et al. 1995). Many of the studies demonstrating reduced acetylcholine responses in heart failure have been conducted in large vessels (Ontkean et al. 1991; Lindsay et al. 1992; Buikema et al. 1993; Teerlink et al. 1993). We hypothesize that stimulated nitric oxide (NO) release may be diminished in heart failure but that the demonstration of endothelium-dependent dilator dysfunction depends on the contribution of NO to agonist-induced dilatations in a given vessel or vascular bed. In agreement with this posit are the results of Baggia and coworkers (1997) who report endothelial 
dilator dysfunction in large, but not in resistance-sized, vessels in experimental heart failure.

Increased peripheral resistance in the compensatory phases of heart failure in this model may thus depend upon active vasoconstriction induced by an unidentified mechanism or by a reduction in a vasodilator substance. Several lines of evidence suggest that basal NO levels may be reduced after $M$ in in the rat. In Chapter 8, chronic NO synthase inhibition increased blood pressure to a much lesser degree in Ml rats compared to sham rats. Since it is impossible to measure systemic NO production directly, the currently acceptable method for ascertaining NO production is to measure vascular or hemodynamic responses consequent to the administration of a nitric oxide synthase inhibitor in the absence of exogenously-administered pharmacologic agonists. Utilizing such an indirect method, the amount of basal NO production ascertained depends not only on the activity of the enzyme itself but also on various biochemical and hemodynamic mechanisms which modulate the ultimate effect of the NO produced. In Figure 9.1. various factors which influence NO synthesis in the endothelial cell are indicated. Several of these may be relevant in the observation that basal NO production is reduced in heart failure. In hemodynamic terms, reductions in shear stress due to reduced blood flow may reduce the quantities of NO synthesized (Langille \& O'Donnell, 1986; Ranjan et al. 1995; Umans \& Levi, 1995). In biochemical terms, recent studies demonstrate decreased expression of NO synthase (Comini et al. 1996; Smith et al. 1996) and also increased plasma concentrations of endogenous NO synthase inhibitors like asymmetrical dimethylarginine (Usui et al. 1997). Furthermore, the availablity of L-arginine, the substrate for NO synthase, may be limiting in heart failure since it has been demonstrated that L-arginine infusions improve endothelial function (Hircoka et al. 1994). In analogy to various other cardiovascular diseases (hypertension, diabetes, hyperlipidemia) (Ignarro, 1990; Dinerman at al. 1993; Rubanyi, 1993; Bouloumie et al. 1997), increased levels of superoxide radicals may reduce NO levels in heart failure (Gutierrez et al. 1997). Lastly, although having received little attention in pathological conditions, reduced quantities of cofactors for NO synthase may likewise temper NO synthesis (Sessa, 1994). Of course, deficiencies in the post-NO signal transduction pathway of the smooth muscle cell may also temper the effects of NO production. However, as exogenous NO donors generated normal responses (Chapter 8 ), this is unlikely. All in all, a reduction in basal NO levels regardless of the underlying mechanism may acutely contribute to the increased peripheral resistance seen at three to five weeks post myocardial infarction. 


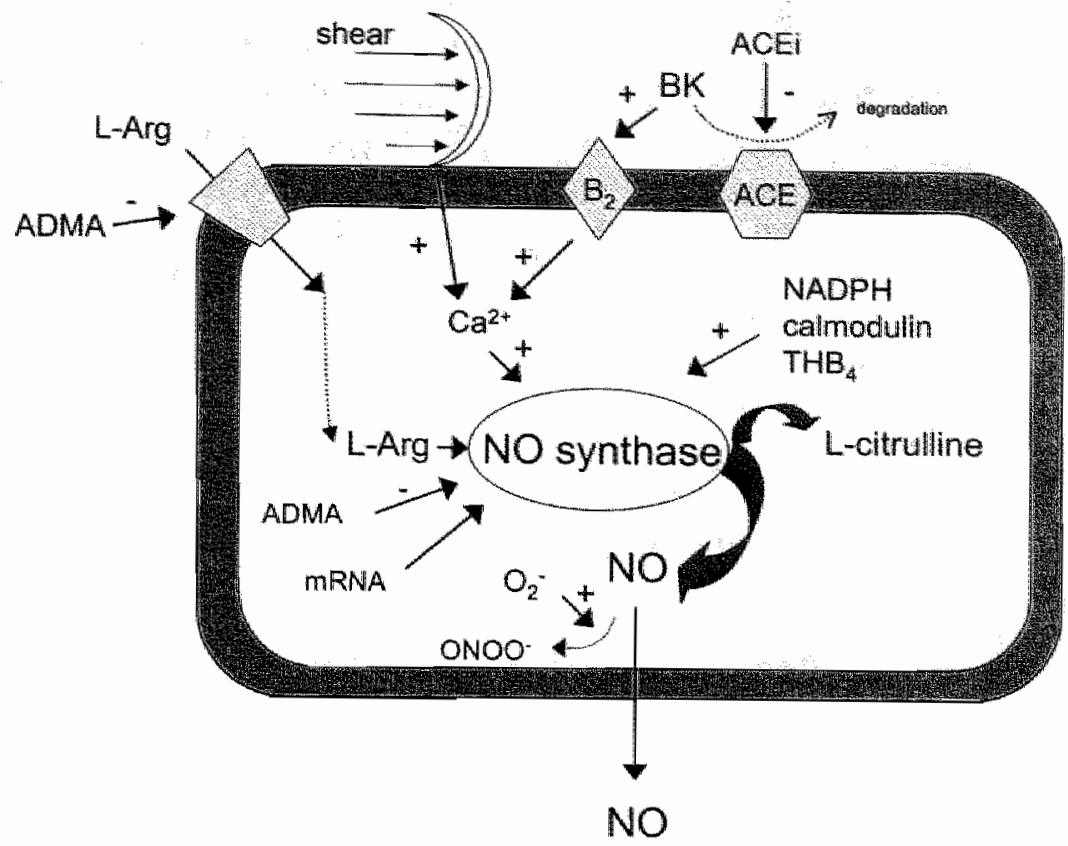

Figure 9.1

Factors affecting basal nitric oxide (NO) production in the vascular endothellal cell. The beneficial effect of angiotensin converting enzyme inhibition (ACEi) in bolstering NO levels is also indicated. L-arg: L-arginine; $B K$ : bradykinin; $B_{2}$ : bradykinin receptor; $A C E$ : angiotensin converting enzyme; ADMA: asymmetrical dimethylarginine, an endogenous NO synthase unhibitor; $\mathrm{THB}_{4}$ : tetrahydrobiopterin; NADPH: nicotine adenine diphosphate.

\section{Resistance artery NO, vasoconstrictor hyporeactivity and the progression of heart failure}

Interestingly, during the time frame in which peripheral resistance is increased, vascular contractile dysfunction develops in the rat hindlimb (Chapter 8 ). Similar observations were made in the mesenteric vasculature (Stassen et al. 1997a, c). In the hindlimb, decreased vasoconstrictor capacity may arise from chronically reduced basal NO concentrations. As presented in Chapter 8 chronic administration of L-NAME reduced vascular contractile ability in sham rats analogous to the vasoconstrictive dysfunction seen in untreated $\mathrm{MI}$ rats two weeks after surgery. On the other hand, L-NAME treatment did not further reduce the depressed vasoconstrictor responses in Ml rats. Deleterious effects of reduced basal NO levels on vascular contractile ability has been previously observed (Dowell et al. 1996; Henrion et al. 1996). 
Although the concept of reduced NO levels leading to constrictor hyporeactivity seems at first glance contradictory, several possible mechanisms exist to explain such a phenomenon. Basal NO arises from endothelial and neuronal NO synthase (Forstermann et al. 1994). It is thus possible that hyporeactivity induced by low basal NO (whether after myocardial infarction or after L-NAME treatment) is due to a reduction of neuronal NO synthase activity. A reduction in NO from neuronal NO synthase located in either nitrergic or sympathetic nerves would lead to heightened sympathetic nerve activity (Forstermann et al. 1994; Sander et al. 1995) and may induce hyporeactivity similar to that seen after chronic catecholamine infusion (Boonen et al. 1993; Brilla, 1994). However, we did not observe heightened catecholamine levels in the time frame corresponding with the development of vasoconstrictor hyporeactivity (Chapter 2 and 8 ). On the other hand, NO acutely induces smooth muscle relaxation indirectly via cGMP by increasing potassium channel activity (Archer et al. 1994), decreasing voltage-operated calcium channel activity (Blatter \& Wier, 1994; Andriantsitohaina et al. 1995), and decreasing sarcoplasmic reticulum $\mathrm{Ca}^{2+}$-ATPase activity, and decreasing the calcium sensitivity of the contractile apparatus (Lee et al. 1997) (Figure 9.2). Furthermore, NO directly relaxes smooth muscle by stimulating calcium-dependent potassium channels (Bolotina et al. 1994) and the sarcoplasmic reticulum $\mathrm{Ca}^{2+}$-ATPase (Cohen et al. 1997). Chronic reductions in NO activity may ultimately increase free cytoplasmic and/or decrease sarcoplasmic reticular calcium levels which in turn may disturb the influx of calcium upon smooth muscle stimulation. A recent study by our group demonstrates that vasoconstrictor hyporeactivity in the mesenteric circulation may be due to impaired agonist-induced calcium influx (Stassen et al. 1997c).

A recent study by Boerth et al. (1997) suggests that NO contributes to the maintenance of a contractile phenotype in vascular smooth muscle cells via cGMP-dependent kinase (PKG) (Figure 9.2). A reduction in NO may thus lead to a shift to a more synthetic phenotype. If chronically reduced NO levels lead to increased free intracellular calcium levels as argued above, synthetic processes may also be stimulated (Mogami \& Kojima, 1993; Simons et al. 1995; Nie of al. 1996). Paradoxically, we did not find evidence for vascular smooth muscle growth in this model of experimental heart failure (Giannattasio ot al. 1995; Stassen et al. 1997a). Although the reasons for this are not clear, it may be that the calcium flux as opposed to the absolute intracellular calcium concentrations is important for stimulating growth. Indeed, cells with lower sarcoplasmatic reticulum $\mathrm{Ca}^{2+}$ ATPase activity exhibit slower growth but unchanged division rate (Nie et al. 1996). On the other hand, synthetic smooth muscle cells actively synthesize protein but may not necessarily grow, i.e., synthetic smooth muscle cells are also highly secretory (Thyberg, 1996). Furthermore, any growth stimuli may be countered by hypotrophic stimuli arising from chronic reductions in blood flow. Although research efforts must be directed towards deciphering the underlying 
mechanisms, it seems possible that a certain amount of NO is required for the maintenance of normal smooth muscle contractile function.

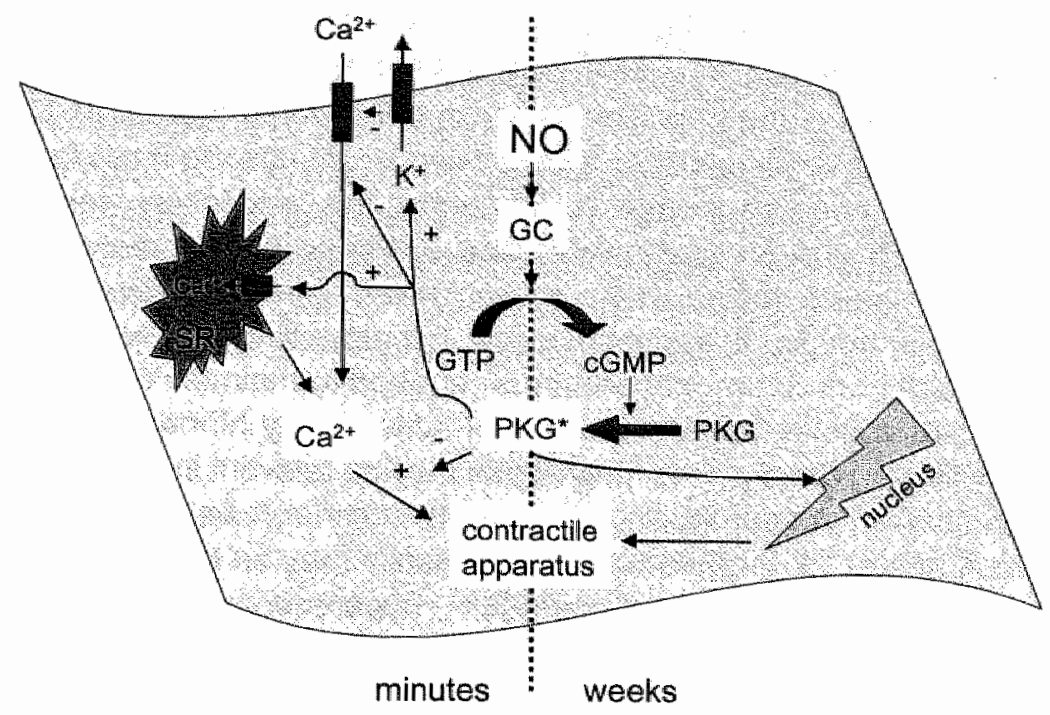

\section{Figure 9.2}

Nitric oxide (NO) exerts both acute (minutes) and chronic (weeks) effects on the function of the vascular smooth muscle cell. Guanylate cyclase (GC) converts guanylate triphosphate (GTP) to cyclic guanylate monophosphate (CGMP), which in turn activates $\left({ }^{*}\right)$ a cGMP-dependent protein kinase (PKG). On an acute basis, $\mathrm{PKG}^{*}$ decreases intracellular calcium levels and increases the affinity of the contractile apparatus for calcium. On a chronic basis. PKG* maintains the contractile phenotype of the smooth muslce cell. SR: sarcoplasmic reticulum.

Reductions in NO levels may contribute to the progression of heart failure as shown in Figure 9.3. Acute reductions in NO may increase total peripheral resistance and thereby undermine cardiac function. On the other hand, chronic reductions in NO may induce vasoconstrictor hyporesponsiveness as argued above. Hyporesponsiveness to vasoconstrictors may provide an unexpected mechanism contributing to the development of the classic symptoms of heart failure, edema and exercise intolerance, and to the shift from compensation to decompensation. The development of edema and exercise intolerance may be precipitated by vascular hypocontractility. For example, if sufficient proximal resistance can not be generated in a vascular bed, the resulting increase in capillary pressure may exaggerate oedema formation. Furthermore, during exercise, sympathetic activation normally induces general vasoconstriction, such 
that blood flow is channeled to metabolite-dilated exercising muscles. If generalized vasoconstrictor dysfunction results in reduced sympathetic-induced vasoconstriction, blood fllow may be siphoned away from exercising muscles, leading to quickened fatigue. Perhaps more importantly , the development of vasoconstrictor hyporesponsiveness may perpetuate a viscous cycle of increased neurohormonal activation, increased peripheral resistance and decreased cardiac function which incites the transition to decompensation (Figure 9.3). Diminished responsiveness to vasoconstrictors implicitly perpetuates the need for additional vasoconstrictor neurohormones to generate the necessary resistance for maintaining perfusion pressure. As shown in Figure 9.4 , increased peripheral resistance in heart failure may be achieved by a relative increase in vasoconstrictor levels. If vasoconstrictor hyporeactivity develops, additional vasoconstrictor neurohormonal activity is required to maintain resistance levels. Continued upregulation of neurohormonal activity may hinder cardiac function both indirectly and directly. This mechanism may be relevant in our model as seen by the reactivation of neurohormonal systems at thirteen weeks after myocardial infarction (Chapter 2). Furthermore, these results may be relevant in the clinical situation since similar vasoconstrictor hyporesponsiveness has been demonstrated in human heart failure (Angus et al. 1993).

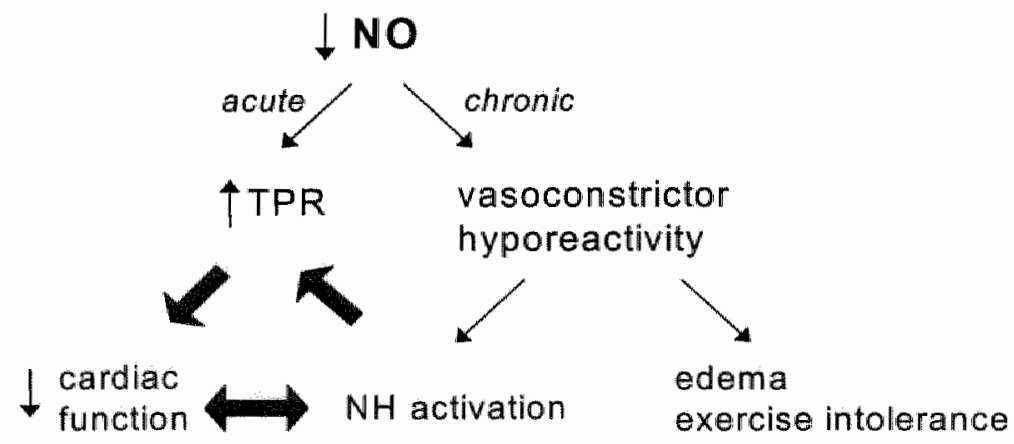

\section{Figure 9.3}

On an acute basis, decreased levels of nitric oxide (NO) may lead to increased total peripheral resistance (TPR). Chronic re-duction in NO levels may contribute to the development of the classic symptoms of heart failure and to a viscous cycle (shaded arrows) which accel-erates the progression of heart failure. $\mathrm{NH}$ : neurohormone. 
Chapter 8 presents evidence that angiotensin converting enzyme (ACE) inhibition may improve vasoconstrictor dysfunction post myocardial infarction. Although the intracellular mechanism behind the hyporeactivity after myocardial infarction remain yet unresolved, chronic administration of the ACE inhibitor captopril improved this dysfunction. ACE inhibitors not only decrease angiotensin II production but also augment NO levels through inhibition of bradykinin degradation (Mombouli et al. 1992) (see Figure 9.1). Henrion and coworkers (1996) recently reported that contractile hyporeactivity consequent to chronic NO synthase inhibition was prevented when an ACE inhibitor was administered concomitantly. From the results of Chapter 8 , it seems possible that the beneficial effect of captopril on vascular contractile function may be due to the enhancement of NO production and/or the decrease in angiotensin II levels.

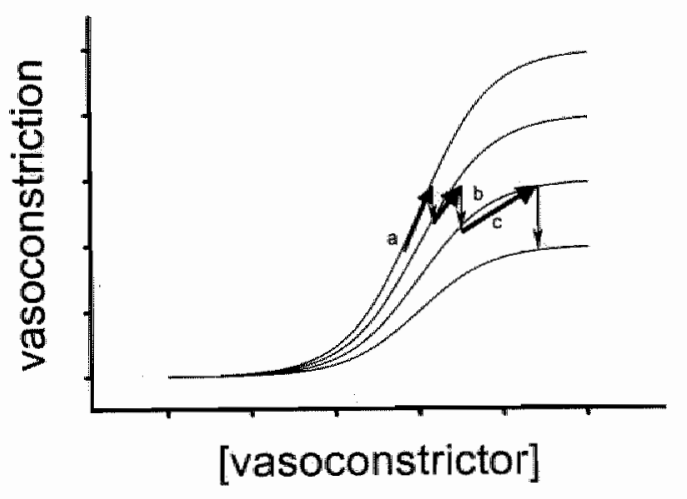

Figure 9.4

Vasoconstrictor hyporeactivity may perpetuate meurohormonal activation in an attempt to maintain increased total peripheral resistance in heart failure. Increased peripheral resistance in heart failure may be achieved by a relative increase in vasoconstrictor levels (a). If vasoconstrictor hyporeactivity develops (b), additional vasoconstrictor neurohormonal activity is required to maintain the necessary resistance (c). 


\section{Integration and perspective}

The aim of this thesis was to investigate the role of large and small artery function in the development and progression of experimental heart failure. While the hemodynamic and neurohormonal abnormalities (Chapter 2) characterizing the coronary artery-ligated rat model might have been suspected to impair (or to be impaired by) aortic mechanical function, we demonstrate that aortic compliance is maintained in compensated heart failure (Chapter 5). The absence of mechanical abnormalities in the aorta during heart failure is perhaps not surprising when considered in relation to Chapter 4 which presents data showing that, at least on an acute basis, pressure is the most important determinant of compliance. Alternatively, the results of Chapters 3-5 further the hypothesis that aortic compliance is chronically autoregulated. On the other hand, the increased peripheral resistance in the compensatory phases of heart failure (Chapter 2) seems to be due to decreased basal NO production which ultimately results in paradoxical vasoconstrictor hyporeactivity (Chapter 8 ).

With respect to the function of large arteries, the obvious question which remains is, "How is compliance regulated?" The answer may lie in factors affecting vascular viscoelasticity. From Chapters 3 and 4 , it is clear that vessel wall mass and tone are not significant effectors. By default, the importance of the extracellular matrix and the adventitia seems possible. Although one can assume that altering the proportion of collagen and elastin fibers must affect vascular elasticity, this is probably not the only effector since in Chapter 5 aortic distensibility was improved with AT receptor antagonism in myocardially infarcted rats in the absence of a change in collagen and elastin densities. Perhaps, future research will attest to the importance of the adventitia. In the scope of heart failure treatment, increasing aortic distensibility with $A T_{2}$ receptor antagonism may decrease cardiac workload despite increased resistance and thus without perturbing organ perfusion. As this effect may be clinically beneficial, additional research into the role of the $\mathrm{AT}_{2}$ receptor in heart failure is warranted. Along these lines, these findings further emphasize the importance of the renin angiotensin system in heart failure.

In terms of the role of resistance artery function in heart failure, several questions remain. On a fundamental basis, the cause of the reduction in basal NO levels remains unknown. This may be due to decreased enzyme expression or activity, which may be due to changes in flow, or perhaps more importantly shear stress. Furthermore, changes in enzyme activity may depend on decreased Larginine or cofactor availability or increased levels of endogenous inhibitors. Furthermore, the intracellular mechanisms by which chronic reductions in NO production may alter vascular function remain unexplored. Perhaps more important is the relationship between vascular contractile dysfunction and the progression of heart failure. We hypothesize that contractile hyporeactivity spurs 
oedema formation and exercise intolerance. Although skeletal muscle function is known to be abnormal in heart failure, it remains to be determined if this abnormality correlates with the observed vascular dysfunction. Additionally, if vasoconstrictor hyporeactivity is one of the missing links which triggers the transition from compensation to decompensation as we suggest, our preliminary results showing that $A C E$ inhibition may improve this abnormality warrant further examination. Future research must be directed towards investigating if the beneficial effects of ACE inhibiton on skeletal muscle function and systemic hemodynamics are due to the improvement of peripheral vascular function or vice versa.

Although the beneficial cardiac effects of angiotensin converting enzyme inhibitors are well described, the peripheral benefits of ACE inhibition may well be the ace in the hole for heart failure treatment.

\section{References}

Agabiti Rosei E, Rizzoni D, Castellano M, Porteri E, Zulli R, Mulesan ML, Bettoni G, SALVETTI M, MUIESAN P \& GIULINI SM (1995). Media:lumen ratio in human small resistance arteries is related to forearm minimal vascular resistance. $J$ Hypertens. 13, 341-347.

Andriantsitohaina R, Lagaud GJ, Andre A, Muller B \& Stoclet JC (1995). Effects of cGMP on calcium handling in ATP-stimulated rat resistance arteries. Am. J. Physiol. 268, $\mathrm{H} 1223-\mathrm{H} 1231$.

ANGUS JA, FERRIER CP, SUdHIR K, KAYE DM \& JENNINGS GL (1993). Impaired contraction and relaxation in skin resistance arteries from patients with congestive heart failure. Cardiovasc. Res. 27, 204-210.

ANVERSA P, LI P, ZHANG X, OLIVETTI G \& CAPASSO JM (1993). Ischaemic myocardial injury and ventricular remodeling. Cardiovasc. Res. 27, 145-157.

ARCher SL, HUANG JMC, HAMPL V, Nelson DP, ShULtZ PJ \& WeIR EK (1994). Nitric oxide and CGMP cause vasorelaxation by activation of a charybdotoxin-sensitive $K$ channel by cGMP-dependent protein kinase. Proceedings of the National Academy of Sciences of the United States of America 91, 7583-7587.

BAGGIA S, PERKINS K \& GREENBERG B (1997). Endothelium-dependent relaxation is not uniformly impaired in chronic heart failure. J. Cardiovasc. Pharmacol. 29, 389-396.

BATTISTINI B, D'ORLEANS-JUSTE P \& SIROIS P (1993). Endothelins: circulating plasma levels and presence in other biologic fluids. Lab. Invest. 68, 600-628.

BECH OM, KaHR O, DIAMANT B \& STEINESS E (1989). Time course of functional deterioration after coronary artery ligation in rats. Cardiovasc. Res. 23, 649-654. 
BLATTER LA \& WIER WG (1994). Nitric oxide decreases $\left[\mathrm{Ca}^{2+}\right.$; in vascular smooth muscle by inhibition of the calcium current. Cell. Calcium 15, 122-131.

BOERTH NJ, DEY NB, CORNWELL TL \& LINCOLN TM (1997). Cyclic GMP-dependent protein kinase regulates vascular smooth muscle cell phenotype. J. Vasc. Res. $34,245-$ 259.

Bolotina VM, NajlBI S, PAlacino JJ, PAGano CJ \& Cohen RA (1994). Nitric oxide directly activates calcium-cependent potassium channels in vascular smooth muscle. Nature 368, 850-853.

BONNEUX L, BARENDREgt J, MEEster K, BONSEL GJ \& VAN DER MAAS PJ (1994). Estimating clinical morbidity due to ischemic heart disease and congestive heart failure. Am. J. Public Health 84, 20-28.

BOONEN HCM, DAEMEN MJAP, EeRdMANS PHA, FAZZI GE, VAN KLEEF EM, SCHIFfers PMH \& DE MEY JGR (1993). Mesenteric small artery changes after vasoconstrictor infusion in young rats. $J$. Cardiovasc. Pharmacol. 22, 388-395.

Bouloumie A, BAUERsaChS J, LINZ W, Schollkens BA, Wiemer G, Fleming I \& Busse R (1997). Endothelial dysfunction coincides with an enhanced nitric oxide synthase production and superoxide anion production. Hypertension 30, 934-941.

BRILLA CG (1994). The cardiac structure-function relationship and the renin-angiotensinaldosterone system in hypertension and heart failure. Curr. Opin. Cardiol. 9(Suppl. 1). S2-S11.

Buikema H, VAN GILST WH, VAN VELdHUISEN DJ, DE SMET BJGL, SCHOLTENis E, LIE KI \& WESSELING H (1993). Endothelium dependent relaxation in two different models of chronic heart failure and the effect of ibopamine. Cardiovasc. Res. 27, 2118-2124.

COHEN RA \& VANHOUTTE PM (1995). Endothelium-dependent hyperpolarization: beyond nitric oxide and cyclic GMP. Circulation 92, 3337-3349.

COHEN RA, WEISBROD RM, GERICKE M \& BOLOTINA VM (1997). Novel mechanism of nitric oxide-induced relaxation: accelerated refilling of intracellular stores and decreased store-operated calcium influx. J. Vasc. Res. 34(Suppl. 1), 12.

COHN JN (1990). Neuroendocrine activation after acute myocardial infarction. Am. J. Cardiol. 65, 281-31।.

Comini l, Bachetti T, Gaia G, Pasinn E, Agnoletti l, Pepi P, Ceconi C, Curello $S$ \& FERRARI R (1996). Aorta and skeletal muscle NO synthase expression in experimental heart failure. J. Mol. Cell. Cardiol. 28, 2241-2248. 
DAEMEN MJAP, LOMBARDI DM, BOSMAN FT \& SGHWARTZ SM (1991). Angiotensin II induces smooth muscle proliferation in the normal and injured rat arterial wall. Circ. Res. $68,450-456$.

DARGIE HJ, MEMURRAY JJV \& POOLE-WILsON PA, eds. (1996). Managing heart failure in primary care. London: Blackwell Healthcare Communications.

DEFELICE A, FRERING R \& HORAN P (1989). Time course of hemodynamic changes in rats with healed severe myocardial infarction. Am. J. Physiol. 257, H289-H296.

De Gasparo $M$, Rogg $H$, Brink M, Wang L, Whitebread $S$, Bullock G \& Erne P (1994). Angiotensïn II receptor subtypes and cardiac function. Eur. Heart. J. 15(Suppl. D), 98-103.

DEPARTMENT OF HEALTH. (1992). The health of the nation. London: HMSO.

DINERMAN JL, LOWENSTEIN CJ \& SNYDER SH (1993). Molecular mechanisms of nitric oxide regulation: potentioal relevance to cardiovascular disese. Circ. Res. 73, 217-222.

DOWELL FJ, HENRION D, DURIEZ M \& MICHEL J-B (1996). Vascular reactivity in mesenteric resistance arteries following chronic nitric oxide synthase inhibition in Wistar rats. $B r . J$. Pharmacol. 117, 341-346.

DREXLER H (1994). Peripheral circulatory adaptations to pump failure of the heart. $\mathrm{Br}$. Heart J. 72, 22-27.

DReXler Hi, Toggart EJ, Glick MR, HeAld J, Fla Mi SF \& ZELIS R (1986). Regional vascular adjustments during recovery from myocardial infarction in rats. $\lrcorner$. Am. Coll. Cardiol. 8, 134-142.

DZAU VJ, PRATT R \& GIBBONS GH (1994). Angiotensin as local modulating factor in ventricular dysfunction and failure due to coronary artery disease. Drugs $47,1-13$.

ERIIKKSON H (1995). Heart failure: a growing public health problem. J. Int. Med. 237, 135141.

FOLKOW B, HALLBACK M, LUNDGREN $Y$ \& WEISS L (1970). Background of increased flow resistance and vascular reactivity in spontaneously hypertensive rats. Acta Physiol. Scand. 80, 93-106.

Forrtermann U, Closs El, Pollock JS, Nakane M, Schwarz P, Gath I \& Kleinert h (1994). Nitric oxide synthase isozymes - characterization, purification, molecular cloning, and functions. Hypertension 23, 1121-1131.

Francis GS, BenEDICT C, JOHNiSTONE DE, KIRLIN PC, NiCKLAS J, LIANG C-S, KubO SH, RUDIN-TORETSKY E, YUSUF S \& FOR THE SOLVD INVESTIGATORS (1990). Comparison of neuroendocrine activation in patients with left ventricular dysfunction with and without 
congestive heart failure. A substudy of the Studies of Left Ventricular Dysfunction (SOLVD). Circulation 82, 1724-1729.

FRANCIS GS, COHN JN, JOHNSON G, RECTOR TS, GOLDMAN S, SIMON A FOR THE V-HEFT COOPERATIVE STUDIES GROUP (1993). Plasma norepinephrine, plasma renin activity, and congestive heart failure: relations to survival and the effects of therapy in V-HeFT II. Circulation 87(Suppl. 6), V/40-VI48.

Gardiner SM, Compton AM, BennetT T, PALMer RMJ \& MonCADA S (1990). Control of regional blood flow by endothelium-derived nitric oxide. Hypertension 15, 486-492.

GaRland CJ, Plane F, Kemp BK \& COCKS TM (1995). Endothelium-dependent hyperpolarization: a role in the control of vascular tone. TIPS 16, 23-30.

GAUDRON P, EILES C, ERTL G \& KOCHSIEK K (1993). Adaptation to cardiac dysfunction after myocardial infarction. Circulation 87(Suppl. 4), IV83-IV89.

Giannattasio C, failla M, Stella ML, Mangoni Aa, Carugo S, Pozzi M, Grassi g \& MANCIA G (1995). Alterations of radial artery compliance in patients with congestive heart failure. Am. J. Cardiol. 76, 381-385.

GRIFFIn SA, BROWN WCB, MACPHERSON F, MCGRATH JC, WILSON VG, KORSGAARD N, MULVANY MJ \& LEVER AF (1991). Angiotensin II causes vascular hypertrophy in part by a non-pressor mechanism. Hypertension 17, 626-635.

GUTIERREZ JA, CLARK SG, GIULUMIAN AD \& FUCHS LC (1997). Superoxide aniona contribute to the impaired regulation of blood pressure by nitric oxide during the development of cardiomyopathy. J. Pharmacol. Exp. Ther. 282, 1643-1649.

HASKINg GJ, Esler MD, Jennings GL, Burton D \& Korner PI (1986). Norepinephrine spillpver to plamsa in patients with congestive heart failure: evidence of increased overall and cardiorenal sympathetic nervous activity. Circulation 73, 615-621.

HASKING GJ, ESLEER MD, JENNIINGS GL, DEWAR E \& LAMBERT G (1988). Norepinephrine spillover to plasma during steady-state supine bicycle exercise: comparison of patients with congestive heart failure and normal subjects. Circulation 78, 516-521.

hayoz D, Rutschmann B, Perret $F$, Niederberger $M$, Tardy $Y$, Mooser $V$, NUSSBERgER J, WAEBER B \& BRUNNER HR (1992). Conduit artery compliance and distensibility are not necessarily reduced in hypertension. Hypertension 20, 1-6.

HEENEMAN S, LEENDERS PJA, AARTS PJJW, SMITS JFM, ARENDS JW \& DAEMEN MJAP (1995). Peripheral vascular alterations during experimental heart failure in the rat: do they exist? Arteriosal. Thromb. Vasc. Biol. 15, 1503-1511. 
HEIN L, BARSH GS, PRATT RE, DZAU VJ \& KOBILKA BK (1995). Behavioural and cardiovascular effects of disrupting the angiotensin lit type-2 receptor in mice. Nature 377, 744-747.

HENRION D, DOWELL FJ, LEVY BI \& MICHEL J-B (1996). In vitro alteration of aortic vascular reactivity in hypertension induced by chronic $N^{G}$-nitro-L-arginine methyl ester. Hypertension 23, 361-366.

HIRAI T, SASAYAMA S, KaWASAKI T \& YAGI S-i (1989). Stiffness of systemic arteries in patients with myocardial infarction: a noninvasive method to predict severity of coronary atherosclerosis. Circulation 80, 78-86.

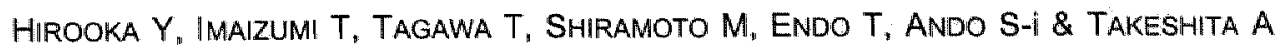
(1994). Effects of L-arginine on impaired acetylcholine-induced and ischemic vasodilation of the forearm in patients with hear failure. Circulation 90, 658-668.

IGNARRO LJ (1990). Biosynthesis and metabolism of endothelium-derived nitric oxide. Ann. Rev. Pharmacol. Toxicol. 30, 535-560.

KALON KL, PINSKY JL, KANNEL WB \& LEVY D (1993). The epidemiology of heart failure: the Framingham study. J. Am. Coll. Cardiol. 22(Suppl. A), 6A-13A.

Katz S, Biasucci L, Sabba C, Strom Ja, Jondeau G, Galvao M, Solomon S, Nikolic SD, FORMAN R \& LEJEMTEL TH (1992). Impaired endothelium-mediated vasodilation in the peripheral vasculature of patients with congestive heart failure. J. Am. Coll. Cardiol. 19, 918-925.

KATZ SD, SCHWARZ M, YUEN J \& LEJEMTEL TH (1993). Impaired acetylcholine-mediated vasodilation in patients with congestive heart failure: role of endothelium-derived vasodilating and vasoconstricting factors. Circulation $88,55-61$.

KOMORI K \& VANHOUTTE PM (1990). Endothelium-derived hyperpolarizing factor. Blood Vessels 27, 238-245.

KONSTAM M, DRACUP K, BAKER D, ET AL. (1994). Heart failure: evaluation and care of patients with left-ventricular systolic dysfunction. Clinical practical guidelines No. 11. AHCPR Publication No. 94-0612. Rockville,MD,USA: US Department of Health and Human Services.

LANGILLE BL \& O'DONNELL F (1986). Reductions in arterial diameter produced by chronic reductions in blood flow are endothelium-dependent. Science 231, 405-407.

LASKEY WK, PARKER HG, FerRaRI VA, KUSSMAUL WG \& NOORDERgRAaF A (1990). Estimation of totoal systemic arterial compliance in humans. J. Appl. Physiol. 69, 112119. 
Laurent $S$, CAVIEZEL B, BECK L; Gierd X, Billaud E, Boutouyrie P, HOEKS A \& Safar M (1994a). Carotid artery distensibility and distending pressure in hypertensive humans. Hypertension 23, 878-883.

LAURENT S, Girerd X, MOURAd J, LACOLLEY P, Beck L, BOUTOUYRIE P. Mognot J \& SAFAR M (1994b). Elastic modulus of the radial artery wall material is not increased in patients with essential hypertension. Arterioscl. Thromb. 14, 1223-1231.

LEE MR, LI L \& KITAZAMA T (1997). Cyclic GMP causes $\mathrm{Ca}^{2+}$ desensitization in vascular smooth muscle by activating the myosin light chain phosphatase. J. Biol. Chem. 272 , $5063-5068$.

LEEER CV (1992). Regional blood flow in human congestive heart failure. Am. Heart $J$. 124, 726-735.

LEJEMTEL TH \& SONNENBLICK EH (1993). Heart failure: adaptive and maladaptive process. Circulation 87(Suppl. 7), VII1-V/I4.

LEVER AF, LYALL F, MORTON JJ \& FOLKOW B (1992). Angiotensin II, vascular structure and blood pressure. Kidney Int. 41(Suppl. 37), S51-\$55.

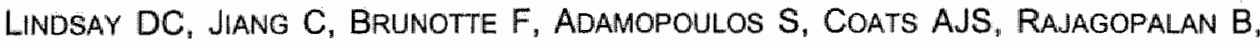
POOLE-WILSON PA \& COLLINS P (1992). Impairment of endothelium dependent responses in a rat model of chronic heart failure: effects of an exercise training protocol. Circ. Res. 26, 694-697.

Luchner A, Stevens TL, Borgeson DD, Redfield MM, Bailey JE, Sandberg SM, HEUBLEIN DM \& BURNETT J JC (1996). Angiotensin II in the evolution of experimental heart failure. Hypertension 28, 472-477.

MOGAMI H \& KOJIMA I (1993). Stimulation of calcium entry is prerequisite for DNA synthesis induced by platelet derived growth factor in vascular smooth muscle cells. Biochem. Biophys. Res. Comm. 196, 650-658.

MOHIADDIN RH, UNDERWOOD SR, BOGREN HG, FIRMIN DN, KLIPSTEIN RH, REES RSO \& LONGMORE DB (1989). Regional aortic compliance studied by magnetic resonance imaging: the effects of age, training, and coronary artery disease. Br. Heart J. 62, 90-96.

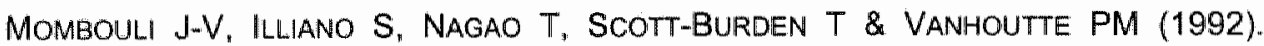
Potentiation of endothelium-dependent relaxations to bradykinin by angiotensin I converting enzyme inhibition inhibitors in canine coronary artery involves both endothelium-dependent relaxing and hyperpolarizing factors. Circ. Res. 71, 137-144.

MONCADA S, PALMER RMJ \& HIGGS EA (1991). Nitric oxide: physiology, pathophysiology, and pharmacology. Pharmacol. Rev. 43, 109-142. 
Mulder P, ElfERtak L, Richard V, COMPAGNON P, DEVAUX B, HeNRY J-P, SCALBert E, DESCHE P. MACE B \& THUILLEZ C (1996). Peripheral artery structure and endothelial function in heart failure: effect of ACE inhibition. Am. J. Physiol. 271, H469-H477.

MUNZENMAIER DH \& GREENE AS (1996). Opposing actions of angiotensin II on microvascular growth and blood pressure. Hypertension 27, 760-765.

Nakajima M, HUtchinson HG, Fujinaga F, hayashida W, Morishita R, Zhang L, HORIUCHI M, PRATT RE \& DZAU VJ (1995). The angiotensin II type 2 (AT2) receptor antagonizes the growth effects of the AT' receptor: Gain-of-function study using gene transfer. Proc. Natl. Acad. Sci. USA. 92, 10663-10667.

NiE L, MOGAMI H, KANZAKI M, SHIBATA H \& KoJIMA I (1996). Blockade of DNA synthesis induced by platlet-derived growth factor by transilast, an inhibitor of calcium entry, in vascular smooth muscle cells. Mol. Pharmacol. 50, 763-769.

NIO Y, Matsubara H, MURASAWA S, KanaSAKI M \& INADA M (1995). Regulation of gene transcription of angiotensin II receptor subtypes in myocardial infarction. J. Clin. Invest. 95, 46-54.

ONTKEAN M, GAY R \& GREENBERG B (1991). Diminished endothelium-derived factor activity in an experimentall model of chronic heart failure. Circ. Res. 69, 1088-1096.

PFEFFER JM, PFEFFER MA \& BRAUNWALD E (1985). Influence of chronic captopril therapy on the infarcted left ventricle of the rat. Circ. Res. 57, 84-95.

PFEFFER MA \& BRAUNWALD E (1990). Ventricular remodeling after myocardial infarction: experimental observations and clinical implications. Circulation 81, 1161-1172.

PINTO YM, BUIKEMA H \& VAN GILST WH (1995). Hyperactive tissue renin-angiotensin systems in cardiovascular dysfunction: experimental evidence and clinical hypotheses. Clin. Exp. Hypertension 17, 441-468.

POURAGEAUD F \& DE MEY JGR (1997). Structural properties of rat mesenteric small arteries after four week exposure to elevated or reduced blood flow. Am. J. Physiol. 273, H1699-H1706.

RANJAN V, XIAO Z \& DIAMOND SL (1995). Constitutive NOS expression in cultured endothelial cells is elevated by fluid shear stress. Am. J. Physiol. 269, H550-H555.

Rouleau Jl, Moye La, de Champlain J, Klein M, Bichet D, Packer M, Dagenais G, SUSSEX B, ARNOLD JM, SESTIER F, PARKER JO, MCEWAN MMP, BERNSTEIN $V$, CUDDY TE, Delage F, nadeau C, lamas ga, Gottlieb SS, Mccans J \& Pfeffer MA (1991). Activation of neurohormonal systems following acute miyocardial infarction. Am. J. Cardiol. 68, 80D-86D. 
RUBANY GM (1993). The role of endothelium in cardiovascular homeostasis and diseases. J. Cardiovasc. Pharmacol. 22(Suppl. 5), S1-S14.

SANDER M* HANSEN PG \& VICTOE RG (1995). Sympathetically mediated hypertension caused by chronic inhibition of nitric oxide. Hypertension 26, 691-695.

SCHIEFFER B, WOLleRT KC, BeRCHTOLd M, SAAL K, SCHIEFFer E, HORNIG B, RIEDE UN \& DREXLER H (1995). Development and prevention of skeletal muscle structural alterations after experimental myocardial infarction. Am. J. Physiol. 269, H1507-H1513.

SCHOEMAKER RG, DEBETS JJM, STRUIJKER BOUdIER HAJ \& SMITS JFM (1990). Beneficial hemodynamics effects of two weeks' milrinone treatment in conscious rats with heart failure. Eur. J. Pharmacol 182, 527-535.

SCHRIFFIN E (1992). Reactivity of small blood vessels in hypertension: relation with structural changes. State of the art lecture. Hypertension 19(Suppl. 2), I11-II9.

SCHUNKERT H, TANG S-S, LITWIN SE, DIAMANT D, RIEGger G, DZAU VJ \& INGELFINGER JR (1993). Regulation of intrarenal and circulating renin-angiotensin systems in severe heart failure in the rat. Cardiovasc. Res. 27, 731-735.

SESSA WC (1994). The nitric oxide synthase family of proteins. J. Vasc. Res. 31, 131143.

Sigurdsson A, AMtorp O, GUNDERSEN T, Nilsson B, ReMES J \& SWEDBERg K (1994). Neurohormonal activation in patients with mild or moderately severe congestive heart failure and effects of ramipri. The ramipril trial study group. Br. Heart J. 72, 422-427.

SIMON G, CSEREP G \& LIMAS C (1995). Development of structural vascular changes with subpressor angiotensin II administration in rats. Am. J. Hypertens. 8, 67-73.

SimONS $M_{n}$ ARIYOSH $H$, SALZMAN EW \& ROSEnBERg RD (1995). c-myb affects intracellular calcium handling in vascular smooth muscle cells. Am. J. Physiol. 268, C856-C868.

SMith CJ, Sun D, HoEgleR C, ROTH BS, ZHANG X, ZHAO G, XU X-B, Kobari $Y$, PRITCCHARD K Jr, SESSA WC \& HINTZE TH (1996). Reduced gene expression of vascular endothelial NO synthase and cyclooxygenase-1 in heart failure. Circ. Res. 78, 58-64.

SMITS JFM, PASSIER RCJJ, NELISSEN-VRANCKEN HJMG, KUIZINGA MC \& DAEMEN MJAP (1995). Does ACE inhibition limit structural changes in the heart following myocardial infarction? Eur. Heart. J. 16(Suppl. N), 46-51.

STASSEN FRM, FAZZI GE, LEENDERS PJA, SMITS JFM \& DE MEY JGR (1997a). Coronary artery hyperreactivity and mesenteric arterial hyporeactivity after myocardial infarction in the rat. J. Cardiovasc. Pharmacol. 29, 780-788. 
STASSEN FRM, RAAT NJH, BROUWERS-CEILER DL, FAZZI GE, SMITS JFM \& DE MEY JGR (1997b). Angiotensin II induces media hypertrophy and hyperreactivity of densely but not sparsely innervated small arteries of the rat. J. Vasc. Res. 34, 289-297.

STASSEN FRM, WILLEMSEN MJJMF, JANSSEN GMJ, FAZZI GE, SCHIFFERS PMH, SMITS JFM \& DE MEY JGR (1997c). Reduced responsiveness of rat mesenteric artery smooth muscle to phenylephrine and calcium following myocardial infarction. Br. J. Pharmacol. $120,1506-1512$.

SUMITANI M, CABRAL AMS, MICHELINI LC \& KRIEger EM (1997). In vivo adaptive responses of the aorta to hypertension and aging. Am. J. Physiol. 273, $\mathrm{H} 96-\mathrm{H} 103$.

SWEDBERG $K$, ENEROTH P, KJEKHUS J, WILHELMSEN L \& FOR THE CONSENSUS TRIAL STUDY GROUP (1990). Hormones regulating cardiovascular function, hemodynamic indexes, and plasma hormones in untreated congestive cardiac failure. Circulation $\mathbf{8 2}$, $1730-1736$.

TEERLINK JR, CLOZEL M, FISCHLI W \& CLOzEL J-P (1993). Temporal evolution of endothelial dysfunction in a rat model of chronic heart failure. J. Am. Coll. Cardiol. 22, 615-620.

THYBERG J (1996). Differentiated properties and proliferationof arterial smooth muscle cells in culture. Int. Rev. Cytol. 169, 183-265.

UMANS JG \& LEVI R (1995). Nitric oxide in the regulation of blood flow and arterial pressure. Ann. Rev. Physiol. 57, 771-790.

USUI M, MATSUOKA H, MIYAZAKI H, OKUDA S \& IMAIZUMI T (1997). Increased endogenous nitric oxide synthase inhibitor in patients with congestive heart failure. Hypertension 30 , 484.

WEBER R, STERIOPULOS N, BRUNNER HR \& HAYOZ D (1996). Contributions of vascular tone and structure to elastic properties of a medium-sized artery. Hypertension 27, 816822.

WILSON JR, MATTHAI W, LANOCE V, FREY M \& FERRARO N (1988). Effect of experimental heart failure on peripheral sympathetic vasoconstriction. Am. J. Physiol. 254, H727H733.

WILSON JR, FREY MJ, MANCINI DM, FERRARO N \& JONES R (1989). Sympathetic vasoconstriction during exercise in ambulatory patients with left ventricular failure. Circulation 79, 1021-1027.

WROBlEWSKI H, KASTRUP J, NøRGAARD T, MORTENSEN S-A \& HAUNø S (1992). Evidence of increased microvascular resistance and arteriolar hyalinosis in skin in congestive 
heart failure secondary to idiopathic dilated cardiomyopathy. Am. J. Cardiol. 69, 769774.

WroblewsKI $H$, NøRGAARD T, HAUNSø S \& KASTRUP J (1995). Microvascular distensibility in two different vascular beds in idiopathic dilated cardiomyopathy. Am. J. Physiol. 269, H1973-H1980.

ZELIS R, SINOWAY L, LeENBERGER U, CLEMSON BS \& DAVIS D (1991). Time-constant adaptations in heart failure. Eur. Heart. J. 12(Suppl. C), 2-7. 


\section{Samenvatting Curriculum vitae Dankwoord}

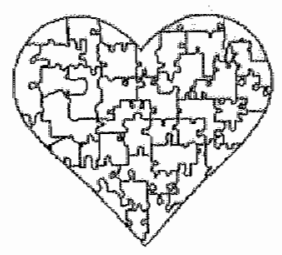




\section{Samenvatting}

Hartfalen kan omschreven worden als het onvermogen van het hart genoeg bloed te pompen om te voorzien in de behoefte aan zuurstof en voedingsstoffen van het lichaam. De aandoeningen die leiden tot hartfalen zijn uiterst divers, wat de diagnose van de ziekte vaak bemoeilijkt. Ironisch genoeg hebben juist de verbeterde overlevingskansen van deze primaire aandoeningen geleid tot een toename in de incidentie van hartfalen. Wanneer de symptomen van hartfalen eenmaal herkend zijn, is de prognose slecht. Niet alleen zijn de sterftecijfers hoog, maar ook de kwaliteit van het leven neemt in ernstige mate af.

De behandeling van hartfalen wordt bemoeilijkt door het progressieve karakter van het ziektebeeld. Als het hart niet in staat is om aan de metabole vraag van het lichaam te voldoen, wordt een reeks compensatie-mechanismen geactiveerd; deze betreffen de nieren, het zenuwstelsel en een aantal hormonen. Op de korte termijn zorgen deze er voor dat de doorbloeding van de belangrijkste organen op peil blijft. Op de lange termijn leiden deze compensatoire mechanismen echter tot een verdere verslechtering van het toestand van de patiënt: ze verhogen van de weerstand waartegen het reeds verzwakte hart in moet pompen. Bovendien zijn er aanwijzingen dat chronische activering van het zenuwstelsel en hormonen (zogenaamde neurohormoon-systemen) een beschadigende invloed op de hartfunctie hebben, los van hun effecten op bloeddruk en doorbloeding. In onze werkhypothese veronderstelden we dat chronische veranderingen in hemodynamica en neurohormonen tot structurele en functionele veranderingen in de bloedvaten zouden kunnen leiden. Zulke vaatveranderingen zouden de hartfunctie verder beperken, wat op zijn beurt de doorbloeding verder aantast en de neurohormonen nog sterker activeert. Zulke negatieve spiralen kenmerken hartfalen.

In dit proefschrift hebben we een aantal factoren onderzocht die de functie van zowel grote als kleine slagaders (arteriën) gedurende de ontwikkeling van hartfallen zouden kunnen beïnvloeden. Om deze experimenten uit te voeren hebben we gebruik gemaakt van een dierexperimenteel model van hartfalen, waarbij de linker kransslagader van de rat wordt afgebonden. Deze ingreep resulteert in het afsterven van een groot gedeelte van de wand van de linkerkamer van het hart, hetgeen vergelijkbaar is met een hartinfarct bij de mens. In hoofdstuk 2, hebben we de hemodynamische en neurohormonale status van deze geïnfarceerde ratten in de tijd bestudeerd. Alhoewel er belangrijke verschillen zijn tussen hartfalen in de rat en de mens, vooral wat relatieve leeftijd en onderliggende ziekte betreft, blijktt hartfalen in de rat veel overeenkomsten te vertonen met het beeld dat in de mens gezien wordt. $\mathrm{Na}$ het induceren van een hartinfarct treedt er een acute fase van onderdrukking van de hartfunctie en neurohormonale activering op. Deze wordt gevolgd door een relatief lange fase waarin de hemodynamica in rust niet verstoord is. Echter, metingen onder 
gestimuleerde omstandigheden lieten zien dat de functie van het hart zelf in ernstige mate verstoord is. Op termijn eindigt deze aanpassingsfase en bloeddruk en doorbloeding kunnen niet op peil gehouden worden, ondanks een verdere neurohormonale activering.

De belasting van het hart, de zogenaamde "afterload", wordt bepaald door de perifere weerstand en compliantie. Weerstand wordt gegenereerd in kleine arteriën, terwijl de grote elastische vaten de compliantie, oftewel het bufferend vermogen, van het arteriële systeem bepalen. Uit klinische studies is bekend dat de compliantie van de grote vaten bij hartfalen vaak verminderd is. Niettemin blijft het onduidelijk of, in het geval van een afgenomen compliantie, dit te wijten is aan het hartfalen of aan onderliggende aandoeningen. In hoofdstuk 5 onderzochten we de compliantie van de rattenaorta drie weken na het induceren van een hartinfarct. In dit stadia was de mechanische gedrag van de aorta niet verschillend in geïnfarceerde en gezonde ratten. Niet alleen bij hartfalen maar in het algemeen blijft het onzeker welke factoren een invloed op compliantie hebben. Er wordt gesuggereerd dat de compliantie van een vat door de druk, de dikte van de vaatwand, de samenstelling van de wand, de tonus van de spieren in de vaatwand en de grootte van de diameter van invloed zouden kunnen zijn. In hoofstukken 3,4 , en 5 , werd de rol van deze factoren bij het bepalen van de compliantie in de rat aorta onderzocht. Uit deze studies blijkt dat acute veranderingen in de druk een rol spelen bij het bepalen van de compliantie. Echter, elk van de andere onderzochte parameters bleek geen invloed op de compliantie te hebben. Op acute basis had het verhogen van de tonus van de gladde spier geen effect op de compliantie. Chronische veranderingen in de heersende bloeddruk, de dikte van de aortawand, en de diameter hebben ook geen effect. Het feit dat compliantie op acute maar niet op chronische basis beïnvloed kan worden, suggereert dat compliantie ge-autoreguleerd is, d.w.z. dat, als een verstoring de compliantie verandert, er een aanpassingsproces optreedt waarbij de compliantie genormaliseerd wordt. Deze data pleiten ervoor dat het handhaven van de compliantie fysiologisch van belang is en verder onderzoek zal moeten uitwijzen welke mechanismen verantwoordelijk zijn voor het reguleren van de compliantie.

In het laatste deel van dit proefschrift is het functioneren van de weerstandsarteriën bestudeerd. Verhoogde totale perifere weerstand is kenmerkend voor hartfalen en draagt aanvankelijk bij tot een adequate perfusiedruk van vitale organen. Een langdurige verhoging van de weerstand kan in stand gehouden worden door structurele veranderingen in de vaten, een verminderde vaatverwijdende, of een verhoogde vaatvernauwende functie. In dit proefschrift hebben we de minimale vaatweerstand, ofwel de weerstand bij maximale vaatverwijding, in de achterpoten van de rat gebruikt als maat voor mogelijke structurele veranderingen die een invloed op de weerstand hebben. 
Echter tot drie maanden na het hartinfarct konden er geen verschillen in minimale weerstand tussen geïnfarceerde en controle ratten worden waargenomen (hoofdstuk 8).

Vervolgens werd de vaatverwijdende functie van het achterpootvaatbed bestudeerd. In klinisch hartfalen is een verminderde vaatverwijdende reactie op acetylcholine reeds uitvoerig beschreven. Daarom werden de reacties op dit farmacon bestudeerd. Tot drie maanden na het induceren van een hartinfarct konden er echter geen verschillen worden aangetoond tussen de antwoorden op acetylcholine in geïnfarceerde en controle ratten (hoofdstuk 8). Acetylcholine induceert vaatverwijding door het stimuleren van de productie van tenminste stikstofoxide, prostacycline en een hyperpolariserende factor (EDHF) afkomstig uit de endotheel-cellen, de cellen die de binnenkant van de bloedvaten bekleden. Recente bevindingen suggereren dat de componenten van de acetylcholinerespons verschillen per vaatbed, zodanig dat stikstofoxide met name belangrijk is voor dilatatie in grote vaten, maar dat EDHF een steeds belangrijkere rol gaat spelen naarmate de diameter van de vaten afneemt. In de achterpoten van de rat bleek dat EDHF primair verantwoordelijk is voor acetylcholine-geïnduceerde vaatverwijding (hoofdstuk 6). Aangezien het merendeel van de studies met acetylcholine in de mens in grote vaten zijn uitgevoerd, zouden de verschillen met de data gepresenteerd in dit proefschrift mogelijkerwijze verklaard kunnen worden vanuit het relatieve belang van stikstofoxide in de acetylcholine-respons.

In hetzelfde achterpoot-model werd ook de vaatvernauwende functie tijdens hartfalen bestudeerd. Na het induceren van een hartinfarct namen de antwoorden op vaatvernauwende substanties af. Zowel de gevoeligheid voor kalium alsook de maximale toename in weerstand waren significant afgenomen in geïnfarceerde ratten. Alhoewel deze bevinding in tegenspraak lijkt te zijn met een toename in perifere weerstand, zou een verminderde vaatvernauwende capaciteit de voortgang van hartfalen kunnen bevorderen. Afgenomen resulteert in een verhoogde afgifte van neurohormonen die dit effect veroorzaken, om de perfusiedruk op peil te houden. Toenemende ongevoeligheid vraagt oplopende neurohormonale activering, hetgeen de functie van het hart vervolgens weer negatief zou kunnen beïnvloeden. Bovendien zou het onvermogen om voldoende weerstand vooraan in een vaatbed te genereren oedeemvorming versnellen door een verhoging van de druk in de haarvaten.

Tijdens de periode waarin de gevoeligheid voor vaatvernauwende stimuli afneemt, is de totale perifere weerstand toegenomen, maar zonder een verhoging in de gemeten spiegels van vaatvernauwende neurohormonen in het bloed. Dit verschijnsel zou misschien verklaard kunnen worden door een belangrijke lokale hormoonproductie die niet in bloed aantoonbaar is, of door een verlaging van vaatverwijdende hormonen. Het mogelijke belang van één van die lokale hormoonsystemen, het renine-angiotensine systeem, in hartfalen en van 
stiktofoxide in de regulering van de vaat-tonus stimuleerde ons om de rol van het hormoon angiotensine $\|$ en stikstofoxide in de vaatvernauwende functie te bestuderen.

In controle ratten leidden chronische infusies van angiotensine $\|$ tot een verminderde vaatvernauwende respons op kalium, maar de maximale toename in weerstand bleef gehandhaafd (hoofdstuk 7 ). Tevens resulteerde de chronische remming van de productie van stikstofoxide in een vermindering van de contractiele vermogen in controle ratten (hoofdstuk 7). Deze verlaging van de vaatvernauwende respons was vergelijkbaar met de verminderde vaatvernauwende respons in geïnfarceerde ratten (hoofdstuk 8). Anderzijds was chronische remming van stikstof oxide synthese zonder effect op de al verminderde vaatvernauwende functie in geïnfarceerde ratten (hoofdstuk 8 ). Ook was het effect van verlaagde stikstofoxide niveau's op bloeddruk veel geringer bij geïnfarceerde dan bij controle dieren. Deze resultaten suggeren dat stikstofoxide spiegels tijdens hartfalen in de rat verlaagd zijn. Bovendien lijkt het alsof verminderde stikstofoxide leidt tot afname van vaatvernauwende effecten.

Omdat geneesmiddelen die de vorming van angiotensine II remmen, de zogenaamde angiotensine converting enzyme (ACE) remmers, tegenwoordig tot de standaardtherapie bij hartfalen horen, hebben we de effecten van de ACE remmer captopril op de vaatvernauwende functie tijdens hartfalen bestudeerd. Chronische behandeling met captopril verbeterde de vaatvernauwende functie in geïnfarceerde ratten. Mogelijkerwijze is dit gunstige effect rechtstreeks te wijten aan een verlaging van de angiotensine II spiegels. Anderzijds zou het effect van captopril gelegen kunnen zijn in het verhogen van de stikstofoxide niveau=s doordat ACE remmers ook de afbraak van een ander hormoon, het bradykinine, remmen; bradykinine verhoogt de productie van stikstofoxide door het endotheel.

Samenvattend, is in dit proefschrift aangetoond dat het infarceren van de linker kamerwand van het rattenhart hemodynamische en neurohormonale veranderingen induceert, die sterk lijken op de symptomen van hartfalen bij de mens. Alhoewel de belasting van het hart door zowell de functie van de kleine weerstandsarteriën, als door de grote elastische arteriën bepaald wordt, zijn, in dit model van hartfalen, de functionele veranderingen in de kleine weerstandsarterieën het meest uitgesproken. De mechanische eigenschappen van de ratten-aorta lijken door een hartinfarct niet te worden beïnvloed. Nader onderzoek naar de mechanismen waardoor compliantie geregeld wordt, suggereren dat compliantie mogelijkerwijze ge-autoreguleerd is. Verder is aangetoond dat de verhoogde perifere weerstand tijdens hartfalen niet te wijten is aan structurele veranderingen in het vasculaire netwerk. Bovendien blijkt er geen verminderde vaatverwijdende capaciteit te ontstaan. De andere resultaten in dit proefschrift wijzen daarentegen op een bijdrage van verlaagde stikstofoxidespiegels aan de toegenomen weerstand. Bovendien zijn er 
aanwijzingen dat chronisch gereduceerde stikstofoxide niveau's tot een afname van het vaatvernauwende vermogen van de arteriën leiden.

Deze afname van het vaatvernauwende vermogen zou kunnen leiden tot een verdere activering van neurohormonale systemen en zou op deze wijze de klassieke vicieuze cirkel van hartfalen kunnen beïnvloeden. Aangezien afname van het vaatvernauwende vermogen de voortgang van hartfalen zou kunnen bevorderen, verdienen de intracellulaire mechanismen die verantwoordelijk zijn voor dit verschijnsel nader onderzoek. Het positieve effect van de ACE remmer captopril op de afname van het vaatvernauwende vermogen draagt mogelijk bij aan het gunstige effect van ACE remmers in patiënten met hartfalen. 


\section{Curriculum vitae}

Deborah L. Ceiler

27 februari 1968

1982-1986

$1986-1990$

1990

1991

$1992-1993$

1993-1997

$1997-$

Geboren te Pittsburgh, Pennsylvania, USA

Brookwood High School. Snellville, Georgia, USA. summa cum laude

B.S. biochemistry. University of Georgia. Athens, Georgia, USA. summa cum laude

Analyste. Biochemistry Department, University of Georgia. Athens, Georgia, USA

Analyste. U.S. Environmental Protection Agency, Environmental Research Lab. Athens, Georgia, USA

M.Sc. biotechnology. Landbouw Universiteit Wageningen. cum laude

Assistente in opleiding. Vakgroep Farmacologie, Cardiovascular Research Institute Maastricht, Universiteit Maastricht

Post-doctoraal medewerkster bij dezelfde vakgroep

\section{Publications}

\section{Full Papers}

Brouwers-Ceiler DL, Nelissen-Vrancken HJMG, Smits JFM: Effect of nitric oxide on the acetylcholine response in the perfused hind limb of rats. Eur $J$ Pharmacol $1996 ; 307: 65-68$.

Brouwers-Ceiler DL, Nelissen-Vrancken HJMG, Smits JFM, De Mey JGR: The influence of angiotensin II-induced increase in aortic wall mass on compliance in rats in vivo. Cardiovasc Res 1997;33:478-484.

Ceiler DL, Nelissen-Vrancken HJMG, De Mey JGR, Smits JFM: Effect of chronic blockade of angiotensin II receptor subtypes on aortic compliance in rats with myocardial infarction. $J$ Cardiovasc Pharmacol, in press.

Ceiler DL, Nelissen-Vrancken HJMG, De Mey JGR, Smits JFM: Time-related adaptations in plasma neurohormone levels and hemodynamics after myocardial infarction in the rat. submitted.

Ceiler DL, Nelissen-Vrancken HJMG, Smits JFM, De Mey JGR: Static and dynamic mechanical behavior of the intact rat aorta is influenced by pressure but not by angiotensin 11 -induced increases in wall mass or tone. submitted. 
Ceiler DL. Nellissen-Vrancken HJMG, De Mey JGR, Smits JFM: Effects of chronic infusion of L-NAME or angiotensin $\|:$ on arterial structure and reactivity in the hindlimb of rats. submitted.

Ceiler DL, Nelissen-Vrancken H.JMG, De Mey JGR, Smits JFM: Role of basal NO synthesis in vasoconstrictor hyporeactivity in the perfused rat hindlimb after myocardial infarction Effect of captopril. submitted.

Langenhoff AAM, Brouwers-Ceiler DL, Engelberting JHL, Quist JJ, Wolkenfelt JGPN, Zehnder A.JB, Schraa G: Microbial reduction of manganese coupled to toluene oxidation. FEMS Microbiol Ecol 1997;22:119-127.

Stassen FRM, Raat NJH, Brouwers-Ceiler DL, Fazzi GE, Smits JFM, De Mey JGR: Angiotensin II induces media hypertrophy and hyperreactivity of densely but not sparsely innervated small arteries of the rat. J Vasc Res 1997;34:289-297.

\section{Abstracts}

Brouwers DL, Nelissen-Vrancken HJMG, Smits JFM: Endothelial function in the rat hindlimb after myocardial infarction. Pharm World Sci 1994;16(Suppl. J):J4.10.

Nelissen-Vrancken HJMG, Brouwers-Ceiler DL, Debets JJM, Snoeckx LHEH, Smits JFM: Increase in functional blood vessels of left ventricle in rat hearts with myocardial infarction. J Mol Cell Cardiol 1994;26:LXXII.

Browers DL, Nelissen-Vrancken HJMG, Smits JFM: Acetylcholine response in the perfused rat hindlimb after myocardial infarction: role of NO. FASEB J 1995;9:A324.

Brouwers DL, Stassen FRM, van Ingen Schenau DS, Fazzi GE, Nelissen-Vrancken HJMG, De Mey JGR, Smits JFM: Effect of chronic angiotensin II infusion on aortic compliance in anesthetized rats. Naunyn Schmiedeberg's Arch Pharmacol 1995;352 (Supp) R26.

Nelissen-Vrancken HJMG, Brouwers-Ceiler DL, Debets JJM, Snoeckx LHEH, Smits JFM: Time-dependent normalization of maximal coronary flow in rat hearts with myocardial infarction. FASEB J 1995;9:A848.

Stassen FRM, Brouwers-Ceiler DL, Fazzi GE, De Mey JGR: Effects of chronic low dose angiotensin If infusions of vascular reactivity in rats. Pflügers. Arch $1995 ; 430: R 140$

Brouwers DL, Stassen FRM, van Ingen Schenau DS, Fazzi GE, Nelissen-Vrancken HJMG, Smits JFM, De Mey JGR: Effect of angiotensin II-induced aortic hypertrophy on vessel mechanics in anesthetized rats. Pharm World Sci 1996;18(Suppl. A):A2.

Brouwers-Ceiler DL, Nelissen-Vrancken HJMG, De Mey JGR, Smits JFM: Effect of chronic blockade of $A T_{1}$ and $\mathrm{AT}_{2}$ receptors on aortic compliance in rats with myocardial infarction. Hypertension 1996;28:696. 
Stassen FRM, Brouwers-Ceiler DL, Fazzi GE, De Mey JGR: Perivascular nerves are involved in the hypertrophy induced by chronic low dose angiotensin II infusions in small arteries of the rat. Hypertension 1996;28:708.

Stassen FRM, Brouwers-Ceiler DL, Fazzi GE, De Mey JGR: Vascular neuroeffector mechanisms after chronic low dose angiotensin $\|$ infusion in rats. J Hypertens 1996;14(Suppl. 1):S139.

Brouwers-Ceiler DL, Nelissen-Vrancken HJMG, De Mey JGR, Smits JFM: Effect of chronic blockade of AT1 and AT2 receptors on aortic structure and mechanics in intact anesthetized rats. Microcirc 1997;4:163.

Brouwers-Ceiler DL, Nelissen-Vrancken HJMG, De Mey JGR, Smits JFM: Effect of chronic vasoconstrictor infusions on hindlimb vascular structure and reactivity. FASEB J 1997:11:A39.

Brouwers-Ceiler DL, Nelissen-Vrancken HJMG, De Mey JGR, Smits JFM: Possible role of basal NO release in hindlimb vascular hyporeactivity after myocardial infarction in rats. $J$ Vasc Res 1997;34(Suppl. S1):9. 


\section{Dankwoord}

In het huis van mijn oma hangt een boordje met het spreekwoord, "Make new friends, keep the old. The one is silver, the other gold." Vanaf mijn peutertijd kon ik dat versje repeteren, maar nu begrijp ik het. Over de afgelopen vier jaren, heb ik wonderbaarlijke steun van jullie allemaal gekregen. Dat is iets wat heel veel voor mij betekend heeft, zodanig dat Nederland mijn tweede "thuis" geworden is. Heel hartelijk bedankt - elk van jullie!

Een aantal mensen hebben een bijzondere bijdrage aan het tot stand komen van mijn proefschrift geleverd. Ik hoop dat mijn dankbaarheid is al gang gebleken, maar ik will ze nu toch even "in the spotlight" zetten.

Aan "de promotie team", c.q. Prof. dr. Jos Smits, Prof. dr. Jo De Mey, en Dr. Marjorie Nelissen-Vrancken:

Beste Jos, Als AlO heb ik het echt getroffen, want een betere begeleider kan ik me niet voorstellen. Op de juiste momenten wist je een stimulerend druk uit te oefenen, maar je besefte ook wanneer de druk enigzins te hoog werd. Bovendien heb je me de vrijheid gegeven om als onderzoekster en schrijvster te ontwikkelen zonder dat ik op een foute pad te lang verdwalde.

Beste Jo, Je fantastische capaciteit om te brainstormen werkt zeer inspirerend. $\mathrm{Na}$ een discussie met jou kon ik nauwelijks wachten om nieuwe experimenten uit te voeren.

Beste Marjorie, Je hebt altijd alle nodige tijd voor me vrijgemaakt. Jouw kritische lezen heeft ervoor gezorgd dat ieder hoofdstuk aanzienlijk duidelijker is geworden.

Aan "het lab":

Beste Caroline, ledere maandag, bij wijze van spreken, hebben we je agenda vol geschreven en ieder dinsdag hebben we het veranderd. Bedankt voor je flexibiliteit! Ik wens jij, Pedro, Patrick en Robin de tijden van jullie leven daar in Zwitserland.

Beste Jacques, Peter en Elsbeth, Jullie hebben talloze ratten voor me ingezet, maar ik ben het meest dankbaar voor de even talloze tijden dat jullie me uit een noodgeval gered hebben - met intuberen, met een mislukte cannulatie, met een te druk geplande dag....

Beste Helma, Na de farmacologiemiddagen was de borrelen altijd gezellig!

Beste Lillian, Je bent altijd vrolijk en ik heb onze tijden in de trein erg leuk gevonden. Jammer dat het squashen is weggevallen, maar nu hoef ik iedere week mijn verlies niet te erkennen.

Beste Dorette, een ander "treinmeisje", bedankt voor alle hulp met het ultrageluidsysteem.

Beste Gwenn en Fazzi, Jullie kunnen niet voorstellen hoe dierbaar jullie vriendschap voor me is. Bedankt voor alle begrip. 
Beste Francy en Jenny, Als het moeilijk ging, wist ik dat ik bij jullie altijd terecht kon.

Beste Richard, "Agenda bijhouden op z"n Debbie's". Bedankt voor je begrip voor alle last minute uitgestelde plannen.

Beste Ferdi, Weleens een keer kom je eindelijk bij mij eten en daarna gaan we samen op stap! Je was moeilijk te leren kennen, maar het was de moeite waard. Beste Ben, Dianne, Luuc en Emma, Bedankt voor alle gezellige avonden bij jullie! Dear Jeff, my email buddy. Whatever would I do without our daily "chats"?

Beste Jan en Maria Brouwers, Jos, Marie-Josée, Huub en Martijn, Het verhuizen naar een vreemd land is geen makkelijke onderneming. Jullie hebben me vanaf het begin in jullie gezin opgenomen. We hebben veel gezellige dingen samen gedaan, helaas voort het leven niet altijd als gepland. Ook mijn dank aan de families Brouwers en Schnackers.

Hans, De trieste momenten moeten we op zij zetten want er zijn veel leuke dingen om te herinneren, bijvoorbeeld de zomer van 1991, wanneer we de oostkust van de VS veroverden. Het feit dat we de dromen die we hadden niet zullen delen, neemt niets weg van de gelukkige tijden die we samen hebben doorgebracht.

Frank, Op 13 december 1993, reden we samen naar de Farmacologie Dagen te Noordwijkerhout. Ik was bang om met een onbekende te rijden, maar daar heb je heel weinig van gemerkt want ik kletsde de hele rit door. Nu ben ik even sprakeloos. Bedankt voor alle steun, kritiek, uitdagingen, concurrentie (welleens zal ik sneller fietsen of een spelletje Risk winnen) en vooral voor alle lachen. Go with the flow and with a smile.

Dear Gram and Papa, I will always cherish the countless memories I have of our "vacations" at your house - running around the dining room table, stories late at night, Lesley Park and slush, Pirate games... You have instilled in me a great sense of respect for other people.

Dear Butch and Stacy, One week per year is short. I miss you guys.

Dear Mom and Dad, "Debbie, Debbie quite contrary" always had to go the other way. Thanks for giving me that opportunity and for helping me pick up the pieces if things didn't quite go as l'd planned. Like Dorothy said, "There's no place like home." 